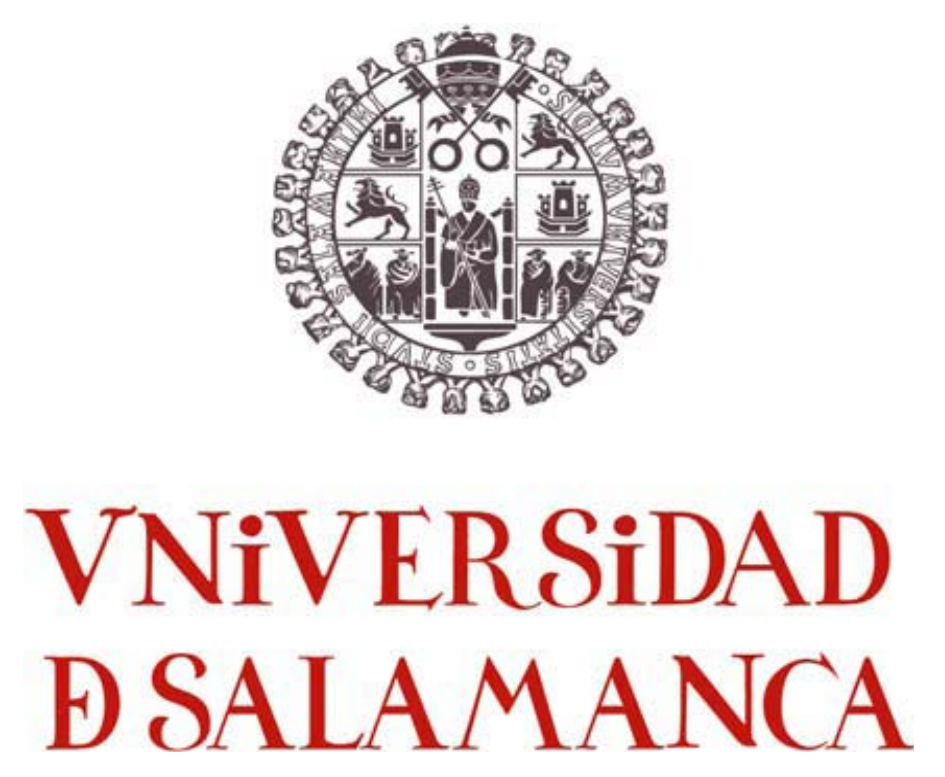

TESIS DOCTORAL

\title{
EVALUACIÓN DE LA INCLUSIÓN EN SERVICIOS PARA PERSONAS CON DISCAPACIDAD
}

Autora: Dña. Mónica Gutiémez Ortega

Dinigida por:

Dra. Cristina Jenaro Río

Profesora Titular del Departamento de Personalidad, Evaluación y Tratamiento Psic ológic os. Fa cultad de Psicología (Universidad de Salamanca)

Dra. Pilar Sarto Martín

Profesora Titular del Departamento de Didáctica, Organización y Méto dos de Investiga ción. Facultad de Educación (Universidad de Salamanca) 


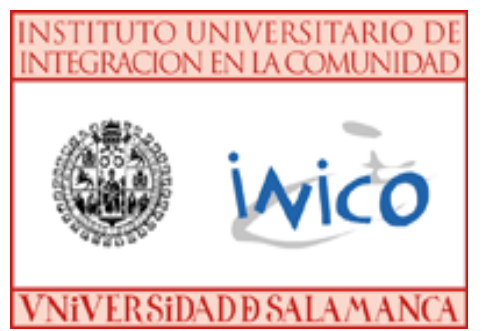

Cristina Jenaro Río, Profesora Titular del Departamento de Personalidad, Evaluación y Tratamiento Psicológicos, de la Facultad de Psicología de la Universidad de Salamanca

Pilar Sarto Martín, Profesora Titular del Departamento de Didáctica, Investigación y Métodos de Investigación, de la Facultad de Educación de la Universidad de Salamanca, y

Siendo ambas Investigadoras del Instituto Universitario de Integración en la Comunidad (INICO)

INFORMAN

De que la Tesis Doctoral realizada bajo su dirección por Dña. Mónica Gutiérrez Ortega, con el título “EVALUACIÓN DE LA INCLUSIÓN EN SERVICIOS PARA PERSONAS CON DISCAPACIDAD", reúne los requisitos de calidad, originalidad y presentación exigibles a una investigación científica, y está en condic iones de ser so metida a la valoración del Tribunal encarga do de juzgarla.

Y para que conste a los efectos oportunos, fimo la presente en Salamanca, a 14 de febrero de 2011.

Fdo. Cristina J ena ro Río Fdo. Pilar Sarto Martín 


\section{Agradecimientos}

Hay momentos en la vida que son especialmente difíciles por lo que te suponen a nivel personal y profesional. En estos momentos es cuando siempre la vida te sonńe y te pone en el camino a personas maravillosas que hacen que todo cobre sentido y que lasfuerzas no te abandonen.

Este es el momento de agradecerles a todas ellas el apoyo que me han brindando ya que sin ella s esta tesis no hubiera sido posible.

En primer lugar, y pidiendo permiso a mis queridas directoras, tengo que dar las gracias a mi marido por el apoyo que me ha dado, sin su mano cogiéndome en los momentos más bajos y su sonrisa en los mejores, no hubiera podido hacer este trabajo.

En segundo lugar, a mis directoras, a mis ángeles de la guarda que han estado minuto a minuto siguiendo mi trabajo y velando para que el camino fuera fácil, sin piedras dónde me pudiera tropezar. Gracias por todo si vosotras tampoco hubiera sido posible.

En tercer lugar, a Tomás Castillo, a María J osé Cabo y a todas las personas maravillosas que he conocido en AMICA. Gracias por ser como sois, por esa fuerza vital, por esa ilusión, por vuestros principios y por haber hecho todo lo posible y lo imposible porque este trabajo se pudiera realizar. Gracias por haberme hecho ver que todo es viable si se cree en los valores de la persona.

En cuarto lugar, a todos los amigos que me han apoyado en los momentos difíc iles y que han sabido comprender lo que conlleva embarcarte en un proyecto como este. Gracias de todo corazón. 

CAPITULO 1. POSICIONANDO ELINDEX PARA LA INCLUSIÓN 23

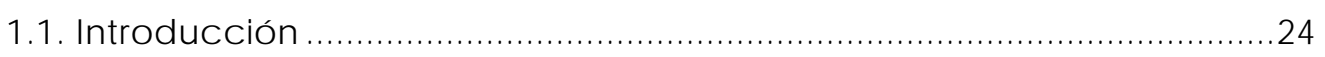

1.2. Inc lusión: presencia, a prendizaje y partic ipación..................................24

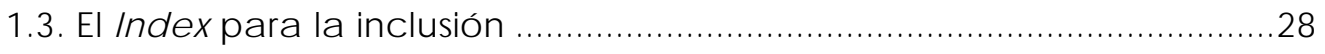

1.3.1. Estructura del Index para la inc lusión ................................................31

1.3.2. El proceso de trabajo con el Index para la inclusión .......................39

1.4. Investigando la a plic ación del Index..................................................47

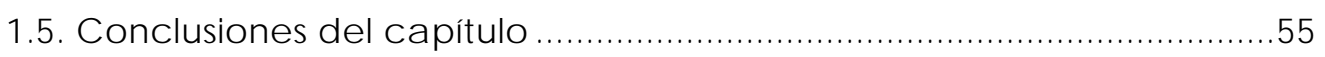

CAPITULO 2. ORGANIZACIONES INCLUSIVAS..............................................59

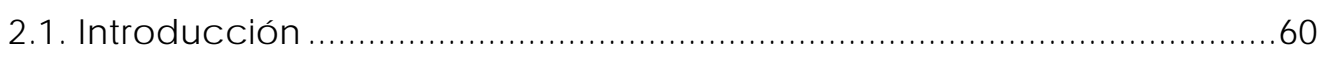

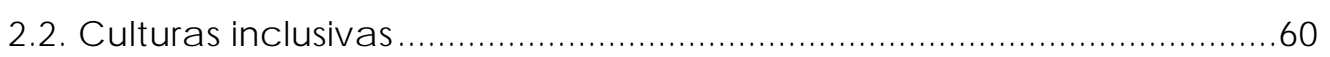

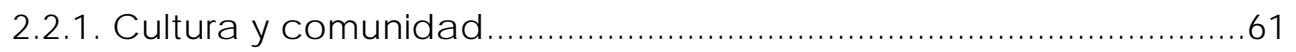

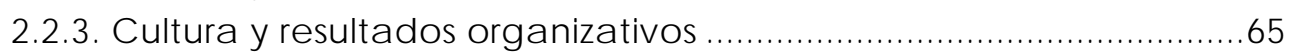

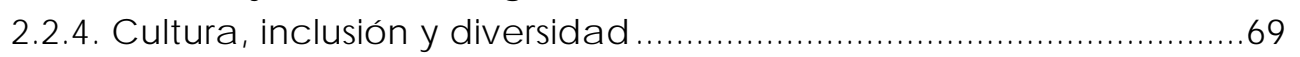

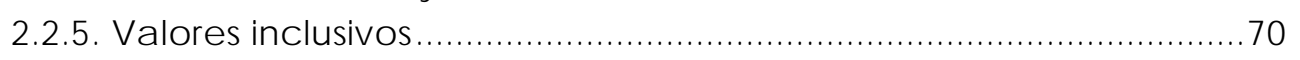

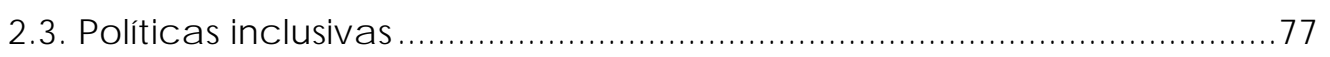

2.3.1. La base de las políticas de inclusión: los derechos de las

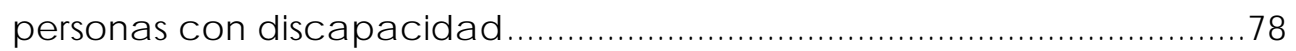

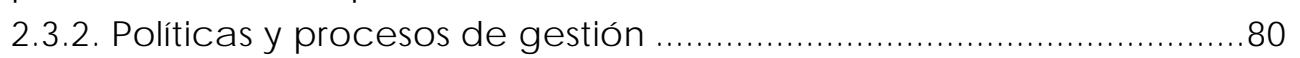

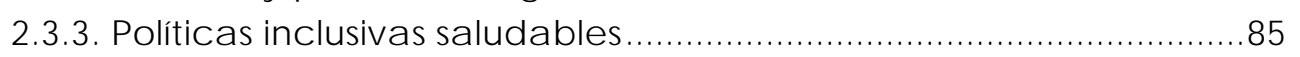

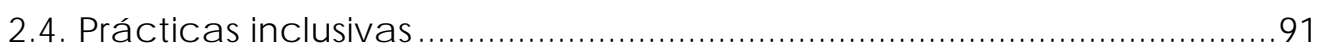

2.4.1. La persona como eje de las prácticas............................................91

2.4.2. Práctica sque promueven la motivación y la autodeterminación 94

2.4.3. Prácticas que promueven la implic ación de la persona ...............100

2.4.4. Prá ctic as que fomentan la resiliencia ............................................107

2.5. Conclusiones del ca pitulo .............................................................. 115

CAPITLO 3. COMUNIDADES DE PRÁCTICA .............................................117

3.1. Introduc ción ............................................................................ 118

3.2. El ap rendizaje situado y la práctic a ..................................................118

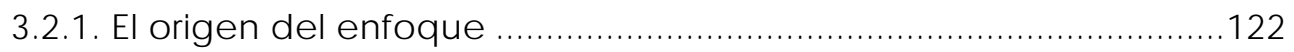

3.3. Concepto de Comunidad de Práctica ...................................................125 
3.4. Evolución histórica de las Comunidades de Práctic a ....................... 129

3.4.1. Evolución históric a: Periodo inicial (1991-1995)............................. 130

3.4.2. Evolución históric a: Periodo medio (1996-1999) ............................ 134

3.4.3. Evolución históric a: Último periodo (2000-ac tualidad) ................ 137

3.5. Característic as de las Comunidades de Práctic a ............................. 139

3.5.1. El compromiso mutuo ............................................................... 140

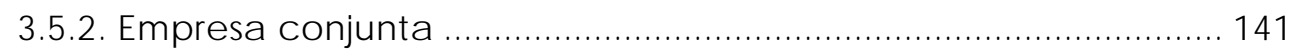

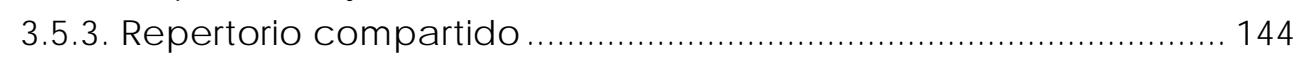

3.6. La participación en una Comunidad de Práctica ............................. 145

3.7. El diseño de una Comunidad de Práctic a ........................................... 148

3.7.1. Los límites de la Comunidad de Práctic a ...................................... 155

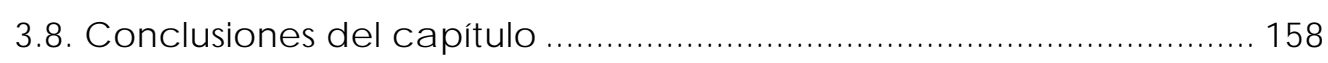

CAPITULO 4. ASOCIACIÓN AMICA: CENTRO DE REFERENCIA......................... 161

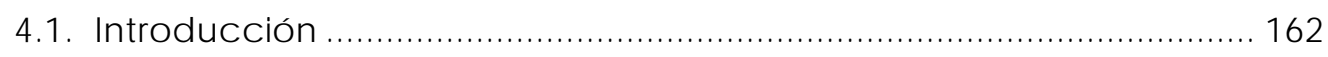

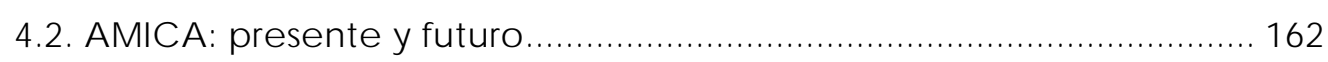

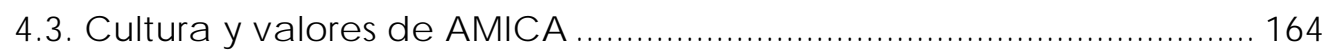

4.4. Polític a s orga niza tivas en AMIC A .................................................... 170

4.5. La participación como eje de la gestión ........................................... 175

4.6. Recursos de AMICA ..................................................................... 177

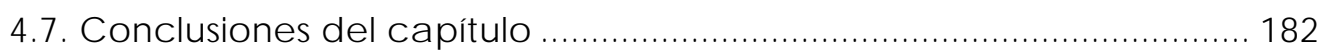

SEG UNDA PARIE. INVESTIGACIÓN EMPÍRICA ........................................... 185

\section{CAPITULO 5. ADAPTACIÓN DEL INDEX PARA LA INCLUSIÓN PARA CENTROS PARA PERSONAS CON DISCAPACIDAD (FASE I Y FASE II) .................. 187}

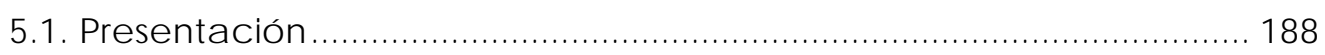

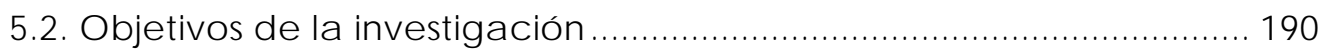

5.3. Hipótesis de la investiga ción .......................................................... 191

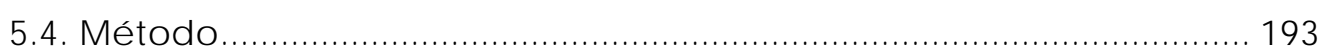

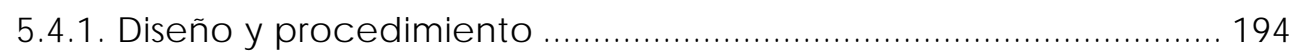

5.4.3. Partic ipantes.............................................................................. 197

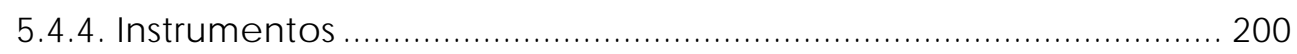

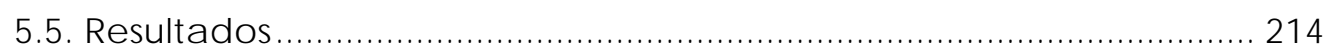

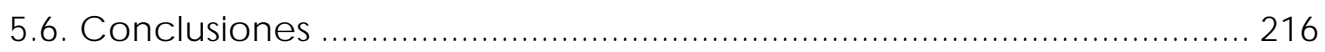

CAPITULO 6. EVALUACIÓN DE LA INCLUSIÓN EN LOS CENTROS PARA PERSONAS CON DISCAPACIDAD (FASE III Y FASE IV) ...................... 223

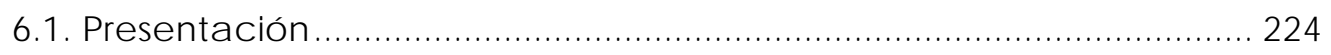

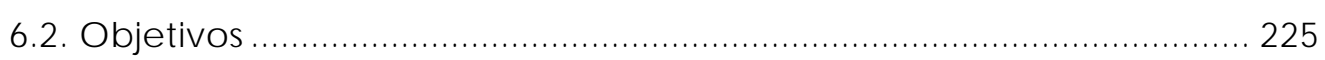

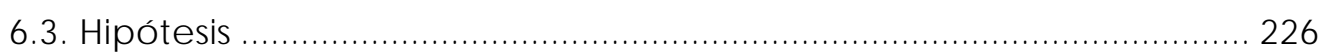




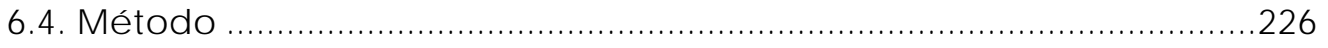

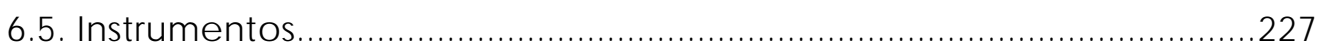

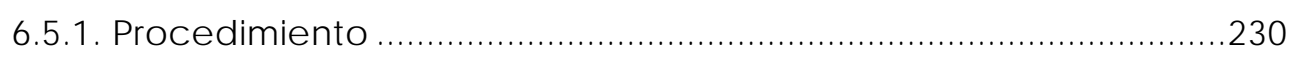

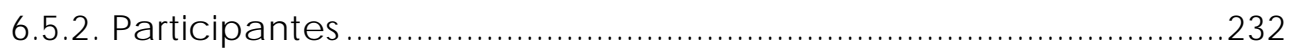

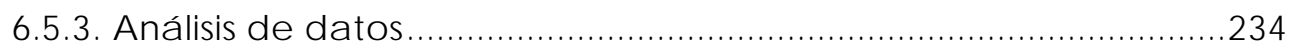

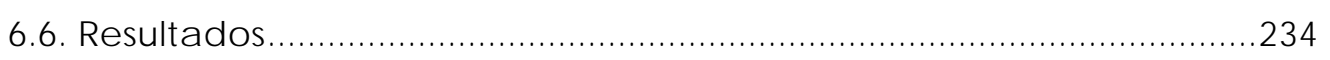

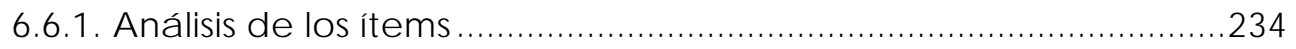

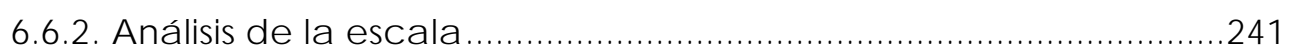

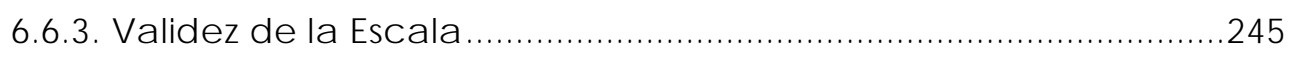

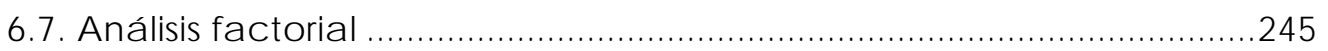

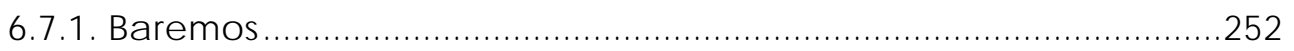

6.8. Contraste de hipótesis sobre valoraciones de las dimensiones de

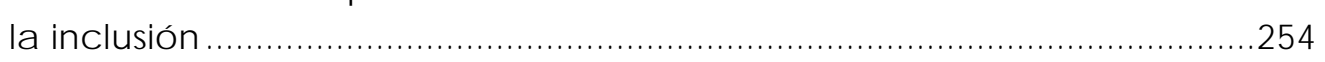

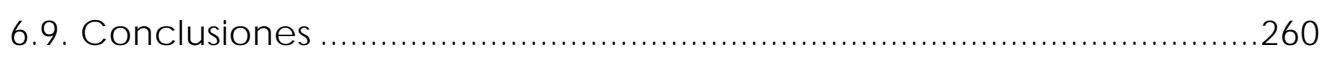

CAPITULO 7. CONCLUSIONES, DISC USIÓN, UMITACIONES Y ÚNEAS FUTURAS DE

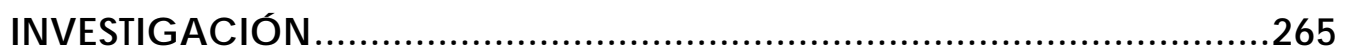

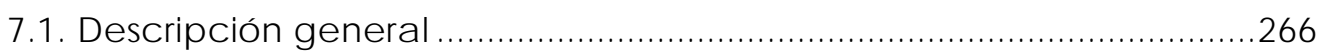

7.2. Disc usión de los resulta dos y conclusiones............................................266

7.2.1. Disc usión y conclusiones del primer objetivo de la investiga ción 266

7.2.2. Disc usión y conc lusiones del segundo objetivo de la

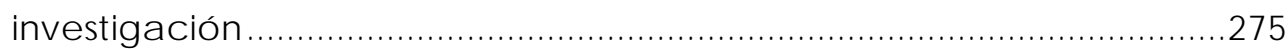

7.2.3. Disc usión y conc lusiones del tercer objetivo de la investiga ción. 276

7.3. Limitaciones y líneas futuras de investiga ción .......................................277

BIBUOG RAF́A ............................................................................................279

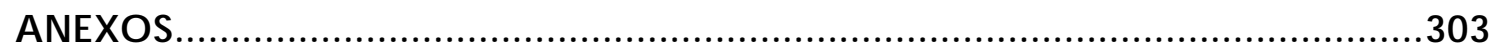

Anexo I. Cuestionario de Evaluación de los Indic adores del Index (CEII)

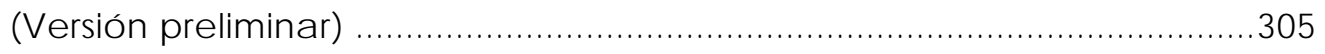

Anexo II. Cuestionario de Evalua ción de los Indic adores del Index

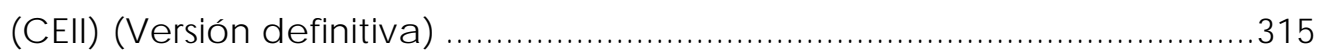

Anexo III. Cuestionario de Indic a dores de Inclusión (C II) ...........................319

Anexo IV. Index para la Inclusión adaptado para centros que prestan servicios a personas con discapacidad: Dimensiones, secciones, indicadores y preguntas. 


\section{Índice de figuras}

FIG URA 01. LAS TRES DIM ENSIO NES DEL INDEX PARA LA INCLUSIÓN (BOOTH Y AINSC OW,

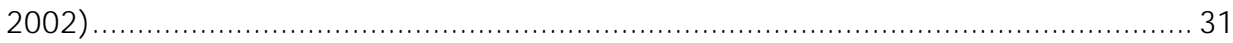

FIG URA 02. ESQ UEMA DEL INDEX PARA LA INCLUSIÓN (ELABORACIÓN PROPIA) ...................... 32

FIG URA 03. SUPERPOSICIÓN DE LAS DIMENSIONES DEL INDEX PARA LA INCLUSIÓN

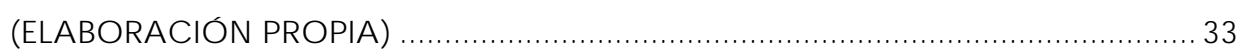

FIG URA 04. DIMENSIO NES Y SEC CIO NES (ELABO RACIÓN PROPIA) ….................................... 35

FIG URA 05. EL PROCESO DEL INDEXY EL CICLO DE PLANIFICACIÓN PARA LA MEJ ORA

DEL C ENTRO (BOOTH Y AINSC O W, 2002) ........................................................ 40

FIGURA 06. PROCESO DE TRABAJ O CON EL INDEX PARA LA INCLUSIÓN (BOOTHY

AINSC OW, 2002) ................................................................................................ 46

FIGURA 07. ESQ UEMA CONCEPTUAL DE CULTURA ORGANIZACIONAL (ABRAVANEL,

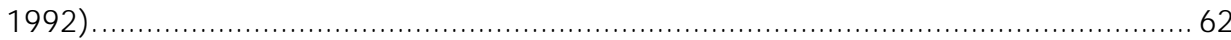

FIGURA 08. VALORES QUE SE ENCUENTRAN TRAS LA FILOSOFÍA DEL INDEX FOR

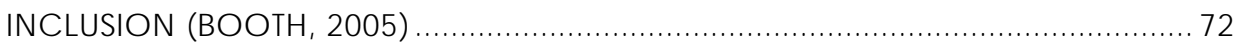

FIG URA 09. CARAC TERÍSTICAS DEL BUEN G OBIERNO (UN ESCAP, 2010) …............................. 84

FIG URA 10. RELACIÓN ENTRE LAS ORIENTACIONES DE METAS DISPO SICIONALES Y EL CONCEPTO DE HABILIDAD (J IMÉNEZ, 2004) …........................................................ 95

FIGURA 11. CONTINUO DE AUTODETERMINACIÓN (DECI Y RYAN, 2000; RYAN Y DECI,

2000)

FIG URA 12. COMPONENTES DEL “FLOW” SEG ÚN J AC KSON Y C SIKSZENTM IHALYI (2002) .... 101

FIGURA 13. "CANAL DE FLUJ O" ENTRE EL GRADO DE DESA FíO DE LA TAREA Y EL NIVEL DE

LAS HABIUDADES REQ UERIDAS (WHALEN, 1997)............................................... 103

FIGURA 14. CONCEPTO DEL ESTADO DE IMPUCACIÓN (J IMÉNEZ, 2004) .............................. 104

FIGURA 15. “LA CASITA” DE LA RESILIENC IA (VANISTENDAEL Y LEC OMTE, 2002),.................... 109

FIGURA 16. PROCESO PARA FOMENTAR LA RESIUENCIA (BROWN, CASTON Y BERNARD,

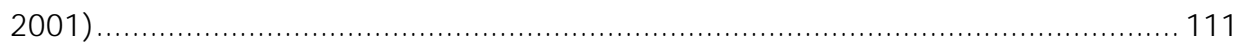

FIG URA 17. PERFIL DE UNA PERSONA RESILIENTE (SAAVEDRA, 2004).................................. 113

FIG URA 18. TEORÍA DE LA ACTIVIDAD (ENGESTRÖM, 1987)............................................... 121

FIG URA 19. COMPONENTES DE LA TEO RÍA SO CIAL DEL APRENDIZAJ E (WENG ER, 2001,

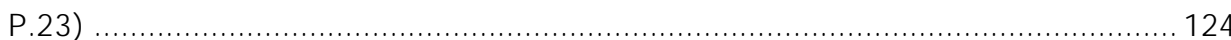

FIG URA 20. CARAC TERÍSTICAS DE LA PRÁCTICA. (WENG ER, 2001) ...................................... 139

FIGURA 21. EL COMPROMISO MUTUO EN UNA COMUNIDAD DE PRÁCTICA

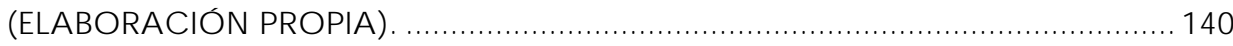

FIGURA 22. LA EMPRESA CONJUNTA EN UNA COMUNIDAD DE PRÁCTICA

(ELABORACIÓN PROPIA) 142 
FIG URA 23. EL REPERTORIO COMPARTIDO EN UNA COMUNIDAD DE PRÁCTICA

(ELABORACIÓN PROPIA).

FIG URA 24. LA DUAUDAD DE LA PARTICIPACIÓN Y LA COSIFICACIÓN

(WENG ER, 2001, P. 88)

FIG URA 25. CONEXIO NES Y LÍMITES ENTRE LAS COMUNIDADES DE PRÁCTICA.

(ELABORACIÓN PROPIA)

FIG URA 26. VALORES QUE MARCAN LA FILOSOFÍA AMICA (AMICA, 2010B) ......................... 165

FIG URA 27. POLITICA ORGANIZATIVA DE AMICA. (ELABORACIÓN PROPIA)...

FIGURA 28. PROCESO EMPÍRICO PARA LA ADAPTACIÓN DEL INDEX PARA LA INCLUSIÓN

Y PARA LA CONSTRUCCIÓN DE UN INSTRUMENTO DE EVALUACIÓN DE LA

INCLUSIÓN

FIGURA 29. ELEMENTOS QUE FORMAN PARTE DEL INDEX Y DEL CUESTIONARIO DE

EVALUACIÓN DE LOSINDICADORES DEL INDEX (CEII). 200

FIGURA 30. RESUMEN POR SEC CIONES (CATEG ORIAS) DE ASIGNACIÓN DE

INDICADORES A CADA UNA DE ELLAS.

FIGURA 31. PROCESO EMPÍRICO PARA LA ADAPTACIÓN DEL INDEX PARA LA INCLUSIÓN

Y PARA LA CONSTRUCCIÓN DE UN INSTRUMENTO BREVE DE EVALUACIÓN

DE LA INCLUSIÓN

FIGURA 32. DISTRIBUC IÓN DE LAS RESPUESTAS A LOS ITEMS EN EL CUESTIONARIO DE

INDICADORES DE INCLUSIÓN (CII)

FIG URA 33. MEDIA Y DESVIACIONES TÍPICAS DE LOS ITEMS DEL C UESTIONARIO DE

INDIC ADO RES DE INC LUSIÓN (CII).

FIG URA 34. DISCRIMINACIÓN DE LOS ITEMS -MEDIAS G RUPO ALTO-BAJ O, EN CADA ITEM

DEL CUESTIONARIO DE INDICADORES DE INCLUSION (CII). 240 


\section{Índice de Tablas}

TABLA 01. EJ EMPLO DE LA ESTRUCTURA DEL INDEX PARA LA INCLUSIÓN (ELABORACIÓN

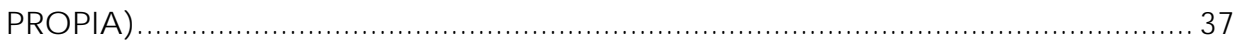

TABLA 02. DIMENSIONES, SECCIONESE INDICADORES DEL INDEX PARA LA INCLUSIÓN. ....... 39 TABLA 03. DESCRIPCIÓN DE LAS ÁREAS DE ACTUACIÓN Y ESTRATEGIAS

MOTIVACIONALES PARA DESARROLLAR UNA IMPLICACIÓN HACIA LA

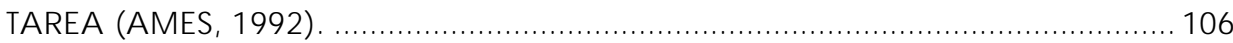

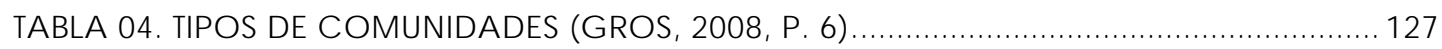

TABLA 05. DIFERENCIAS ENTRE CO MUNIDADES DE PRÁCTICA, GRUPOS, EQUIPOSY REDES

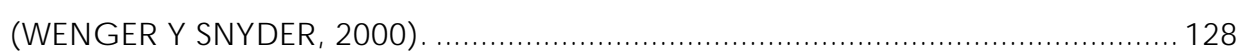

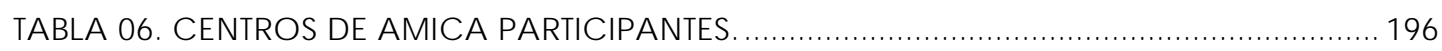

TABLA 07. PRO FESIO NALES Q UE TRABAJ AN EN LOS DIFERENTES CENTROS DE AMICA.......... 198

TABLA 08. DIMENSIONES, SECCIONESE INDICADORES DEL INDEX PARA LA INC LUSIÓN

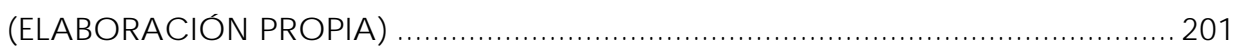

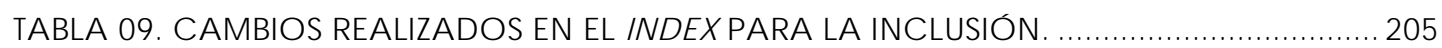

TABLA 10. CAMBIOS REAUZADOS EN LOS INDICADORES PARA LA ADAPTACIÓN DEL

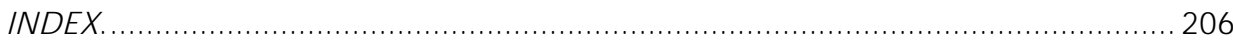

TABLA 11. CAMBIOS REALIZADOS EN LAS PREG UNTAS PARA LA ADAPTACIÓN DEL INDEX. 206 TABLA 12. ÍTEMS DEL CEII Y SU RELACIÓN CON LAS DIMENSIONESY SEC CIONES DEL INDEX ADAPTADO (VERSIÓN PRELIMINAR) ........................................................ 207

TABLA 13. CATEG ORÍAS Y DESC RIPCIÓN VERSIÓN FINAL. ..................................................... 210

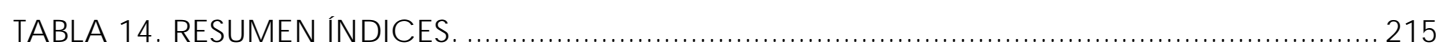

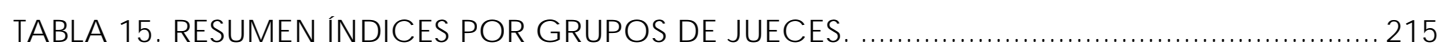

TABLA 16. DENO MINACIÓN DE CATEG O RÍAS Y DESC RIPCIÓN DE LAS MISMAS ...................228

TABLA 17. CATEG ORIAS E INDICADORES DEL INDEX PARA LA INCLUSIÓN (VERSIÓN

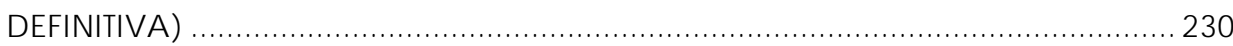

TABLA 18. FREC UENCIA Y DISTRIBUC IÓN SEG ÚN GRUPO DE EDAD DE LOS PARTICIPANTES 233 TABLA 19. FREC UENCIA Y DISTRIBUCIÓN DE LOS PARTICIPANTES, DE ACUERDO AL

TIEMPO DE RELACIÓN CON AMICA 233

TABLA 20. FREC UENCIA Y DISTRIBUCIÓN DE LOS PARTICIPANTES, DE ACUERDO AL CENTRO DE PERTENENCIA 234

TABLA 21. MEDIA MÁS-MENOS UNA DESVIACIÓN TÍPICA DE LOS ITEMS DEL

CUESTIONARIO DE INDICADORESDE INCLUSIÓN (CII) 237

TABLA 22. FREC UENCIASY PORCENTAJ E DE LA DISTRIBUC IÓN DE RESPUESTAS DE LOS ITEMS DEL CUESTIONARIO DE INDICADORES DE INCLUSIÓN (C II) 238 
TABLA 23. DISC RIMINACIÓN DE LOS ITEMS DEL C UESTIONARIO DE INDICADORES DE INCLUSIÓN (CII): RESULTADO DEL CONTRASTE ENTRE MEDIAS (PRUEBA T. DIFERENCIAS EN VALORES ABSOLUTOS)

TABLA 24. COEFICIENTES DE CORRELACIÓN DE PEARSON ENTRE LOS ITEMSY LA PUNTUACIÓN TOTAL DEL CUESTIONARIO DE INDICADORES DE INC LUSIÓN (CII).

TABLA 25. VALORACIONES DE LOSJ UEC ES RESPEC TO A LA CATEG ORÍA DE PERTENENCIA DE LOS ITEMS DEL CUESTIONARIO DE EVALUACIÓN DE LOS INDICADORES DEL INDEX

TABLA 26. PORCENTAJ E DE ACUERDO ENTRE PARES DE J UEC ES Y ESTA DÍSTICO KAPPA DE COHEN EN EL CUESTIONARIO DE EVALUACIÓN DE LOS INDICADORES DEL INDEX.

TABLA 27. RESULTADOS DEL ANÁLISIS DE FIABILIDAD DE LA ESCALA CONSIDERADA

GLOBALMENTE

TABLA 28. MATRIZFACTORIAL ROTADA DEL CUESTIONARIO INDICADORES DE INC LUSIÓN 247 TABLA 29. VARIANZA TOTAL EXPLICADA (C UESTIONARIO DE INDICADORES DE

INCLUSIÓN) 247

TABLA 30. ESTADÍSTICOSTOTAL-ELEMENTO (SUBESCALA 1: PRÁCTICAS) ... 248

TABLA 31. ESTADÍSTICOS TOTAL-ELEMENTO (SUBESCALA 2: COMUNIDAD)............................. 249

TABLA 32. ESTADÍSTIC OS TOTAL-ELEM ENTO (SUBESCALA 3: POLITTCAS) …............................... 250

TABLA 33. ESTADÍSTIC OS TOTAL-ELEM ENTO (SUBESCALA 3: POLITICAS) …............................... 251

TABLA 34. MATRIZDE CO RRELACIONES ENTRE FACTORES DE PRIMER ORDEN …...................2252

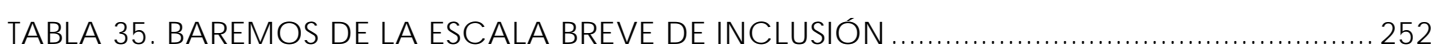

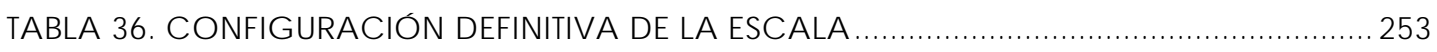

TABLA 37. ESTADÍSTIC OS DESC RIPTIVOS Y DISPERSIÓN DE LAS PUNTUACIO NES OBTENIDAS

POR LOS PARTICIPANTES EN LA ESCALA BREVE DE INCLUSIÓN. 254

TABLA 38. PUNTUACIONES MEDIASY SIG NIFICACIÓN DE LAS DIFERENCIAS EN LA ESCALA

BREVE DE INCLUSIÓN, EN FUNCIÓN DEL GÉNERO 255

TABLA 39. PUNTUACIONES MEDIASY SIG NIFICACIÓN DE LAS DIFERENCIAS EN LA ESCALA

BREVE DE INCLUSIÓN, EN FUNCIÓN DE LA EDAD DE LOS RESPO NDIENTES....... 257

TABLA 40. PUNTUACIONES MEDIASY SIG NIFICACIÓN DE LAS DIFERENCIAS EN LA ESCALA BREVE DE INCLUSIÓN, EN FUNCIÓN DE LA TIPOLOGÍA DE LOS RESPONDIENTES. 258

TABLA 41. PUNTUACIONES MEDIASY SIG NIFICACIÓN DE LAS DIFERENCIAS EN LA ESCALA BREVE DE INCLUSIÓN, EN FUNCIÓN DEL TIEMPO DE RELACIÓN CON LA ASOCIACIÓN. 259

TABLA 42. PUNTUACIONES MEDIAS OBTENIDAS POR LOS PARTICIPANTES EN FUNCIÓN DEL CENTRO DE PERTENENCIA. 260 


\section{INTRODUCCIÓN}

La inclusión tiene que ver con el proceso de incrementar y mantener la participación de todas las personas en la sociedad, escuela o comunidad de forma simultánea (Meza, 2010), procurando eliminar y/o disminuir todo tipo de procesos que lleven a la exclusión (Booth, 1996). Como indica Booth (2006) tiene que ver, en el fondo, con "el proceso de tratar de llevar determinados valores y principios étic os a la práctica" (p. 211).

El concepto ha evolucionado hacia la comprensión de que todas las personas con sus diferencias culturales, sociales y de a prendizaje, deben gozar de los mismos derec hos que el resto de ciudadanos (Meza, 2010).

La inclusión, por tanto, debe ser considerada como una búsqueda permanente de procedimientos, cada vez más adecuados, para responder a la diversidad, aprender a convivir con la diferencia y aprender a aprender de ella. De este modo la diversidad es vista desde un punto de vista positivo y como un estímulo para el aprendizaje de menoresy adultos.

En la presente Tesis Doctoral, nos alejamos del contexto educativo, que es dónde habitualmente se utiliza y se aplica el témino inclusión, para adentramos en los contextos socioeducativos de los centros que prestan servicios a personas con disca pacidad. En estos centros, como nos señalan Palacios y Bariffi (2007), hay que seguir promoviendo: 
“una mirada diferente hacia las personascon discapacidad, centrada en primer término en su condición de ser huma no en igualdad de derechos y dignidad que los demás, y en segundo lugar en una condic ión (la disc apacidad) que le acompaña, y que requiere en determina dascircunstancias de medidas específic as para garantizar el goce y ejercicio de los derechos, en igualdad de condic iones que el resto de personas". (p. 23)

Para evaluar la situación de los centros que prestan servicios a personas con discapacidad en relación con la inclusión, no contamos con instrumentos que nos permitan conocer la realidad de los mismos. Por ello, desde la presente investigación se parte de un instrumento, a fianzado a nivel intemacional, que tiene como uno de sus principales objetivos promover prácticas más inclusivas en las escuelas (Vislie, 2003). El Index para la inclusión (Booth y Ainscow, 2000) es una herra mienta integral que ofrece a los centros educativos apoyo y colaboración en el proceso de autoevaluación y en la planificación e implementación de futuras práctic a sinclusivas.

Teniendo en cuenta lo a nterio mente expuesto, en esta Tesis Doctoral hemos pretendido abordar tres cuestiones fundamentales: (1) adaptar el Index para la Inclusión, diseñado originalmente para el ámbito escolar (Booth y Ainscow, 2000), para su aplicación en centros que prestan servicios a personas con discapacidad, (2) construir un Cuestionario de Evaluación de los Indic a dores del Index (CEII) con adecuadas propiedades psicométricas que nos proporcione evidencias de la adecuación de la adaptación y de la pertinencia de los cambios realizados partiendo de una base teórica sólida, y (3) evaluar la inclusión en un centro que presta servicios a personas con discapacidad determinando el posible impacto de variables sociodemográficas en la percepción de la inclusión. 
De lo a nterior se desprenden las dos vertientes básicas de esta investigac ión: la profundización teórica y la investigación empírica. La vertiente teórica del trabajo se plasma en los cuatro primeros ca pítulos y la empírica en los tresúltimos.

La intención del primer capítulo es ofrecer una revisión de la conceptua liza ción de la inc lusión para profundiza posteriomente en el Index para la Inclusión diseñado por Booth y Ainscow (2000) para contextos educativos. En este apartado se analiza tanto la estructura del Index como el proceso de trabajo propuesto por sus autores. Una vez presentado el instrumento, base de este trabajo, se recogen las principales investigaciones que se han realizado desde su lanza miento en el año 2000.

En el segundo capítulo se ana lizan las característic as de las orga nizaciones inclusivas partiendo de las tres dimensiones que nos presenta el Index: cultura, políticas y prácticas inclusivas. En los tres a partados se ha realizado una búsqueda documental que nos servirá de base para la parte empírica de la tesis. En el primer apartado, se señalan los aspectos básicos que subyacen a la cultura de una organización con especial atención en aquellos que se reflejan en el Index como elementos clave: la comunidad y los valores inclusivos. En el segundo, se han investigado qué elementos deben caracterizar las políticas inclusivas que se pongan en marcha en los centros que prestan servicios a personas con discapacidad. Se han considerado como pilar de dichas políticas inclusivas los derechos de las personas con discapacidad. El tercer y último apartado, se ha centrado en las prácticas inclusivas y en su diseño para que, estando orientadas a fomentar el aprendizaje y la participación, cada persona pueda satisfacer sus necesidades, aspiraciones y expectativas.

El tercer capítulo se centra en las Comunidades de Práctica (CoPs) y en la base científica de la que parten: el aprendizaje situado. Se abordan las CoPs 
desde la perspectiva de Wenger (2001) y se analizan los procesos que se producen en sus dinámicas y los principios que sugieren diversos autores para promover y guiar la evolución de una Comunidad de Práctica dentro de una organización. En las últimas publicaciones realizadas sobre el Index (Ainscow y Sandill, 2010) ya se empieza a destacar las Comunidades de Práctica como una nueva metodología para trabajar con él, alejada de la propuesta inicial que se ha señalado en el primercapítulo.

En el cuarto capítulo se presenta AMICA, la organización que ha servido de referencia para la elaboración de la tesis. El objetivo del mismo es mostrar todos a quellos aspectos relaciona dos con sus va lores, políticas y prácticas orga niza tivas que hacen a la organización diferente de otros centros. En él se hace especial hinc apié en su filosofía de trabajo y su método de gestión.

Una vez presentados los bloques correspondientes a la "vertiente teóric a" de este trabajo, los capítulos quinto y sexto se dedic an por completo a la "vertiente empíric a" del mismo.

En el capitulo quinto, nos proponemos, adecuar el Index para la Inclusión (enfoque, teminología, etc.) al contexto socio-educativo de los centros que prestan senvicios a personas con discapacidad (Fase I del proceso de investigación); en segundo lugar, para someter a la adaptación del Index a un proceso de validación de su contenido (validez aparente) por parte de jueces expertos, profesionales, personas usuarias y familiares de personas con discapacidad, se ha elaborado una versión preliminar del Cuestionario de Evaluación de los Indicadores del Index (CEII)) (Fase II del proceso de investigación). El capitulo se divide en tres apartados principales, uno en el que se plantean los objetivos de la investigación y las hipótesis, otro en el que se describe la metodología y el último dedicado a la presentación de los resultados. 
El capitulo sexto, partiendo de los resultados de la Fase II, se realiza una readaptación del instrumento y se analizan las propiedades psicométricas del Cuestionario de Evaluación de los Indicadores del Index (CEII), para obtener la versión definitiva (Fase III del proceso de investigación). En segundo lugar, la Fase IV de la investigación, se centra en evaluar la inclusión en un centro de personas con discapacidad (AMICA) y determinar el posible impacto de variables sociodemográficas en la percepción de la inclusión, para lo cual, se ha elaborado el Cuestionario de Indicadores de Inclusión (CII). El capitulo se divide en tres grandes bloques: en el primero, se plantean los objetivos y las hipótesis, en el segundo se exponen el método y los instrumentos, y en el tercero se recoge el a ná lisis, los resulta dos y la s c onc lusiones del c a pítulo.

Para finalizar, el séptimo capítulo se dedica a presentar las principales conclusiones de la Tesis, discutir los resultados, resaltar las limitaciones y proponer líneas futuras de investiga ción. Las evidencias encontra das a lo largo del estudio, y que se recogen ampliamente en este capítulo, permiten sugerir que el Index para la inclusión adaptado ha mostrado ser un instrumento que nos permite trabajar todos aquellos temas relacionados con la inclusión en los centros que prestan servicios a personas con discapacidad. 
PRIMERA PARIE.

PUNDAMENTACIÓN TEÓRICA 



\section{Posicionando el Index para la Inclusión}

Booth, T. y Ainsc ow, M (2002)

El Index es un conjunto de materiales diseñados para apoyar a los centros educativos en el proceso de avance hacia escuelas inclusivas, teniendo en cuenta los puntos de vista del equipo docente, de los miembros del consejo escolar, del alumnado, de las familias y de otros miembros de la comunidad. (p. 19) 


\subsection{Introduc ción}

A lo largo de este primer capítulo vamos a analizar qué se entiende por inclusión para pasar a continuación a presentar el Index para la inclusión. Nos detendremos en su estructura, ya que a tra vés de ella podemos conocer la filosofía que está en la base del instrumento, y en la metodología de trabajo que plantea su utilización en los centros. Para complementar la visión se a nalizarán a lgunas de las principales investigaciones realizadas a nivel intemacional sobre la aplicación del Index para Inclusión.

\subsection{Inc lusión: presencia, aprendizaje y participación}

El concepto de inclusión surgió, y se empezó a utilizar inicialmente, en los entomos educativos si bien en la actualidad se aplica a la comunidad en general (J enaro, 2000). Pese a la extensión de su uso, no ha sido suficientemente definido hasta la fecha, lo que permite que sea utilizado con múltiples significados, no siempre compatibles (Villa lobos y Za la ka in, 2010).

Como nos señala la UNESCO (FEAPS, 2009)

La noción de inclusión no es algo propio del sistema educativo, más bien debería estar en armonía con la noción de una sociedad inclusiva que aprecia ese valor y en la que cada miembro tiene su lugar. Los costes sociales de la exclusión, estigmatización, segregación, a lienación, quedan más allá de la responsabilidad del sistema educativo, y hay que buscarlos en la ética de la sociedad en su conjunto. La inclusión está impulsada y dirigida por valores y son nuestros valores y creencias los que modelan la política y la cultura que tenemos y que queremos. (p.23)

La inclusión tiene que ver con el proceso de incrementar y mantener la participación de todas las personas en la sociedad, escuela o comunidad de 
forma simultánea (Meza, 2010), procurando eliminar y/o disminuir todo tipo de procesos que lleven a la exclusión (Booth, 1996). Por ello, una orga niza ción inclusiva se caracterizará, tal y como señala Ainscow (1999), por la ausencia de toda forma de discriminación; en ella, cuestiones tales como la justicia social, la equidad, los derechos humanos y la no discrimina ción serán claves (Barton, 2009; Meza, 2010).

La inclusión tiene muchos significados o facetas (Booth, Nes y Stromstad, 2003). Según Echeita (2007) es más un poliedro de múltiples caras, que una figura plana, razón por lo cual todas ellas contienen algo de su esencia pero ninguna agota el significado pleno de la misma (p.4), que finalmente, como indica Booth (2006) tiene que ver, en el fondo, con “el proceso de tratar de llevar determinados valores y principios éticosa la práctica" (p. 211).

De acuerdo con Booth (2005) la inclusión no es otro término más para referirse a la integración de las personas con discapacidad. El concepto ha evolucionado hacia la comprensión de que todas las personas con sus diferencias culturales, sociales y de aprendizaje, deben gozar de los mismos derechos que el resto de ciudadanos (Meza, 2010). Hoy en día, según Villalobos y Zalakain (2010) cabe hablar de una concepción de la inclusión que supera el concepto tradicional de integración, ya que busca adaptar la sociedad a las necesidades y características individuales de todos sus miembros, y no a que las personas con algún tipo de limitación se adapten a la noma social marcada.

La inclusión debe ser considerada como una búsqueda permanente de procedimientos, cada vez más adecuados, para: responder a la diversidad, aprender a convivir con la diferencia y aprender a aprender de ella. De este modo la diversidad es analizada desde un punto de vista positivo y como un estímulo para el aprendizaje de menores y adultos.

La inclusión conlleva la recopilación y evaluación de información de fuentes muy diversas con el objeto de planificar mejoras en políticas y prácticas inclusivas. 
Se trata de utilizar la información adquirida para estimular la creatividad y la resolución de problemas.

La utilización del concepto "barreras al aprendizaje y a la participación", tanto en el Index original (Booth y Ainscow, 2002) como en la adaptación del mismo que presentaremos, implica un modelo social respecto a las dificultades de aprendizaje y a la discapacidad.

Como señala el Index (Booth y Ainscow, 2002) entendemos que las barreras al a prendizaje y a la partic ipación a parecen en los procesos de interacción que se dan entre las personas y sus contextos: las personas, las políticas, las instituciones, las culturas, y las circ unstancias sociales y económic a s que afectan a sus vidas.

Consecuentemente, en el Index, la inclusión implica identificar y minimizar las barreras para el aprendizaje y la participación y maximizar los recursos que apoyan ambos procesos. Las barreras, al igual que los recursos para reducirlas, se pueden encontrar en todos los aspectos y estructuras del sistema: dentro de las organizaciones, en la comunidad o en las políticas locales y nacionales. Las ba rreras pueden impedir el acceso al centro o limitar la participación dentro de él.

Mientras que es posible que las organizaciones tengan poco que hacer para ayudar a superar las discapacidades, sí que pueden producir un impacto considerable en la reducción de las limitaciones derivadas de las barreras de acceso y de participación, tanto físicas como personales e institucionales.

Ainscow, Booth y Dyson (2006, p. 25) hacen referencia a tres variables relevantes para la participación de cualquier persona en las actividades que se llevan a cabo en una organización: (1) presencia, (2) aprendizaje y (3) participación.

(1) Presencia tiene que ver con el lugar adonde acuden las personas con algún tipo de limitación, con los contextos donde se van a producir los procesos de aprendizaje y de partic ipación. 
(2) Por aprendizaje se debe entender que la organización se preocupa por adoptar las medidas necesarias para que, en este caso, las personas con discapacidad, consigan mejores resultados en todas las áreas de su vida. Por lo tanto, las acciones que se desarrollen para potenciar su desarrollo personal, profesional y social no se deben conformar con lo básico o descuidar ámbitos que fomenten la vida independiente.

(3) La participación se concreta en el deber de reconocery apreciar la identidad de cada persona y la preocupación por su bienestar personal (por ejemplo, la autoestima) y social (por ejemplo, relaciones de amistad y compañerismo) y, por lo tanto, por la ausencia de situaciones de maltrato, exclusión o a islamiento social.

De acuerdo con la Clasificación Intemacional del Funcionamiento de la discapacidad y de la salud (CIF) (OMS, 2001), la participación es el acto de involucrarse en una situación vital en la que los factores físicos, sociales y actitudinales pueden actuar como barreras o como facilitadores de la misma (Meza, 2010).

La participación es un elemento clave para definir la inclusión. Para Booth y Ainsc ow (2000) no es otra cosa más que ser reconocido, aceptado y valorado por lo que uno es. Para Norwich (2008) esta partic ipación debe extenderse más allá de las organizaciones para reflejarse en las culturas, en las comunidades, en el conjunto de la sociedad, ya que no sólo se refiere a estarcon los otros sino también a compartir con ellos ideas, acciones, sentimientos, aprendizajes, valores, etc. Según Meza (2010) conlleva una implicación activa en la toma de decisiones, en el desarrollo de los hechos y en la evaluación de los resultados. 


\subsection{E Index para la inclusión}

Mittler (2000) posiciona el Index para la inclusión como un compañero de viaje para aquellos centros educativos que estén interesados en explorar un enfoque inclusivo que se puede aplicar en todos los niveles de la organización.

Ainscow (1998) señala que el proyecto del Index se basa en trabajos anteriores realizados por investigadores en Australia (Centre, Ward y Ferguson, 1991) y Améric a del Norte (Eic hinger, Meyer y D’Aquanni, 1996). Estos proyec tos de investigación animaban a pasar del énfasis del modelo médico, en busca de los "problemas" en los alumnos, hacia una exploración más profunda de los procesos a través de los cuales una escuela incluye y excluye a los estudiantes (Ainscow, 1999:148). Este mismo autor en 1998 y 1999, sostiene que el trabajo realizado para desarrollar el Index para la inclusión está más cerca de su predecesor estadounidense, el Programa de Indicadores de Calidad (PQI), que del enfoque Australiano.

El Index para la inclusión fue desarrollado en el Centro de Estudios sobre Educación Inclusiva (CSIE) en colaboración con la Universidad de Manchester (Camington y Robinson, 2006; Mittler, 2000) y el Colegio Christ Church University de Canterbury (Inglaterra) y representa el producto obtenido tras tres años de trabajo experimental y de su aplicación en 25 escuelas de Inglaterra (Rustemier y Booth, 2005).

El Index para la inclusión es, pues, el resultado de un proceso intenso de investigación colaborativa. Se diferencia de sus homólogos de Australia y de América en tres puntos importantes: (1) la atención se centra no sólo en los estudiantes con necesidades especiales sino en todos los que forman parte de la Comunidad Educativa, (2) se centra en la participación y en los procesos que se desarrollan en las escuelas y no sólo en la medida como sucedía en el PQI 
estadounidense, y (3) todas las estrategias para llevar a cabo la revisión y el desa rrollo están acordadas dentro de la escuela (Ainsc ow, 1998; 1999).

El Index para la inclusión se publicó por primera vez en el año 2000 (Booth y Ainsc ow, 2000) y fue revisa do en 2002 (Booth y Ainsc ow, 2002). En 2006 se revisó el “Index for Inclusion: developing play, leaming and participation in early years and childc are" (Booth, Ainsc ow y Kingston, 2006).

En la actualidad, el Index para la inclusión se ha afianzado a nivel intemacional como un instrumento que promueve prácticas más inclusivas en las escuelas (Vislie, 2003). Booth y Ainsc ow (2002) lo describen como una herramienta integral que ofrece a los centros educativos apoyo y colaboración en el proceso de autoevaluación y en la planificación e implementación de futuras prácticas inclusivas. Todo ello, a partir de los recursos y de las opiniones del equipo directivo, el profesorado, los alumnos y padres o cuidadores, así como los miembros de la comunidad en la que está inmersa la escuela. Es un marco de apoyo cuyo valor reside en su potencial para promover la reflexión y el desarrollo de prácticas que promueven el aprendizaje y la participación, tanto en las escuelas de primaria como en los centros de secundaria (Vaughan, 2002).

El Index no ofrece una planificación exacta sino que implica un proceso de autoevaluación sistémico a través de tres dimensiones superpuestas con la vida escolar: (1) la cultura escolar, (2) la política y (3) la práctica. Pretende estimular a las escuelas para que inicien procesos de planificación y colaboración acordes a sus valores y contextos, que sean sostenibles en el tiempo y que se puedan gestionar desde el propio centro (Rustemier y Booth, 2005). Uno de los objetivos que persigue es facilitar un proceso profundo de exploración que suscite el cambio y que haga al centro educativo embarcarse en un viaje que le lleve desde su actual posición a convertirse en un centro inclusivo. 
Es fundamental para el Index para la inclusión la creación de una cultura escolar que fomente la preocupación por el desarrollo de formas de trabajar que traten de reducir las barreras al aprendizaje y a la participación de todos los estudiantes; independientemente de quién las experimente y de que dichas barreras se encuentren, en la cultura, la política y/o las prácticas de la escuela (Booth y Ainsc ow, 2002; Rustemier y Booth, 2005).

El Index alienta a los profesionales que trabajan en el centro a compartir y construir nuevos conocimientos a partir de la información que tienen sobre los a spectos que impiden el aprendizaje y la participación de sus estudiantes. A través de un análisis de la escuela en su conjunto, inician un proceso que les lleva a realizar un examen detallado, cada vez más exigente, de las posibilidades para inc rementar el a prendizaje y la participación. Todo ello, no debe ser visto como un trabajo adicional para los centros educativos, sino más bien como una forma sistemática de participar en la planificación organizativa y escolar, que implica (1) el establecimiento de prioridades para el cambio, (2) la aplicación de nuevas prácticas y la revisión del progreso realizado, y (3) la movilización de recursos infra utiliza dos dentro del personal, los estudiantes, los equipos, los padres y otros miembros de la comunidad escolar.

La investigación-acción que subyace al proceso está organizada a través de un conjunto de indicadores y preguntas, que facilitan el establecimiento del perfil de la escuela y la orientan sobre las áreas en las que es conveniente realizar un a nálisis exhaustivo de su situación presente y de sus posibilidades futuras para alcanzar ma yores cotas de inclusión. 
En el Index, tanto la inclusión como la exclusión, se exploran a tra vés de tres dimensiones interrelacionadas en la dinámica diaria de los centros educativos y que tienen igual importancia e incidencia en el proceso de desarrollo de la inclusión. Son aquellas que se relacionan con su cultura, con su política y con su práctica.

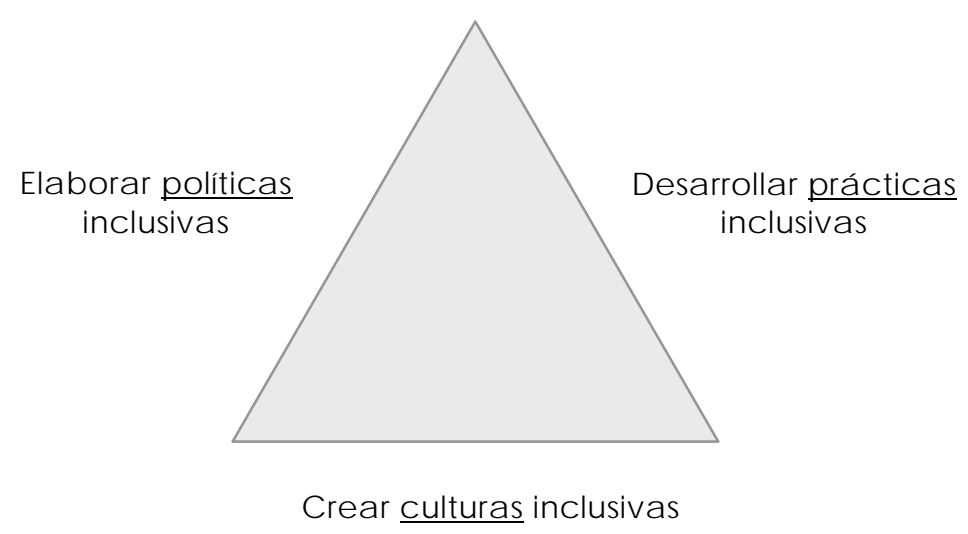

FIG URA 01. LAS TRES DIMENSIO NES DEL INDEX PARA LA INCLUSIÓN (BO OTH Y AINSC O W, 2002)

En el instrumento las dimensiones se concretan a través de secciones, dos por dimensión. Las secciones se desarrollan a través de indicadores y preguntas. El conjunto nos proporciona un mapa detalla do que guía el a nálisis de la situación de la organización en ese momento y determina futuras posibilida des de acción.

\subsubsection{Estructura del Index para la inclusión}

Los materiales del Index contienen una estructura ramificada que permite de forma progresiva realizar un examen detallado de todos los aspectos de la escuela. El esquema global del instrumento es el que se presenta a continuación, aunque en páginas siguientes se desa rolla rá a mpliamente. 


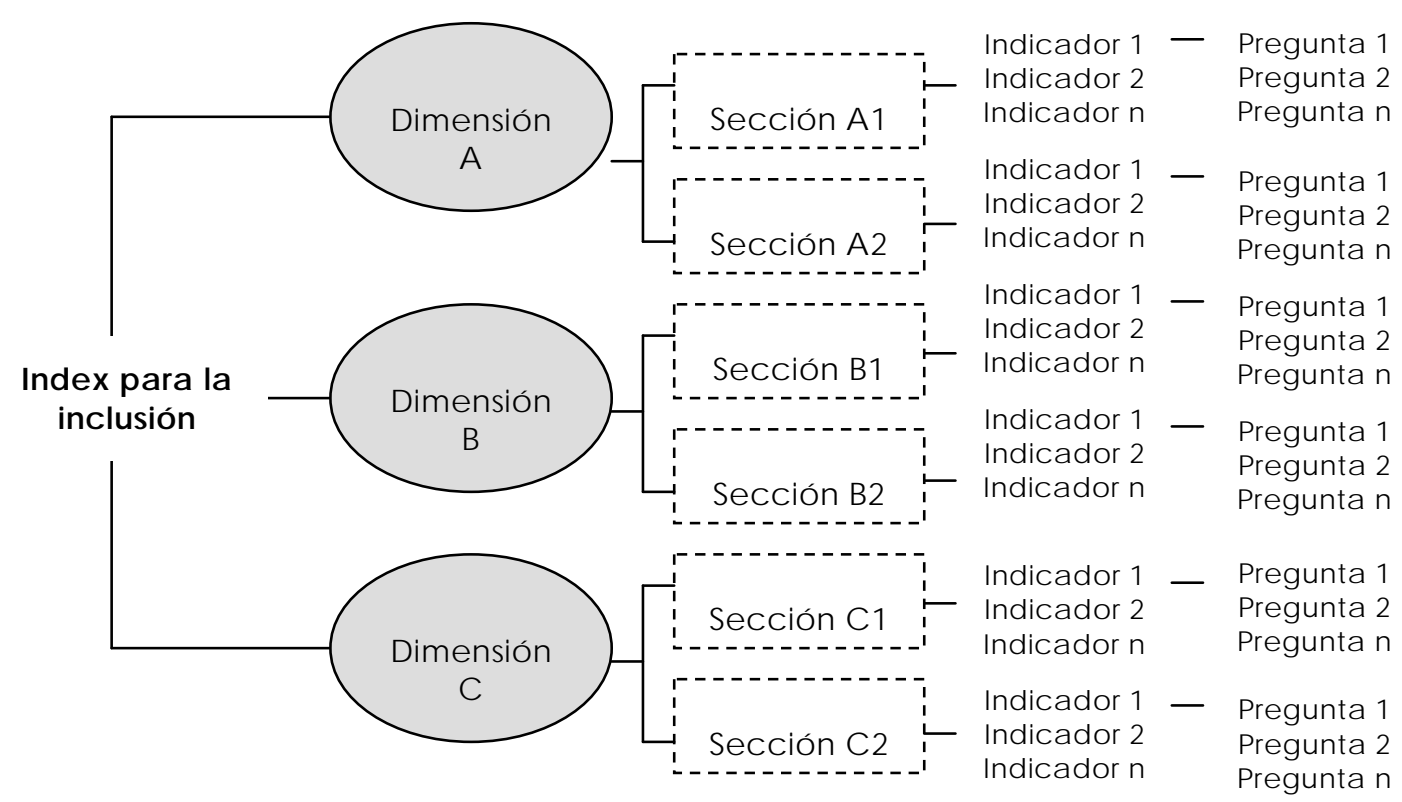

FIG URA 02. ESQ UEMA DEL INDEX PARA LA INCLUSIÓN (ELABORACIÓN PROPIA)

Las dimensiones tienen la función de dirigir el pensamiento de la escuela hacia el cambio y representan áreas relativamente distintas de la actividad escolar. Las tres dimensiones se desarrollan a través de 6 secciones, dos por dimensión y cada una de ellas se despliega a través de indicadores. En el instrumento nos encontramos con 45 indicadores cuyo significado se esclarece a través de unas 500 de preguntas, aproximadamente de 10 a 12 por indicador (Rustemier y Booth, 2005). De forma conjunta, las dimensiones, las secciones, indic adores y preguntas proporcionan un mapa cada vez más detallado que va a orientar la exploración de la posición actual y va a permitir trazar las posibilidades de un futuro más inclusivo (Booth y Ainscow, 2000). 
Las tres dimensiones del Index no se dan de forma aislada en la organización, si no que se superponen entre sí, ya que los a vances en la cultura de la organización requieren a su vez la formulación de políticas y la implementación de prácticas.

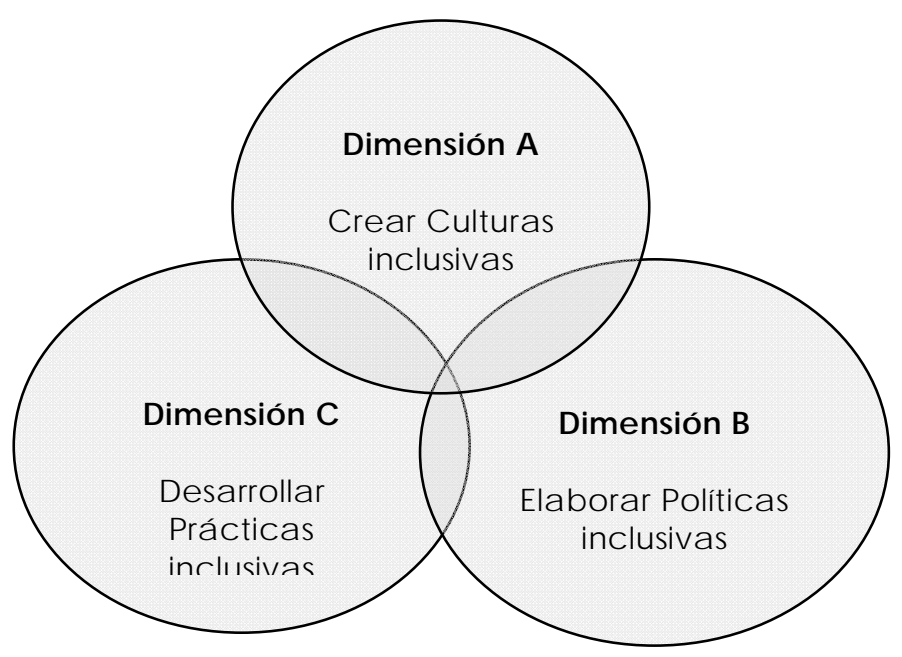

FIG URA 03. SUPERPOSICIÓN DE LAS DIMENSIONES DEL INDEX PARA LA INCLUSIÓN (ELABORACIÓN PROPIA)

En la Guía para la evaluación y mejora de la educación inclusiva (Booth y Ainsc ow, 2002) podemos ver cómo se describen las tres dimensiones.

Dimensión A. Crear Culturas inclusivas. Esta dimensión está orienta da hacia la creación de una comunidad escolar segura, acogedora, colaboradora y estimulante en la que cada uno es valorado como el fundamento primordial para que todo el alumnado tenga mayores niveles de logro. Pretende desarrollar valores inclusivos, compartidos por todo el profesorado, los estudiantes, los miembros del consejo escolar y las familias, de forma que se transmitan a todos los nuevos miembros de la comunidad escolar. Los principios que se derivan de esta cultura escolar son los que guían las dec isiones que se concretan en las políticas escolares de cada centro y en el quehacer diario, y de esta forma el 
aprendizaje de todos encuentra apoyo en el proceso continuo de innova ción educativa.

Dimensión B. Eaborar políticas inclusivas. Esta dimensión pretende asegurar que la inclusión esté en el corazón del proceso de innovación, empapando todas las políticas, para que mejore el aprendizaje y la participación de todos los estudiantes. En este contexto se considera que "apoyo" son todas aquellas actividades que aumentan la capacidad de un centro educativo para atender a la diversidad del alumnado. Todas las modalidades de apoyo se reúnen dentro de un único marco y se perciben desde la perspectiva del desarrollo de los alumnos, más que desde la perspectiva del centro o de las estructuras administrativas.

Dimensión C. Desamollar Prácticas inclusivas. Esta dimensión pretende que las prácticas de los centros reflejen la cultura y las políticas inclusivas. Intenta asegurar que las actividades en el aula y las actividades extraescolares motiven la participación de todo el alumnado y tengan en cuenta el conocimiento y la experiencia de los estudiantes fuera del entomo escolar. La docencia y los apoyos se integran para orquestar el aprendizaje de forma que se superen las barreras para el aprendizaje y la participación. El profesorado moviliza recursos del centro educativo y de las comunidades locales para mantener el aprendiza je activo de todos. (p.21)

A la hora de establecer prioridades y promover cambios en las organizaciones se ha de tener presente la superposición de las dimensiones del Index, y sería adecuado que se considerara que una prioridad específic a a sociada a una dimensión requerirá, sin lugara dudas, cambios en las otras. 
Cada dimensión, a su vez, se divide en dos secciones, que se centran en un conjunto de actividades en las que las organizaciones deben comprometerse como vía para ir mejorando el aprendizaje y la participación.

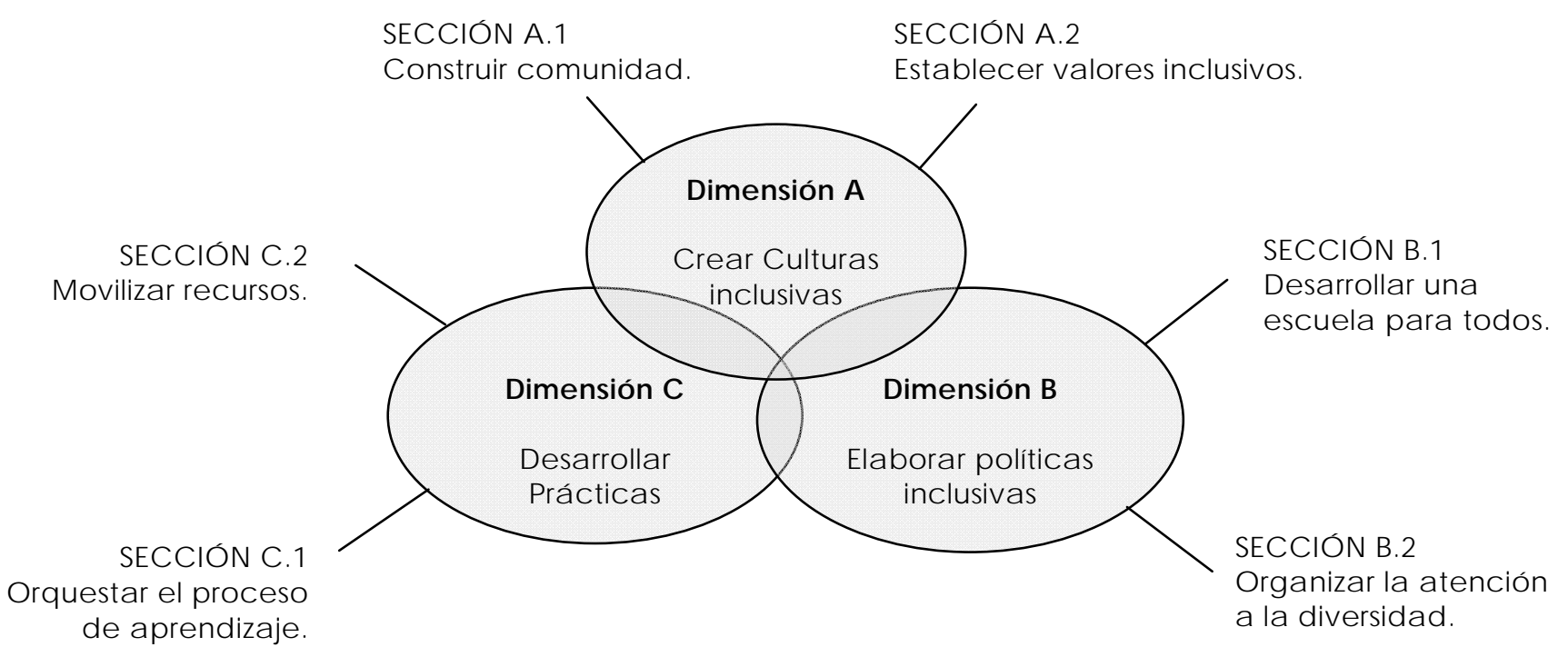

FIG URA 04. DIMENSIONES Y SECCIONES (ELABORACIÓN PROPIA)

Cada sección está formada porindicadores, hasta un máximo de doce, y el significado de cada uno se concreta a través de una serie de preguntas. Los indicadores son declaraciones de la aspiración inclusiva con los que se pueden comparar los acuerdos ya existentes en la escuela para, de este modo, establecer prioridades para la evolución.

Como nos indic an Booth y Ainsc ow (2002) "los indicadores representan una formalización de aspiraciones con las que se compara la situación existente en la organización, para poder llegar a establecer determina das prioridades de mejora" (p.23). Las preguntas vinculadas a cada indic ador ayudan a definir su significado de una forma que invita a las organizaciones a explora ro con detalle.

Tales indicadores pueden cumplir varias funciones, por ejemplo, pueden 
servir para impulsar la reflexión de grupos de trabajo dentro de la organización y sacar a la luz su conocimiento previo acerca del funcionamiento de la organización, o para moldear los procesos de investigación que se quisieran llevar a cabo y servir como criterio de evaluación de los progresos.

Cada indicador se codifica con una letra y dos números: las letras $A$ (Culturas), o B (Políticas), o C (Prácticas) de las dimensiones, seguida s por el número 1 y 2, en función de las secciones y a partir de ahí se añade un nuevo número que va ordenando los indicadores dentro de cada sec ción. Se muestran a continuación las dimensiones, sec cionese indic adores.

Presentamos a continuación, a modo de ejemplo, el desglose del Indic ador A.1.1. "Todo el mundo merece sentirse acogido", perteneciente a la Dimensión A "Crear CULTURAS inclusivas" y la sección A.1. "Construir comunidad" con sus preguntas, tal y como se recoge en el Indexpara la Inclusión.

\begin{tabular}{|c|c|}
\hline Dimensión A & Crear CULTURAS inclusivas \\
\hline Sección A.1. & Construir comunidad \\
\hline Indic ad or A.1.1. & Todo el mundo merece sentirse acogido \\
\hline Preguntas & $\begin{array}{l}\text { i. ¿Es a mistoso y acogedor el primer contac to que la gente } \\
\text { tiene con el centro educa tivo? } \\
\text { ii. ¿Es el centro acogedor para todo el a lumnado, inc luyendo } \\
\text { los estudiantes con defic iencias y los que están } \\
\text { temporalmente? } \\
\text { iii. ¿Es el centro acogedor para todas las fa milias y otros } \\
\text { miembros de sus instituciones de la comunidad? } \\
\text { iv. ¿Es la información sobre el centro accesible para todos, } \\
\text { independientemente de su lengua de origen o de a lguna } \\
\text { defic iencia (por ej. en Braille, grabado en audio y video, en } \\
\text { letras grandes, cuando sea necesario)? } \\
\text { v. ¿Hay intérpretes de lengua de signos y de otras lenguas de } \\
\text { origen disponibles cuando sean necesarios? } \\
\text { vi. ¿En los documentos del centro, incluso en los folletos } \\
\text { informativos, está claro que es parte de la rutina escolar } \\
\text { respondera toda la diversidad del a lumnado y de sus } \\
\text { contextos? }\end{array}$ \\
\hline
\end{tabular}


vii. ¿Los órganos de comunic ación del centro (boletín, revista...) recogen los intereses de todos los miembros de la comunidad escolar?

viii. ¿El centro tiene en cuenta las culturas locales y de los colectivos de nueva inmigración a través de símbolos y exposiciones?

ix. ¿Hay actos sociales para dar la bienvenida o para despedir al a lumnado y al profesorado?

x. ¿El alumnado siente pertenencia a su clase o a su aula de tutoría?

xi. ¿El a lumnado, el profeso ra do, los miembros del consejo escolar y los miembros de la comunidad sienten pertenencia al centro?

TABLA 01. EJ EMPLO DE LA ESTRUC TURA DEL INDEX PARA LA INCLUSIÓN (ELABORACIÓN PROPIA).

No debe olvidarse que una parte esencial del uso del Index lo constituye el intercambio de información acerca de lo que se conoce sobre el funcionamiento actual de la organización y las barreras para el aprendizaje y la participación que existen dentro de ella. Por ello, es importante indic a r que el trabajo con el Index no pretende obviar las soluciones potenciales que ya estén bien articuladas en la organización, todo lo contrario, en lo posible intentará enfa tizarlas.

También consideramos importante señalar que existen centros educativos donde no se podrán aplicar algunos indicadores, pero a pesar de estas limitaciones, esta s orga nizaciones genera Imente están dispuestas a realizar un plan de mejora de la organización con una orientación inclusiva y, por tanto, a daptarán los indicadores y las preguntas a sus propósitos y características.

Para finalizar este apartado presentamos las Dimensiones, Secciones e Indic a dores del Index para Inclusión de Booth y Ainsc ow (2002). 
Dimensión A Crear CULTURAS inc lusivas

A.1. Construir comunidad.

A.1.1. Todo el mundo merece sentirse acogido.

A.1.2. Los estudiantes se ayudan unos a otros.

A.1.3. Los profesores colaboran entre ellos.

A.1.4. El profesorado y el alumnado se tratan con respeto.

A.1.5. Existe colaboración entre el profesorado y las familias.

A.1.6. El profesorado y los miembros del consejo escolar trabajan bien juntos.

A.1.7. Todas las instituciones de la comunidad están involuc radas en el centro.

A.2. Establecerva lores inc lusivos.

A.2.1. Se tienen expectativas altas sobre todo el alumnado.

A.2.2. El profesorado, los miembros del consejo escolar, el alumna do y las fa milias comparten una filosofía de inclusión.

A.2.3. El profesorado piensa que todo el alumnado es igual de importante.

A.2.4. El profesorado y el alumnado son tratados como personas y como poseedores de un «rol».

A.2.5. El profesorado intenta eliminar todas las barreras al a prendizaje y la partic ipación en el centro.

A.2.6. El centro se esfuerza en disminuir las prác tic as disc rimina torias.

Dimensión B Elaborar POÚTC AS inclusivas

B.1. Desa mollar una escuela para todos.

B.1.1. Los nombramientos y las promociones de los docentes son justas

B.1.2. Se ayuda a todo nuevo miembro del profesorado a adaptarse al centro.

B.1.3. El centro intenta admitir a todo el a lumnado de su localidad.

B.1.4. El centro hace que sus instalaciones sean físic amente accesib les para todos.

B.1.5. Cuando el alumnado accede al centro porprimera vez se le ayuda a adaptarse.

B.1.6. El centro organiza grupos de aprendizaje para que todo el alumna do se sienta valorado.

B.2. Organizar la atención a la diversidad.

B.2.1. Se coordinan todaslas formas de apoyo.

B.2.2. Lasactividades de desarrollo profesional del profesorado lesayudan a dar respuestas a la diversidad del alumnado.

B.2.3. Las polític as de «necesida des especiales» son polític as de inclusión.

B.2.4. El Código de la Práctica* se utiliza para reducir las barreras al a prendizaje y la participación de todos los alumnos.

B.2.5. El apoyo de losalumnos que aprenden castellano como segunda lengua se coordina con otros tipos de a poyo pedagógico.

B.2.6. Laspolíticas de orientación educativa y psicopedagógica se vinculan con las 
medidas de desa rrollo cumiculary de apoyo pedagógico.

B.2.7. Se han reducido las prácticas de expulsión por indisciplina.

B.2.8. Se ha reducido el absentismo escolar.

B.2.9. Se han reducido las relaciones de abuso de poder entre iguales o bullying.

\section{Dimensión C Desa rollar PRÁCTICAS inclusivas}

C.1. Orquestar el proceso de aprendizaje.

C.1.1. Las unidades didác tic as responden a la diversidad de los alumnos.

C.1.2. Las unidades didácticas se hacen acc esib les a todos los estud ia ntes.

C.1.3. Las unidades didácticascontribuyen a una mayor comprensión de la diferencia.

C.1.4. Se implica activamente a los estudiantes en su propio aprendizaje.

C.1.5. Los estudiantes aprenden de manera colaboradora.

C.1.6. La evaluación motiva los logros de todos los estudiantes.

C.1.7. La disciplina de la clase se basa en el respeto mutuo.

C.1.8. Los docentes planific an, revisan y enseñan en colaboración.

C.1.9. Los docentes se preoc upan de apoyar el aprendizaje y la participación de todos los estudiantes.

C.1.10. El profesorado de apoyo se preocupa de facilitar el aprendizaje y la participación de todos los estudiantes.

C.1.11. Los «deberes para casa» contribuyen al a prendizaje de todos.

C.1.12. Todos los estudiantes participan en las activida des complementarias y extraescolares.

C.2. Movilizar recursos.

C.2.1. Los recursos del centro se distribuyen de forma justa para a poyar la inclusión.

C.2.2. Se conocen y se a provechan los recursos de la comunidad.

C.2.3. La experiencia del profesorado se aprovecha plenamente.

C.2.4. La diversidad entre el alumnado se utiliza como un recurso para la enseñanza y el aprendizaje.

C.2.5. El profesorado genera recursos para a poyar el aprendizaje y la participación.

TABLA 02. DIMENSIONES, SECCIONES E INDICADO RES DEL INDEX PARA LA INCLUSIÓN.

\subsubsection{El proceso de trabajo con el Index para la inclusión}

La metodología de trabajo del Index para la inclusión ha sido una de las principales preocupaciones sobre la que se han centra do diferentes investigadores (Ainsc ow, 1998; Ainscow, 1999; Ainsc ow, 2003; Ainscow, Booth y Dyson, 2001; 
Ainsc ow, Howes, Fa rell y Frankham, 2003; Ainsc ow, Booth y Dyson, 2004; Ainsc ow y Kaplan, 2004; Ainscow, 2007; Rustemier y Booth, 2005; West, Ainsc ow y Stanford, 2005).

El ciclo que propone el Index implica algo más que una exhaustiva planificación de un proceso de cambio progresivo en las organizaciones, ya que tiene como objetivo generar cambios en la cultura y en los valores que posibiliten tanto a los profesionales como a los estudiantes adoptar práctic as inclusivas que vayan más allá de cualquier prioridad partic ular id entific a da.

El proceso de trabajo, según sus autores, se debe realizar a través de un ciclo de actividades que tienen como objetivo revisar y desamollar las políticas y prácticas ya existentes. El proceso se inicia con un primer encuentro con los materiales para, a continuación, implicarse de forma progresiva a través de una serie de cinco etapas que giran en tomo al plan de mejora de la organización. Cada organización puede elegir pasar por el ciclo en más de una ocasión.

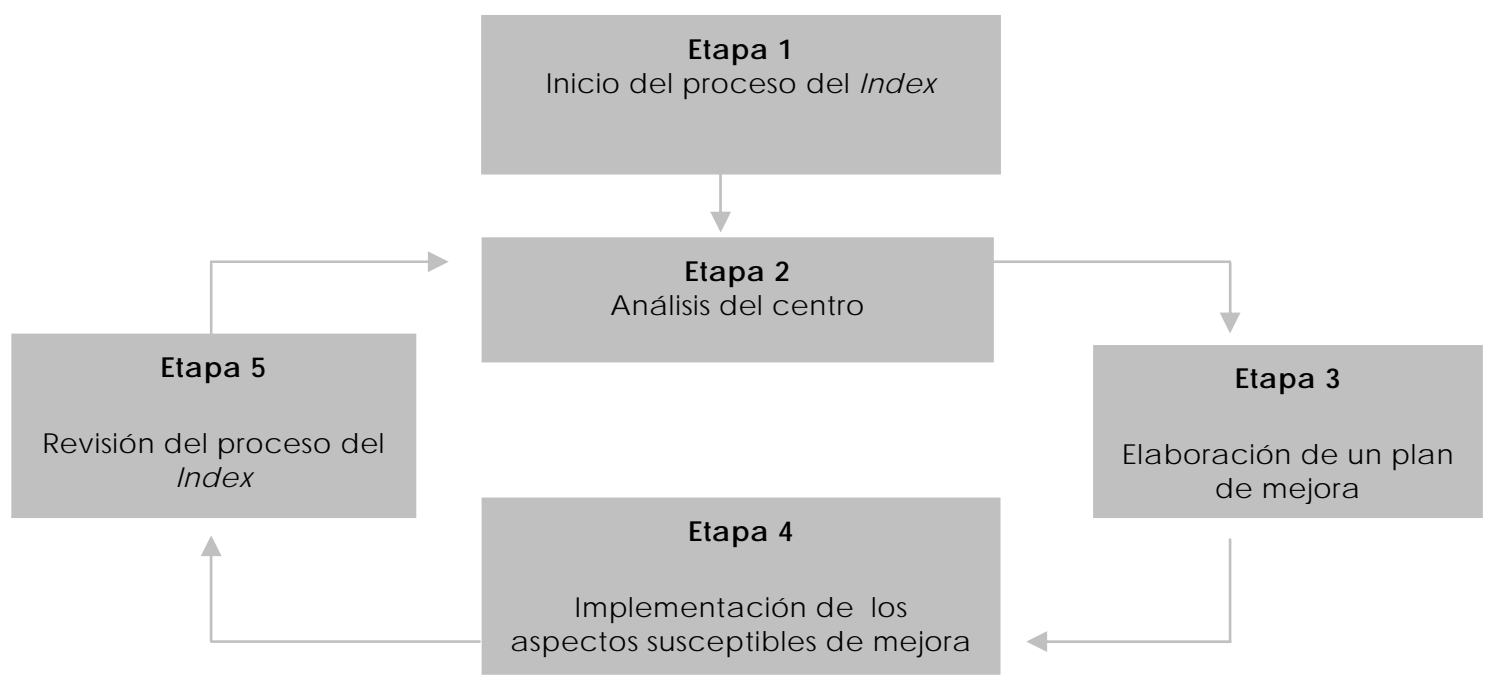

FIG URA 05. EL PROCESO DEL INDEX Y EL CICLO DE PLANIFICACIÓN PARA LA MEJ ORA DEL CENTRO (BOOTH Y AINSCOW, 2002). 
A continuación se presenta de forma breve el proceso de trabajo que se refleja en la Guía para la evaluación y mejora de la educación inclusiva (Booth y Ainsc ow, 2002).

\section{Etapa 1. Inic io del proceso del Index}

La primera etapa se inicia cuando se establece un equipo de coordinación cuya función, en este primer momento, será la de recoger la información relativa al Index (conceptos, materiales y metodología) para, en fa ses posteriores, compartirla y enriquec enla con el resto de profesiona les de la organiza ción.

El equipo coordinador deberá estar constituido desde un principio por el director, un coordinador del equipo multidisciplinar y por otros profesionales de la organización con experiencia que sean responsables en la actualidad de la planificación del centro. Se recomienda incluir en el equipo a "un a migo crítico" u obsenador externo cuya principal responsabilidad será la de ayudar a garantizar que el a nálisis de la organización se realice en profundidad. No obstante, todos los profesionales necesitarán compartir este rol, ofreciendo un "desafío constructivo" a sus colegas para que planteen opiniones y conclusiones sobre la organización.

Es importante que el equipo coordinador se convierta en un modelo de práctica inclusiva dentro de la organización, garantizando que las discusiones que se establezcan no sean monopolizadas por ningún participante y que todos sean escuchados independientemente de su género, su historia profesional o su estatus.

Es necesario que quede claro desde el principio que el Index no se utilizará como instrumento para poner en cuestión las competencias profesionales de nadie, sino como un modelo de apoyo a la organización y para la mejora profesional de sus miembros. Los componentes del equipo necesitarán sentir que pueden confiar en los otros y que pueden hablar libremente y cuando sea necesario, en un a mbiente de confianza. 
La primera fase concluye cuando el equipo coordinador establece el proceso de trabajo de las siguientes fases del Index para el resto de la comunidad escolar.

\section{Etapa 2. Análisis del centro}

En la segunda etapa, se utilizan los materia les del Index como base para el a ná lisis de la organizac ión socioeducativa y la identific ación de las prioridades que se quieren acometer.

En ella, los miembros del equipo coordinador utilizarán sus conocimientos sobre el proceso del Index para trabajar con otros equipos de la organización, garantizando de este modo que estarán representadas las perspectivas de todos los equipos existentes. El equipo analizará los resultados de estas consultas e iniciará, si es necesario, nuevas investigaciones para completar el estudio de la cultura, las políticas y las prácticas que se llevan a cabo en la entidad. A continuación se acuerda con los profesionales las priorida des de mejora.

El equipo coordinador será el responsable de decidir el mejor modelo para realizar el proceso y el modo de ofrecer la mayor cantidad de oportunidades de mejora. Estas oportunidades se van presentando a lo largo del intercambio de conocimiento de los miembros de la comunidad y del examen de los aspectos del centro.

\section{Etapa 3. Elaboración de un plan de mejora}

En la tercera etapa se elaborará un plan de mejora que refleje los objetivos inc lusivos y las priorida des identific adas en la eta pa de análisis, lo cual va a requerir que los miembros del equipo coordinador revisen el plan estratégico de la organización. 
El equipo tendrá que decidir hasta qué punto, a la luz del trabajo con el Index, algunas de las áreas de mejora detectadas se deben incluir en dicho plan y cómo van a serintegradas. Cada prioridad se deberá a nalizar en detalle, teniendo en cuenta la temporalidad, los recursos y las implicaciones en téminos de formación.

\section{Etapa 4. Implementac ión de los aspec tos susceptibles de mejora}

La cuarta etapa del Index implica implementar las prioridades del plan de mejora y promover su desa rollo.

Las a ctivida des de mejora requerirán investiga ciones continuas dentro de la organización, por lo que se convierte en una forma de investigación-acción. Los avances se mantienen a través de la motivación del trabajo colaborativo, una buena comunicación y el fomento de un compromiso general para hacer que las organizaciones sean más inclusivas para los profesionales y para los alumnos. Los avances se observan, se evalúan según el criterio del plan de mejora y se hacen informes de progreso cada medio trimestre. Esta etapa continuará su curso una vez que las prioridades formen parte de la planificación de la organización.

Poner en práctica las prioridades puede requerir un periodo de investigación en profundidad dirigida hacia la mejora. Esta exploración más profunda puede serguiada a través de los indicadores y las preguntas.

La mejora de relaciones de colaboración es un rasgo esencial del Index. El equipo coordinador debeńa ayudar a asegurar que los avances contribuyan a la participación de los profesionales y de los demás miembros involucrados en el centro, además de contribuir al a prendizaje y la participación de los alumnos. Los profesionales pueden aprovecharse de la experiencia de los otros sectores, compartir tareasy brindarsu a poyo mutuo.

Se debe mantener el compromiso de todas las personas involucradas a lo 
largo de la etapa de implementación. Mantener este compromiso general será esencial para proporcionar la motivación necesaria para continuar el trabajo de mejora hacia una educación inclusiva. El proceso del Index conlleva un profundo examen crítico de las creencias de todos los miembros de la organización. Ésta no es una actividad superficial, completada durante la exploración realizada en la etapa 2. Los miembros del equipo coordina dor necesitarán orga nizar activida des que, a lo largo de los años, creen una cultura más inclusiva. Esto, en parte, mantendrá la implicación de los profesionales, los miembros del equipo directivo, los a lumnos y las familias en el cambio de las políticas y las prácticas dentro de la organización.

\section{Etapa 5. Revisión del proceso del Index}

Finalmente en la etapa 5 se evaluará el progreso del proceso inclusivo en relación con el desarrollo de culturas, políticas y prácticas inclusivas. En ella los miembros del equipo coordinador revisarán el progreso general de las mejoras identific adas como prioridades en la etapa 2 y puestas en práctica en la etapa 4.

Se debe considerar también cualquier progreso en la creación de culturas inclusivas, producción de polític as inclusivas y mejora de práctic as inclusivas como parte de una revisión del uso del Index en el apoyo a la mejora. Las dimensiones, las secciones, los indicadores y las preguntas, al adaptarse a un centro concreto, desempeñan un papel central en la exploración de la difusión de los cambios dentro de la misma y en el comienzo de la fomulación de nuevas prioridades para el plan de mejora del año siguiente. Esta etapa, como la etapa 4, comenzará en el momento en que las prioridades hayan sido identific a das.

En esta etapa final del proceso, el equipo coordinador revisa el modo en que la aplicación del Index debe coordinarse y se prepara para iniciar un nuevo 
examen de la organización, inspirándose en las dimensiones, secciones, ind ic a dores y preguntas.

A estas alturas, la mayoría de los profesiona les estarán familia riza dos con el Index. Se deberían explic ar sus procesos a los nuevos profesionales en el momento en que entren a formarparte de la organización, dentro del programa de acogida. Entonces, esta quinta etapa del Index se transforma poco a poco en un regreso a la etapa 2 y en la continuación del ciclo de planificación escolar.

A modo de resumen se presentan las fases de las distintas etapas que forman parte del proceso de trabajo del Index.

\section{Etapa 1 Inicio del proceso del Index (medio trimestre)}

- Constitución de un equipo coordinador.

- Sensibilización del centro respecto al Index.

- Exploración del conocimiento del equipo.

- Preparación para usar los indic adores y las preguntas.

- Preparación para trabajarcon otrosequipos.

\section{Etapa 2 Análisis del centro (un trimestre)}

- Exploración del conocimiento de los profesiona les y de los miembros del equipo directivo.

- Exploración del conocimiento del alumnado.

- Exploración del conocimiento de las familias y de los miembros de las instituciones de la comunidad.

- Decisión de las priorida des susceptibles de mejora.

Etapa 3 Eaboración de un plan de mejora con una onientación inclusiva (medio trimestre)

- Introducción del Index en el proceso de planificación de la organización.

- Introducción de las prioridades en el plan de mejora.

Etapa 4 Implementación de los aspectos susceptibles de desamollo (continuo)

- Poner en práctica las prioridades.

- Mejora sostenida.

- Registro del progreso.

Etapa 5 Evaluación del proceso del Index (continuo)

- Evaluación de lasinnovaciones. 
- Revisión del tra bajo realizado con el Index.

- Continuación el proceso del Index.

FIG URA 06. PROC ESO DE TRABAJ O CON EL INDEX PARA LA INCLUSIÓN (BOOTH Y AINSCOW, 2002).

El Index se va construyendo sobre el conocimiento de todos los miembros de la comunidad y se adapta a sus circ unstancias específic as. De este modo, a nima a toda la organización a sentirse partícipe y protagonista del proceso de mejora. Este paso puede que sea el más crítico. Si se pretende que se mantengan los cambios introducidos como resultado del trabajo con el Index, necesitan ser experimentados como mejoras en los procesos tanto por los profesionales como por los estudiantes. Estos cambios necesitan ser incomorados a la cultura de la organización.

Es necesario completar a decuadamente las etapas 1,2 y 3 antes de que termine el año para que se puedan introducir las prioridades en el plan de mejora del año siguiente. Las etapas 4 y 5 se llevarán a cabo cuando comience el plan anual. La etapa 4 implica poner en práctica todas las prioridades del plan de mejora, incluyendo a quéllas identificadas a través de los materia les del Index. En la etapa 5, se revisa el progreso y se hacen modificaciones al proceso de utilización del Index en el centro. Los materia les del Index se utilizan para a naliza r lo que se ha logra do y para identific ar nuevas priorida des para el siguiente a ño.

Al mismo tiempo que se procede con el análisis de la cultura, las políticas y las prácticas de la organización, puede que aparezcan oportunidades de cambio, en el ámbito de la inclusión, que no se habían detectado anteriomente. Puede que los profesionales experimenten la sensación de que la organización es menos inclusiva en algunos aspectos de lo que pensaban antes de trabajar con el Index. Esto se puede equilibrar descubriendo todos aquellos recursos de apoyo a la 
participación y al a prendizaje que se pueden encontrar en los profesionales, en los estudiantes, en las familias y en la comunidad.

\subsection{Investigando la aplicación del Index}

Diseñado y publicado por primera vez en el año 2000, el Index for inclusion ha sido traducido a múltiples idiomas entre otros al Noruego, Español, Finlandés, Rumano, Catalán, Alemán, Chino o Portugués. La necesidad de una adaptación del instrumento a los diferentes contextos sociales, culturales y educativos a los que se pretende aplicar su filosofía ha conllevado la realización de diferentes investigaciones para analizar, en primer lugar, la adecuación de las adaptaciones $y$, en segundo lugar, los éxitos e inconvenientes que se estaban obteniendo en las diversas aplicaciones realizadas en los centros escolares. Se presentan, a continuación, algunas de las principales investigaciones que se han realizado a nivel intemacional.

Norwich et al. (2001) realizaron dos investiga ciones sobre la aplicación del Index en Inglaterra. En el primer estudio se analizó la participación de las Autoridades Educativas Locales (LEA) en la promoción del uso del Index en las escuelas. Aunque los resultados señalaron que el Index resultaba una herramienta de gestión valiosa y estaba ayudando a obtener una perspectiva más amplia sobre la inclusión, se señaló también que el proceso promovido en el marco del Index, es desalentador, demasiado extenso, demasiado detalla do y abstracto, y muy largo. También se estimó que no se centraba suficientemente en los resultados de los estudiantes y que, aunque tiene un gran potencial, precisa de una gran cantidad de tiempo, compromiso y un liderazgo fuerte para conseguir los resulta dos que se pretenden alcanzar (Norwich et al., 2001). 
Corbett (2001) utilizó en su investigación el Index for Inclusion como una herramienta para analizar la cultura, política y prácticas de una escuela que es referente en la educación inclusiva por llevar trabajando en la promoción de la inclusión desde hace más 15 años. Aunque el estudio no nos informa sobre el valor del instrumento para el fomento de la educación inclusiva en las escuelas, sí que nos señala que para que una escuela pueda llegar a ser una escuela inclusiva eficaz debe conseguir (1) que los miembros de la comunidad educativa tengan una visión compartida, (2) que exista un liderazgo comprometido y entusiasta, (3) que existan profesionales con experiencia y cualificados, y (4) que existan los recursos adecuados y una receptividad para aprender nuevas habilidades y estrategias que puedan proporcionar un valor añadido a sus actuaciones.

Vaughan (2002) y Vislie (2003) han investigado sobre la implantación del Index en Noruega. Además de ejemplos de consecuencias derivadas de la implementación del Index, la investiga ción nos señala diferentes aspectos positivos y negativos destacados por sus participantes. Como aspectos positivos señalaron que el Index para la inclusión (1) es flexible, (2) puede potenciar el entendimiento entre los diferentes equipos del centro, (3) se pueden realizar adaptaciones en los cuestionarios para adecuarlos a los centros, (4) el proceso ayuda a la sensibilización y concienciación sobre la inclusión, (5) es una buena herramienta para el cambio de valores y creencias e informa al centro sobre las evoluciones que se van logrando.

Los aspectos negativos recogidos indican que la amplitud que presenta el instrumento es abrumadora, hay una falta de orientación sobre cómo utilizar los cuestionarios, es demasiado difícil de utilizar sin ayuda extema al centro dónde se aplica, presupone que los directores de los centros educativos están a favor de la inclusión, y que es difícil de aplicar junto a todas las presiones que ya tienen los centros, tanto intemascomo extemas. 
Channon (2003) expone cómo el Index fue utiliza do en Eritrea como una forma de incentivar a los educadores a pensar en el desarrollo de su propia institución, todo ello, en una situación en la que aún se estaban recuperando de los efectos de una larga guerra. Profesionales de la University College de Ingla terra trabajaron de forma conjunta con el Asmara Teacher Education Institute para producir su propia versión del Index for Inclusion, para explorar barreras al aprendizaje y desa rollar recursos en sus propias instituciones (Booth, 2008). El resulta do más importante del proyecto fue la confimación de que los conceptos y la estructura del Index ofrecen un marco de trabajo común que orienta la reflexión y la identificación de prioridades a profesionales provenientes de diferentes culturas y circ unstancias (Booth, 2008).

Hick (2005) realizó un estudio basado en un proyecto piloto centrado en la aplicación del Index en diferentes escuelas y en la intervención de psicólogos educativos con el rol de "amigos críticos". A lo largo del proyecto los psicólogos a poyaron el desarrollo de prácticas inclusivas de diferentes formas: ayudando a las escuelas a conocer y adaptar los materiales del Index; ofreciendo sus propias perspectivas sobre la inclusión que a menudo servía n como nexo entre las escuelas y el proceso marcado por el Index; gestionando la colaboración profesional con las escuelas; y facilitando la toma de conciencia sobre lo que hay detrás de los procesos inclusivos. Los resulta dos obtenid os por la investigación indic aron que los "amigos críticos" deben ser conscientes de la importancia de incluir la perspectiva de los estudiantes en la evaluación de las prácticas inclusivas. Los alumnos deben trabajar de forma colaborativa como un miembro más de la organización y deben estar preparados para comprometerse con el proceso que promueve el Index.

Rustemier y Booth (2005) han realizado una investigación sobre la a plic ación del Index for inclusion en las esc uelas del Reino Unido y han detectado que tanto 
su interpretación como su aplicación en los centros educativos se han realizado bajo presiones contradic torias.

El Index for inclusion fue distribuido en Inglaterra por el gobiemo y, poco más tarde, se difundió también en Gales con el apoyo de la Asamblea Nacional. De los informes elaborados se puede extraer como conclusión que el Index se puede utilizar claramente con éxito para implantar políticas de inclusión en las escuelas, aunque su uso no está legislado y, por lo tanto, su utilización es completamente voluntaria. El estudio de Rustemier y Booth (2005) señala cómo las escuelas han encontrado interesantes maneras de integrar en el día a día los materiales del Index. Sin embargo, si analizamos sus aportaciones finales sobre los resultados obtenidos, podemos ver, de forma rotunda, que no hay una satisfacción total con el alcance obtenido en el Reino Unido y con el compromiso de los centros con la filosofía de trabajo que propone el Index. Esto se debe a que el Index en muchos sentidos está en directa oposición con las iniciativas del gobiemo británico, lo cual hace que no se puedan llevar a la práctica muchos de los aspectos señalados en el instrumento.

Mientras el proceso del Index pone en primer plano los enfoques participativos para el desarrollo escolar y alienta "el diálogo, la colaboración, el apoyo, la construcción de cultura s inclusivas, la partic ipa ción en los más profundos valores, y el intento de poner esos valores en acción" (Rustemier y Booth, 2005, p.46), el planteamiento del gobiemo pone de relieve la competencia, los controles y la identificación de "buenas prácticas" en los procesos de desarrollo escolar. Mientras que el gobiemo prefiere iniciativas de amiba hacia abajo, el Index for inclusion fomenta que las escuelas puedan decidir sobre sus propias prioridades para el cambio. Otra gran diferencia que señalan los autores es que mientras el Index hace referencia a la eliminación de barreras para el aprendizaje y la 
participación de todos los estudiantes, los documentos gubemamentales se centran en la inclusión de a lumnos con "nec esida des educa tiva s especiales".

Heung (2006) ha investigado sobre la promoción de prácticas inclusivas en las escuelas en 2004 a través de la introducción de una versión adaptada del Index for Inclusion, denominada "Indic adores para la Inclusión en Hong Kong". La adaptación del Index, apoyada por el gobierno, ha sido más necesaria que en otros casos por las diferencias culturales de existentes entre Inglaterra y China. La versión adaptada se ha desa rrollado conforme a los estándares de calidad para evaluaciones exteriores de las escuelas de Hong Kong. Las tres dimensiones del Index se ampliaron a cuatro. El cuarto dominio se dingió al resulta do de a prendizaje del estudiante, aspecto señalado por otras investigaciones como una de las debilidades del instrumento (Rose, 2002; Dyson 2001), y trata aspectos como la partic ipa ción, la motivación, el auto concepto y otras habilida des de a prendizaje.

Heung (2006) expone que la introducción del Index en Hong Kong ha sido oportuna y puede proporcionar a las escuelas un lenguaje común que les permita comunicarse y cuestionar sus prácticas. Sin embargo, también identific a ciertas barreras a la inclusión en las esc uelas. Se ha rea liza do un estudio de impacto inicial que ha concluido que éstas aun se sienten abrumadas por la idea de incluir la autoevaluación como un aspecto integral de la escuela y la práctica en el aula, y por la necesidad de dirigir con éxito la forma de pensar y las prácticas del profesorado. Otro aspecto señalado es que en la actualidad es difícil equilibrar la mejora en los procesos de inclusión en los centros educativos con el logro de los resultados que se exigen. En las escuelas públicas de Hong Kong aún se pone énfasis en el logro como uno de los objetivos más importantes a conseguir en el aula. Esta cultura ha sido dominante en la educación durante muchos años, lo que genera grandes resistencias al cambio en el profesorado. 
Las investigaciones que se están realizando en la actualidad se basan en estudios de caso centrados en la aplicación del Index a nivel intemacional. Un estudio intemacional que está en curso examina las formas en que el instrumento ha sido adaptado y usado en diferentes países alrededor del mundo, incluyendo Australia, Inglaterra, Enitrea, Alemania, India, Oriente Medio y África del Norte, Nueva Zelanda, Noruega, Pa kistán y Gales.

Ainscow (2007) está convencido de que el Index puede ayudar a desesta bilizar las prácticas de las escuelas por su insistencia en el replanteamiento de los discursos existentes y en la necesidad de centrar la atención en las posibilidades habitualmente pasadas por alto y que pueden hacer avanzar la práctica.

La investigación, sin embargo, indica que los profesores con experiencia encuentran dificultades en realizar cambios en su práctica cuando no están ac ostumbrados a ver otras concepciones de la educación adaptadas a las nuevas tendencias inclusivas. Ainsc ow (2007) también sugiere que los maestros tienen que desarrollar un lenguaje común con respecto a su práctica con el fin de adoptar nuevos enfoques. El Index para la inclusión puede ofrecer un marco de referencia para desarrollar un lenguaje compartido sobre la inclusión en las escuelas. Es a través de experiencias compartidas como los ma estros pueden comenzar a realizar cambios en su práctica.

Ainscow (2007) también resalta, por una parte, la importancia de las evidencias, encontradas en el proceso de aplicación del Index, como "palanca de cambio" y, por otra, el uso de la observación mutua para hacer conscientes a los profesores de las diferentes maneras de enseñar. Es fundamental también tener en cuenta las evidencias que se pueden encontrar mediante la participación de los estudiantes. 
Las investigaciones basadas en el Index para la inclusión señalan ta mbién la importancia de los factores culturales en las escuelas. Las creencias deben ser cuestionadas, especialmente aquellas que indican una visión deficitaria de la diferencia.

Los valores se construyen en las escuelas en la compleja interacción entre individuos y grupos. Se ha demostrado que es imposible separar los valores y las creencias de las relaciones en las que se ponen de manifiesto. Al trabajar con personas extemas a la escuela y comprometidas con la promoción de la inclusión es necesario tener en cuenta los valores sociales y morales, las creencias y sus conexiones con las políticas y las prácticas en las escuelas. A menudo, esto contribuye a un creciente compromiso con la inclusión. Según Ainscow (2007) la investigación indica de manera significativa que las prácticas de liderazgo en las esc uelas pueden facilitar o limitar el desa rrollo de la inclusión.

Otras investigaciones que han ahondado en la aplicación del Index en Gran Bretaña han sido documentadas por Corbett (2001); Norwich, Goodchild y Lloyd (2001); Vaughan (2002); Dyson, Gallannaugh y Millward (2003); Hick (2005), Hodson, Baddaley, Layc ock y Williams (2005). Dyson (2001) y Rose (2002) y ofrecen algunos comentarios sobre las evoluciones realizadas pero no ofrecen una base de investiga ción empírica.

En España el Index for Inclusión ha sido traducido, a daptado y difundido por el Consorcio Universitario para la Educación Inclusiva que está formado por un grupo de profesores y profesoras interesados en impulsar el conocimiento y desarrollo de la inclusión educativa en España.

A partir de la difusión del instrumento (Durán et al., 2005; Durán et al., 2003) algunos centros de la Comunidad de Madrid solic itaron asesoramiento. Uno de los primeros que empezó a trabajar con el instrumento fue el Instituto de Educación 
Secundaria Severo Ochoa de Alcobendas en su afán de ofrecer una mejor respuesta a la diversidad del alumnado basada en un proceso de mejora.

A su vez, en Cataluña la traducción y adaptación del Index fue realizada por el Grup de treball sobre Escola Inclusiva del Instituto de Ciencias de la Educación de la Universidad de Barcelona. Con el fin de poner a prueba la versión catalana, durante el curso 2003-04, se inició el trabajo en tres centros educativos interesados en una mejora de la atención a la diversidad del alumnado y, en general, en un avance hacia la inclusión (Duran et al., 2005).

Dentro de las iniciativas del Departamento de Educación del Gobiemo Vasco (España) para la promoción de buenas prácticas en la respuesta educativa inc lusiva, a sí como en las responsabilidades en la supenisión de la edición bilingüe castellano-euskera, se realizaron ya durante el 2003 las primeras pruebas de la versión vasca del Index para la inclusión en doscentros.

Tras las experiencias realizadas en España, Duran et al. (2005) nos señalan que es fundamental que los centros hagan "suyos" los materiales y que no se limiten a poner en marcha una metodología generalista no diseñada para un contexto de actuación determinado.

Los a utores también nos indic an que “la experiencia del Index, tiene efectos que van más allá del propio proceso, puesto que promueve, dentro del centro, la reflexión sobre la práctica y el trabajo colaborativo; y, fuera del centro, el establecimiento de redes orientadas a que los centros se puedan ayudar unos a otros". (p.467) 


\subsection{Conclusiones del capítulo}

Según Villalobos y Zalakain (2010), a pesar de la complejidad y el carácter dinámico de la inclusión, hay un cierto consenso en tomo a su naturaleza multidimensional que incluye dific ulta des o ba rrera s en diversos a spectos.

En este sentido y siguiendo a Booth, Nes y Stromstad (2003) hay que resaltar cinco de los aspectos que han surgido a lo largo del capítulo sobre la multidimensionalidad del término y que se van a desa mollar con mayor detalle en el apartado siguiente.

En primer lugar el valor que se otorga a la diversidad es el elemento clave en el cambio de concepción. La inclusión no se concibe como un sinónimo de integración, ya que esta no tiene que ver con ningún grupo de personas en particular, sino que concieme a todos los miembros de la comunidad educativa y hace que se aprecie la diversidad humana como un valor.

En segundo lugar, el énfasis dado al a prendizaje y a la participación, implica eliminar las barreras que afectan tanto al profesorado como a los alumnos, y que conlleva poner en valor los derec hos de las personas ante cualquier otro aspecto.

En tercer lugar la democracia, ya que se deben promover estrategias y procesos en los centros donde todo el mundo tenga la oportunidad de exponer sus ideas y de que estas sean esc uchadas.

En cuatro lugar, hay que entender los centros como una totalidad, ya que la inclusión no se refleja sólo en las práctic a s escolares, sino también en la cultura y las políticas de las instituciones educativas. Las barreras al aprendizaje y la participación pueden aparecer en todos los ámbitos de la organización. Por ello, las ba rreras que existen en las personas no deberían ser considera da s las primeras y mucho menos lasúnicas. 
En último lugar, señalar que la inclusión va más allá de lo que sucede en los centros, es una dinámica que afecta a la sociedad en su conjunto y, por lo tanto es un proceso continuo y sostenible, no un estado que pueda ser alcanzado, ni un certifica do que una vez que se adquiere no se puede perder. Por todo ello, la inclusión compromete la tarea ineludible de identificar y eliminar (Echeita y col., 2008) las barreras que desde distintos planos de la vida pudieran limitar la presencia, el aprendizaje o la participación, al interactuar negativamente, en determinados momentos, con las condiciones personales o sociales de las personas (p.159).

La inclusión pone una atención especial en aquellos grupos de personas en peligro de ser marginadas, excluidas o con riesgo de no alcanzar un rendimiento óptimo. Ello implica la responsabilidad moral de toda organización educativa de garantizar que tales grupos, que estadísticamente son "de resgo", sean seguidos con atención y que se tomen, siempre que sea necesario, todas las medidas oportunas para garantiza r su presencia, partic ipación y rendimiento.

En este sentido el Index para la inclusión nos ofrece una altemativa para conocer los centros yendo desde lo más general: la cultura, las políticas y las prácticas, a lo más concreto con preguntas que van directamente a descubrir si desde el centro se están poniendo obstá culos a la inclusión.

El Index, según las investigaciones realizadas por diferentes autores en distintos países, no es un instrumento fácil de aplicar en su conjunto pero sí que tiene múltiples aspectos que son destacables. Por primera vez, un instrumento aborda la inclusión a través de una triple dimensión que aúna, por una parte, los puntos de vista de todos los miembros de la comunidad educativa y, por otra, observa el proceso de inclusión desde un prisma que considera a la organización en toda su complejidad ya que analiza su cultura, el despliegue de esta a través de las diferentes políticas que pone en marcha en el centro $y$, en último lugar, 
cómo las prácticas del día a día reflejan la misión, visión y valores del centro respecto a la inclusión.

El hecho de iniciar un procedimiento de trabajo como el señalado por el Index para la inclusión va a hacer que: (1) la comunidad en su conjunto participe en un proceso de reflexión sobre deteminados temas que en el día a día quedan enmascarados por otros aspectos; (2) se hable con un mismo lenguaje, y de forma abierta, sobre el estado de ciertas formas de pensar, hacer y actuar que van a marc ar la cultura del centro, sus polític as y sus prá c tic as inc lusivas.

En el capítulo que se presenta a continuación se abordarán con detalle los elementos que se esconden detrás de las tres dimensiones del Index para la inc lusión. 



\section{CAPIULO 2. \\ Organizaciones inclusivas}

Lacasta, J . J . (2010).

El diagnóstico es claro: no toda asociación o entidad que trabaja a favor de las personas con discapacidad tiene claro el objetivo, ni la función o la acción, ni la forma de organizarse para trabajar por la inclusión. En muchas organizaciones de los movimientos asociativos de la discapacidad, los paradigmas de la protección y del asistencialismo -como principales referentes- han bloqueado el desarrollo de los tres objetivos clave que han de perseguir los movimientos asociativos de la discapacidad: la inclusión, los derechos y el empoderamiento de las personas. Deberían ser éstos los objetivos principales de su acción y, sin embargo, no forman parte de ella, aunque no siempre tengan consciencia o voluntad de ello. (p. 59). 


\subsection{Introducción}

Una vez analizado qué entendemos por inclusión y cuál es la estructura del Index para la inclusión, vamos a ver a lo largo de este capítulo qué aspectos caracterizan a las organizaciones inclusivas tomando como referencia las tres dimensiones que están en la base del Index: cultura, política y práctic as inclusivas.

En el primer apartado analizaremos los aspectos básicos que subyacen a las culturas y comunidades inclusivas y veremos como éstos pueden relacionarse con los resulta dos organiza tivos que se obtienen en los centros. Para teminar este a partado haremos especial énfasis en los va lores inclusivos de la organización, que son la base de cualquier cultura y filosofía de inclusión.

A continuación se aborda rán a quellos aspectos que están relacionados con las polític as inclusivas y que ayudan a desplegar en la organización la misión, visión y valores inclusivos.

Para finalizar este capítulo se analizarán las claves que sustentan las prácticas inclusivas. El apartado se centrará primordialmente en la persona y en aquellos aspectos que promueven la motivación, la autodeterminación, la implic ación en las diferentes tareas que se emprenden y la resiliencia. En definitiva, aquellos aspectos que hacen crecer al ser humano e implicarse en la consec ución y defensa de sus derechos como persona.

\subsection{Culturas inc lusivas}

La cultura en una organización es mucho más de lo que se expresa en la Misión, son límites de entendimiento tácitos, lenguaje común y expectativas compartidas mantenidas en el tiempo por sus miembros (Aiman-Smith, 2004). Son “las formas, dadas por hecho, compartidas y tácitas en que se percibe, piensa y reacciona en diferentes contextos" y a nte situaciones diversas (Schein, 1996). 
La cultura organizativa puede relacionarse también con factores asociados a la eficiencia, productividad y calidad y puede considerarse como un mecanismo de control asociado a aspectos como la lealtad, el compromiso y la cohesión ta nto individual como grupal (Wilkins y Ouchi, 1983).

Aunque la cultura es difícil de describir, puede afimarse que cada organización desarrolla suposiciones, conocimientos y reglas que dirigen el comportamiento cotidiano en los contextos laborales. Dichas premisas y creencias definen, de forma inconsciente, la visión que los miembros tienen de la organización y de sus relaciones con el entomo (Priante, 2003; Zucker, 1988; Richardson, 1996) y ponen a su disposición un conjunto de actitudes ante determinadas situaciones que les permiten obrar conforme a las normas del grupo - a las expectativas que se tienen de ellos. Esta manera de actuar da a las personas y a sus acciones sentido y legitimidad, y hace que se fortalezca su pertenencia e identific a ción a sí como su diferencia ción con otras entidades.

\subsubsection{Cultura y comunidad}

La cultura es asumida por las personas que forman parte de la organización porque les da seguridad y determina la forma en la que funciona ya que se refleja en las estra tegias, estruc turas y sistemas (Deal y Kennedy, 1985).

Según Abravanel (1992) la cultura se basa principalmente en tres elementos ligados entre sí (ver figura 07): (1) la sociedad, que incluye el sistema cultural, social, polític o y juńdico; (2) la historia, que integra la visión del fundador y los valores de los lideres pasados y, (3) las contingencias, que son la tecnología, el mercado y su competencia así como las reglas que regulan a la organización y al ámbito profesional en el que se desenvuelve. A partir de esta composición se forman el sistema socioestruc tural y cultural. 


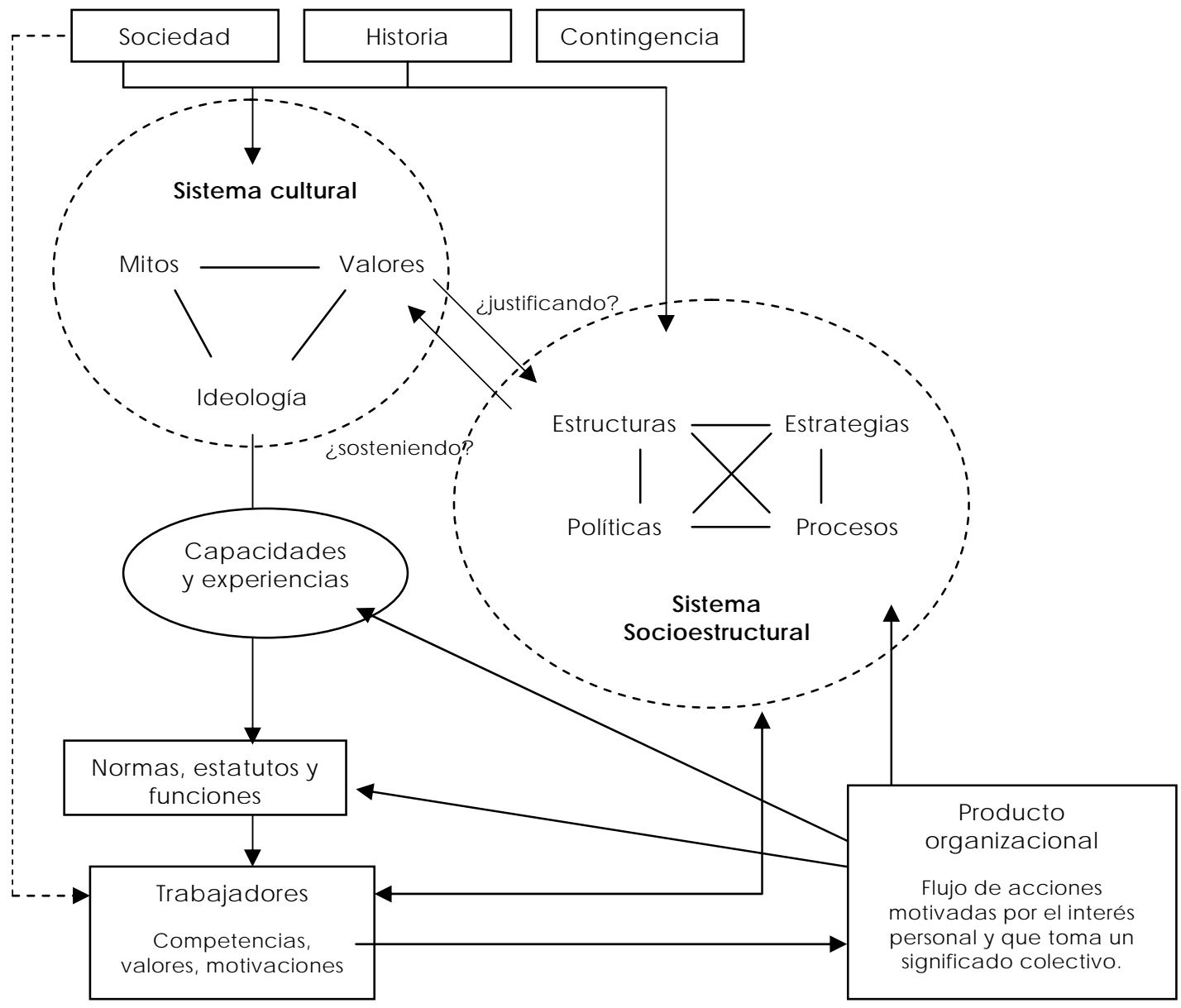

FIG URA 07. ESQ UEMA CONCEPTUAL DE CULTURA ORGANIZACIONAL (ABRAVANEL, 1992).

El sistema socioestructural está formado por las estructuras formales, las estra tegias, polític as y procesos que permiten el funcionamiento orga nizativo.

En el sistema cultural, en cambio, se incluyen los aspectos expresivos y afectivos de la organización en un sistema colectivo de significados simbólicos: mitos, ideologías, valores, artefactos, ritos, ceremonias y costumbres, entre otras. Este sistema está influenciado por la historia y evolución de la organización, sus contingencias y porla sociedad que la rodea. 
El sistema cultural justific a al sistema socioestructural y, al mismo tiempo, el sistema socioestructural sostiene al cultural, debido a que ambos están mediados por nomas, estatutos y funciones, los cuales servirán de referencia para toda la organización (Abravanel, 1992). A su vez cada persona que tiene vinculación con la entidad está dispuesta a integrarse en el esquema organizacional y en las dinámicas de trabajo que surjan de los intereses organizativos, personales y del significado colectivo que se negocie. Estos procesos de adaptación siempre estarán influenciados por las competencias, conocimientos y rasgos de personalidad de cada uno de los miembros de la organización; ya que cada persona llega a la misma con un bagaje cultural derivado de la experiencia personal, familiar, profesional y social que ha vivido.

En una organización pueden darse también subculturas que pueden surgir en distintas áreas o departamentos o entre miembros con funciones o responsabilidades similares que interactúan regulamente dentro del día a día del centro, que comparten problemas y nomalmente toman decisiones partiendo de las pautas del grupo (Robbins, 1999).

Los procesos de interacción que se van a dar, tanto a nivel cultural como subcultural, entre las personas que forman parte de la organización pueden dar lugara la creación de comunidades.

Una comunidad es una experiencia subjetiva de pertenencia a una colectividad mayor que conlleva formar parte de una red de relaciones de a poyo mutuo en la que se puede confiar (Sarason, 1974). Los elementos que le dan forma a esta valoración personal son (Sarason, 1974): 
La percepción de similitud con otros, el reconocimiento de la interdependencia con los demás, la voluntad de mantener esa interdependencia dando o haciendo por otros lo que uno espera de ellos, [y] el sentimiento de que uno es parte de una estructura más amplia, estable y fiable (p.157).

De acuerdo con esta definición, el sentido de comunidad (a) tiene un núcleo importante en tomo a la interacción social entre los miembros de un colectivo, y se complementa con (b) la percepción de arraigo temitorial y (c) un sentimiento general de mutualidad e interdependencia (Sá nchez Vidal, 2001).

La idea de sentimiento psicológico de comunidad presupone una noción de comunidad propiamente dicha. Con más propiedad, podńamos hablar de separar, por un lado, la identidad y las dinámicas sociales, y por otro, el campo social en el que se generan. Seymour Sarason (1974) concebía la comunidad como "una red de relaciones de a poyo mutuo de la que uno puede depender".

Según McMillan y Chavis (1986) son cuatro los componentes que forman parte del sentido psic ológico de comunidad: pertenencia, influencia, integración y sa tisfacción de necesida des y conexión emocional compartida.

Maya Jariego (2004) nos desc ribe cada una de ellas:

- La pertenencia consiste en el sentimiento de haber invertido parte de sí mismo en la comunidad, y de pertenecer a ella.

- La influencia hace referencia al poder que los miembros ejercen sobre el colectivo, y recíprocamente al poder de las dinámicas del grupo sobre sus miembros. 
- La integración y satisfacción de necesidades tiene que ver con los valores compartidos por los miembros del grupo y con el intercambio de recursos para satisfacer las necesidades de los integrantes.

- La conexión emocional compartida va a surgir cuando los miembros reconocen la existencia de un lazo compartido. Este vínculo es el resultado del contacto positivo prolongado y de participar de experienciasy una historia comunes. (p. 6)

Los centros que prestan servicios a las personas con discapacidad deben tender a ser comunidades en las que todos los que forman parte de ellos, desde el equipo directivo a los proveedores y a liados estratégicos, compartan unos valores y principios básicos de actuación.

Cómo nos señala el Index para la inclusión los centros deben c rear culturas inclusivas orientadas a la creación de comunidades seguras, acogedoras, colaboradoras y estimulantes en la que cada individuo es valorado. Para que los centros puedan crear estas comunidades deben construir un mundo en el que todas las personas implic adas, equipos directivos, profesionales, personas usuarias, fa miliares, Administraciones Públic as, otras organizaciones, etc., deseen pertenecer y quieran permanecer (Moreno, Giménez y García, 2009). Liderar la construcción de una comunidad supone una oportunidad de crear una gran e inevitable ventaja competitiva basada en las relaciones.

\subsubsection{Cultura y resultados organizativos}

La cultura organizativa tiene un impacto signific ativo en la organización, ya sea a través del comportamiento de los profesionales, de sus motivaciones o de los resulta dos que se alcanzan (Deal y Kennedy, 1982; Peters y Waterman, 1982; Siehl y Martin, 1990) 
Muchos han sido los investigadores que han analizado la relación entre cultura y resultados (Barley y otros, 1988; Bamey, 1986; Denison, 1990; Ott, 1989; Saffold, 1988; Wilkins y Ouchi, 1983), pero no se han desarrolla do teońas explícitas que relacionen cultura y eficacia, ni se ha presentado evidencia empírica concluyente al respec to (Owens, 1987; Siehl y Martin, 1990; Uttal, 1983).

Sin embargo Sánchez (2009) nos señala tres aspectos que nos ayudan a conocer cómo los resultados que se están obteniendo en los centros que prestan servicios a las personas con discapacidad pueden estar influencia dos por la cultura predomine en ellos: (1) la fortaleza de su cultura, (2) los rasgos que la definen y (3) el ajuste a su estrategia.

Diversas investigaciones se han centrado en estudiar la influencia de una cultura fuerte en los resultados que tienen las organizaciones. Aunque se ha determinado que una cultura de este tipo puede influir tanto positivamente (Barney, 1986; Gord on y DiTomaso, 1992; Schein, 1985; Weick, 1985; Deal y Kennedy, 1982; Mitroff y Kilmann, 1984; Ouchi y Price, 1978; Pascale, 1985) como negativamente (Anand, Ashforth y J oshi, 2004; Pierre y otros, 2006; Wilmott, 1993), ya que puede hacer que se reduzca su capacidad de adaptación a los cambios; se ha visto que las culturas organizativas fuertes se encuentran en aquellas organizaciones en las que la mayoría de sus miembros poseen unos valores compartidos.

La forma en que esta cultura puede influir en los resultados depende de cinco argumentos (Sánchez, 2009). Una cultura orga niza tiva fuerte:

(1) facilita el logro de los objetivos ya que la visión compartida hace que toda la energía, los esfuerzos y el entusiasmo se canalizen en la misma dirección. Hanges y Dickson, (2004) nos indican que esto hace que los problemas que puedan surgir como resultado de los procesos organizativos 
sean prácticamente inexistentes y los recursos no se malgasten en acciones ineficaces.

(2) da lugar a una mayor motivación de los empleados puesto que al trabajar en una organización con una cultura distinta y compartida, las personas se sienten unidas por los signific a dos y la s práctic as que comparten (Denison y Mishra, 1995; House y otros, 2002).

(3) tiene una mayor capacidad de aprender del pasado. Los trabajadores de estas organizaciones tienen una historia compartida, cargada de significados, valores, rituales y ceremonias que orientan y apoyan la adaptación a los cambios y desafíos.

(4) contribuye a mejores resultados porque crea un lazo de unión entre los trabajadores, que fomenta procesos de comunicación más eficientes y una mayor cooperación (Cooke y Rousseau, 1988; Klein y otros, 1995).

(5) hace más fácil para los integrantes de la organización interpretar los a contec imientos organizativos y clarific a a los partic ipantes las actitudes y comportamientos que serán sancionados o recompensados por la orga niza ción (G lisson y J a mes, 2002; Kotter y Heskett, 1992; Sorensen, 2002).

A pesar de todo ello, y siempre que no estemos hablando expresamente de una cultura orientada al cambio, la innovación y la mejora, no se debe olvidarque la fortaleza de la cultura puede actuar como una barrera que perpetúa competencias que se deberían cambiar para adecuarse a los movimientos cambiantes del entomo (Litzky y otros, 2006; Wilmot, 1993).

El segundo aspecto que nos señala Sánchez (2009) es que existen deteminados rasgos organizativos que fomentan la eficacia. Según esta perspectiva (Saffold, 1988) aquellas entidades que valoran a sus profesionales, 
promueven el trabajo en equipo y favorecen la participación (Becker, 1976; La wler, 1996) son más efic aces porque los trabaja dores de to dos los niveles se sienten parte de la organización, perciben que se les considera, que sus objetivos están directamente conectados con los de la entidad y, por lo tanto, contribuyen de una mejor forma a lograrlos (G illett y Stenfer-Kroese, 2003).

Louis et al. (1996) indicaron que existen ciertos rasgos que hacen que la cultura organizativa sea una base para la mejora continua. Entre otros, señala ron la facilidad y predisposición de los profesionales para formar equipos de trabajo y la orientación de los directivos a entregar a éstos una cuota importante de autonomía y liderazgo.

La confianza es otro de los rasgos de las culturas orga nizativas efic ientes ya que aparece tanto en las conductas individuales como en las colectivas (Tschennan-Moran, 2004; Tschennan-Moran y Hoy, 2000). En las culturas dónde hay confianza aparece junto a ella la colaboración, el aprendizaje profesional (Muijs et al., 2004), el intercambio de prácticas, recursos y conocimientos entre los profesionales y el control mutuo.

La tercera aportación que hace Sánchez (2009) no depende tanto de que los valores o creencias que defienda la organización sean o no adecuados si no que postula que las organizaciones que tengan culturas que encajen tanto con el entomo como con la estrategia organizativa tendrán mejores resultados (Weiner, 1988; Wilkins y Ouchi, 1983) e incluso llegará a convertirse en un activo de la misma (Sa the, 1983).

Partiendo de esta aportación podemos decir, por tanto, que los centros que tengan una cultura coherente con la estrategia y el contexto de la organización, serán más eficaces, eficientes y tendrán en ella un activo que apoyará tanto a la productividad como a la rentabilidad de la organización (Sathe, 1983). 
Por todo ello, aquellos centros que prestan servicios a personas con discapacidad, a la hora de fomentar un enfoque inclusivo que apueste por la diversidad deberán prestar atención tanto a la estrategia organizativa como a su cultura. Deberán promover culturas basadas en los va lores inclusivos, en el trabajo multidisplinar, en una visión compartida y en la aceptación de la diversidad como elemento enriquecedor del centro. Teniendo siempre en cuenta que la cultura organizativa no es estática si no que se reformula en función del contexto histórico y social (Wamier, 2002).

\subsubsection{Cultura, inc lusión y diversidad}

El éxito de una cultura inclusiva en un centro de atención a personas con discapacidad puede depender mucho de los valores e ideas subyacentes y de las subculturas que operan en su interior que afectan a los procesos y prácticas que se ponen en marcha en el día a día (Partson, 2010). Idea Imente, la evolución de una cultura organizativa inclusiva debe contar con el apoyo y el compromiso de un grupo diverso en el que participen personas con diferentes competencias, limitaciones, ideologías y culturas (Schein, 2004) y, a unque, por supuesto, no todas las organizaciones pueden siempre garantizar esta diversidad, desde la dirección del centro se debe apostar porque todos los miembros de la comunidad tengan la oportunidad de partic ipar.

La diversidad conlleva entendimiento y va más allá de la simple tolerancia (Partson, 2010) porque incluye en la organización los diferentes matic es que posee cada persona (Schein, 2004) e implica la comprensión y el reconocimiento de cada individuo en una organización como único y diferente (Cox y Cox, 2001; Schein, 2004). Las diferencias pueden ser por razón de la raza, etnia, estatus socioeconómico, género, edad, capacidad o discapacidad, religión, creencias polític as, orientación sexual o ideología (Cox y Cox, 2001). 
Sin embargo, en las orga nizaciones, los sistemas esta blecidos, las estruc turas orga niza tivas y las prácticas, las creencias y nomas insta ura das, a vec es tienden a reflejar los valores y situa ciones de la vida de los equipos directivos o de los líderes de la organización y no de su comunidad. Schein (2004) nos señala que este es un aspecto a vigilar en los centros porque los líderes de una organización deben estimular la diversidad y difundir que esta es deseable tanto a nivel individual como en los equipos. Sin embargo, no se debe perder de vista en las organizaciones que la diversidad puede tener un lado no tan positivo, ya que las idiosincrasias individuales pueden ser obstáculos para el desarrollo exitoso de una cultura inc lusiva y varia da (Partson, 2010).

Los centros que prestan servicios a personas con discapacidad deberán tener en cuenta todos aquellos factores personales, sociales y culturales que pueden interceder a la hora de implementar políticas inclusivas. Hay que tener presente que lo que hace unos años era "lógico" o "normal” poco a poco se va reinventando. $Y$, en estos procesos de cambio, es dónde los nuevos significados y valores, que la inclusión lleva asociados, deben ir interpretándose e integrándose en el quehacer organizativo. Los nuevos significados se deberán ir negociando entre todas laspersonas que forman parte de la comunidad.

\subsubsection{Valores inclusivos}

Los valores organizativos, según Hamburger (2008), establecen directrices para el compromiso diario, humanizan las relaciones en la organización, dan sentido a la vida laboral, cohesionan los grupos, aumentan la producción y la calidad de los bienes y servicios, configuran la idiosincrasia de la entidad, generan confianza y credibilidad en las personas usuarias de sus servicios y fomentan el sentido de pertenencia de los trabajadores (Velásquez et al., 2009).

Por ello, los valores son un componente importante de la cultura de una organización (Pasmore, 1988; O'Reilly, Chatman, y Caldwell, 1991; Schein, 2004) y 
representan formas ideales de comportamiento (Argyris y Schön, 1974; Schein, 2004). Como los valores so cia les se utilizan para juzgar no sólo las propias acciones sino también las acciones de otros (Dewey, 1939; Rokeach, 1973) son un aspecto clave porque van a influir en las nomas y en el comportamiento de los miembros de la organiza ción (Seiler, 1967).

Las nomas culturales actúan como principios que se deben seguir y están reconocidos socialmente, es decir, su aceptación fomenta la integración en los grupos e influye en el estatus social (Schein, 2004). Por lo tanto, los valores orga nizativos y las nomas socia les crean un contexto laboral que hacen necesario que los sistemas de liderazgo establecidos se adapten a dicho contexto (Kull y Narasimhan, 2010). Según Pasmore (1988), en la medida en que el diseño organizacional sea coherente con los procesos sociales que se establezcan, mejorarán los resultados y la sa tisfacc ción de todos los implic a dos.

González Licini (1992) establece los siguientes aspectos esenciales de los valores: (1) son proyectos ideales de comportamiento y de existencia que el ser humano aprecia, desea y busca; (2) son opciones personales que se adquieren desde las posibilidades activas de la voluntad; (3) son creencias que se integran en la estructura del conocimiento y (4) son características de la acción humana que mueven la conducta, orientan la vida y marcan la personalidad.

Los centros que prestan servicios a las personas con algún tipo de limitación se deben comprometer a promover un contexto laboral basado en valores inclusivos en el que las personas, tanto a nivel individual como colectivo, puedan disfrutar de una vida plena desde su diferencia. Para ello, deben establecer una serie de valores inclusivos que sean transversales a todas las práctic as y personas de la organización. 


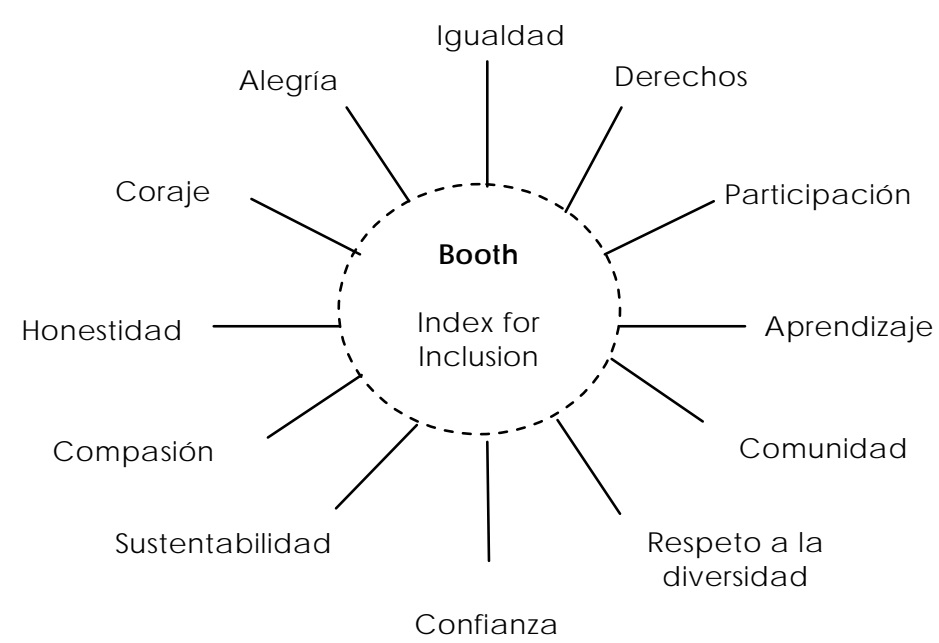

FIG URA 08. VALORES Q UE SE ENCUENTRAN TRAS LA FILOSO FÍA DEL INDEX FOR INCLUSION (BOOTH, 2005)

En este momento nos vamos a detener en los valores que se encuentran detrás de la filosofía del Index para la inclusión porque según Shields (2003) y Rustemier y Booth (2005) deben ser defendid os por las orga niza ciones inclusivas.

1. Igualdad. La igualdad se sitúa en primer lugar porque sin ella no puede haber derechos. Preocuparse por la igualdad requiere un compromiso en los centros para superar la disparidad y significa que cada persona debe ser vista como portadora de un valor propio y con unos derechos adquiridos para poder acceder a aquellos recursos que le faciliten la participación plena en la sociedad. La preocupación por la igualdad no debe confundirse con igualdad de oportunidades (Booth, 2008).

2. Derechos. Valorar los derechos es una forma de afimar que todos somos seres humanos y, por lo tanto, debemos tener la misma prerrogativa para que nuestras necesidades básicas, de aprendizaje y de participación en la sociedad sean satisfechas (Booth, 2008). 
3. Participación. Muchos centros no buscan la participación activa de las personas usuarias e, incluso tampoco, de los profesionales. La partic ipación conlleva "estar con" y "colaborar con otros" lo cual supone un compromiso activo y una implicación total en la toma de decisiones. Implica el reconocimiento y valoración de una variedad de identidades, para que las personas sean valoradas y aceptadas por lo que son (Booth, 2008).

4. Aprendizaje. Un compromiso con el aprendizaje conlleva valorar los logros de todos y no un conjunto limita do de logros básic os de a lgunos. El aprendizaje inclusivo se construye desde lo que las personas ya saben y han experimentado hasta las realidades tanto del ámbito local como global. No hay límites artificiales para los logros impuestos basándonos en supuestas competencias, características de la familia o del entomo, género o raza (Booth, 2008). El a prendiza je es visto “sin limites" (Hart et al., 2004).

5. Comunidad. La importancia de la construcción de una comunidad se refleja en la vida diaria del centro (Booth, 2008). Los centros que establecen relaciones de apoyo, que pueden desamollarse entre los diferentes escenarios en los que se mueven sus miembros, aportan un incentivo para el desarrollo sentimientos de hemandad que van a ir más allá de la familia, del centro o de la localidad.

6. Respeto a la diversidad. Respetar la diversidad implica, en primer lugar, reconocerla; ya que está siempre presente. La importancia del respeto a la diversidad nos lleva a entender el daño que se ocasiona cuando rechazamos a otros a causa de una diferencia percibida y los consideramos menos importantes o incluso con menos derechos que el resto de seres humanos. (Booth, 2008). 
7. Confianza. La confianza es un prerrequisito para establecer el dialogo entre las personas y está involucrada en los procesos de participación independiente, ya que al estar mediados por ella, el aprendizaje no depende de la constante vigilancia y control. En los centros es fundamental para el desa rollo profesional de los colaboradores porque si la confianza se reduce, la credibilidad también puede verse resentida (Booth, 2008).

8. Sustentabilidad. Los centros deben preocuparse por brindar información sobre la inclusión y ofrecer respuestas a las situaciones que plantea la inclusión en ámbitos educativos, laborales y sociales. No tiene sentido la inclusión en escenarios o comunidades sin preocuparse por la calidad y sustentabilidad del proceso (Booth, 2008).

9. Compasión. La compasión implica una voluntad de entender el mundo, incluso el mundo emocional, desde el punto de vista del otro. La consideración de la compasión como un valor central para la inclusión provino de obsenar el rechazo constante de estudiantes que rompen con las reglas esc ola res en a lgunas esc uelas del Reino Unido (Booth, 2008).

10. Honestidad. La inclusión requiere integridad de quienes trabajan para promoverla. La falta de honestidad e integridad de los adultos en ambientes educativos, laborales y sociales priva a las personas de poder participar de una forma plena. En una comunidad, aquellos que poseen menor poder dependen de la honestidad e integridad de aquellos con más poder para tomarlasriendas de su vida (Booth, 2008).

11. Coraje. El coraje es un elemento esencial de una estructura en la que otros valores deben ser defendidos. La honestidad requiere coraje para hacer frente, a una idea equivocada pero socialmente adquirida, a una persona poderosa o para serparte de una minoría de opinión (Booth, 2008). 
12. Alegńa. Los procesos inclusivos conllevan un compromiso gratificante hacia el aprendizaje, la participación y las relaciones constructivas y positivas. Pero, en muchos casos, el ambiente que se respira en los centros que prestan servicios a las personas con discapacidad no es alegre y positivo porque están centrados en la problemática que se esconde detrás de la deficiencia y la discapacidad que esta conlleva (Booth, 2008).

A modo de resumen, podemos dec ir que los centros que prestan servic ios a personas con algún tipo de limitación deben definir sus valores inclusivos para adaptarlos a la idiosincrasia del centro y a su momento evolutivo. Esta tarea va a requerir diálogo, reflexión, debate y consenso (Andrés y Sarto, 2009).

En todo momento se debe tener presente en los centros que los valores que guían las acciones y las prácticas son la base de todas las políticas, actuaciones y planes de acción que se lleven a cabo (Andrés y Sarto, 2009).

En definitiva, y teniendo en cuenta las diferentes a portac iones rea liza das en este apartado sobre la cultura inclusiva, podemos decir que los valores culturales sobrevuelan a los equipos y a las personas que forman parte de la entidad (Schein, 2004) por lo que el desarrollo de una filosofía de inclusión y de apoyo a la diversidad implica a toda la organización y traslada a niveles más operativos las intenciones que se reflejan en la misión y visión del centro.

A la hora de fomentar una cultura inclusiva en los centros que prestan servicios a personas con algún tipo de limitación, los beneficios previstos pueden tardar en aparecer más de lo esperado. Una de las razones que pueden estar detrás es que los valores del centro son incompatibles o se encuentran en discrepancia con los va lores inclusivos. Es decir, los profesionales de los centros se 
pueden resistir a una iniciativa que apoye la inclusión o la diversidad porque simplemente entra en conflic to con la "forma de hacer las cosas" que existe en ese momento en el centro (Kull y Narasimhan, 2010).

Dado que los valores culturales afectan a cómo percibe la gente el mundo (Schein, 2004) y tienen gran influencia sobre las nomas de comportamiento (Dewey, 1939), si en el centro se ponen en macha prácticas que contradicen los valores cultura les pueden ser rechazadas por sus profesionales (Kull y Narasimhan, 2010). De hecho, como nos señalan McDermott y Stock (1999) uno de los obstáculos identific a dos para realiza r un cambio en una organización es la falta de apoyo de su cultura.

En investigaciones realizadas sobre la implantación de sistemas de excelencia en las organizaciones, aspecto que puede tener en muchos sentidos semejanzascon el de implantación de filosofías inclusivas, se ha demostra do que la puesta en marcha de prácticas de gestión de calidad puede afectar a los valores culturales de la organización (Boggs, 2004; Naveh y Erez, 2004) y, a la vez, ser afectadas por ellos (Kujala y Lillrank, 2004; Miron, Erez, y Naveh, 2004); desde la presente investigación, se cree que los resultados pueden ser extrapolados al desarrollo de nuevas práctic a sinclusivas en los centros.

Diferentes autores han sugerido que los valores culturales deben estar alineados con la práctica deseada por lo que son necesarias intervenciones organizativas destinadas a cambiar la cultura antes de intentar implantar las nuevas prácticas en los centros (Flanagan, 1995; McDermott y Stock, 1999). Sin embargo, las iniciativas de cambio cultural son lentas (Ogbonna y Hamis, 1998) y puede tener consecuencias inesperadas (Hamis y Ogbonna, 2002); en cambio, si se modifican los valores culturales indirectamente a través de las nuevas prácticas inc lusivas, los recursos y esfuerzos pueden dedic a rse a su a plic ación. 
Por todo ello y a poyándonos en las diferentes investigaciones realizadas sobre la aplicación del Index en diferentes países e instituciones (Corbett, 2001; Norwich et al., 2001; Vaughan, 2002; Vislie, 2003; Channon, 2003; Booth, 2008; Hick, 2005; Rustemier y Booth, 2005; Heung, 2006; Rose, 2002; Dyson 2001a; Ainsc ow, 2007; Corbett, 2001; Dyson, Gallannaugh y Millward, 2003; Hick, 2005; Hodson, Baddaley, Laycock y Williams, 2005; Norwich, Goodchild y Lloyd, 2001; Vaughan, 2002; Duran et al., 2005) podemos decir que la utilización de un instrumento como el que se presenta en esta investigación puede ser el detonante para que algunas organizaciones inicien o continúen con un cambio en la cultura, los valores, las políticas y las prácticas para orientarse hacia los principios que sustentan la inclusión y la aceptación de la diversidad.

\subsection{Políticas inclusivas}

Las políticas que se pongan en marcha en los centros deberán estar diseñadas para que toda persona, independientemente de sus limitaciones, su situación de origen, posición u ocupación social, pueda desarrollar plenamente sus capacidades, tanto en el plano físico como intelectual y personal. Para ello, el entomo, la cultura y el ambiente social no deberán actuar como factores de disc rimina ción (C.E., 2001).

Las polític as de los centros defenderán los valores inclusivos promoviendo entomos de trabajo en los que todas las personas de la organización se sientan partícipes. Si la vida y la sociedad son diversas también lo deben ser este tipo de orga nizaciones (Ca meiro, 2002).

Los centros, bajo el paraguas de la Convención de Derechos de las personas con discapacidad celebrada en 2006, deberán poner en marcha políticas organizativas que protejan los derechos humanos que asisten a todos y Tesis Docto ral 
que son exigibles por todas las personas. Polític as que deberán estar a linea das con la cultura del centro y con los valores y los principios de inclusión que se promueven desde la misión.

Como a poyo al despliegue de las políticas inclusivas se deberán instaurar en los centros sistemas de dirección y gestión que permitan el ejercicio de derechos de ciudadanía, la adaptación a los cambios constantes de la sociedad en la que vivimos, la excelencia en los servicios que se presten y la creación entomos en los que todo el mundo se sienta bien acogido y partícipe de un proyecto común.

Para ello, los líderes de los centros que prestan servicios a las personas con discapacidad deberán tener una visión clara y centrada en los valores de la comunidad a la que pertenecen. Serán un ejemplo de la visión en todos los sentidos y tendrán como uno de sus principales retos conseguir y promover que en la organización esté presente el mensaje que se desprende de la misión y los va lores del centro (Strully y Broderick, 2010).

\subsubsection{La base de las políticas de inclusión: los derechos de las}

\section{personas con discapacidad}

A lo largo de la presente investigación se refleja que la defensa de los derechos debe formar parte de la razón de ser de los centros que prestan servicios para personas con discapacidad por lo que su misión, visión, valores y políticas deben darcuenta de ello.

La noción de derechos ha ido tomando una importancia progresiva en los últimos siglos y las demandas que se han realizado se han encaminado tanto hacia la defensa de algo tan sencillo como que todos tenemos los mismos derechos, como hacia la necesidad de que estos sean efectivamente ejercidos en la práctic a (Booth, 2008; AMICA, 2009). 
Las políticas inclusivas que se pongan en marcha en los centros que prestan servicios a personas con discapacidad tienen un gran referente intemacional, la Convención de Derechos de las Personas con Discapacidad de la ONU, ratificada en España en abril de 2008 (BOE núm. 96 de 21 de abril). El objeto de la Convención es promover que todas las personas tienen los mismos derechos y que deben ser objeto de especial protección aquellos que tienen mayores dificultades para ejercerlos (AMICA, 2009).

Como nos señala el Comité Español de Representantes de Minusválidos (CERMI) la Convención destaca: (1) la "visibilidad" de las personas con a lgún tipo de limitación dentro del sistema de protección de derechos humanos de Naciones Unidas, (2) la asunción irreversible del fenómeno de la discapacidad como una cuestión de derechos humanos, y (3) el contar con una herramienta jurídica vinculante a la hora de hacervaler los derechos de estas personas (CERMI, 2010).

La Convención señala, en su artículo 3, una serie de principios que están relacionados con la filosofía de inclusión, y que por tanto, nos están guiando en la presente investigación:

a) El respeto de la dignidad inherente, la autonomía individual, incluida la libertad de tomar las propias decisiones, y la independencia de las personas;

b) La no discriminación;

c) La participación e inclusión plenas y efectivas en la sociedad;

d) El respeto por la diferencia y la aceptación de las personas con disc a pacidad como parte de la diversidad y la condición humanas;

e) La igualdad de oportunidades;

f) La accesibilidad;

g) La igualdad entre el hombre y la mujer; 
h) El respeto a la evolución de las facultades de los niños y las niñas con discapacidad y de su derecho a presenvar su identidad.

Los derechos marcados en la Convención deberán estar presentes en las polític as inclusivas que se pongan en marcha en los centros socio-educativos para ofertar servic ios que respeten a la persona en todas sus dimensiones.

El desarrollo de la declaración de la misión, visión y políticas de una organización exigirá un compromiso compartido entre todos los miembros del centro para que refleje los valores de una verdadera cultura inclusiva.

Tener una visión compartida de lo que somos y de lo que queremos llegar a ser es funda mental, a ntes de iniciar el proceso de elaboración de las polític as de la organización, y más cuando estamos hablando de centros que prestan servicios a personas con algún tipo de limitación.

La declaración de unas políticas organizativas enunciadas de forma inc lusiva y con un enfoque claramente orientado a la atención a la diversidad va a guiar tanto a quienes toman las decisiones como a quienes las despliegan a tra vés de las prácticas que se llevan a cabo en el centro.

\subsubsection{Políticas y procesos de gestión}

Mantener una cultura de inclusión y unas políticas inclusivas activas en una organización requiere de unos procesos de gestión que sean transparentes e inclusivos (Blair, 2010). Es dec ir, los procesos de toma de decisiones, los procesos de selección y de formación, las práctic as de promoción, los sistemas de incentivos o los sistemas de comunic a ción deben ser accesibles y deben potenciar los derechos de todos los miembros de la organización. Crear procesos en los que todos puedan sentirse incluidos es esencial para crear oportunidades de desarrollo personal y profesional. 
Los procesos de toma de decisiones deberán ser objeto de estudio en el centro si lo que se persigue es fomentar la inclusión, ya que éstos no podrán ir de arriba hacia abajo. La toma decisiones deberá ser participativa y las ideas deberán generarse a partir de la participación de toda la comunidad, para que cada persona que forma parte de ella sienta que está contribuyendo al proceso. La toma de decisiones descentralizada puede contribuir a la eficiencia, a la calidad y a la innovación, puesto que los profesionales del centro son conscientes de que su punto de vista y su saber hacer tienen influencia en la definición de su entomo de trabajo (Blair, 2010). Del mismo modo, puede tener como una de sus consecuencias la creación de equipos de a lto rendimiento.

Para conseguir la creación de equipos en los que se trabaje con un enfoque inclusivo, se deberán desarrollar políticas de gestión de recursos humanos y de formación orientadas a promover que todos los profesionales alcancen el perfil competencial adecuado, que cada profesional sea capaz de asumir la responsabilidad de su trabajo y que todos los miembros de la organización desarrollen actitudes de confianza y respeto. El resultado se reflejará en el centro ya que, basándose en una cultura de trabajo compartida, se habrá promovido que esté orientado a los resultados y a la obtención de un alto rendimiento.

El centro también deberá velar por la igualdad de oportunidades de acceso en los procesos de selección de personal y por las posibilidades de progresión y ascenso organiza tivo para las mujeres y las personas con algún tipo de limitación, evitando cualquier tipo de discriminación. Y deberá promover la eliminación de los tra tos discrimina torios, es decir, establecerá medidas para evitar cualquier tipo de acción que suponga dar un trato de inferioridad a una persona o colectivo o grupo por motivos extemos a los mismos.

Por todo ello, aquellos centros que quieran mantener una política de recursos humanos libre del uso de la discriminación y la desigualdad deberán 
fomentar no sólo comportamientos funda dos en el respeto y la tolerancia sino que deben orientar dicha política a conseguir cambios en la gestión de las personas que logren la eliminación de los tratos desiguales y discrimina torios.

Pero no en todas las estructuras organizativas es posible desarrollar procesos y políticas como las que se están señalando. Skrtic (1991) indicó que en los centros que existían estructuras organizativas adhoc ráticas la respuesta a la diversidad se rea lizaba de forma más positiva y con mayor creatividad (Ainscow y Sandill, 2010). Por lo tanto, en los centros se tendrá que considerar este factor a la hora de promover polític as inc lusivas.

No se ha de olvidar que un cambio organizacional, orientado a la creación y promoción de centros inclusivos que carezca de claridad, transparencia y un propósito real, será ineficaz. Muchos expertos reconocen que el cambio es un proceso a largo plazo, no una solución rápida. Para que el cambio tenga éxito, los líderes deben estar dispuestos a invertir plenamente en el proceso (Blair, 2010).

El proceso de cambio afecta a la organización de forma conjunta, y por lo tanto los desafíos están presentes en todos los niveles (Bla ir, 2010). Los líderes de los centros que prestan servicios a las personas con discapacidad deben escuchar a todas las personas que forman parte de la comunidad y hacer que participen de una manera signific ativa.

El liderazgo inclusivo podría definirse como el liderazgo que está abierto al cambio, porque la inclusión se considera ante todo un proceso de adaptación a las personas. Sin embargo, antes de realizar ningún tipo de acción (Pettigrew y Whipp, 1993), el líder debe desa rollar una forma personal de ver la inclusión y un punto de vista de cómo la inclusión se vincula con la visión de la organización (Beare et al., 1989). También cabe destacar que un líder inclusivo es probable que tenga características espec ífic as ta les como la a pertura de espíritu (Adair, 1983), el a ltruismo (Sta rratt, 1988), la visión, la sensibilidad y la subsidia riedad (West-Bumham, 
1997), y una orientación hacia el apoyo de la diversidad (Kouzes y Posner, 1996). Zollers et al. (1999) sostuvo en su estudio que el liderazgo inclusivo se basa en un enfoque democrático, en valores positivos, en la capacidad de ser visto como modelo y de transmitir una visión a mplia de la comunidad (Cameiro, 2004).

Los líderes de los centros de atención a personas con discapacidad deben inspirar y apoyar a las personas a formar parte de una comunidad que está en continuo cambio y adaptación. Cambiar nos obliga a renunciar a lo que esfamiliar a favor de lo se desconoce, con lo que en la mayoría de los casos el mayor reto que tiene el cambio para las personas es el cambio en sí mismo (Blair, 2010). Por ello, desde el centro y, desde la comunidad, se debe hacer que los profesionales se sientan seguros en su lugar de trabajo, que puedan desarrollar un sistema de pertenencia, un sentimiento de comunidad y un sentido de conexión. En to do ello van a jugar un papel fundamental los valores de la organización y de las personas que forman parte de ella, que la visión del centro esté bien articulada, y que desde la organización haya un apoyo a la diversidad de opinión y perspectivas, ya que todo ello fomenta el sentido de la inclusión. La flexibilidad evita el etiquetado y promueve la motivación (Albericio, 1991; Santos Guerra, 1993).

El papel del líder en los centros será estar con las personas durante su viaje, ayudándolas y a poyándolas para que defina n lo que quieren en su vida. Los líderes deben tener la capacidad de verlas competencias, la fuerza y talento en todos los miembros de la comunidad. Constantemente deben ser capaces de buscar otra forma de hacer algo cuando la respuesta no es simple, pero esto solo se podrá hacer si conocen a las personas, si son capaces de ponerse en su lugary, si son honestos y leales (Strully y Broderic k, 2010).

Los líderes inclusivos deberán establecer políticas y procesos de buen gobiemo que reflejen el conjunto de dispositivos, mecanismos y estructuras que van 
a determinar la forma en la que el centro se dirige y gestiona. El buen gobiemo comorativo implica que los centros pongan los medios adecuados para salvaguardar los intereses de todos los miembros de su comunidad (De la Cuesta González, 2004).

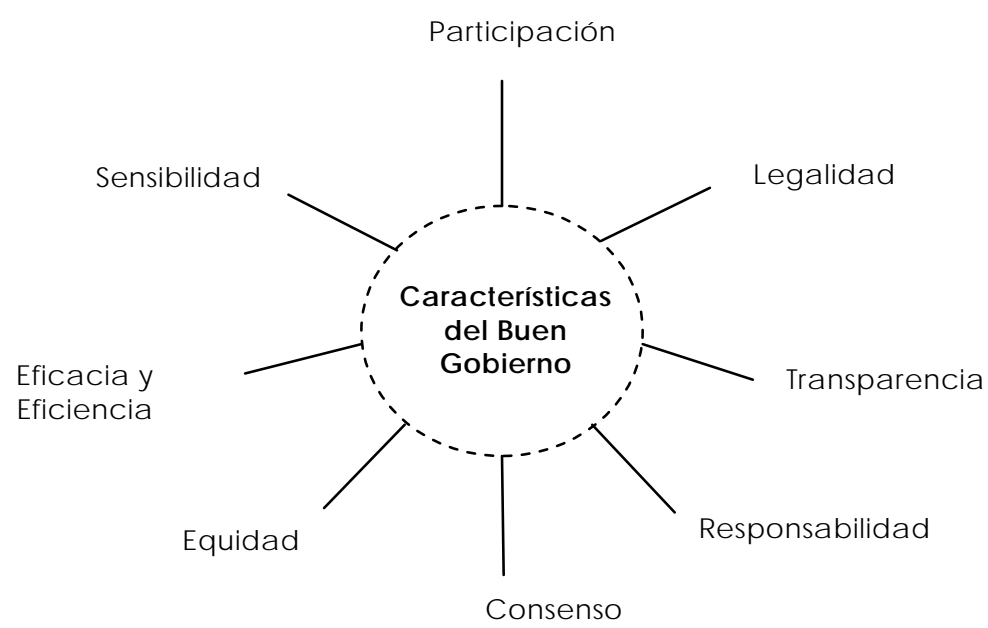

FIG URA 09. CARACTERÍSTICAS DEL BUEN G OBIERNO (UN ESCAP, 2010)

El buen gobiemo según United Nations Economic and Social Commission for Asia and the Pacific tiene ocho características que le sustentan: participación, legalidad, transparencia, responsabilidad, consenso, equidad, eficacia y eficiencia, y sensibilidad. Los líderes de los centros deberán velar para estén presentes en ellos. Se presenta a continuación, de forma breve, una descripción de las ocho característic as del buen gobiemo (UN ESCAP, 2010):

- Participación: para que se produzcan procesos de participación deberá existir libertad de expresión, una buena organización y la información deberá estar al alcance de todos. La participación tanto de hombres como de mujeres es el punto clave de un buen gobierno.

- Legalidad: el buen gobiemo precisa que su marco legal sea justo y que se aplique de forma imparcial. 
- Transparencia: se refiere a que todo el mundo pueda acceder a la información que está detrás de las decisiones y formas de hacer del centro.

- Responsabilidad: el buen gobiemo requiere que los centros estén al servicio de todos los grupos de interés dentro de un marco de tiempo razonable.

- Consenso: partiendo de la historia, cultura y características de la comunidad, el buen gobiemo establece procesos de mediación y consenso para satisfacer el mayor número de intereses de todos los implic ados de forma sostenible.

- Equidad: el centro debe asegurarse de que todos sus miembros sienten que forman parte de un proyecto común.

- Eficacia y Eficiencia: los centros deben llegar a a lc a nzar los resultados planific ados utilizando de la mejor forma posible los recursos de los que disponen.

- Sensibilidad: la sensibilidad es una de las claves para el buen gobiemo. Los centros deben ser sensibles a los derechos y necesidades de quienes están afectados por sus decisiones y acciones.

\subsubsection{Polític as inc lusivas saludables}

Existe un creciente consenso sobre la necesidad de que el clima organizacional sea adecuado para que una organización inclusiva pueda ser efectiva (Miller, 1998; Thomas, 1990; Triandis et al, 1994.). Si los centros que prestan servicios a las personas con discapacidad son capaces de crear un clima que incluya a sus miembros, conseguirán mejores resultados tanto organizativos como personales. En cambio, si los centros no son capaces de realizar una gestión 
eficiente pueden acabar convirtiéndose en organizaciones enfermas que se caracterizarán por su falta de flexibilidad y de adaptación al entomo.

Los centros que prestan servicios para personas con discapacidad, ahora más que nunca, deben centrarse en un enfoque que va a trascender, en su caso, de lo organizativo porque va a impactar de forma directa en sus prácticas laborales. No se puede apostar por un enfoque de inclusión si no se habla en los centros de la gestión de las emociones positivas, las formas efectivas de a frontamiento de situaciones conflic tivas, la resistencia psic ológica, la autenticidad en las relaciones sociales en el trabajo, la esperanza, la autoeficacia y la autodeterminación, la conducta cívica en las organizaciones y el engagement (Sa la nova y Schaufeli, 2004).

En un estudio realizado por la empresa Kenexa (Hayes, 2010), se ha demostrado que la inclusión organizativa tiene influencia sobre los estilos de liderazgo, el equilibrio de la vida personal y laboral, el trabajo en equipo y la colaboración multidisciplinar, los programas de formación y de desarrollo profesional y la efectividad de las iniciativas que se ponen en marcha en la organización.

Por lo tanto, los centros que pongan en marcha políticas y procesos de gestión coherentes con los valores inclusivos, estarán más cerca de ser organizaciones saludables y de calidad (Salanova, 2008; Salanova y Schaufeli, 2009), es decir, entidades que funcionan con efectividad en relación a las demandas, condiciones económicas y sociales actuales. De esta manera, la calidad se extiende portodas las á reas de actividad de la organización.

Por ello, podríamos dec ir que las organiza ciones sa luda bles son a quéllas que tienen empleados y resultados saludables. $Y$ ello lo consiguen mediante la realización de esfuerzos sistemáticos, planificados y proactivos cuyo objetivo está 
centrado en la mejora de la salud de los empleados y la salud financiera de la organización.

Esos esfuerzos se podrían traducir en buenas prácticas relacionadas con la promoción y optimización de una serie de recursos orientados a la mejora de las tareas (por ejemplo, en el diseño de nuevos puestos y en la redefinición de los ya existentes), el ambiente social de la organización (por ejemplo, canales de comunicación abierta, estilos de liderazgo transparentes) y la organización (por ejemplo, selección y socialización laboral, formación y desarrollo, políticas de estabilidad en el empleo, estrategias de conciliación trabajo/vida privada, estrategias de implicación de los trabajadores, reconocimiento de los resultados alcanzados).

Una organización saludable gestiona de forma activa la promoción y la conservación del más alto nivel de bienestar físico, mental y social de los profesionales que trabajan en ella. Algunos ejemplos de práctic as orga nizacionales que contribuyen a crear ambientes de trabajo psicológicamente saludables incluyen entre otras (1) la participación de los profesionales en la toma de decisiones, (2) desarrollo de planes de formación para el desarrollo de competencias de liderazgo, trabajo en equipo y de gestión efectiva del estrés, (3) acuerdos laborables de trabajo flexible y conciliación entre la vida personal y profesional, (4) acciones para priorizar la salud y la seguridad de los trabajadores, (5) reconocer el desempeño individual y de los equipos de trabajo.

Como ya se ha señalado a lo largo de los puntos anteriores, las organizaciones encuentran valor en la diversidad de sus miembros. Según la profesora Susan Woods de la Universidad de Comell mientras que cuando hablamos de diversidad hablamos de las personas, cuando hablamos de inclusión nos referimos a la organización (Craig, 2010; Woods, 2002). Y es, por tanto, ésta la 
que tiene que crear los procesos y estructuras que potencien y sean capaces de obtener ventaja competitiva de esa diversidad.

Según Woods las organizaciones inclusivas y saludables deben tener ciertas cualidades que hagan posible la puesta en marcha de procesos organizativos que obtengan valor de la diversidad (Craig, 2010; Woods, 2002).

(1) Compromiso con la diversidad: la organización valora a las personas por sus diferencias y sus similitudes; esta actitud debe extenderse desde amiba hacia abajo para que pueda difundirse en toda la organización.

(2) Las personas son el núcleo de la organización: las personas y sus derechos son su razón de ser, por ello, se pondrán en marcha procesosque fomenten la igualdad de oportunidades, la participación plena y que los profesionales se sientan orgullosos de trabajar en un lugar con estas características.

(3) Información accesible: la información en el centro fluye en todas direcciones y se anima a todos los niveles de responsabilidad a que promuevan su difusión. Las personas sienten que pueden hablar con cualquier persona independientemente de su rango o condic ión.

(4) Igualdad: la organización reconoce las contribuciones de todos los profesionales. Todo el mundo tiene responsabilidad y la acepta por el bienestar del conjunto. Esta actitud se extiende más allá de las paredes de la organización y se ve reflejada en las entidades y personas que la a poyan.

(5) Compromiso con el aprendizaje: todo el mundo es visto como una persona con posibilidades de aprender y de enseñar. Dentro de la organización, el aprendizaje se fomenta de forma participativa en todos los departamentos, áreas o equipos.

(6) Maximizar el potencial humano: la organización considera que todas las personas, independientemente de su experiencia y/o formación, tienen un 
gran potencial y trabaja para puedan encontrar en la comunidad un rol que lo maximice. La cultura es vista como una herramienta que se utiliza para a linear los valores orga niza cionales c on los valores ind ivid ua les.

(7) Colaboración: la organización lleva a cabo, cuando son necesarios, procesos para evitar la exclusión, para que todos sus miembros se sientan bien acogidos y partícipes de un proyecto común. Para ello, deberá promover: (1) buenas relaciones entre los profesionales y la dirección, (2) buenas relaciones interpersonales entre empleados, (3) buenas relaciones entre los empleados y su propio trabajo/empresa.

(8) Participación: la participación comunitaria es una característica de las organizaciones inclusivas, por ello, el centro llevará a cabo acciones para difundir en la sociedad la idea de inclusión y la necesidad de que todas las personas puedan ejerc er los derechos de ciudadanía.

Como se ha visto a lo largo de las aportaciones realizadas por diferentes autores y organismos, para que una organización sea capaz de alcanzar resultados organizativos onientados a la inclusión deberá tener unas características institucionales determinadas y deberá poner en marcha unos procesos de gestión basados en el buen gobierno para que, de este modo, la inclusión, el ejercicio de derechos y la creación de una comunidad en la que todos se sientan incluidos, sea una realidad y no un proyecto de futuro que nunca que se alcanzará.

Resumiendo los diferentes aspectos vistos en este segundo a partado sobre políticas inclusivas, podemos decir que la diversidad y la inclusión son cuestiones que atañen al centro en todo su conjunto y que sitúan a sus miembros en la necesidad de mirar al contexto organizativo en el que están inmersos: los valores y políticas que orientan el funcionamiento del centro, las prácticas y rutinas 
asentadas en él, las normas y modos de hacer compartidos por todos (González, 2008). Todos y cada uno de estos aspectos pueden esta r facilitando la inclusión o, por el contrario, representar barreras para la misma; en tal caso contribuirán, probablemente de modo sutil y no explícito, a que los procesos de inclusión y la creación de una comunidad en la que todo el mundo se sienta acogido, se aleje de la realidad (González, 2008).

Por ello, los centros que deseen centrar su mirada en la inclusión y la atención a la diversidad deberán revisar sus polític as y práctica s orga nizativas pa ra asegurarse de que no sólo no son discriminatorias, sino que apoyan y defienden los valores inclusivos. Para promover la inclusión en los centros no es suficiente con incorporar nuevas formas de trabajar o modificar las existentes, si no que hay que eliminar los viejos sistemas y/o polític as ya implantados que refuerzan las prácticas de exclusión.

Desa rrollar políticas de inclusión en los centros que prestan servicios a las personascon discapacidad es una propuesta a largo plazo puesto que conlleva un proceso de modificación de actitudes y prácticas (Blair, 2010). La creación de una organización inclusiva requiere abrir las mentes y las puertas a nuevas perspectivas y visiones del mundo. Es un proceso continuo de repensar el trabajo que se realiza, a sí como las relaciones que se establecen con la comunidad en general.

En un centro inclusivo todas las partes forman un todo (Blair, 2010); se ponen en marcha procesos interactivos que apoyan al entomo, a las estructuras y a los sistemas que permiten a los profesionales del centro desplegar todas sus competencias y conseguir los resultados de manera más eficiente. Una organización inclusiva tiene la capacidad de liberar el potencial humano, por lo que la creatividad y la innovación pueden florecer.

Las políticas organizativas han de estar fundamentadas en la concepción de que las personas usuarias, sus familias, los profesionales y todos los miembros de 
la comunidad que conforma el centro, tienen derecho a una adecuada dirección para que los resulta dos que se alcancen sean los consesuados por la comunidad.

Los líderes de las orga nizaciones nec esitan crista lizar la misión y la visión de los centros a través de acciones y comportamientos que inspiren, motiven y mantengan un ambiente donde cada uno encuentra en el trabajo la dignidad, el sentido y el sentimiento de pertenencia a una comunidad (Senge, 1993).

\subsection{Práctic as inc lusivas}

En los últimos años se ha producido un cambio en la gestión de los centros para personas con discapacidad y en las prácticas que desarrollan. Se ha pasado, en muchos casos, a prácticas centradas en la calidad de vida de la persona que han hecho que muchos centros giren 180 grados su forma de concebir la disc a pacidad .

A pesar de ello, queda mucho por hacer porque en muchos centros se sigue situando a la discapacidad como centro de las prácticas que se ponen en marcha, mientras que debería ser la persona la que ocupe el eje sobre el que deben pivotar todos los servicios.

Como se ha señalado en los a partados anteriores todos los esfuerzos de los centros deben centrarse en defender los derechos que tienen las personas con algún tipo de limitación y, por todo ello, las prácticas en los centros deben tener a la persona como eje y protagonista.

\subsubsection{La persona como eje de las prácticas}

La filosofía del centro, sus normas, prácticas, comportamientos de los profesionales y de la comunidad, la estructura de la organización y sus sistemas de gestión, entre otros aspectos, van a influir en las prácticasque se lleven a cabo. Por 
ello, estas deberán estar basadas en unos valores que promuevan, la defensa de derechos, la vida independiente y la mejora de la calidad de vida.

Las prácticas deberán ser diseñadas para cada persona, porque cada individuo tiene sus propias necesidades, aspiraciones y expectativas (AMICA, 2009) y estarán orientadas a fomentar el aprendizaje y la participación, ya que sólo de este modo se podrán poner en valor las ideas marcadas desde Europa (EUSE, 2005) y apoyadas por la ONU (2006), basadas en el empoderamiento, la integración social, la dignidad y el respeto hacia el ser humano.

En Europa se ha llegado a un acuerdo en cuanto a los valores y principios que deben estar presentes en todas las etapas y actividades del Empleo con Apoyo (EUSE, 2005), y que por ser coherentes con los valores inclusivos y por a poyar los derechos de plena ciudadanía de los individuos, según la perspectiva de la autora de la presente investigación, se deberían extrapolar a las prácticas que se realizan en los centros que prestan servicios a personas con discapacidad.

Las prácticasque se lleven a cabo en los centros deben promover:

- la individualidad: las práctic as deben contemplar el c a rác ter único de cada individuo teniendo en cuenta sus propios intereses, gustos, condiciones e historia personal.

- el respeto: las prácticas deben ajustarse siempre a la edad, deben dignific ar a la persona y sercapaces de enriquecerla.

- la autodeteminación: las práctic as deben a yuda ra los individuos a desarrollar sus intereses y preferencias, a expresar sus gustos y a definir su plan de trabajo/vida, según sus condic iones persona les y contexto. Igua Imente deben fomentar los princ ipios de autogestión entre las personas usua rias.

- la elección informada: las prác ticas deben promover que los individuos lleguen a tener plena conciencia de sus oportunidades, a 
fin de que puedan elegir de acuerdo a sus preferencias y conscientes de las consecuencias de su elección.

- el empoderamiento: las práctic as deben ayudar a las personas a tomar decisiones sobre su modo de vida y su participación en la sociedad. Los individuos deben estar activa mente involucrados en la planific ación, evaluación y desa rollo de los servicios.

Los centros deberán orientar sus prácticas hacia modelos (Bradley, 1994; 1994b) que estén basados en el ciudadano, en el futuro, en la persona y sus círculos de apoyo, en la autodeterminación, en las relaciones persona les y sociales y en la inclusión; en definitiva, en la calidad de vida del individuo. Por todo ello, las prácticas que se lleven a cabo en los centros deben ser motivadoras y capaces de implicar a la persona en su consecución, ya que sólo de este modo se podrá tender a la autodeterminación, la vida independiente y el bienestar subjetivo.

Para que las personas con algún tipo de limitación puedan ser capaces de tomar las riendas de su propia vida, las prácticas que se lleven a cabo desde los centros deberán estar orientadas a desa rollar las competencias necesarias para ello. Es fundamental que el desa rollo de competencias personales, que dan fuerza y poder a la persona con discapacidad, vayan más allá de las competencias instrumentales. Ya que de este modo, como se verá más adelante, se podrán conseguir procesos de aprendizaje y participación más enriquecedores y más norma liza dos.

Por otra parte, las prácticas deberán estar centradas en los múltiples aspectos positivos que tiene cada persona y orientadas a su crecimiento positivo y no a la "acomodación" (Carver, 1998) ya que esto supone que las personas rebajen las demandas que hacen a la sociedad y aminoren sus expectativas (McMillen, Zuravin y Rideout, 1995). Aunque unas prácticas orientadas a la 
acomodación pueden dar lugar a unos resultados positivos que mejoren la adaptación de la persona a sus contextos, no van a producir procesos de enriquecimiento y crecimiento personal que son los que promoverán la vida independiente de las personas con discapacidad.

En los próximos apartados diferentes autores defienden la necesidad de desarrollar prácticas que promuevan la motivación y la autodeterminación, la implicación, la resiliencia y se mostrarán los efectos de dichas prácticas en las personas y en las orga niza ciones.

\subsubsection{Prácticas que promueven la motivación y la autodeterminación}

La motivación es un elemento clave para lograr el compromiso y la implic ación de una persona con una tarea (Iso-Ahola y St.Clair, 2000) ya que es un mecanismo interno que dirige y determina la intensidad y persistencia de la conducta (Kanfer, 1994; Sage, 1977).

A continuación se va a analizar la motivación de las personas con discapacidad ante una práctica desde la perspectiva de la Teoría de las Metas de Logro (Ames, 1987; Dweck, 1986; Maehr, 1974; Nicholls, 1978, 1989, entre otros) y la Teoría de la Autodeterminación (Deci y Ryan, 1980,1985, 1991; Ryan y Deci, 2000; Ryan, 1982) por ser las que nos proporcionan un marco conceptual más relac iona do con las práctic as inc lusivas.

Teoría motivacional de las Metas de Logro

La Teoría motivacional de las Metas de Logro establece que las metas, junto con los valores personales, son los verdaderos resortes de la vida (Oishi, 2000), por lo que la motivación se mantendrá únicamente en aquellas prácticas a las que la persona les otorgue una verdadera importancia. 
La teoría establece que la meta principal de un individuo en un contexto de logro es demostrar habilidad, existiendo dos concepciones de la misma que se crean por influencia social: (1) la orientación a la tarea o al aprendizaje, en la que el éxito viene definido como el dominio de la tarea y el progreso personal, y (2) la orientación al resultado, en la que el éxito se define como la superación a los rivales y la demostración una de mayor capacidad (Nicholls, 1984a).

El significado otorgado al concepto habilidad puede variar de una persona a otra (Allen, 2003; Maehr, y Braskamp, 1986; Nicholls, 1989; Nicholls, Patashnick, y Nolen, 1985) como consecuencia de las primeras experiencias de socialización así como de factores disposicionales, sociales y contextuales (Duda, 1992; Roberts, 1992). Por ello, esta Teońa no considera la habilidad como un constructo unidimensional, sino que defiende que existen las dos perspectivas presentadas (Nic holls, 1984a, 1984b).

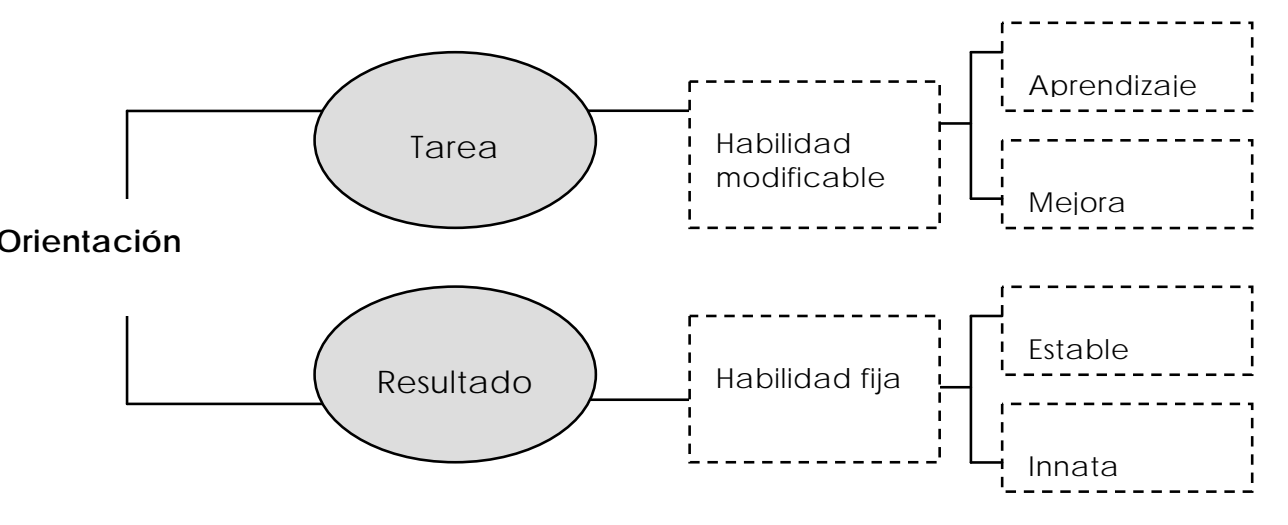

FIG URA 10. RELACIÓN ENTRE LAS O RIENTA CIO NES DE METAS DISPO SICIO NALESY EL CONCEPTO DE HABILIDAD (J IMÉNEZ, 2004)

La onientación a la tarea entiende que la habilidad es modificable y hace referencia a la preocupación por el aprendizaje y a los procesos de aprendizaje y mejora, donde las percepciones de habilidad son auto-referenciales y dependientes del progreso personal y donde el éxito o el fracaso dependen de la valoración subjetiva de si se aprendió o se mejoró en la tarea. La segunda Tesis Doc to ral 
concepción de habilidad se corresponde con una entidad fija e innata que hace referencia a los procesos de comparación social, donde el individuo juzga su capacidad en relación a los demás y donde el éxito o el fracaso depende de la valoración subjetiva que resulta de comparar la habilidad propia con la de otros "relevantes". De esta forma, estas personas se esfuerzan por evitar mostrar una falta de capacidad al compararse con otras.

Nicholls (1984b, 1989), al respecto, propone tres factores a los que según él se encuentran unidas la percepción de éxito y fracaso. Estos son: (1) la percepción que tiene la persona de su demostración de una alta o baja habilidad; (2) las distintas variaciones subjetivas de cómo se define el éxito y el fracaso desde la concepción de habilidad que se ha adoptado; (3) la concepción de habilidad que se tenga, ya que está influenciada por cambios evolutivos, disposicionales y situa c ionales.

Otro aspecto destacable en la consecución de metas, es la predisposición optimista de la persona con discapacidad (Scheier y Carver, 1985) ya que si posee una actitud positiva hacia el futuro será más fácil que oriente todos sus esfuerzos hacia la consecución de los objetivos propuestos (Diener, Suh, Lucas, y Smith, 1999).

La Teoría de la Autodeterminación

La autodeteminación según Deci y Ryan (1985) es una condición que se debe producir necesariamente para que la persona pueda disfrutar de una tarea que le ha conllevado un esfuerzo y una implicación.

El comportamiento autodeterminado se refiere, según Wehmeyer (2005, p.117) a "acciones volitivas que permiten a una persona actuar como agente causal primario en la vida de uno mismo y mantener o mejorar la calidad de su 
vida". Por lo tanto, podemos decir que un acto es a utodetermina do si la acción del individuo refleja las siguientes carac terístic as (Wehmeyer, 2009):

- la persona es la que causa la acción basándose en su propio deseo.

- la persona actúa de modo autónomo.

- los comportamientos están autorregula dos.

- la persona inició a contecimientos y respondió ante ellos de una forma efic iente.

- la persona actúo conscientemente sobre los actos que estaba realizando.

La Teoría de la Autodeterminación (Deci y Ryan, 1980, 1985, 1991) establece que la motivación es un continuo que va surgiendo a lo largo de la vida; desde la infancia y adolescencia se van aprendiendo determinadas habilidades, actitudes y creencias que van a facilitar a la persona ser agente causal de su vida (Wehmeyer, Sands et al., 1997; Wehmeyer, 1998, 2001; Wehmeyer et al, 2003). Estas competencias son identificadas por Wehmeyer (2009) como "elementos componentes del comportamiento autodeterminado" y engloban habilidades relacionadas con ser capaz de hacer elecciones, resolver problemas y tomar decisiones, establecer objetivos personales y ser capaz de poner los medios para a lc anza rlos, y establecer actitudes de a utod efensa y habilida des de a utocontrol.

La motivación a la hora de participar en determinadas prácticas se ve influenciada por los diferentes niveles de autodeteminación que la persona posee; de tal forma, que de menor a mayor autodeteminación tendríamos la desmotivación, la motivación extrínseca y la motivación intrínseca (Deci y Ryan, 1985). 


\begin{tabular}{|c|c|c|c|c|c|c|}
\hline $\begin{array}{l}\text { Tipo de } \\
\text { motivación }\end{array}$ & $\begin{array}{c}\text { Des } \\
\text { motivación }\end{array}$ & \multicolumn{4}{|c|}{ Motiva ción extrínseca } & $\begin{array}{l}\text { Motiva ción } \\
\text { intrínseca }\end{array}$ \\
\hline $\begin{array}{l}\text { Tipo de } \\
\text { regulación }\end{array}$ & $\begin{array}{l}\text { Sin } \\
\text { regulación }\end{array}$ & $\begin{array}{c}\text { Regulación } \\
\text { externa }\end{array}$ & $\begin{array}{l}\text { Regulación } \\
\text { introyectada }\end{array}$ & $\begin{array}{l}\text { Regulación } \\
\text { identific ada }\end{array}$ & $\begin{array}{l}\text { Regulación } \\
\text { integrada }\end{array}$ & $\begin{array}{l}\text { Regulación } \\
\text { intrínseca }\end{array}$ \\
\hline $\begin{array}{l}\text { Locus de } \\
\text { causalidad }\end{array}$ & Impersonal & Externo & Algo extemo & Algo interno & Intemo & Interno \\
\hline $\begin{array}{l}\text { Procesos } \\
\text { reguladores } \\
\text { relevantes }\end{array}$ & $\begin{array}{l}\text { No intencional } \\
\text { No valorado } \\
\text { Incompetencia } \\
\text { Pérdida de } \\
\text { control }\end{array}$ & $\begin{array}{l}\text { Obediencia } \\
\text { Recompensas } \\
\text { extemas } \\
\text { Castigos }\end{array}$ & $\begin{array}{c}\text { Autocontrol } \\
\text { Implic a ción ego } \\
\text { Recompensas } \\
\text { intemas } \\
\text { Castigos }\end{array}$ & $\begin{array}{l}\text { Importancia } \\
\text { personal } \\
\text { Valoración } \\
\text { consciente }\end{array}$ & $\begin{array}{c}\text { Congruencia } \\
\text { Conciencia } \\
\text { Síntesis con uno } \\
\text { mismo }\end{array}$ & $\begin{array}{l}\text { Interés } \\
\text { Disfrute } \\
\text { Satisfacción } \\
\text { Inherente }\end{array}$ \\
\hline
\end{tabular}

FIGURA 11. CONTINUO DE AUTO DEIERMINACIÓN (DECIY RYAN, 2000; RYAN Y DECI, 2000)

La desmotivación se caracteriza por que el sujeto no tiene intención de participar en las diferentes prácticas que se proponen, lo cual va a ocasionar sentimientos de frustración (Deci y Ryan, 1991; Ryan y Deci, 2000).

Dentro de la motivación extrínseca podemos encontrar, según Ryan y Deci (2000): la regulación integrada, la regulación identificada, la introyección y la regulación extema (ordenadas de mayora menorautodeteminación).

(1) La regulación integrada implica en el sujeto una valoración y a similación de lo que conlleva la práctica, lo que conlleva una evaluación y confrontación con otros va lores y nec esidades.

(2) La regulación identificada implica que el sujeto se identifique con la importancia que tiene la actividad para sí mismo, por lo que los comportamientos resultan autónomos, pero la decisión de participar en la actividad viene dada por una serie de benefic ios extemos y no por el placer y la satisfacción inherente a la propia actividad (Ntoumanis, 2001). Por ello, la participación sigue siendo instrumental (Deci y Ryan, 2000). 
(3) La introyección, conllevaría participar en las prácticas por evitar sentimientos de culpabilidad (Ryan y Deci, 2000), simplemente por basarse en el "deber" o "tener" que hacer algo (Ntoumanis, 2002; Sarrazin, Vallerand, G uillet, Pelletier y Cury, 2002).

(4) La regulación extema se caracteriza por una actuación en búsqueda de un incentivo extemo, y por tanto el sujeto se compromete en una actividad poco interesante para él sólo por conseguir una recompensa o evitar un castigo (Deci y Ryan, 2000).

Por último, la motivación intrínseca supone el compromiso de un sujeto con una actividad por el placer y el disfrute que le produce y por tanto, la realización de la actividad es un fin en sí mismo (Deci, 1975; Deci y Ryan, 1985).

Ryan y Deci (2000) identifican la motivación intrínseca como:

Aquella tendencia inherente a la búsqueda de la novedad y de los retos, a la extensión y ejercicio de las capacidades personales, a la exploración y al aprendizaje. Lo intrínseco tiene que ver, por tanto, con una dimensión enriquecedora y de avance en la construcción personal. (p.70)

En los centros se deberán promover prácticas para que las personas con algún tipo de limitación evolucionen en el continuo de la autodeteminación para que lleguen a a lcanzar esta dos de motiva ción intrínsec a que les permitan aprender y rea lizar esfuerzos para a lc a nzar a quellas metas que son signific ativa s pa ra ellos. Si las prácticas son capaces de conseguir una elevada motivación en las personas se podrán, incluso, compensar determinadas carencias en las habilidades (Amabile, 1993). 


\subsubsection{Prácticas que promueven la implicación de la persona}

La felicidad, como nos señala Wilson (1967), es causada por la satisfacción de las necesidades que una persona tiene, portanto, va a depender tanto de las aspiraciones personales, del nivel de adaptación alcanzado, así como de las comparaciones con los demás y las experienc ias vividas.

Si damos un paso más relacionando lo visto en el apartado anterior, podemos decir, que el sentimiento de bienestar y felicidad se alcanza cuando se aúnan los desafíos de la tarea y de las habilidades personales para afrontar positivamente un nuevo proyecto (Csikszentmihalyi, 1975, 1988, 1996, 1998). La felicidad se alcanzaría cuando el esfuerzo físico y psíquico aplicado a tareas voluntarias ha alcanzado su límite, habiendo conseguido algo difícil que merecía la pena.

Cuando una persona cree que una tarea tiene un interés y una importancia superior a otrastareas, escapaz de implicarse de tal modo que puede entrar en un estado que implica una total absorción y la creación de un estado de concentración que facilita la aparición del rendimiento óptimo (Csikszentmihalyi, 1990), es lo que el autor denomina "flow".

Este estado, según Csikszentmihalyi (1990, 1993) se compone de nueve dimensiones: equilibrio entre reto y habilidad, unión de la acción y el pensa miento, claridad de objetivos y las metas que se persiguen, feedback claro y sin ambigüedades, concentración sobre la tarea que se está realizando, sentimiento de control, pérdida de autoconciencia, transformación en la percepción del tiempo y experiencia a utotélic a. 


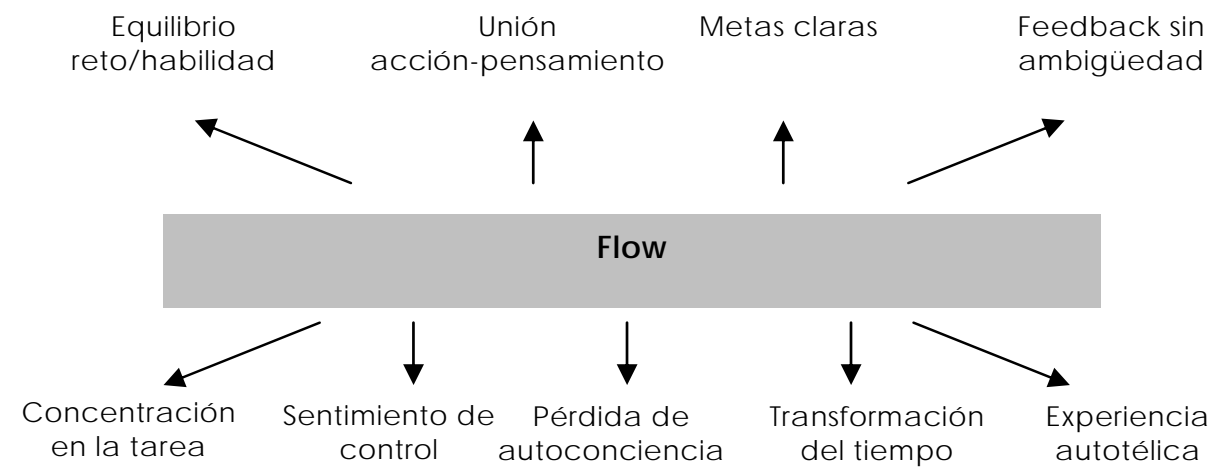

FIG URA 12. COM PONENTES DEL “FLOW” SEG ÚN J AC KSON Y C SIKSZENTMIHALYI (2002)

Para que las personas se sientan implicadas en lastareas que se propongan desde los centros deberán, por tanto, converger, por una parte, un desafío ante la ta rea que están realizando y, por otra, un despliegue de las habilidades necesarias para resolverlas.

Si en los centros sólo se ponen en marcha tareas repetitivas, sobre las que la persona no tiene ninguna capacidad de control y no se aumenta de forma progresiva y con apoyos el nivel de dificultad ni el de habilidad necesaria, se estaría ante un proceso de habituación generando experiencias de abumimiento. En cambio si las prácticas están basadas en un óptimo equilibrio, entre los desafíos y las habilidades, se podrán llegar a experiencias de flujo.

Quien consiga alcanzar este estado positivo de la mente durante la participación en las prácticas que se pongan en marcha desde el centro o las promovidas por la persona, obtendrá grandes niveles de disfrute, diversión y logro, y esta experiencia tan valiosa será el origen de la motivación de muchos individuos que intenten comprometerse con una vida independiente. El flow, por tanto, 
constituye una experiencia intrínsecamente placentera que las personas intentarán repetir, siempre que sea posible, para volver a experimentar o sentir esa sensación. Pero, la activación motivacional no depende sólo de la novedad o del interés intrínseco de la práctica en cuestión, sino de la correspondencia entre ésta y los recursos personales de los que se dispone para afrontar la situación en un equilibrio óptimo entre la competencia del individuo y el desafío percibido implicado en la tarea.

Csikszentmihalyi (2002) advierte que cuando no existe ese equilibrio, se pueden ocasionar dos situaciones diferentes: (1) si los desafíos superan las competencias individuales se genera un estado de ansiedad por exceso de dific ultad, mientras que si, por el contrario, (2) las habilida des superan demasiado los desafíos propuestos, el individuo estará a burrido y, por ende, poco motivado.

Whalen (1997) nos indica, como se puede ver en la figura que se presenta a continuación, que existe una relación entre los distintos grados de desafío y los de habilidad y, que si se combinan de forma compensada, podremos encontrar un área de equilibrio. Por ejemplo, si a una persona se le propone un desafío moderado y posee unas bajas habilidades o competencias para desempeñarlo, se generarán en ella experiencias de preocupa ción y de ansiedad; por el contrario, si existiera un equilibro entre el desafío propuesto y unas habilidades altas para persona vivińa una experiencia óptima o de flujo (Csikszentmihalyi y Csikszentmiha lyi, 1998). 


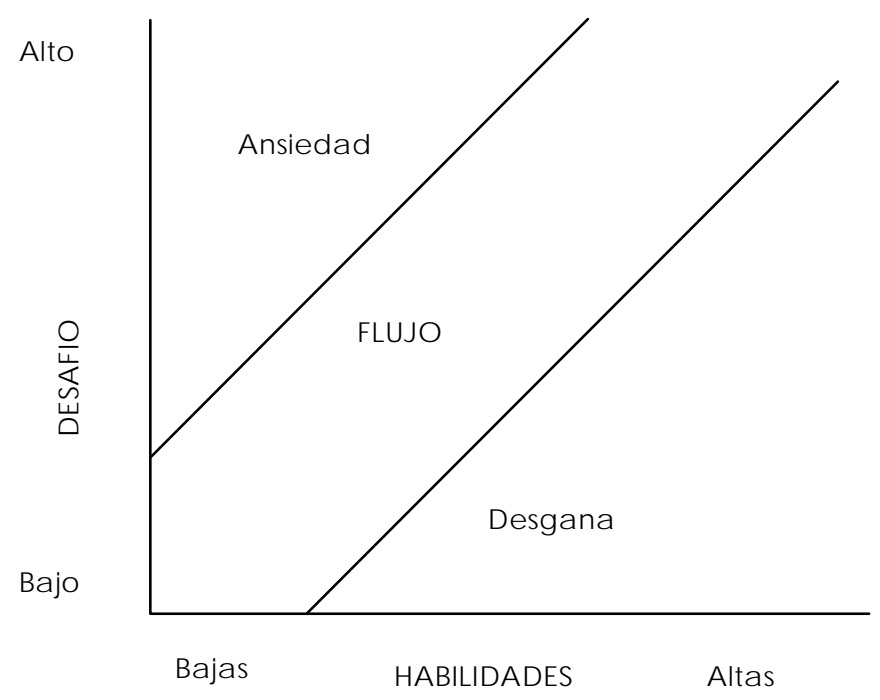

FIGURA 13. “CANAL DE FLUJ O" ENTRE EL GRADO DE DESAFÍO DE LA TAREA Y EL NIVEL DE LAS HABILIDADES REQ UERIDAS (WHALEN, 1997).

Portanto, podemos decir que una persona con discapacidad se involucrará en una tarea con una implicación absorbente $y$, con un gran control sobre sus actuaciones, cuando exista: (a) el equilibrio adecuado entre el desafío propuesto por la tarea y las habilidades disponibles, (b) la sensación de oportunidad de éxito o de alcanzar la meta pretendida, (c) la capacidad o las condiciones necesarias para concentrarse en la tarea emprendida (d) una tarea y unas metas a cumplir claramente definidas y, (e) una retroalimentación inmediata.

En palabras del propio Csikszentmihalyi (1992) las actividades que llevan al "flow":

Son situaciones en las que una persona puede emplear libremente la atención para alcanzar sus objetivos, pues no hay ningún desorden que corregir ni ninguna amenaza para la personalidad de la que haya que defenderse. Hemos llamado a este estado, experiencia de flujo. (p. 230) 
A la hora de planificar prácticas en los centros, se deberá tener en cuenta que la felicidad en relación a la consecución de metas, se alcanza mediante la continua satisfacción de proyectos personales marcados por la propia persona, tanto a corto, como a medio y largo plazo. Las personas que lograrán niveles superiores de satisfacción serán, por tanto, aquellas que se han marcado unas metas fácilmente alcanzables en un corto o medio plazo, beneficiándose así de percibir un refuerzo más inmediato porque están constantemente participando en ac tividades que son por sí misma s intrínsec a mente gratific antes (Palys y Little, 1983).

Pero, además de los factores motivacionales personales que ya se han señalado, hay otros condic ionantes que influyen en el estado de implic ación, que son los factores situacionales. Estos engloban a todo el conjunto de señales contextuales y situacionales a través de las cuales los agentes sociales relacionados con los sujetos definen las claves de éxito y fracaso (Ames, 1992; Maehr, 1984).

Algunos autores como Ames (1992b) y Nicholls (1989, 1992) los han relacionado con los conceptos de la Teoría del Logro de la Meta y se han referido a ellos como el clima motivacional orientado al rendimiento y clima motivacional orienta do al aprendizaje.

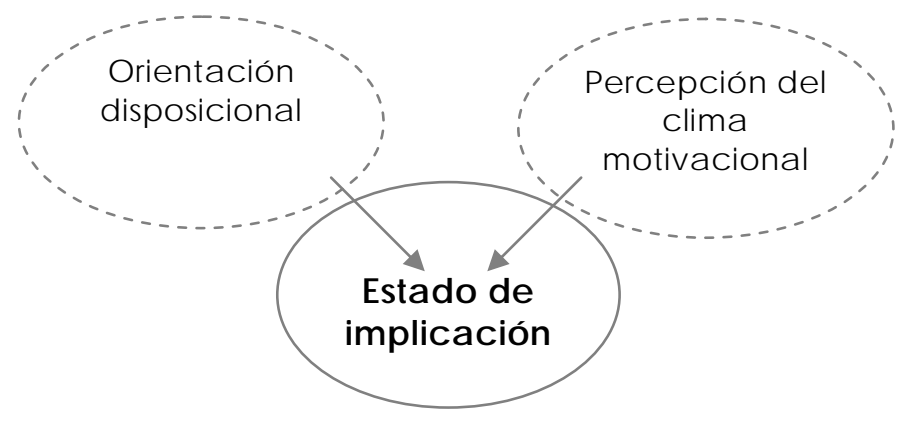

FIGURA 14. CONCEPTO DEL ESTADO DE IMPLICACIÓN (J IMÉNEZ, 2004) 
Estas señales que conforman el clima motivacional pueden manipularse para crear diferentes contextos en los que los factores situacionales tomen fuerza y puedan influir sobre el esta do de implic ación motivacional de las personas. Por ello se hace necesario desarrollar estrategias y prácticas que posibiliten a los profesionales de los centros crear climas motivacionales de implicación con la ta rea o con el aprendizaje.

Epstein $(1988,1989)$ y Ames (1992) señalan que el clima motivacional que se percibe en los centros que prestan servicios a personas con discapacidad está definido por un conjunto de variables interdependientes o rasgos estruc tura les, que fueron denominados con el acrónimo TARGET (Task, Authority, Recognition, Grouping, Evaluation, Time).

Ames (1992) sugiere que para lograr un clima orientado a la tarea, las práctic as deben ser desafiantes y va ria das, las personas deben tomar decisiones y roles de liderazgo, el reconocimiento debe ser privado y basado en el propio progreso, el agrupamiento debe favorecer el aprendizaje cooperativo y la interactividad, la evaluación debe estar basada en la mejora individual en la actividad y, finalmente, el tiempo debe a justarse a las necesidades personales (Ver Tabla 03).

\footnotetext{
ÁREAS DE UN AMBIENTE DE APRENDIZAJ E ESTRATEGIAS

TAREA

Diseño de tareasy actividades

AUTORIDAD

Participación de la persona en el proceso de aprendizaje.
} 
REC ONOCIMIENTO

Razones para el reconocimiento: distribución de las recompensas, oportunidadespara las recompensas.

AG RUPACIÓN

Forma y frecuencia en que las personas interactúan juntas.

EVALUACIÓN

Establecimiento de los estándares de rendimiento. Guía de rendimiento, feedback evalua tivo.
Reconocimiento del proceso individual de aprendizaje y de mejora.

Asegurar las mismas oportunidades para la obtención de recompensas.

Centrarse en el valor de cada individuo.

Agrupara las personas de forma flexible y heterogénea.

Posibilitar múltiples formas de agrupa miento.

Utilizar c riterios relativos al progreso personal y al dominio de la tarea. Implicarla persona en la auto evalua ción. Utilizar evalua ción privada y signific ativa.
TIEMPO

Flexibilidad de la programación. Pasos del a prendizaje, direc ción del trabajo
Posibilitar oportunidades y tiempo para el progreso.

Ayudara las personasa establecer el trabajo y la programación de la práctica.

Cervelló (2002) avanza sobre la propuesta de Ames (1992) y defiende que existe una interacción entre las variables disposicionales y las situacionales que influye en el esta do de implicación final de la persona. Ambas variables pueden ser coincidentes o por el contrario conflic tivas entre ellas, en c uyo caso la implicación del individuo dependerá de la evaluación subjetiva que se realice y de la variable que presente mayor fuerza en un momento determina do (Roberts, 1992).

Los profesionales de los centros deberán prestar atención a las claves contextua les y sociales que estén influyendo en las prácticas que se rea lizan ya que pueden afectar tanto a la motivación como a la implicación de las personas y, pueden llegar incluso, como nos señala Roberts (1992), a modificar la conducta ante un proceso de aprendizaje y de participación. 


\subsubsection{Prácticas que fomentan la resiliencia}

La resiliencia es un fenómeno ampliamente observado (Vera, Carbelo y Vecina Jiménez, 2006) que incluye dos aspectos relevantes: resistir a un suceso y rehacerse del mismo (Bonanno, Wortman et al, 2002; Bonanno y Kaltman, 2001).

Michel Manciaux (2010) nos señala:

A pesar de traumas graves, incluso muy graves, o de desgracias más comunes, la resiliencia parece una realidad confirmada por muchísimas trayectorias existenciales e historias de vida exitosas. De hecho, por nuestros encuentros, contactos profesionales y lecturas, todos conocemos niños, adolesc entes, familias y comunidades que "encajan" shocks, pruebas y rupturas, y las superan y siguen desenvolviéndose y viviendo -a menudo a un nivel superior- como si el trauma sufrido y asumido hubiera desarrollado en ellos, a veces revelado incluso, recursos la tentes y a un insospechados.

El enfoque existente en la actualidad sobre la resiliencia ha evolucionado del propuesto en los primeros estudios en los que se consideraba como una característica personal, propia de todo ser humano, que evoluciona de acuerdo con cada etapa del ciclo vital (Grotberg, 1995; Luthar y Zngler, 1991; Wemer y Smith, 1992; Vanistendael, 1996). En la actualidad existe otro enfoque, surgido a finales del siglo pasado, basado en la teoría ecológica de Bronfenbrenner (1979), desde el que se considera la resiliencia como proceso dinámico en el que el ambiente y el sujeto se influyen mutuamente en una relación recíproca que les permite adaptarse y funcionar adecuadamente, gracias a la presencia de la adversidad (Infante, 2002) 
Cyrulnik (2001) nos señala que la respuesta resiliente no surge de forma automática si no que se va entretejiendo a partir de la conservación de su identidad, sus sentimientos, sus va lo res y sus sueños.

La resiliencia genéricamente se define como la capacidad humana de superar la adversidad; no se trata de una característica innata, ni que se adquiera "de forma natural", ni que una vez adquirida se posea para siempre. Se tata del resultado de un proceso dinámico y evolutivo, que varía según las circunstancias, las característic as de la experiencia adversa, el contexto, la etapa de la vida en la que se encuentre la persona, y que incluso se puede expresar de distintas maneras en diferentes culturas (Cyrulnik, 2001; Mancia ux et al., 2001).

Precisamente, y como fruto de una interacción entre la persona y el entomo, Huntington (2003) define la resiliencia como "la capacidad potencial y reparadora del ser humano de salir herido, pero fortalecido de una experiencia traumática" (p.117); Grotberg (2002) la define como “la capacidad humana para enfrentar, sobreponerse y salir fortalecido o transformado por experiencias de adversidad" o Wemer (1989) como la "adaptación exitosa después de la exposición a acontecimientos vitales estresantes". En definitiva, la resiliencia es la capacidad de una persona o grupo para seguir proyectándose en el futuro a pesar de acontecimientos desestabilizadores, de condiciones de vida difíc iles y de traumas, a veces, graves.

La resiliencia se muestra claramente relacionada con una actitud optimista y esperanzadora frente a la vida, ante el futuro. Parte de una dimensión preventiva y proactiva que está directamente relacionada con el enfoque de inclusión que se está ofreciendo en la presente investigación y con la propuesta del Index para la inclusión. 
Según Manciaux (2003) la resiliencia se constituye así como el resultado de la interacción de dos capacidades: resistir, ante la destrucción en situaciones difíciles y rehacerse ante una dificultad desde una visión positiva de la vida.

Empleando como metáfora la "casa" de Vanistendael (1996) podemos ana lizar las cinco áreas interc onectadas, ni exclusivas ni excluyentes, que propone el autor y que se han de tener en cuenta si deseamos favorecer la resiliencia en los centros que prestan servicios a personas con discapacidad: (1) la aceptación incondicional de la persona como tal, (2) la capacidad del individuo de descubrir un sentido a la vida, de ser a utónomo, de tomar decisiones, es decir, capacidad de autodeterminación, (3) un clima emocionalmente positivo, que facilite el desarrollo de aptitudes y/o habilidades potenciales, intelectuales y emocionales, (4) autoestima, confia nza en sí mismo y bienestar emocional, (5) otra s experiencias a desc ubrir.

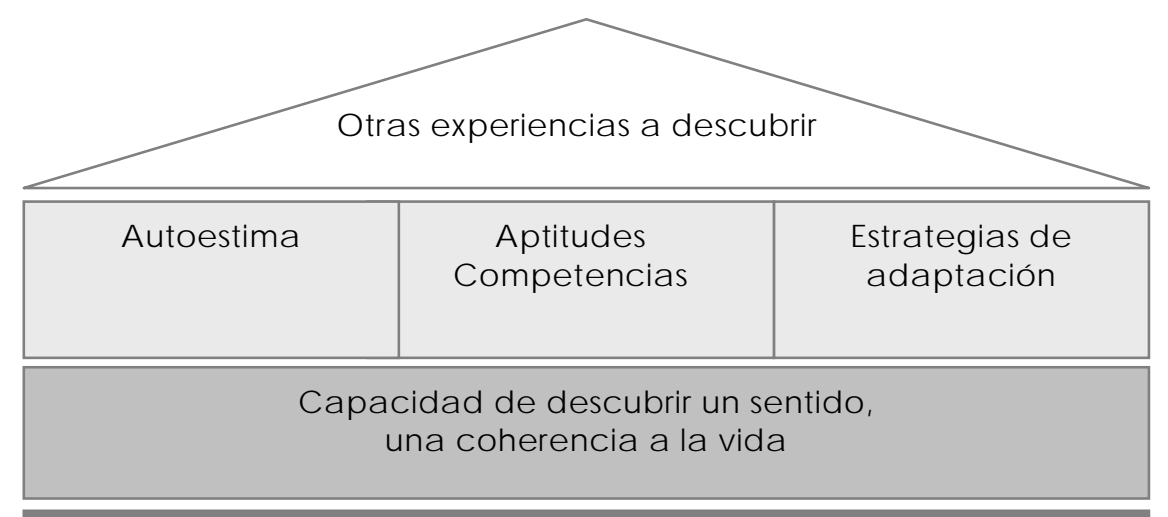

Redes de contac tos informales:

Fa milia, amigos, vecinos, $\ldots$

Aceptación fundamental de la persona: (no del comporta miento)

Nec esidades materia les básicas

FIGURA 15. “LA CASITA” DE LA RESILIENCIA (VANISTENDAEL Y LECOMTE, 2002). 
Según Vanistendael (2005) la resiliencia, como una verdadera casa, se construye de una forma más o menos estable y requiere mantenimiento a lo largo de los años. La casa puede ofrecer protección pero también, como una verdadera casa, puede no resistir siempre a todas las dificultades o catástrofes que se experimenten.

Brown, Caston y Bemard (2001) consideran que cuando las personas aprenden a utilizar sus intereses y habilidades se involucran mejor en su proceso de aprendizaje a lo largo de la vida. Por lo tanto, desde los centros se deberán desarrollar prácticas que fomenten los lazos de confianza entre las personas usuarias y aquellas personas que puedan ayudarles a mejorar su capacidad de resiliencia (profesionales, familiares, vecinos, amigos, compañeros de trabajo, etc.).

Brown, Caston y Bernard (2001) identific a n ciertas prá c tic as esencia les de las cuales destacamos aquellas que son más relevantes para la investigación que se presenta:

- Reforzar los procesos de toma de decisiones en las personas, proveyéndolas de información adecuada para que puedan actuar de un modo coherente y adecuado a cada situación.

- Fomentar la motivación intrínseca, ya que origina conexiones más profundas y signific ativas en la vida y da su lugar a los pensamientos, los sentimientos, las emociones y las conductas que se integran en los procesos de aprendizaje y participación.

- Enfatizar la relación de las personas usuarias con otras pertenecientes a los diferentes contextos sociales en los que participa (la familia, el centro, el lugar de trabajo, amistades, organizaciones de ocio, etc.) para fomentar el desa rrollo de su identidad, sus intereses y fortalezas. 
Los mismos a utores, de cara a a poyar las prácticas esenciales, señalan una serie de principios para fomentar la competencia de la resiliencia como son: la participación, la observación, la reflexión y la transformación.

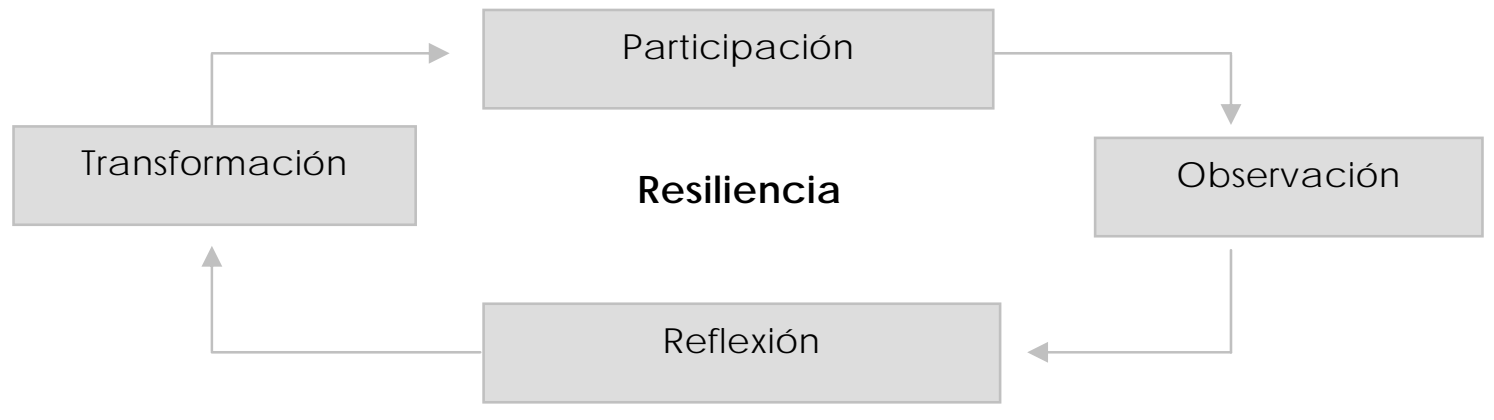

FIG URA 16. PROCESO PARA FOMENTAR LA RESILIENCIA (BROWN, CASTON Y BERNARD, 2001)

(1) La participación activa es esencial en el proceso de aprendizaje y debe estar enfocada en el presente y en las experiencias diarias (Brown, Caston y Bemard, 2001). Por ello, desde las prácticas que se pongan en marcha en los centros se deberá hacer consciente a la persona de los diferentes procesos y situa c iones que oc urren en sus vidas de los c uales ellos son partíc ipes directos.

(2) La obsenvación implica no dejar pasar las experiencias y ser consciente de todo lo que vivimos, ya que esto ayuda a la persona a conocerse mejor y a tomar conciencia de su comportamiento, a la vez que le fortalece como persona y le ayuda a conectar mejor con otros.

(3) La reflexión requiere interpretar y a nalizar las experiencias y es uno de los factores más importantes, según los autores, porque intensifica las fortalezas de la persona y facilita la reposición.

(4) La transformación es el resultado final de la participación, observación y reflexión y, para que se produzca, la persona debe ser consciente de las conexiones que existen ante los actos y los cambios que ocurren como consecuencia de estos; conlleva no sólo su reconocimiento sino también la Tesis Doctoral 
asunción de la responsabilidad sobre las consecuencias que pueden ocasionar. Cada persona deberá poder seleccionar qué experiencias quiere vivir y el proceso que quiere poner en marcha para lograr dichas transformaciones.

Este enfoque de resiliencia propuesto por Brown, Caston y Bemard (2001) es un proceso donde se van interiorizando las experiencias, se experimentan algunos cambios y se desarrollan sentimientos que siven de base para el aprendizaje y la superación.

En los centros que prestan servicios a personas con discapacidad muchas veces se concentran más esfuerzos en conocer la historia personal de cada usuario, su familia y su contexto socio-laboral, la enfermedad, los síntomas y aquellas características que se asocian con una elevada probabilidad de daño biológico, psicológico o social, que en descubrir la existencia de verdaderos escudos protectores contra fuerzas negativas que a tenúen sus efectos.

Las prácticas deben cambiar de enfoque y centrarse en fomentar las característic as resilientes de las personas para que tengan una imagen positiva de sí mismas y sean capaces de: establecer relaciones sociales constructivas, dimensionar los problemas y sus repercusiones; tener esperanza frente a las dific ultades; extraer significa do de las situaciones de estrés que se pueden vivir en diferentes contextos; iniciar nuevas acciones cada vez con menos apoyo y ser capaces de fijar metas persona les posibles de a lc anzar (Sa a ved ra, 2004).

Sa avedra (2004) nos señala las ca racterístic as que forman parte del perfil de una persona resiliente: (1) presta servicio a los otros o a una causa; (2) tiene un fuerte control intemo frente a los problemas; (3) es sociable; (4) tiene sentido del humor; (5) es flexible; (6) manifiesta autonomía; (7) emplea estrategias de convivencia, es a sertivo, controla sus impulsos; (8) tiene capacidad para aprender y conectar los aprendizajes; (9) capacidad para automotivarse; (10) percibe competencias personales; (11) tiene confianza en sí mismo. 


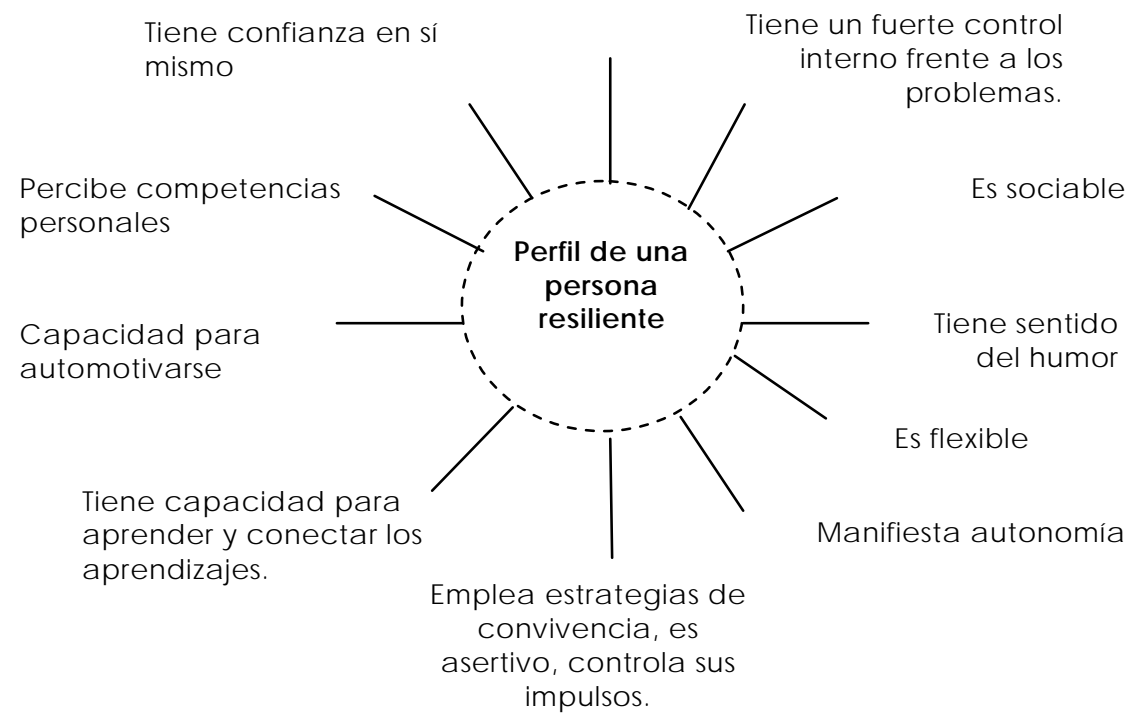

FIG URA 17. PERFIL DE UNA PERSONA RESILIENTE (SAAVEDRA, 2004).

Desde los centros que prestan servicios a personas con discapacidad se deberán potenciar el desarrollo de habilidades para enfrentarse a la adversidad, ya que de este modo las personas estarán preparadas para participar en las actividades habituales que se dan en la sociedad. Algunas de las estrategias que se podrán reflejar en las prácticas pueden ser las siguientes (Henderson y Milststein, 1996; Sa a vedra, 2004; Carega, 2003):

- Enriquecer los vínculos entre las personas de la comunidad, fortaleciendo y resaltando los puntos de acuerdo y de conexión existentes y estableciendo canales y puentes que motiven el contacto con los otros.

- Fijar límites claros y fimes que permitan a las personas conocer las nomas de funcionamiento del centro. Es deseable que dichos límites 
sean consensuados entre todos los miembros de la comunidad logrando así un mayor compromiso con ellos.

- Enseñar habilidades de convivencia que incluyan, entre otros, la cooperación, la resolución positiva de conflictos, la asertividad en el planteamiento de problemas, la toma de decisiones, el manejo del estrés y la promoción de ambientes saludables (físic os y psic ológicos).

- Ofrecer apoyo y afecto a las personas, lo que implica motivar, a preciar los a ciertos de los demás, mira r los errores como tra nsitorios y como áreas a mejorary fortalecer la comunicación a nivel personal.

- Desarrollar expectativas elevadas pero realistas, lo que implica creer en el potencial de todas las personas, pero a la vez no generar frustrac ión al esta blecer ta rea s imposibles de cumplir.

- Promover la participación de todos los miembros de la comunidad, para que sean partícipes en las tomas de decisiones, en la generación de nuevas ideas y en la búsqueda colectiva de soluciones, en el afrontamiento colectivo de las dific ultades y en la distribuc ión de las responsabilidades.

Claramente no se espera que todos estos elementos estén presentes en la persona o en los centros que prestan servicios a personas con discapacidad para que se favorezca la aparición de conductas resilientes, pero es deseable que gran parte de ellas estén total o parcialmente desarrolladas (Sa a vedra, 2004).

Por todo ello, las prácticas en los centros deben estar orientadas al desarrollo de competencias que fortalezcan a las personas y no únicamente al desarrollo de habilidades instrumentales que no pueden ser extrapoladas a los múltiples contextos en los que se debe desenvolver una persona con disc a pacidad. 
Todo ello, conlleva un cambio en los centros y en sus prácticas. Por las consecuencias que se derivan de ese cambio debe estar apoyado por la cultura y las polític as orga niza tiva s.

Si en los centros se desa rrollan prácticas que promuevan la individualidad, el respeto, la autodeteminación, la elección informada, y el empoderamiento, se estarán poniendo en marcha modelos basados en la persona y en sus derechos y no en los objetivos del sistema en el que está inmerso el c entro.

\subsection{Conclusiones del capitulo}

La cultura, las políticas y las prácticas forman un entramado que está en la base de todas las organizaciones, por lo que conocer tanto el enfoque organizativo que está detrás de cada una de ellas como los valores que las sustentan, es fundamental para entender el modo de actuación de una determina da entidad.

Aunque a lo largo del capítulo se han separado los tres apartados para seguir la estructura del Index para la inclusión, se ha podido ver en múltiples ocasiones cómo los diferentes temas que están detrás de cada uno de ellos se van entretejiendo y construyendo, apoyándose unos en otros.

En los centros que prestan servicios a personas con discapacidad, al igual que en otro tipo de organizaciones, los valores influyen en las prácticas, la cultura en las comunidades que se establec en y las polític as existentes reflejan la forma de ser de laspersonas que forman parte de la organización. Todo tiene un reflejo, to do tiene un efecto.

Si nos centramos en las personas con discapacidad, que son al fin y al cabo el eje desde el que deben pivotar el resto de los elementos, podremos ver en ellas el reflejo de la cultura, de las políticas, y de las prácticas. 
Si estamos en una organización inclusiva nos encontraremos con: personas que presentan algún tipo de limitación pero que no les impide ser felices, tener aspiraciones y ser capaces de liderar su propia vida (Wilson, 1967; Csikszentmihalyi, 1975, 1988, 1996, 1998; Whallen, 1997); personas implicadas, con necesidad y capacidad de participar en diferentes actividades tanto personales, como laborales y sociales (Ames, 1992; Csikszentmihalyi, 1996, 1998; Palys y Little, 1983; Maehr, 1984); personas que quieren enfrentarse a retos y nuevas situaciones que les hagan sentir miembros de una comunidad que respeta sus derechos (AMICA, 2009); líderes y profesionales motivados por todo lo que implica su trabajo y las consecuencias que tiene (Senge, 1993; Strully y Broderick, 2010); una organización que se despierta para defender los derechos de las personas que colaboran con ella (C.E., 2001; Cameiro, 2002; Strully y Broderick, 2010; AMICA, 2009; Booth, 2008); una comunidad en la que sus miembros se sienten seguros y partícipes de un proyecto común (Sarason, 1974; McMillan y Chavis, 1986; Maya, 2004; Moreno, Giménez y García, 2009). 


\section{CAPITULO 3.}

\section{Comunidades de Práctica}

Wenger (2001)

El hecho de vivir como seres humanos significa que iniciamos constantemente empresas de todo tipo, desde procurar nuestra supervivencia física hasta buscar los placeres más elevados. Cuando definimos estas empresas y participamos en su consecución, interaccionamos con los demás y con el mundo y, en consecuencia a justamos nuestras rela ciones con el mundo y con los demás. En otras palabras, a prendemos.

Con el tiempo, este aprendizaje colectivo desemboca en unas prácticas que reflejan tanto la búsqueda del logro en nuestras empresas como las relaciones sociales que la acompañan. Por lo tanto, estas prácticas son la propiedad de un tipo de comunidad creada, con el tiempo, mediante la intención sostenida de lograr una empresa compartida. Por ello tiene sentido llamar comunidades de práctica a esta clase de comunidades. (p.69) 


\subsection{Introduc ción}

En los últimos años ha habido un cambio en la concepción sobre cómo las personas aprenden y hacen uso del conocimiento dentro y fuera de los contextos educativos. Desde el momento en que diversos autores argumentan científicamente que el aprendizaje se produce en los contextos socio-culturales, emergen las Comunidades de Práctica (CoP) como un nuevo escenario en el que el aprendizaje y la participación se aúnan para dar sentido a la práctica que se produce en el día a día de lasorganizaciones.

En el presente capítulo vamos a abordar, en primer lugar, la base teórica desde la que parten las Comunidades de Práctica, el aprendizaje situado; para posterio mente, a hondar en el concepto de CoP y su evolución histórica.

Una vez posicionado el enfoque, se abordan las características de las comunidades, desde la perspectiva de Wenger (2001) y los procesos de partic ipación y cosific ación que se producen en sus dinámicas.

Para teminar el capítulo se a nalizan los principios que nos sugieren diversos autores para promover y guiar la evolución de una Comunidad de Práctica dentro de una organización.

\subsection{El aprendizaje situado y la práctica}

Tradicionalmente, el aprendizaje se ha considerado como un proceso que tiene lugar exclusivamente en la mente de las personas (Gagné, Yekovich y Yekovich, 1993); esta convicción ha encontrado su expresión en conceptos tales como la capacidad, el talento y la inteligencia, y es una consecuencia, como a punta Barab y Plucker (2002) “de la separación del a prendiz respecto al contexto de aprendizaje" y "del a islamiento del cuerpo respecto de la mente" (p.165). En 
definitiva, podemos decir que se ha entendido el aprendiza je como el resultado de procesos intemos e innatos, y que, consecuentemente, están vinculados a las diferentes etapas del desarrollo que se experimentan a lo largo de la vida. Esta manera de ver el aprendizaje y el conocimiento es totalmente opuesta a la del aprendizaje situado que es un movimiento en el campo de la educación que ha surgido para abordar las especificaciones de estos dos conceptos desde una perspectiva diferente.

En lugar de centrarse únicamente en la mente y sus procesos intemos, un creciente número de investigadores han empezado a considerar el aprendizaje y la adquisición del conocimiento en téminos de interacciones y construcción de signific ados dentro de un contexto so ciocultural (Brown et al., 1989; La ve y Wenger, 1991). Los investigadores son cada vez más concientes del hec ho de que las teorías tradicionales del aprendizaje son insuficientes para explicar las formas en las que los individuos aprenden y hacen uso del conocimiento dentro y fuera de las escuelas.

Las teorías del aprendizaje situado están ampliamente basadas y relacionadas con la filosofía de la cognición situada en la que un asunto clave es que la cognición se da por la acción (por ejemplo, Clark, 1997; Suchman, 1987; Varela, Thompson y Rosch, 1991; Wilson, 2003).

El paradigma de la cognición situada representa una de las tendencias actuales más representativas de la teoría y la actividad sociocultural (Daniels, 2003). Toma como punto de referencia los escritos de Lev Vygotsky (1986; 1988), Leontiev (1978), Luria (1987) y más recientemente, los trabajos de Rogoff (1993), Lave (1997), Bereiter (1997), Engeström y Cole (1997) y Wenger (2001). 
Esta visión, relativamente reciente, ha desembocado en un enfoque instruccional, el aprendizaje situado, que destaca la importancia de la actividad y el contexto y reconoce que el aprendizaje es, ante todo, un proceso de enculturación en el cual la persona se integra gradualmente en una comunidad o cultura en la que realiza determinadas prácticas sociales. En esta misma dirección, se comparte la idea de que aprendery hacer son acciones inseparables.

Desde este enfoque se apuesta por un proceso de enseñanza-aprendizaje centrado en prácticas educativas auténticas, las cuales requieren ser coherentes, signific a tivas y propositivas (Brown, Collins y Duguid, 1989). Además, la a utenticidad de una práctica educativa puede deteminarse por el grado de relevancia cultural de las tareas y, por el tipo y nivel de actividad social que éstas promueven (Demy, Levin y Schauble, 1995).

De esta manera, una situación educativa, para efectos de su a nálisis e intervención instruccional, requiere concebirse como un sistema de actividad, cuyos componentes a ponderar incluyen (Engeström, citado en Baquero, 2002): (1) el sujeto que a prende, (2) los instrumentos utiliza dos en la a ctividad, especia Imente aquellos que se utilic en en la vida social, (3) el objeto a apropiarse u objetivo que regula la actividad (saberes y contenidos), (4) una comunidad de referencia en la que se insertan la actividad y el sujeto, (5) las nomas o reglas de comportamiento que regulan las relaciones sociales de esa comunidad y, por último, (6) las reglas que esta blecen la división de ta reas en la misma actividad. 


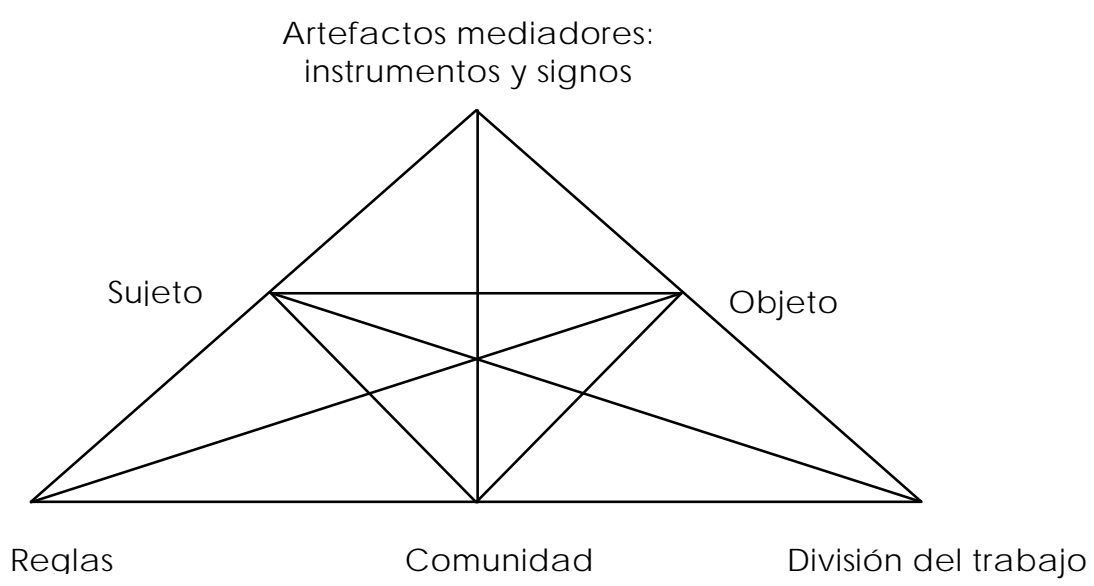

FIGURA 18. TEORÍA DE LA ACTIVIDAD (ENGESTRÖM, 1987)

A manera de síntesis, en la perspectiva de la cognición situada, el aprendizaje se entiende como los cambios en las formas de comprensión y participación de los sujetos en una actividad conjunta. Debe verse como un proceso multidimensional de apropiación cultural, ya que se trata de una experiencia que involucra el pensamiento, la afectividad y la acción (Baquero, 2002). La idea subyacente es que el poseedor del conocimiento no puede ser separado de éste, conduciendo a una posición en la cual el conocimiento y el aprendizaje son considerados como el resultado de la actividad social en un contexto determinado (Brown, Collins y Duguid, 1989; Greeno, 1998; Lave, 1991; Lave y Wenger, 1991).

El aprendizaje situado se refiere a cómo se produce el aprendizaje cada día. No es una recomendación para que la enseñanza sea "situada" o "relevante"; es una teoría sobre la naturaleza del aprendizaje humano, que se basa en la afimación de que este se construye de forma dinámica y sobre nuestra forma de ver las experiencias que estamos viviendo y las prácticas que esta mos realizando. La concepción de nuestra actividad, en el marco de una matriz social, da forma y 
restringe lo que pensamos, hacemos, y decimos. Esto es, nuestra acción está situada en nuestro rol como miembros de una comunidad (Clancey, 1995).

El aprendizaje situado hace que la adquisición de competencias, como resulta do del a prendizaje, no sea tanto la consecuencia de la dimensión individual, sino de la posibilidad de participación activa en actividades colectivas, es decir, de la dimensión social del a prendizaje.

Este tipo de aprendizaje tiene que ver con el desarrollo de nuestras prácticas y con nuestra capacidad de negociar significados. En palabras de Wenger, no se basa en la creación de recuerdos, hábitos y capacidades, sino en la formación de una identidad.

\subsubsection{El origen del enfoque}

El origen del enfoque de la cognición y el aprendizaje situado dentro de la corriente cognitiva se remonta a los años treinta con los trabajos de Dewey (1938/ 1963), Mills (1940) y Vygotsky (1932/ 1978).

En estos años, en los que en la investigación psicológica dominaban las teorías conductistas surgió el aprendizaje situado ofreciendo un nuevo enfoque que iba más allá de los límites marcados. Estos autores ofrecieron una nueva perspectiva del proceso de aprendizaje, ya que pasaron de centrarse en la conducta y la cognición en términos de estímulos y respuestas, a un enfoque centrado en el carácter social y cultural de la cognición humana.

Vygostsky (1988), por ejemplo, consideró la cognición como un resultado de procesos sociales, donde el aprendizaje implica (1) el entendimiento e intemalización de los símbolos y signos de la cultura y grupo social al que se pertenece, y (2) que los aprendices se apropien de las prácticas y herramientas culturales a través de la interacción con miembros más experimentados. Sin 
embargo, por diferentes razones, estas ideas no c uajaron en el esc enario científico, dando lugar a un largo período en el que los aspectos sociales y culturales de la cognición humana se ignoraron e incluso rechazaron, sobre todo en la ciencia cognitiva, que desde sus orígenes en el década de 1950 se centró en el conocimiento como un proceso intemo.

Años más tarde, en la década de los ochenta, Suchman (1987) redescubrió estas ideas y las aportó al mundo científic o como una altema tiva al proc esa miento de la información del enfoque cognitivista.

Hoy en día, existe una conciencia creciente de la naturaleza cultural de la cognición humana en diferentes campos de la ciencia cognitiva. Las teorías de la cognición situada están basadas en la idea principal de que el pensamiento y la acción humana están situa dos, en el sentido de que lo que la gente percibe, cómo concibe su propia actividad y qué hace físicamente, se desarrollan como un todo (Clancey, 1997).

El cambio de paradigma del cognitivismo a la cognición situada también tiene importantes implic aciones para la investigación educativa. Tradicionalmente, se ha concebido el conocimiento y el aprendizaje como procesos ind ividuales que se desarrollan en contextos controlados, estables y objetivos. Esta forma de entender los procesos de enseñanza-aprendizaje ha llevado a que los contextos dónde supuestamente se debe promover el aprendizaje sean neutrales respecto a lo que se aprende, ya que al ser elaborados ex profeso para el proceso dejan de tener rela ción con el escena rio vital del a prendiz (Brown, Collins y Duguid, 1989). La educación tradicional también ha basa do en gran medida sus práctic as en la idea de que el conocimiento es algo que reside en el interior de la persona, por lo que el proceso de enseñanza-aprendizaje ha de centrarse en la transmisión de contenidos (Barab y Plucker, 2002). 
En los últimos años, la visión tradicional ha sido criticada dando lugar a teorías que abordan el aprendizaje y el conocimiento desde un punto de vista diferente, basado en gran medida en la psicología histórico-cultural (Leontiev, 1978; Vygotsky, 1978). Estos nuevos enfoques conciben el aprendizaje como un proceso que surge de la actividad en un mundo subjetivo y el socialmente construido (Brown et al., 1989; La ve y Wenger, 1991; Rogoff, 1990). Se centran en los procesos del andamiaje del aprendiz y los pares, la negociación mutua de significados y la construcción conjunta de los saberes. Así, en un modelo de enseñanza situada, resaltarán la importancia de la influencia de los agentes educativos, que se traducen en prácticas pedagógicas deliberadas, en mecanismos de mediación y ayuda ajustada a las necesidades del alumno y del contexto, así como de las estrategias que promuevan un aprendizaje colaborativo o recíproco. Y postulan que sólo el conocimiento que se adquiere de forma activa nos va a permitir adquirir un conocimiento que sea aplicable, más adelante, a dife rentes situac iones y contextos.

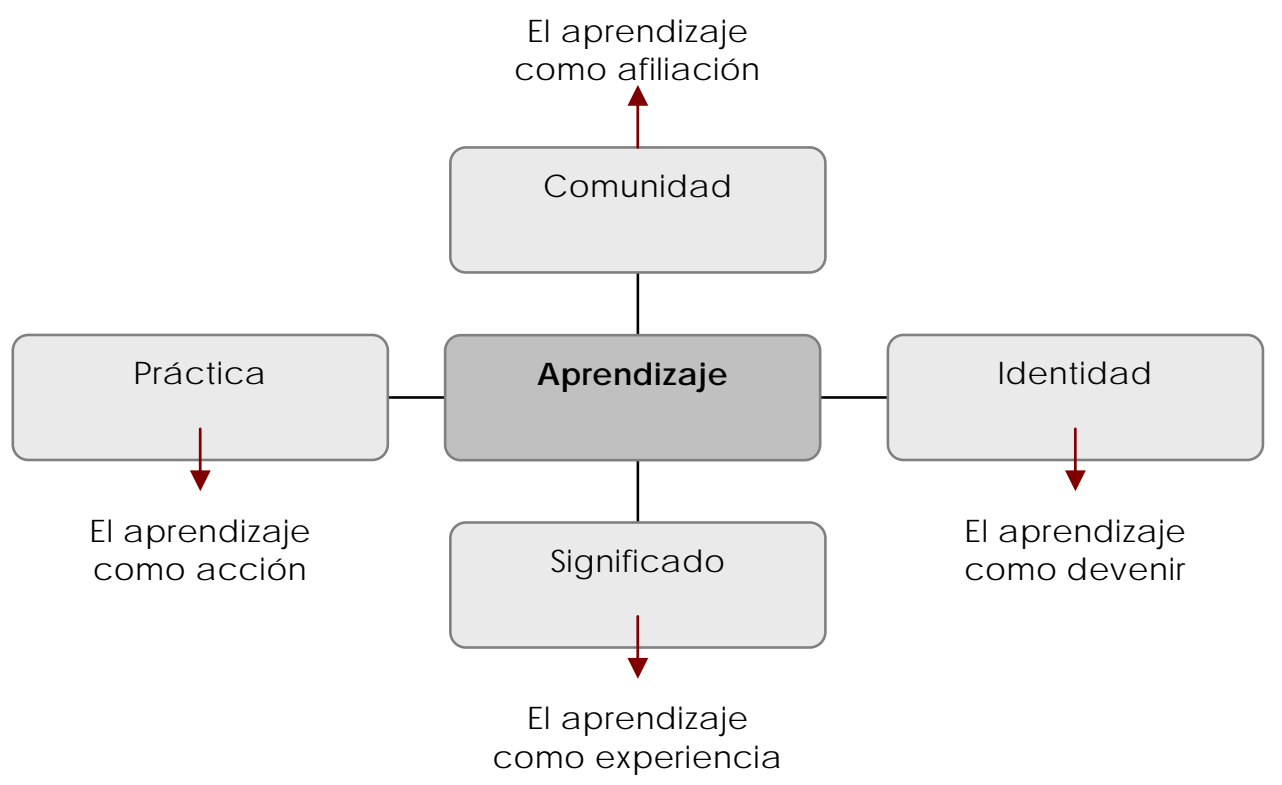

FIG URA 19. CO MPONENTES DE LA TEO RÍA SO CIAL DEL APRENDIZAJ E (WENG ER, 2001, P.23) 
El aprendizaje situado, a raíz de las investigaciones realizadas por Vygotsky $(1986,1988)$, además de en la actividad, se ha centrado en la naturaleza sociocultural del aprendizaje y el conocimiento, es decir, el aprendizaje es visto como un proceso en el que la interacción social y el uso de diferentes tipos de recursos se consideran factores claves para adquirir el conocimiento de forma efic az (Resnick, 1989).

\subsection{Concepto de Comunidad de Práctica}

El concepto de Comunidad de Práctica (CoP) se encuentra muy cerca de los postulados sobre aprendizaje a lo largo de la vida y formación profesional permanente. Esta idea la vemos reflejada por primera vez en 1991 en Situated learning. Legitimate Peripheral Participation, donde Wenger y Lave defienden la idea de que el aprendizaje implica participación en comunidad y que la adquisición de conocimientos se considera un proceso de carácter social.

Dicho de otro modo, por primera vez se pone de relieve la concepción del aprendizaje como un hecho colectivo frente a la idea clásica que lo limita a un proceso individual. Esta idea ha sido apoyada también por J ohn Seely Brown y Paul Duguid (1991) en su artículo Organizational leaming and communities of practice a través del caso de la empresa Xerox. Posteriomente a estas dos publicaciones han sido muchos los autores que se han intentado definir el concepto de Comunidad de Práctica.

En 2001, Wenger utiliza el concepto Comunidad de Práctica para asociar el desarrollo de una práctica al contexto en el que tiene lugar, lo que sirve para dos propósitos, en primer lugar, para distinguirla del concepto más amplio de cultura, y en segundo lugar, para definirla como un tipo específico de comunidad. 
De acuerdo con Wenger y sus colaboradores (Wenger, McDemott et al., 2002a), las Comunida des de Práctica son “grupos de personas que comparten una preocupación, un conjunto de problemas o un interés común acerca de un tema, y que profundizan su conocimiento y pericia en esta área a través de una intera c ción continua" (Sanz y Montoro, 2009, p. 104). Los miembros de estos grupos no trabajan necesariamente juntos todos los días, pero las interacciones que se producen en sus encuentros les aportan valor, ya que discuten sus vivencias, aspiraciones y necesidades a la vez que comparten tiempo, información, comprensiones y consejos, y se ayudan a resolver problemas.

En la actualidad, existen diversos términos que parecen esconder en su interior la misma filosofía que subyace a las Comunidades de Práctica cuando en verdad, su razón de sery los objetivos que persiguen no son los mismos. Algunos de estos voca blos son comunida des de a prendizaje, comunida des de conocimiento o comunidades virtuales, entre otros. En todos los casos (Gros, 2008) se enfatiza la idea del aprendizaje como construcción social, sin embargo, existen diferencias entre los conceptos mencionados. Estas diferencias radican principalmente en si están centradas en las actividades, en las prácticas o en el conocimiento. Gros (2008) nos señala las diferencias que existen entre las comunidades centradas en estos tres aspectos.

\begin{tabular}{|l|l|l|l|}
\hline Dimensiones & $\begin{array}{l}\text { Centradasen las } \\
\text { actividades }\end{array}$ & $\begin{array}{l}\text { Centradas en la } \\
\text { práctica }\end{array}$ & $\begin{array}{l}\text { Centradas en el } \\
\text { conocimiento }\end{array}$ \\
\hline Miembros & $\begin{array}{l}\text { Se asignan o agrupan } \\
\text { en función de las } \\
\text { tareas. }\end{array}$ & $\begin{array}{l}\text { Los miembros } \\
\text { buscan la } \\
\text { participación para } \\
\text { mejorar su práctica } \\
\text { laboral. }\end{array}$ & $\begin{array}{l}\text { Participan en virtual } \\
\text { de la experiencia } \\
\text { relevante y el interés } \\
\text { común. }\end{array}$ \\
\hline $\begin{array}{l}\text { Se conocen entre } \\
\text { ellos. }\end{array}$ & $\begin{array}{l}\text { No necesariamente } \\
\text { hande conocerse. }\end{array}$ & $\begin{array}{l}\text { Pueden conocerse o } \\
\text { no. }\end{array}$ \\
\hline $\begin{array}{l}\text { El grupo se constituye } \\
\text { en función de la } \\
\text { tarea. }\end{array}$ & $\begin{array}{l}\text { Fuerte identidad } \\
\text { profesional. }\end{array}$ & $\begin{array}{l}\text { Fuerte identidad con } \\
\text { el objeto de } \\
\text { conocimiento. }\end{array}$ \\
\hline
\end{tabular}




\begin{tabular}{|c|c|c|c|}
\hline Dimensiones & $\begin{array}{l}\text { Centradas en las } \\
\text { actividades }\end{array}$ & $\begin{array}{l}\text { Centradas en la } \\
\text { práctica }\end{array}$ & $\begin{array}{l}\text { Centradas en el } \\
\text { conocimiento }\end{array}$ \\
\hline & $\begin{array}{l}\text { Se realiza una división } \\
\text { de las funciones } \\
\text { dentro del grupo. }\end{array}$ & $\begin{array}{l}\text { El liderazgo emerge } \\
\text { de la experiencia y } \\
\text { del grado de } \\
\text { experiencia. }\end{array}$ & $\begin{array}{l}\text { División formal del } \\
\text { trabajo basada en } \\
\text { rolese identidades. }\end{array}$ \\
\hline $\begin{array}{l}\text { Características } \\
\text { de las tareas o } \\
\text { de los objetivos }\end{array}$ & $\begin{array}{l}\text { Tema, proyecto o } \\
\text { problema bien } \\
\text { definido con un inicio } \\
\text { y un final claros. } \\
\text { Objetivos de } \\
\text { aprendizajes como } \\
\text { parte del proyecto. }\end{array}$ & $\begin{array}{l}\text { Actividad } \\
\text { productiva, con } \\
\text { múltiples ta reas. } \\
\text { Aprendizaje como } \\
\text { consecuencia de la } \\
\text { práctica, continuo } \\
\text { rediseño y } \\
\text { experimenta ción. }\end{array}$ & $\begin{array}{l}\text { Evolución y } \\
\text { acumulación del } \\
\text { conocimiento } \\
\text { producido. } \\
\text { Aprendizaje como } \\
\text { conocimiento. }\end{array}$ \\
\hline $\begin{array}{l}\text { Estructuras de } \\
\text { participación }\end{array}$ & $\begin{array}{l}\text { Grupos pequeños. } \\
\text { Finaliza con la } \\
\text { realización del } \\
\text { producto que refleja } \\
\text { el aprendizaje. }\end{array}$ & $\begin{array}{l}\text { Acceso abierto a } \\
\text { múltiples } \\
\text { participantes. }\end{array}$ & $\begin{array}{l}\text { Diálogo escrito, } \\
\text { documentos y } \\
\text { enlaces. } \\
\text { Creación de base de } \\
\text { conocimiento. } \\
\text { Organización } \\
\text { definida por la } \\
\text { producción del } \\
\text { trabajo intelectual. }\end{array}$ \\
\hline $\begin{array}{l}\text { Mecanismos de } \\
\text { reproducción y } \\
\text { de crecimiento }\end{array}$ & $\begin{array}{l}\text { Transferencia explicita } \\
\text { de prácticas, } \\
\text { procedimientosy } \\
\text { productos. } \\
\text { Lenguaje compartido. }\end{array}$ & $\begin{array}{l}\text { Evolución de las } \\
\text { prácticas a tra vés } \\
\text { del disc urso, } \\
\text { herramientas y } \\
\text { a rtefactos. } \\
\text { Lenguaje } \\
\text { compartido. }\end{array}$ & $\begin{array}{l}\text { Organizado y } \\
\text { definido por la } \\
\text { producción del } \\
\text { trabajo intelectual y } \\
\text { losconstructos } \\
\text { teóricos. } \\
\text { Lenguaje } \\
\text { compartido. }\end{array}$ \\
\hline
\end{tabular}

TABLA 04. TIPOS DE C O MUNIDADES (GROS, 2008, P. 6).

Las Comunidades de Práctica tampoco representan lo mismo, a unque en ocasiones se confunde, que un grupo formal de trabajo que se crea en una organización, un equipo que se constituye para poner en marcha un proyecto o una red informal que se desarrolla tanto dentro como fuera de la entidad. Wenger 
y Snyder (2000) nos señalan a lgunas de las diferencias cuando nos exponen que las CoP son informales, flexibles y se organizan así mismas. Se marcan su propia estructura, sus tiempos y sus líderes. Por ello, no deben confundirse con el resto de grupos de trabajo, que son formales, que trabajan juntos por designación de un superior, para desarrollar un proyecto o trabajo concreto, y que están sujetos a la duración de ese proyecto, o trabajo, o a los cambios que puedan darse en la orga nización de la empresa.

\begin{tabular}{|c|c|c|c|c|}
\hline Tіро & $\begin{array}{c}\text { ¿Cuál es el } \\
\text { objetivo? }\end{array}$ & $\begin{array}{l}\text { ¿Quién forma } \\
\text { parte? }\end{array}$ & $\begin{array}{l}\text { ¿Qué lo } \\
\text { mantiene } \\
\text { unido? }\end{array}$ & $\begin{array}{c}\text { ¿Cuánto tiempo } \\
\text { dura? }\end{array}$ \\
\hline $\begin{array}{l}\text { Comunidad de } \\
\text { práctica }\end{array}$ & $\begin{array}{l}\text { Desamollarlas } \\
\text { capacidades } \\
\text { de sus } \\
\text { miembros: } \\
\text { construir } \\
\text { e intercambiar } \\
\text { conocimiento }\end{array}$ & $\begin{array}{l}\text { Miembros que } \\
\text { se } \\
\text { seleccionan } \\
\text { mutuamente }\end{array}$ & $\begin{array}{l}\text { Pasión, } \\
\text { compromiso } \\
\text { e identific ación } \\
\text { con la "expertez" } \\
\text { del grupo }\end{array}$ & $\begin{array}{l}\text { Tanto tiempo } \\
\text { como } \\
\text { haya interés en } \\
\text { el } \\
\text { mantenimiento } \\
\text { del grupo }\end{array}$ \\
\hline $\begin{array}{l}\text { Grupo } \\
\text { formal } \\
\text { de trabajo }\end{array}$ & $\begin{array}{l}\text { Proporcionarun } \\
\text { producto o } \\
\text { servicio }\end{array}$ & $\begin{array}{l}\text { Cualquiera que } \\
\text { reporte al } \\
\text { responsable } \\
\text { del grupo }\end{array}$ & $\begin{array}{l}\text { Requisitos del } \\
\text { trabajo } \\
\text { y objetivos } \\
\text { comunes }\end{array}$ & $\begin{array}{l}\text { Hasta la próxima } \\
\text { reorganización }\end{array}$ \\
\hline $\begin{array}{l}\text { Equipo } \\
\text { De proyecto }\end{array}$ & $\begin{array}{l}\text { Cumplir con una } \\
\text { tarea específica }\end{array}$ & $\begin{array}{l}\text { Empleados } \\
\text { a signa dos } \\
\text { por un superior }\end{array}$ & $\begin{array}{l}\text { Los objetivosy } \\
\text { éxitos } \\
\text { del proyecto }\end{array}$ & $\begin{array}{l}\text { Hasta que se } \\
\text { haya } \\
\text { completa do el } \\
\text { proyecto }\end{array}$ \\
\hline Red informal & $\begin{array}{l}\text { Recogery hacer } \\
\text { circular } \\
\text { información } \\
\text { sobre negocios }\end{array}$ & $\begin{array}{l}\text { Amigosy } \\
\text { conocidos } \\
\text { en el ámbito } \\
\text { de losnegocios }\end{array}$ & $\begin{array}{l}\text { Necesidades } \\
\text { mutuas }\end{array}$ & $\begin{array}{l}\text { Mientrassus } \\
\text { miembros } \\
\text { tengan una } \\
\text { razón } \\
\text { para conectarse }\end{array}$ \\
\hline
\end{tabular}

TABLA 05. DIFERENCIAS ENTRE C OMUNIDADES DE PRÁC TICA, GRUPOS, EQ UIPOS Y REDES (WENG ER Y SNYDER, 2000).

En definitiva, podemos decir que las Comunidades de Práctica se diferencian tanto por la orientación que se esconde detrás de ellas (ver tabla 04), como por el modo en que se originan, organizan y establecen sus procesos de trabajo (vertabla 05). 
Según Wenger y Snyder (2000), las Comunidades de Práctica son informales, flexibles y se organizan ellas mismas, lo que no quiere decir que sean equipos sin estructura: la tienen y ésta se basa en establecer sus propias agendas y elegir a sus propios líderes.

Las Comunidades de Práctica consiguen superar la jerarquía tradicional, pero al mismo tiempo mantienen una forma organizacional más duradera fuera de las fronteras estructurales que pueda imponer o modificar la organización. Las Comunidades de Práctica tienen una habilidad que los equipos de trabajo convencionales no tienen y es la de poder establecer conexiones con profesionales de otros departamentos/equipos dentro de la misma organización (Lesser y Stork, 2001), lo cual enriquece, crea compromiso y da valor a la práctica diaria .

Resumiendo, podemos decir que una Comunidad de Práctica vuelve explícita la transferencia informal de conocimiento dentro de redes y grupos sociales, ofreciendo una estructura formal que permite adquirir conocimiento a través de las experiencias compartidas dentro del grupo. Desde las dinámicas que se desencadenan en ella, su identidad se fortalece al reforzar el aprendizaje como un proceso de participación y liderazgo compartido.

\subsection{Evolución histórica de las Comunidades de Práctica}

Las Comunidades de Práctica son un área de interés creciente para académicos, consultores y profesionales. Este interés radica en que proporciona tanto una teoría socio-constructivista del a prendizaje aplicado a grupos, como una útil descripción socio-cultural del proceso de creación y reproducción del conocimiento y de su a plic ación a un contexto organizativo. 
La popularidad del término y las grandes ventajas que aportan las Comunidades de Práctica han hecho que con el mismo término se esté hablando de cuestiones diferentes (ver tablas 04 y 05).

Basándonos en Cox (2005), Roberts (2006) y Kimble (2006), se presenta a continuación la evolución del concepto de Comunidades de Práctica durante los tres perío dos de su desa rrollo.

La revisión que se presenta seguidamente parte de las dos obras que introdujeron el término en 1991, El aprendizaje situado: participación periférica legítima (Lave y Wenger, 1991) y Organización de aprendizaje y Comunidades de Práctica (Brown y Duguid, 1991). Posteriomente se centra en Wenger y su trabajo de investigación que concluyó con la publicación de Comunidades de Práctica: Aprendizaje, signific ado e identidad (Wenger, 1998a) y, concluye, con a lgunas de las a portaciones más recientes.

\subsubsection{Evolución histórica: Periodo inicial (1991-1995)}

La mayoría de las actuales concepciones existentes sobre Comunidades de Práctica se originaron a finales de los años 1980 en el Work Practice and Technology Group del Institute for Research on Leaming (IRL) del “Xerox Palo Alto Research Centre (PARC)" donde se creó un equipo de trabajo multidisciplinar forma do por profesionales como Lucy Suchman, Jean Lave, Etienne Wenger, John Seely Brown y Paul Duguid.

Durante estos años, surgieron los modelos constructivistas y las investiga ciones comenzaron a centrarse en los aspectos sociales que rodeaban al proceso de aprendizaje. Se dejaron atras los predominantes modelos conductistas que se centraban en la unidireccionalidad del proceso de aprendizaje, consistente en la transmisión de conocimientos del profesor al alumno; el conocimiento era entendido como un objeto que podría ser "transferido" de una persona a otra. 
A diferencia del conductismo, el constructivismo concebía el aprendizaje como un proceso en el que el conocimiento mutuo es "co-construido". Gran parte del marco conceptual de estas teorías se basa en el trabajo de Vygotsky (1978) que se centra en el modo en el que el aprendizaje se produce dentro de las comunidades. Vygotsky sostiene que el conocimiento se construye socia Imente a través de la colaboración y la interacción en las actividades y, utiliza el concepto Zona de Desarrollo Proximal ( $\triangle \mathrm{PD}$ ) para describir la forma en que un alumno interactúa con otros en una a ctividad partic ular.

En 1990, Wenger, considerado por muchos como el principal teórico sobre las Comunidades de Práctica, a través de un impresionante estudio etnográfico rea liza do en su tesis "Toward a theory of cultural transparency: elements of a social discourse of the visible and the invisible" comenzó su investigación sobre las c a rac teństic as de la s comunida des, las personas y las prác tic as que las conforman.

En este período destacan las a portaciones realizadas Lave y Wenger (1991) y J ohn Seely Brown y Paul Duguid (1991); a unque sus obras nos ofrecen puntos de vista diferentes tienen un nexo común: ambas se centran en los procesos de aprendizaje.

Investigación sobre las Comunidades de Práctica en este período

En sus primeros trabajos, Lave y Wenger sugineron que la mayor parte del aprendizaje de los profesionales se produce en las relaciones sociales que se establecen en los lugares de trabajo, concepto conocido como aprendizaje situado (Lave y Wenger, 1991) y, relacionado ampliamente con el de Comunidad de Práctica (CoP). Estos autores conciben una CoP como un mecanismo para la reproducción de los conocimientos ya existentes y, reflejados en alguna forma de 
"práctica", a través de la participación activa. Visto de esta manera, el aprendizaje es esencialmente el proceso de socialización en una comunidad.

Lave y Wenger (1991), en estos primeros momentos, acuñaron también el concepto "Participación Periférica Legítima" (LPP) para describir el proceso social por el que los nuevos miembros de una organización se convierten en parte de una Comunidad de Práctica ya existente. El proceso compromete los propósitos de la persona para aprender y configura el signific ado del aprendizaje. La LPP permite hablar de las relaciones entre novatos y veteranos y de las actividades, id entid a des, a rtefactos, y comunidades de conoc imiento y práctica.

En este periodo, destacan también las investigaciones de Brown y Duguid (1991) sobre Comunidades de Práctica, las cuales se basan fundamentalmente los estudios etnográfic os realizados a finales de los años 80 por J ulián Or, una de las contribuciones más sobresalientes en el ámbito del aprendizaje organiza tivo (Orr, 1987, 1990a, 1990b).

Los estudios de Orr fueron desarrollados en el PARC, el Centro de Investigaciones de Xerox. Su trabajo describía cómo los técnicos de reparación de fotocopiadoras batallaban con los problemas de funcionamiento de los equipos que manejaban. Al estudiar la naturaleza del conocimiento de estos técnic os y los cana les mediante los cuales era compartido este conoc imiento, Orr descubrió una comunidad al margen de la estructura organizativa oficial.

El objetivo de Brown y Duguid fue asociar a las teorías de trabajo el aprendizaje y la innovación, con el fin de proporcionar nuevas perspectivas sobre el aprendizaje organizacional y el papel de las comunidades en los lugares de trabajo. Especialmente se centraron en el desarrollo de las prácticas de aprendizaje informal y señalaron, como conclusión a sus estudios, que los procesos de formación y de socialización probablemente serán ineficaces si se basan en la 
rutina formal, en vez de en experiencias más informales, contingentes e improvisa das.

Su punto de partida fue la diferencia entre la forma en la que una organización describe el trabajo de una persona y, la forma en que el trabajo se realiza efectivamente en la práctica. El primer tipo las denominaron "prácticas canónic as" y, al segundo, "práctic as no canónicas". Su objetivo era mostrar cómo, cuando los procesos de trabajo canónic os se descomponen, las comunidades de práctica continúan funcionando improvisando nuevas soluciones. Para Brown y Duguid $(1991,2000,2001)$ las prácticas no canónicas o el conocimiento informal son la llave del a prendizaje organizativo.

Brown y Duguid describen las CoP como comunidades intersticiales que existen en las "brechas" que se crean entre los procedimientos de trabajo definidos por la organización y, las tareas que se realizan de verdad para llevarlo a la práctica. Para ellos, las Comunidades de Práctica son grupos surgidos de las actividades y procesos emergentes que existen fuera de los límites orga nizativos; se organizan de un modo fluido y dinámico que les hace poder adaptarse de forma constante a los cambios y a las circunstancias en las que viven (Brown y Duguid, 1991).

Dichos autores reconocen el papel de la Participación Periférica Legítima (LPP) en el fomento del aprendizaje, pero señalan tres factores que consideran claves en esta dinámica, la narración, la colaboración y la construcción social. Según ellos, el proceso de aprendizaje que surge de la narración de “las historias del día a día" hace exista una inteligencia colectiva y colaboradora (Brown y Duguid, 2000, pp. 94-95).

Aunque hay algunas diferencias obvias en el enfoque de Lave y Wenger (1991) y Brown y Duguid (1991) están de acuerdo sobre los aspectos básicos: qué 
tipo de grupo es una Comunidad de Práctica y por qué existen. Son comunidades autónomas y centradas principalmente en el aprendizaje.

\subsubsection{Evolución histórica: Periodo medio (1996-1999)}

El periodo medio de la investigación sobre las Comunidades de Práctica está fuertemente marcado por el sentimiento de cambio, tanto a nivel económico como social. Las predicciones que se habían realizado por autores como McLuhan (1964, 1989), Ellul (1964), Toffler (1972, 1980), Bell (1974) y Hiltz y Turoff (1978) empiezan a cobrarvida graciasal cambio radical impulsa do por las tecnologías.

En la década de los noventa, en plena fiebre de las "punto.com", se empieza a dar prioridad a lasorganizaciones en la que el conocimiento sustenta su ventaja competitiva y que se pueden definir como organizaciones basadas en proyectos, con flujos inestables e imprevisibles de trabajo, donde no se da prioridad a las estructuras formales (Do Nac ismento, 2005).

En esta década empieza a utilizarse el término "gestión del conocimiento". Hildreth, Wright y Kimble (1999) señalan que la evolución del término, y lo que conlleva, fue impulsada por las implicaciones de la globalización y la reducción y la extemalización que se empezó a dar en las organizaciones. Se empezó a constatar la falta de eficiencia en la gestión del conocimiento y el peligro que corría las empresas al no poder controlar las pérdidas de conocimiento.

Wenger con su obra Comunidades de Práctica: Aprendizaje, significado e identidad (Wenger, 1998a) fue el únic o autor del período. 
Investiga ción sobre las Comunida des de Práctic a en este perío do

Como hemos señalado, los hallazgos obtenidos en las investigaciones rea liza das por Lave y Wenger (1991) llevan a Wenger en esta época a profundizar en el aprendizaje social y, en 1998, publica Comunidades de práctica. Aprendizaje, Signific a do e Identidad.

Wenger, en su libro, construye el concepto de Comunidad de Práctica sobre los cimientos del a prendizaje situado. Para realizar su investigación a naliza la participación en el contexto de las organizaciones sociales, sean éstas ac a démic as, laborales, polític as, religiosa s o familia res.

Su investigación se basó en un estudio de caso sobre cómo una comunidad de tramitadores de solicitudes de seguros médicos de EE.UU. desa rollaban su práctica en el día a día, contando con una visión mínima de todo el sistema de salud, y por tanto, con conocimientos parciales e incluso, en algunas ocasiones, inconexos. A pesar de tener únicamente conocimiento de aspectos muy conc retos, los tra mita dores desa rrollaban diferentes tareas para las cua les muchas veces debían entrar en contacto con otras comunidades adyacentes, intemas y extemas. Como resultado de estos contactos y de los debates sobre cómo desarrollar mejor el trabajo, surgían desde innovaciones procedimentales a nuevas visiones del sistema al que pertenecían. El conocer el punto de vista del otro y de los problemascon los que se encuentra en su trabajo hace que entiendan mejor la parte del proceso que se les asigna. En la investigación se descubrió también que hay una jerarquía simple que diferencia a los veteranos de los aprendices así como prácticas especiales destinadas a permitir la entrada de nuevos miembros.

En lugar de ampliar el concepto basado en la relación entre aprendices y veteranos, en este libro se describe cómo una Comunidad de Práctica es una entidad limitada por tres premisas interrelacionadas: compromiso mutuo, empresa 
conjunta y un repertorio compartido (de esos elementos trataremos más adelante). A través de estas dimensiones, la práctica se convierte en la fuente de coherencia de una comunidad.

Wenger nos señala que todos participamos en Comunidades de Práctica, en espacios compartidos de aprendizaje, donde colectivamente construimos significados e identidad. El autor incide en que la construcción de significados es un proceso de negociación que implica interacción. Esta interacción es continua, gradual y supone un tipo de experiencia a través de un intercambio continuo. La negociación de signific a dos envuelve dos procesos constitutivos: participa ción y la cosificación. Siendo la participación la experiencia social de vivir en el mundo desde el punto de vista de la afiliación a las comunidades sociales y de la intervención activa; y la cosificación el proceso de darforma a nuestra experiencia produciendo objetos que plasman esta experiencia en una cosa. Cosific ar significa convertir a lgo en cosa.

En téminos de Wenger, una organización que pretenda desarrollarse deberá equilibrar restos dos procesos.

En 1997, Snyder basándose en Wenger y en estudios que se había n realizado hasta el momento, identificó a las CoPs como una herramienta fundamental para mejorar el aprendiza je orga niza tivo, construir competencias orga nizativas y mejorar el desempeño organizacional. Para respaldar su teoría, Snyder (1997) sostuvo que las competencias en la sociedad actual raramente son estáticas, por lo que es fundamental participar en actividades de aprendizaje continuo promovidas en Comunidades de Práctica de alto rendimiento para garantizar que las competencias se construyan, se compartan y se a pliquen efic a zmente.

La contribución más importante de Snyder fue la realizada en 1997 con la aportación de un conjunto de hipótesis comprobables sobre cómo influían las Comunidades de Práctica en el cambio, cómo desarrollaban competencias y qué 
condiciones facilitaban el desarrollo de dichas competencias. Estas 33 hipótesis pueden ser utilizadas para valorar la relación existente entre las CoPs y el a prendizaje organizativo, las competencias orga nizativa s y el cambio orga nizativo. Esta aportación ha desencadenado múltiples investigaciones sobre el tema entre otros las de Lesser y Prusak, Dove, Lorenz, Smith y McKeen, Webb, Wunram, Lettice y Klein (Donnan, 2008).

\subsubsection{Evolución histórica: Último periodo (2000-actualidad)}

En este periodo empieza a desarrollarse una clara tendencia hacia el cambio conceptual. El principal trabajo de esta fase es Cultivando Comunidades de Práctica (Wenger et al., 2002a) aunque también se pueden señalar otras obras (Wenger, 2000), (Wenger y Snyder, 2000), (Snyder et al., 2003), (Snyder y Briggs, 2003), (Wenger et al., 2002b), (McDermott, 2004) y (Wenger et al., 2005) que ilustran más claramente el cambio en el centro de atención de la literatura existente sobre el tema, que pasa del a nálisis a la práctica.

En los últimos años (Hara, 2009) el término se ha consolidado en el mundo empresarial y se ha asociado a la gestión del conocimiento en las organizaciones (Brown y Duguid, 2000; Hildreth, 2004; Ruhleder et al., 1996; Wenger et al., 2002a; Wenger y Snyder, 2000). Como consecuencia, muchas empresas han tratado de facilitar la creación formal de Comunidades de Práctica para mejorar los flujos de intercambio de conocimiento en su interior.

Investigación sobre las Comunidades de Práctica en este perío do

Las líneas de investigación en estos años, según Hara (2009), se a partan de la definición original de Lave y Wenger, centrándose en el fomento de las oportunidades de intercambio de conocimientos en las Comunidades de Práctica 
profesionales. El enfoque actual es más similar a la propuesta de Orr (1990a, 1990b, 1996), y de Brown y Duguid (1991) en su orientación de la actividad en el lugar de trabajo.

El concepto de Comunidad de Práctica en el último período representa un profundo alejamiento de las anteriores nociones. Cox (2005) nos habla de una reinvención de las Comunidades de Práctica como un concepto gerencial. Vann y Bowker (2001) describen esta situación como la comercialización o merca ntilización de la noción.

En 2002, Snyder y Wenger colaboraron, junto con McDermott, en la redacción del libro Cultivando Comunidades de Práctica: Una Guía para la Gestión de Conocimiento, en el que se presentaban siete principios de diseño de una CoP (Wenger, McDermott, y Snyder, 2002, p. 51):

1. Diseño para que evoluc ione convenientemente.

2. Diálogo abierto sobre perspectivas intemas y extemas.

3. Distintos niveles de participación.

4. Desa rrollo de espa cios públic os y privados de la comunidad.

5. Foco en el valor.

6. Combinar fa milia ridad e ilusión por el reto.

7. Creación de un "ritmo".

Este trabajo también condujo a Wenger a la creación de una “quick start-up guide" en la se que presentan los principales conceptos relacionados con las Comunidades de Práctic a (Wenger, 2002). Posterio mente, en 2004, Wenger reforzó su idea sobre el carácter social del conocimiento argumentando que las CoP eran una "fábricas de conocimiento social" (Donnan, 2008). Asimismo, describió los 
elementos básicos que componen una Comunidad de Práctica (dominio, comunidad, y práctica) y defendió la postura de que la dirección de las organizaciones tenía el deber de facilitar a las comunidades su evolución para favorecer el impacto en el desempeño organizativo (Wenger, 2004, p. 7).

En este momento histórico, hay una explicitación sobre la distribución geográfica de las Comunidades de Práctica e incluso de las ventajas de apoyarse en las tecnologías de la información y la comunicación para el desarrollo de sus actividades (por ejemplo, Wenger, et al., 2005). Se trata de un cambio signific ativo de lasprimerasobras en lasque el tema apenasse mencionó.

\subsection{Caracteństicas de las Comunidades de Práctica}

Wenger (2001) nos señala tres características de la práctica que sirven para sustentar y dar coherencia a una comunidad: el compromiso mutuo, la empresa conjunta y el repertorio compartido.

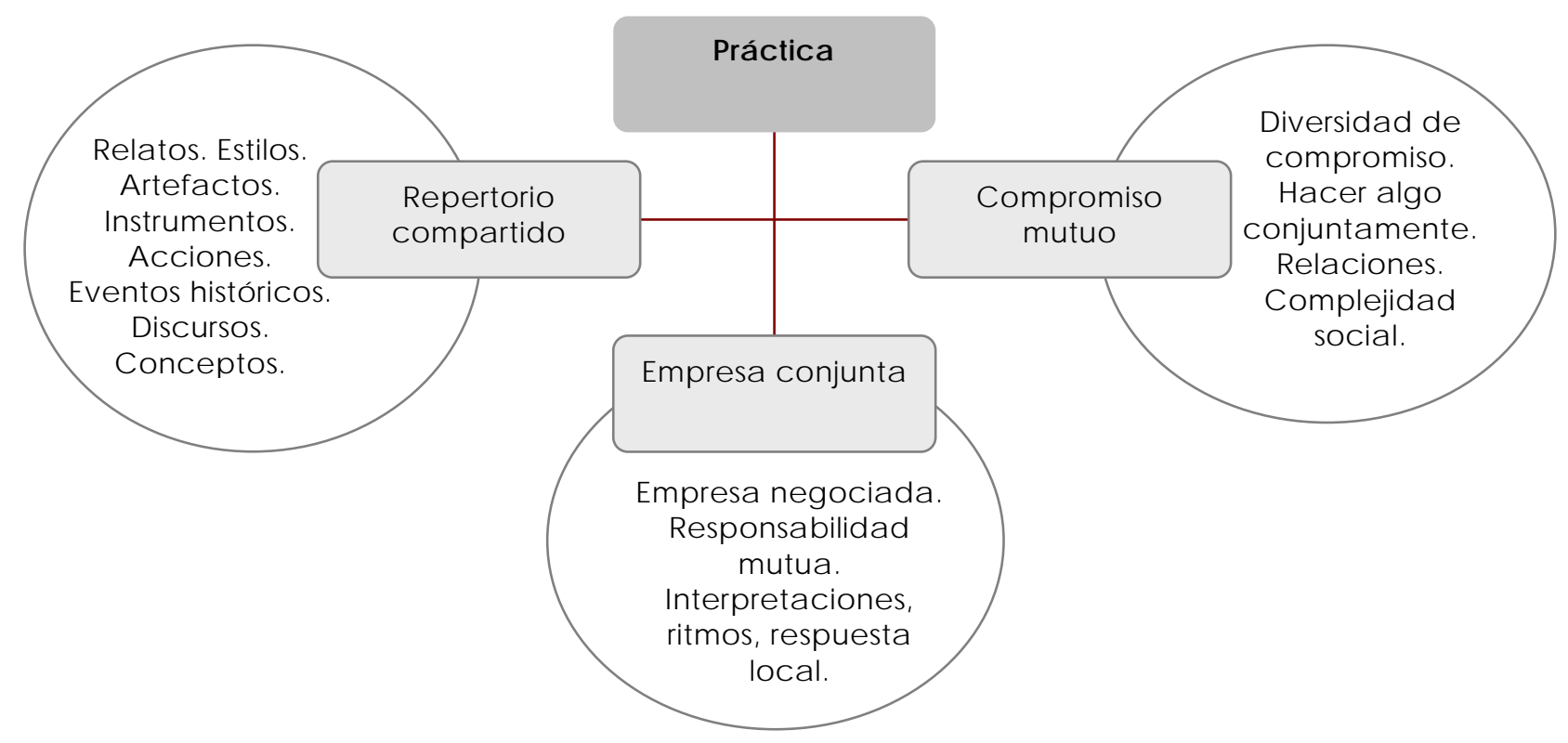

FIG URA 20. CARACTERÍSTIC AS DE LA PRÁCTICA. (WENG ER, 2001) 


\subsubsection{El compromiso mutuo}

La práctica no existe en abstracto, existe porque hay personas que partic ipan en acciones cuyo signific a do se negocia mutuamente.

Según Wenger (2001) la CoP existe porque las personas que forman parte de ella mantienen unas relaciones de participación mutua muy fuertes que se han establecido a través de la práctica diaria, de las funciones y tareas que se ejecutan, de los problemas y de las soluciones que se ponen en marcha en el día a día.

Para participar en la práctica de una comunidad y establecer lazos de compromiso mutuo es necesario que sus miembros se involucren en lo que para ellos tiene importancia. Los aspectos que pueden facilitar la cohesión pueden ser muy sutiles y delicados, ya que en un momento dado puede ser tan importante conocery comprender un comentario que está fluyendo por la organiza ción como conocer los datos a portados en el último informe que se haya elaborado.

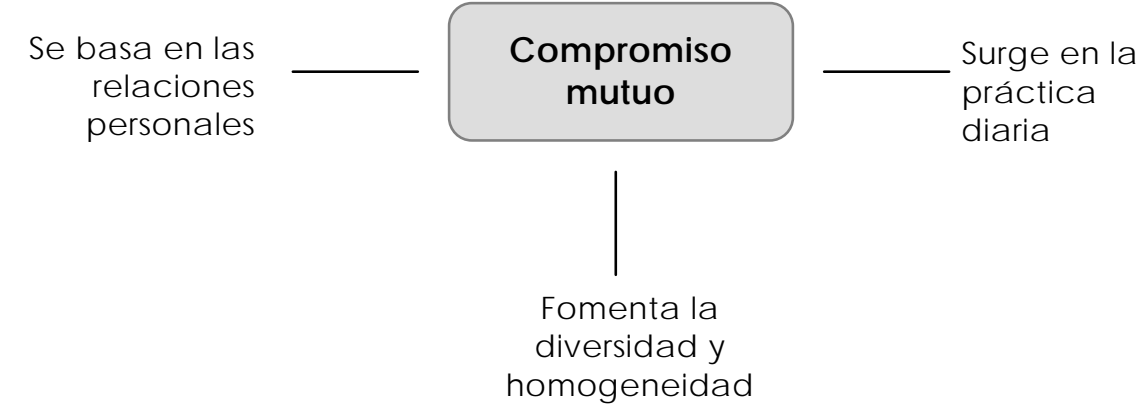

FIG URA 21. EL COMPROMISO MUTUO EN UNA COMUNIDAD DE PRÁCTICA (ELABORACIÓN PROPIA).

Lo que hace que el compromiso con la práctica sea posible y productivo es tanto una cuestión de diversidad como de homogeneidad. Cada participante encuentra en la Comunidad de Práctica un lugar único, a través del cual adquiere 
una identidad propia que se va definiendo, cada vez más, por medio del compromiso en la práctica.

Las relaciones mutuas de compromiso pueden producir por igual diferencia y homogeneización. Como señala Wenger (1991) el compromiso mutuo no supone homogeneidad pero crea relaciones muy profundas entre las personas. En este sentido una CoP puede convertirse en un núcleo muy fime de relaciones interpersonales, cuyas relaciones resultantes reflejan la plena complejidad de hacer algo conjunta mente.

Otro aspecto a tener en cuenta es que el compromiso mutuo no solo supone nuestra competencia, si no también la de los demás. El compromiso se basa en lo que hacemos y en lo que sabemos, además de en nuestra capacidad de relacionamos significativamente con lo que hacemos y con lo que no hacemos y lo que no sabemos; es decir, con las contribuciones y el conocimiento de los demás. Es más importante saber cómo dary recibir a yuda que intentar saber todo.

\subsubsection{Empresa conjunta}

La segunda característica de la práctica como fuente de coherencia de una comunidad es la negocia ción de una empresa conjunta.

Las acciones o tareas que se llevan a cabo en una Comunidad de Práctica son el resultado de un proceso colectivo de negociación que refleja toda la complejidad del compromiso mutuo y que promueve en los participantes unas relaciones de responsabilidad que se convierten en una parte integral de la práctic a (Wenger, 1991; Wenger, 2001). 


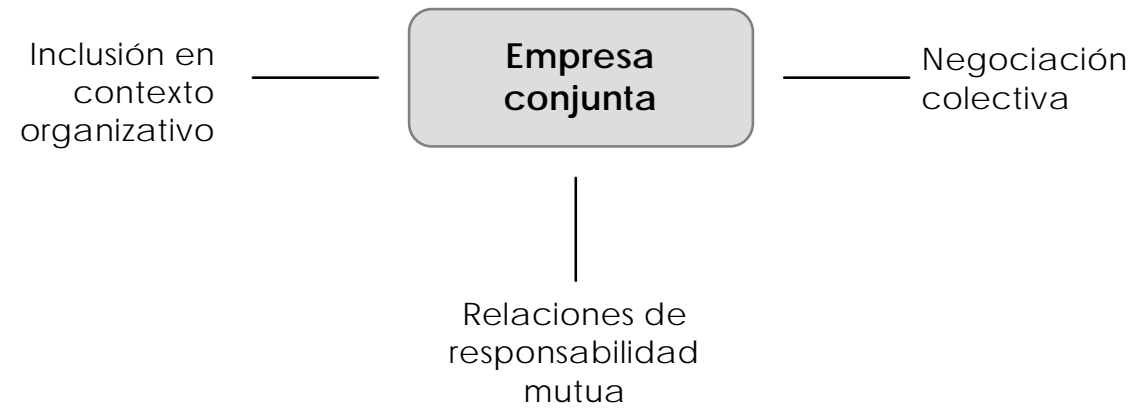

FIG URA 22. LA EMPRESA CONJ UNTA EN UNA COMUNIDAD DE PRÁCTICA (ELABORACIÓN PROPIA).

La empresa no es conjunta en el sentido de que todos creen lo mismo o están de acuerdo en todo, sino en el sentido de que todo se negocia colectivamente. Aspecto que se llevará también a la práctica porque los profesionales deben encontrar una forma de trabajar e incluso de vivir con sus diferencias y deben saber coordinar sus aspiraciones personales como parte del proceso de aprendizaje.

El propio proceso dinámico de negociación da origen a unas relaciones de responsabilidad mutua entre los implicados y es lo que mantiene unida a la comunidad (Wenger, 2001). Estas relaciones incluyen lo que importa y lo que no; lo que es importante y por qué; qué hacer y qué no hacer; a qué prestar atención y qué no; de qué hablar y de qué no; qué justificar y qué dar por descontado, qué mostrar y qué ocultar o cuándo los resultados de las acciones que se están llevando a cabo tienen la calidad o idoneidad suficiente o se deben mejorar o refinar. Algunos aspectos relacionados con la responsabilidad que tienen sus miembros esta rán cosific a dos en reglas, políticas, nomas u objetivos, pero otros no se mostrarán de forma explícita, lo cual no indica que sean menos importantes. 
Del mismo modo hay que entender a la empresa dentro del contexto dónde ésta se desarrolla, ya que las Comunidades de Práctica no son entidades independientes si no que se dan en contextos más amplios con unos recursos y unos límites concretos. Será fundamental en la negociación, su posición dentro del sistema y la influencia que tenga la institución sobre ella.

Como nos señala Wenger(2001)

“una empresa es un recurso de coordinación, de comprensión, de compromiso mutuo; desempeña el mismo papel que el que desempeña el ritmo para la música". (p.109)

En definitiva según Poole (2002), todos los miembros de la Comunidad de Práctica deben sentirse y hacerse responsables de alguna manera de su futuro, ya que sólo en la medida en la que una persona se involucra, forma parte de la comunidad.

Todos los participantes deben tener presente en todo momento que la comunidad debe estar abierta a nuevas prácticas, a nuevos aprendizajes y a nuevos miembros. El compromiso de cada miembro debe orientarse a compartir experiencias y conocimientos e igualmente enriquecerse con los aportes de los demás, con lo cual la comunidad se dinamiza, crece y se fortalece (Poole, 2002).

En su razón de ser se encuentra la esencia del trabajo de cada uno de sus miembros: comunidad es común y es unidad. La práctica individual se enriquece cuando se comparte y forma parte de los propósitos del conjunto (Galvis, Tobón y Salazar, 2008). 


\subsubsection{Repertorio compartido}

Finalmente, el repertorio compartido es la tercera característica de la práctica, la que da coherencia a la comunidad mediante la creación de recursos compartidos necesarios tanto para la negociación de significados como para promover el compromiso con la práctica.

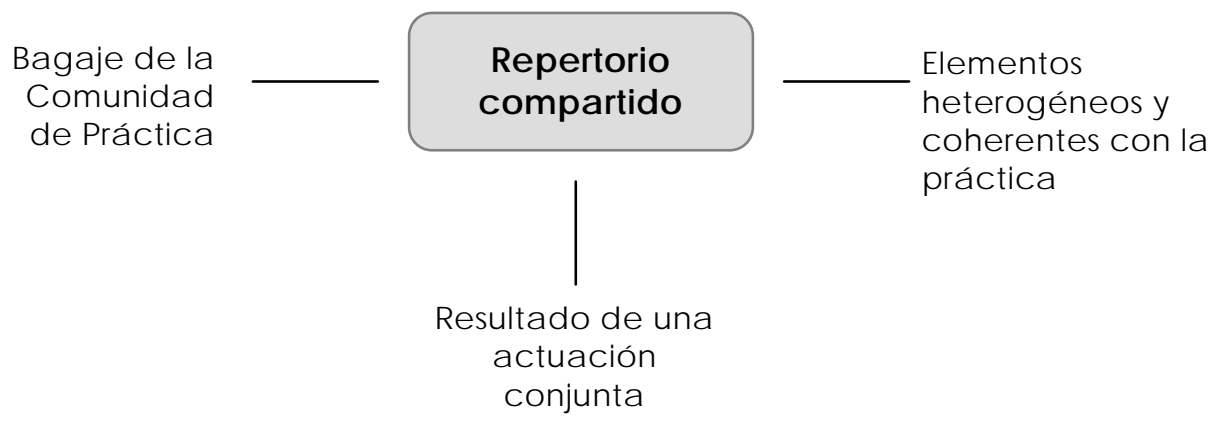

FIGURA 23. EL REPERTORIO COMPARTIDO EN UNA COMUNIDAD DE PRÁCTICA (ELABORACIÓN PROPIA).

Las Comunidades de Práctica van adquiriendo rutinas, formas de hacer, expresiones, símbolos o conceptos cargados de signific a do para sus miembros que se van forjando a lo largo de su existencia y que se integran en su práctica.

Los elementos del repertorio de una comunidad pueden ser muy heterogéneos y no tienen coherencia por sí mismos sino que la adquieren al pertenecer a la práctica que les da sentido. Ayudan a la comunidad a construir su visión histórica, porque tanto los artefactos lingüísticos como son las metáforas, historias, explicaciones, como los no lingüísticos, como pueden ser las cosificaciones de experiencias, son productos resultantes de la experiencia y cobran un significado importante para la justificación de las acciones que se llevan a cabo y la negociación de significados; y ayudan a avanzar hacia el futuro 
porque posibilitan el surgimiento de nuevos significados y pueden reutiliza rse para nuevos fines, por ejemplo, incluyen el discurso por el que los miembros de la comunidad crean a firmaciones signific a tivas so bre el mundo, a demás de los estilos por medio de los cuales expresan sus formas de afiliación y su identidad como miembros.

El repertorio es un conjunto de recursos compartidos de una comunidad que refleja una historia de compromiso mutuo y combina aspectos cosificadores y de participación.

\subsection{La participación en una Comunidad de Práctica}

A medida que las personas trabajan juntas, además de aprender de la práctica, desarrollan una visión compartida de cómo y qué se debe hacer en el trabajo (Stamps, 1997). La práctica como significado es el proceso por el cual se experimenta el mundo y el compromiso con él como algo significativo (Wenger, 2001).

La práctica adquiere significado cuando vivimos ciertas experiencias, cuando nos comprometemos con ella. Según Wenger (2001) en el día a día negociamos con las personas con las que trabajamos el significa do de la práctica; cuando repetimos situaciones, impresiones, experiencias que hemos vivido, oído o contado en el pasado en un nuevo contexto o con unas nuevas personas, las dotamos de nuevos significados que amplían, desvían, ignoran reinterpretan, modific a n o confiman la historia de significados que lleva a sociada esa práctica.

Por todo ello, la negociación implica un compromiso con la práctica y con el contexto dónde se desarrolla y, por tanto, con las personas que participan de forma directa o indirecta. 
En las organizaciones se negocian los signific ados que tienen asociadas las prácticas que se llevan a cabo, porque nada es estático, porque todo está en movimiento. Lo que hace unos años era lo "lógico" o lo "normal" poco a poco se va reinventando. $Y$, en estos procesos de cambio, es dónde los nuevos significados deben ir interpretá ndose e integrándose en el quehacer orga niza tivo.

La negociación se va a dar en los procesos de participación que se producen en las organizaciones. La participación es un proceso complejo que combina hacer, pensar, sentir y pertenecer, en el que interviene toda nuestra persona incluyendo cuerpo, mente emociones y relaciones sociales.

Según Wenger (2001) la participación va más allá de un simple compromiso con la práctica, va más allá de la intervención en unas activida des espec ífic as con unas personas concretas; forma parte de quienes somos y tendrá un reflejo en todas las situaciones de nuestra vida.

La participación se complementa con la cosificación. Si la primera hace referencia a los procesos mediante los cuales nos reconocemos, en la cosificación nos proyectamos al mundo.

La cosificación es un proceso mediante el cual damos forma a nuestra experiencia convirtiéndola en "cosas" como documentos, fotografías, procedimientos, actas, libros, historias, anécdotas, etc. Con este proceso se crean puntos de enfoque en tomo a los cuales se organiza la negociación de significados; un ejemplo, puede ser la elaboración de un procedimiento de trabajo y la negociación de significado que va a producir tanto en su elaboración como en su posterior a plic ación.

La participación y la cosificación no se pueden considerar por separado, forman una unidad en su dualidad. Como nos señala Wenger (2001), en presencia de la una, esútil preguntarse dónde está la otra. 


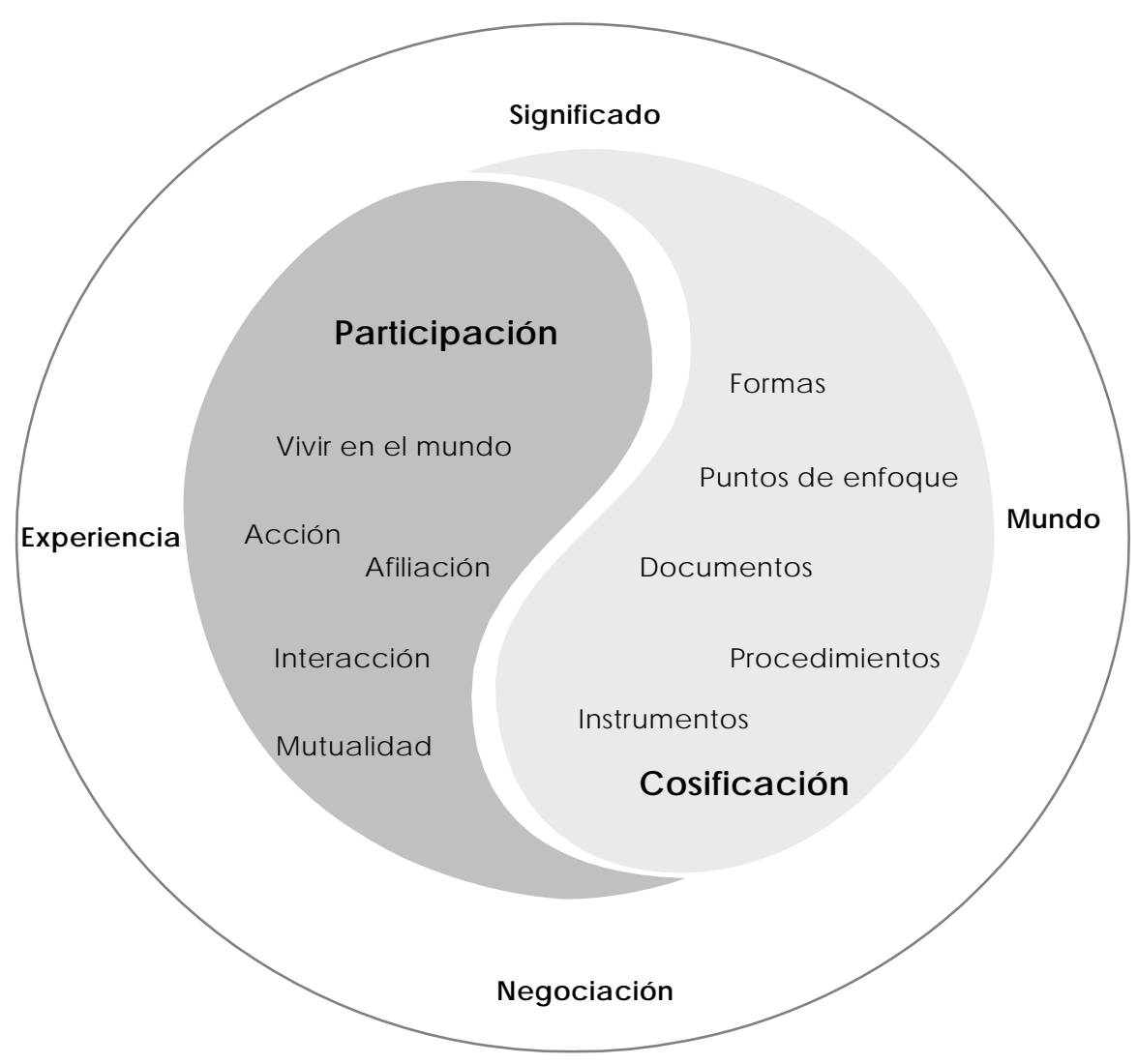

FIGURA 24. LA DUALIDAD DE LA PARTICIPACIÓN Y LA COSIFICACIÓN

(WENGER, 2001, P. 88).

Un ejemplo de forma de cosificación, son las palabras. Según Wenger las palabras influyen en la negociación de significado mediante un proceso de pura partic ipación.

Dado que cada Comunidad de Práctica existe dentro de un contexto específic o (Wenger, 1998a), los signific ados compartidos que en ella se desarrollan se encuentran dentro de este contexto. Para comunicarse de manera efectiva, los miembros de una Comunidad de Práctica deben desamollar un vocabulario común, un lenguaje común, que va a ser clave tanto para una comprensión compartida de conocimiento explícito (por ejemplo, el sentido de las palabras) como del tácito (por ejemplo, las metáforas y valores) (Davenport y Hall, 2002; Kra uss y Fussell, 1990; Pla skoff, 2003). 
La complementariedad entre la participación y la cosificación debe mantener una compensación que equilibre sus respectivas limitaciones. Cuando nos basamos en una a expensas de la otra, es probable que la continuidad de significado sea causa de problemas en la práctica. En estos casos las organizaciones deberán analizar la situa ción y, en función de la dualidad, realizar un ajuste.

Como nos señala Wenger (2001) si predomina la participación puede que no exista material suficiente para anclar las especificidades de la coordinación y sacar a la luz supuestos disc repantes. Si predomina la cosific ación, es decir, todo se cosifica, pero con pocas oportunidades para la experiencia compartida y la negociación interactiva puede que no se den suficientes situaciones para recuperar un significado coordinado, pertinente o generador de nuevas y enriquecedoras prácticas.

En la realidad, la cosificación siempre se apoya en la participación: lo que se dice, se representa o lo que constituye el centro de atención, por la razón que sea, siempre supone una historia de participación como contexto para su interp retación.

\subsection{El diseño de una Comunidad de Práctica}

Las Comunidades de Práctica emergen y se foman de forma natural. A pesar de ello, como nos señalan Wenger, McDermott y Snyder (2002) las organizaciones necesitan ser más proactivas y sistemáticas con su desarrollo e integración dentro de la estrategia organizativa para que alcancen su máximo potencial.

Por lo tanto, aunque no podemos hablar de diseño en el sentido tradicional sí que podemos hablar de unos principios de diseño que, como nos señalan 
McDermott, Snyder y Wenger (2002a), no son recetas, sino la comprensión sobre cómo los elementos de diseño operan juntos.

Estos autores nos sugieren que desde las organizaciones se puede promover y guiar su evolución, ayudando a sus miembros a identific ar el conocimiento, eventos, roles y actividades que cataliza rán su crecimiento. Para ello, basándose en la escucha, el a compañamiento y la facilitación, se deberán redefinir las reglas que van a marcarsu diseño.

Los principios de diseño según los autores son: (1) diseñar para la evolución, (2) a brir el diálogo entre las perspectivas intemas y extemas, (3) invitar a diferentes niveles de participación, (4) desa rollar ambos espacios comunitarios, públicos y privados, (5)focalizar en el valor agregado, (6) combinar familiaridad con entusia smo y (6)c rear un ritmo para la comunidad.

(1) Diseña r para evolución

Dado que las Comunidades de Práctica se gestan espontáneamente, las organizaciones deberán tener en cuenta que el diseño es más una tarea de acompañamiento y facilitación que una tarea de creación pautada y estructurada.

En los primeros momentos las organizaciones deberán emplear una metodología que oriente a la comunidad y fomente su evolución de modo natural (McDemott, Snyder y Wenger, 2002a). Generalmente, las Comunidades de Práctica surgen en redes de trabajo preexistentes y evolucionan sin un diseño particular, dependiendo de los nuevos miembros que se van sumando y de la evolución de los asuntos que tratan. Por ejemplo, los cambios en la tecnología o en la organización pueden implicar 
nuevas demandas para la comunidad y esta constantemente se reformará a sí misma.

Cuando se menciona una metodología que catalice la comunidad para su evolución y desarrollo, McDermott, Snyder y Wenger, (2002a) se refieren a una sistemática que se basa en cuestiones tan sencillas como por ejemplo, generar reuniones para analizar y resolver problemas que promueva n finalmente el desa rollo de la comunidad.

(2) Abrir el diálogo entre las perspectivas intemas y extemas

Considerando que las Comunidades de Práctica se diseñan a sí mismas a partir de la experiencia desarrollada en su seno, sólo se podrán apreciar los asuntos de interés, que surgen desde el corazón de su dominio, desde su interior. Y sólo desde aquí, se podrá identificar quiénes son los actores claves y cómo son sus interacciones. El problema puede residir en que no todos los miembros de la comunidad se van a dar cuenta de los temas candentes que se están perfilando.

Cuando en una organización se promueve el desarrollo intencional de una Comunidad de Práctica, generalmente se ponen en marcha largas sesiones de discusión entre sus miembros para la búsqueda de cuestiones que están latentes, o se parte del a nálisis de la experiencia desarrollada por otras comunidades. En muchas ocasiones, esto implica abrir la participación a personal ajeno a la comunidad; el referente extemo partiendo de la comprensión de los asuntos de interés de la CoP puede actuar como un potente agente de cambio. Se trata de sesiones de facilitación, donde el conocimiento exteriorizado por una comunidad (de tácito a explícito) es compartido para fomentar el desa rrollo de otra comunidad. 
La existencia de actividades y eventos comunes ayuda a generar un sentido de pertenencia y una historia común que permite aglutinar a los miembros de la comunidad. Las actividades comunes que se producen dentro de una comunidad y que generan sentido de pertenencia son fundamentales para que todas las personas que forman parte de la organización se sientan partícipes de la comunidad y puedan encontrar en ella el sentido, la pertenencia y el significado que buscan.

Según Garber (2004) la existencia de actividades compartidas y de un propósito común hace necesaria la existencia de políticas y mecanismos de participación que ayuden a los miembros de una comunidad a lograr sus objetivos. Estos mecanismos pueden incluir desde reglas de convivencia hasta estructura sorganizacionales que orientan la acción de la comunidad.

Del mismo modo, la adopción de un modelo de aprendizaje horizontal y colaborativo va a contribuir a fortalecer y mantener la Comunidad de Práctica (Galvis, Tobón y Salazar, 2008). Con este modelo va a ser posible que la CoP se concentre en sus propios problemas y prácticas y que la participación de los líderes no esté limitada por jerarquías org a nizativas.

(3) Invitara diferentes niveles de partic ipación

Los miembros de una Comunidad de Práctica tienen distintos niveles de participación, unos valoran lo que aprenden, otros la red de contactosy también están los que valoran la pertenencia. Todos deberemos tener en cuenta estos aspectos los a la hora de diseñar una CoP.

Las Comunidades de Práctica, promovidas desde la organización o surgidas espontáneamente, cuentan con un coordinador y también con diferentes líderes, que emergen según la tarea que encaran. Hay un grupo 
de miembros claves que son los que asumen la responsabilidad de su funciona miento, " 10 al $15 \%$ del tota I de la comunidad, otro 15 al $20 \%$ son los miembros activos" (Wenger, McDermott y Snyder, 2002a) y el resto son miembros periféricos, que observan y aprenden de la interacción que desarrollan los claves y a ctivos.

En las organizaciones se deberá tener en cuenta que también la comunidad tiene miembros que están interesados en su funcionamiento, pero que están fuera de ella, se trata de aliados estratégic os, proveedores o simplemente "vecinos" que analizan su funcionamiento.

La participación activa en los eventos y actividades de la comunidad es indispensable para dar sentido a la presencia de cada uno de sus miembros. Si no existe participación real de una persona, en verdad esa persona no se encuentra integrada en la comunidad.

En las Comunidades de Práctica deberán implementarse estrategias para estimular y reconocer la labor de todas las personas que se vinculen, de forma que se concrete su compromiso con el grupo. Estas estrategias pueden estar orientadas a un reconocimiento en tiempo o dinero o a la divulgación del trabajo de la comunidad, con los correspondientes méritos para autores individuales y grupales.

Las comunidades constituyen medios ideales para que los profesionales, además de compartir experiencias y conocimientos, hallen respuestas a diversidad de casos cotidia nos que van más a llá del sabery del trabajo directamente relacionado con su área, pero que tienen que vercon su práctica.

Las CoP son un punto de encuentro entre generaciones de profesionales con más y menos experiencia, con mayores y menores 
conocimientos, pero todos interesados en mejorar su práctica en beneficio de las personas usuarias.

La actividad en las CoP debe aprovec harse en todas sus fases, desde la inicial hasta la final. La organización y la comunidad deben encargarse de conservar, en la memoria de todos, los aprendizajes y las participaciones realizadas, para que exista una memoria compartida de las experiencias y ap rendiza jes vividos.

(4) Desa rrollar a mbos espacios comunita rios, públic os y privados

La mayoría de las Comunidades de Práctica organizan eventos donde los miembros se congregan para interactuar, ya sea en reuniones cara a cara o encuentros electrónicos. En estos encuentros puede que haya presentaciones formales pero la mayoría de las veces se trata de intercambios informales sobre los asuntos que atañen a la comunidad. Cuando los vínculos entre los miembros son más estrechos los eventos son más ricos.

En la CoP hay que promover el "afecto societatis", pero no se puede imponer, dado que surge naturalmente. Su existencia se va a traducir en que todos los miembros de la comunidad tienen la intención de cooperar ac tiva mente y de orga niza r sus esfuerzos para conseguir el fin común.

No todas las actividades de una comunidad pueden ser pragmáticas. Los espacios sociales (bien sean de discusión o de esparcimiento) son vitales para consolidar lazos personales entre los miembros. El compartir un tiempo social va a hacer que se consoliden lazos entre los miembros de la comunidad (personas usuarias, familias, equipo directivo, profesionales, otros miembros de la comunidad, etc.) ya que permiten interac tuar con más confianza y en a mbientes más distendidos. 
(5) Foca lizar en el valor añadido

Las Comunidades de Práctica existen porque agregan valor a sus miembros, a la comunidad y, cuando están alineadas a la estrategia, a la organización. Los encuentros que otorgan un mayor valor, son los que ocurren día a día, resolviendo problemas y dando satisfacción a las necesida des de sus miembros. No obstante, muchas veces es difícil evaluar el resulta do de estos encuentros hasta pasados varios meses.

La pertinencia y valor real que cada miembro percibe en las relaciones que tiene con otro son claves para fortalecer el compromiso con la Comunidad de Práctica.

Sólo en la medida en que la interacción con otros agregue valor, se puede esperar un involucramiento en las actividades de un grupo humano específico.

Una comunidad debe ser capaz de generar el sufic iente valor como para que todos sus miembros encuentren aquello que buscan con su pertenencia a ella.

(6) Combinar fa milia ridad con entusia smo

Hay determina dos momentos que hay que cuidar especialmente en la dinámica de la comunidad, por ejemplo, la llegada de nuevos miembros a una comunidad no debería pasar desapercibida, ya que va a constituir un evento especial en la vida del recién llegado. Los rituales de entrada y salida ayudan a las organizaciones y a las Comunidades de Práctica que hay en ellas, a consolidar un sentido de identidad y de pertenencia, y una posibilidad tangible de interacción entre los miembros veteranos y los nuevos. 
En este primer momento, desde la comunidad se deben establecer canales para que el primer contacto sea amistoso y acogedor, sea accesible para todos, por lo que el centro deberá estar preparado para desplegar los niveles de apoyo necesarios. Desde las organizaciones y desde la comunidad se debería establecerplanes de acogida en los que se recoja el despliegue que se va a realizar.

Ya en el día a día, otro a specto a cuidar son los encuentros regulares, teleconferencias o encuentros a través de la Web ya que cuando se realizan habitualmente fomentan el intercambio. "Son encuentros regulares separados de las presiones del trabajo" (Wenger, McDemott y Snyder, 2002a). Muchos de esos encuentros son familiares y forman parte de la rutina de la comunidad, pero otras veces implican un desafío, estimulan la búsqueda de soluciones a problemas concretos y proveen sentido de aventura compartida.

(7) Crear un ritmo para la comunidad

Cada comunidad debe encontrar su propio ritmo, su "tempo", porque es el indicador de su vitalidad. Si sus encuentros son demasiado frecuentes o rápidos, la comunidad siente el ahogo y sus miembros dejan de participar porque se sienten superados. Si sus encuentros son demasiado espaciados y lentos la comunidad se vuelve perezosa. No hay una receta y además el ritmo de una comunidad evoluciona con ella, pero es fundamental prestar atención a la búsqueda del ritmo correcto.

\subsubsection{Los límites de la Comunidad de Práctica}

Schwen y Hara (2004) advierten que las Comunidades de Práctica no se pueden crear de forma artificial e incluso que son difíciles de identificar y a islar ya 
que muestran patrones de organización que no se reflejan en los organigramas institucionales. Esto se debe a que las Comunidades de Práctica son informales. En este sentido, se asemejan a las relaciones que se desarrollan a lo largo del tiempo entre a migos y colegas.

A medida que las CoPs se diferencian y se entrelazan van constituyendo un complejo panorama social de prácticas compartidas, límites, periferias, conexiones y encuentros (Wenger, 2001) no acorde con las estructuras fomales de las a filiaciones, divisiones y límites instituciona les.

Los límites de las Comunidades de Práctica no coinciden necesariamente con los límites organizativos porque la afiliación de sus miembros no está definida por categorías instituc ionales.

Como nos señala Wenger(2001)

La práctica es la fuente de su propio límite porque en ella (1) los partic ipantes establecen relaciones estrechas y desa rollan maneras idiosincrásicas de participación mutua a las que alguien ajeno no puede incorporarse fácilmente; (2) tienen una compresión detallada y compleja de su empresa tal y como la definen y que alguien ajeno puede no compartir; (3) han desarrollado un repertorio para el que alguien ajeno puede crecer de referencias compartidas. (p.146)

Tanto la participación como la cosificación originan discontinuidades y conexiones entre las prácticas que dan lugar a los límites y periferias dentro de las Comunidades de Práctica. 


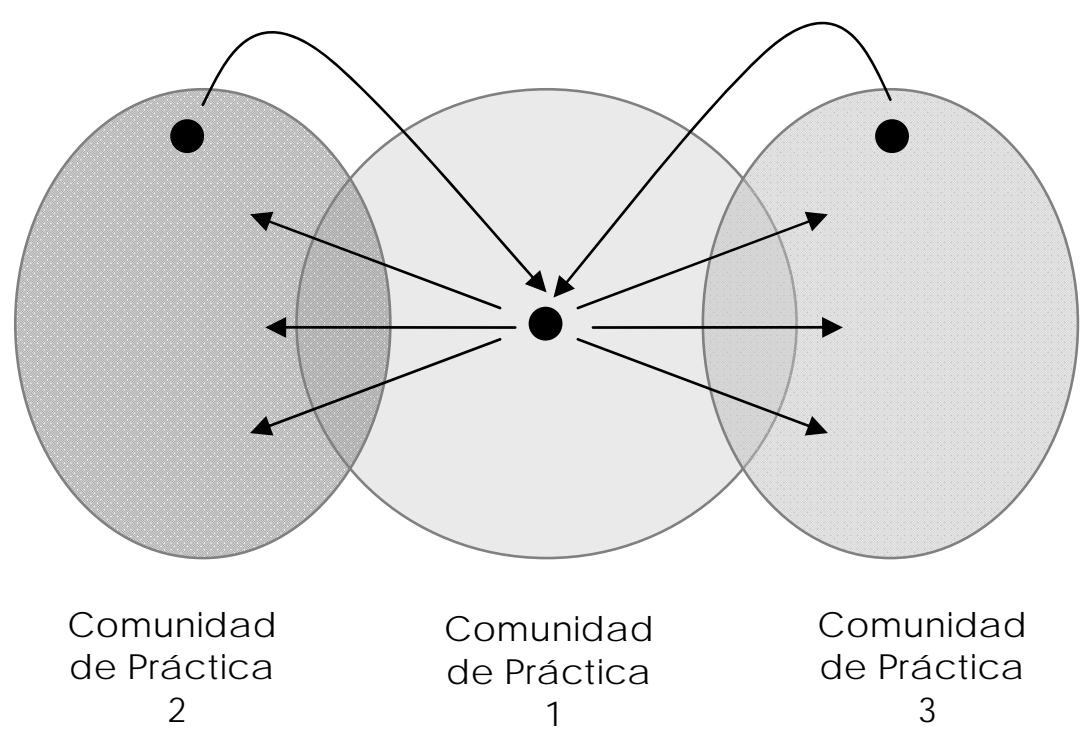

FIG URA 25. CONEXIONESY LIMITES ENTRE LAS CO MUNIDADES DE PRÁCTICA (ELABO RACIÓN PROPIA).

Los límites se refieren a discontinuidades, a líneas de distinción entre lo interior y lo exterior, la afiliación de la no afiliación, la inclusión de la exclusión. Las periferias son las continuidades, los lugares de encuentro y a las posibilidades organizadas y causales de participación que se ofrecen a los participantes o a personas ajenas (Wenger, 2001). Se nos puede permitir "entrar" en una Comunidad de Práctica con una aparente participación plena pero de vez en cuando pueden aparecer sutiles elementos que nos recuerden que somos una persona ajena, por ejemplo, una expresión que no podemoscomprender, una historia sobre un suceso pasado o una mirada de desconfianza.

La periferia puede ser una posición donde el acceso a una práctica es posible, pero también donde se impide a las personas ajenas aproximarse más al centro.

Para conectar unas prácticas con otras se pueden utilizar lo que Etienne Wenger (2001) ha denominado objetos limitáneos, ya que nos van a facilitar la Tesis Doctoral 
coordinación de las perspectivas de varios grupos o personas para un fin común y la conexión entre diferentes CoPs.

\subsection{Conclusiones del capítulo}

Las Comunidades de Práctica son un medio ideal para compartir el conocimiento individual y crear conocimiento colectivo (Hara, 2009); para desarrollar la capacidad de crear y retener el conocimiento, las organizaciones deben comprender los procesos por los cuales las comunidades evolucionan y se interrelacionan. Las organizaciones no deben ni descartar ni obstaculizar estos procesos, sino más bien reconocer, a poyary aprovecharse de los flujos que se dan ellos.

Una comunidad es más que una red ya que no se basa solamente en las relaciones que se establecen entre sus miembros, sino en la búsqueda de un objetivo común, que genera una identidad. Por esta razón es imprescindible trascender la idea de red y evidenciar cuáles son las metas conjuntas que se persiguen al propiciar una reunión de personas, para identificar el valor real que cada miembro obtiene de su participación (Garber, 2004).

Los miembros de una comunidad comparten, en mayor o menor medida, un conjunto de características, creencias o intereses que generan un sentido de pertenencia individual. La identidad compartida va a permitir que cualquier miembro de la misma tenga la misma misión y visión de lo que es la CoP a la que pertenece.

La vinculación a una Comunidad de Práctic a es una experiencia dinámica y recíproca que también debe entenderse como un trabajo en equipo que incentiva y da sentido a la producción de sus integrantes; y una oportunidad para hacer extensivos a otra s instituc iones los logros alc anza dos. 
Para que las relaciones informales funcionen realmente dentro de la Comunidad de Práctica hay que encontrar un equilibrio entre la confianza y el control en la dinámic a de grupo (O 'Leary, Orlikowski y Yates, 2002).

Kling (1996) nos señala que, sin embargo, muchas veces los equipos directivos prestan una atención inadecuada a las comunidades profesionales informales porque están generalmente basadas en redes sociales. Como Huysman (2003) argumenta, la gestión puede perjudicar, a veces sin querer, a los mecanismos por los cuales las Comunidades de Práctica favorecen la gestión del conocimiento.

En el día a día, desde las Comunidades de práctica, se deben trabajar los elementos clave, que ya se han señalado a lo largo del capítulo, para que sea estable en el tiempo y siga c umpliendo los objetivos por los que surgió. 



\section{CAPITULO 4.}

\section{Asociación AMICA: centro de referencia}

AMICA (2009)

AMICA y su historia, es una realidad de principios difíciles y de convic ciones extra ord ina rias.

Los que hemos tenido la fortuna de conocerla, envidiarla y quererla vemos como AMICA es única. Hay reparto de tareas. Hay igualdad de trato. Hay reparto de criterios fabricados por todos.

Un pensar colectivo de TODOS, hace viable la diversidad, permite hacer fácil lo difícil, y lo que es más importante, fabrica el camino a realizar facilitando el de los que menos pueden, que teminan descubriéndonos sus capacidades.

AMICA, es una orquesta bien a finada, donde la batuta se comparte en cada momento y todos participan de una partitura impensable, extraordinariamente digna, que siempre suena muy bien y que convence a todos, a todos lo que tienen buena voluntad para aceptar los triunfos de otros. [...]

El intento está logrado, los que han de participar participan y participan todos, todos están representados, todos son protagonistas, pero por bien que se haga, "se ha hecho bien", AMICA hay que verla en vivo y en directo para creer lo que ha conseguido, tratarde imitarlo y hacerle ver a la sociedad que todos debemos intentarlo. (p107) 


\subsection{Introducción}

Se ha elegido como organización de referencia para la presente investigación a la asociación AMICA por diferentes motivos; en primer lugar, por ser un referente en la promoción la autonomía personal y la participación tanto a nivel nacional como intemacional; en segundo lugar, porque es una organización inclusiva en la que tanto su cultura, sus políticas y sus prácticas promueven la defensa de los derechos de las personas con algún tipo de limitación y, por tanto, la inclusión a todos los niveles. Y en tercer lugar, porque la gente que forma parte de la organización constituye una auténtica Comunidad de Práctica, en la que existe una empresa conjunta, un compromiso mutuo y un repertorio compartido.

A lo largo de este capítulo se expone qué es AMICA, cuál es su filosofía de trabajo y qué método de gestión utiliza, ya que sólo partiendo de esta base podremos llegar a analizar cómo se desarrollan sus procesos de trabajo. Para la elaboración de este capítulo se ha realizado un análisis documental de la información corporativa, de la que se han extraído textos que nos darán a conocer la organización de referencia para la investigación.

\subsection{AMICA: presente y futuro}

AMICA es una iniciativa social, declarada de utilidad pública el 26 de marzo de 1993, cuya misión es la atención a la limitación de la persona, cuando dificulta su a ctividad y participación social, en cua lquier etapa de la vida (Castillo, 2010).

Su objetivo es promover el desarrollo integral, la autonomía e independencia, la igualdad de oportunidades y derechos, para evitar cualquier 
situación de discriminación o exclusión social. Aportando los apoyos, que respondan a las necesidades y demandas ind ividuales (Ca stillo, 2010).

El Grupo está constituido por la Asociación, que realiza las ta reas de a poyo y forma ción de las personas, y dos sociedades instrumentales SOEMCA S.L. y SAEMA S.L., que dan oportunidades de empleo a más de 300 personas con discapacidades. Después de 25 años de andadura cuenta con 1.050 socios, 26 centros y núcleos de actividad repartidos por toda la Comunidad Autónoma de Cantabria (España), donde trabaja una plantilla media de 500 trabajadores y trabaja doras, entre profesiona les y personas con discapacidad (Ca stillo, 2010).

Desde 1999 desarrolla un proyecto de cooperación al desarrollo en Bolivia, creando y manteniendo servicios de atención de día, formación para el empleo y ayuda a domicilio a más de 50 personas, atendidas por 11 profesionales (Castillo, 2010). Y recientemente ha inicia do colaboración con dos entidades en Argentina, y una en Nicaragua.

Los servicios que presta la entidad van dirigidos a personas con todo tipo de discapacidades y su proyecto intenta a portar soluciones y apoyos en cada etapa de la vida, desde la infancia a la ancianidad (Castillo, 2010). Cuenta para ello con un Centro de recursos, donde además de los servicios administrativos y de dirección, se presta servicio a la primera infancia; 4 centros de día dedicados a personas con discapacidades más graves; 4 centros de formación para el empleo; 14 centros de trabajo que ofrecen la primera oportunidad de empleo a las personas ya formadas, 4 viviendas que albergan tanto a personas a las que sus familiares no pueden apoyar por su avanzada edad como a jóvenes que aspiran a vivir con independencia. La Asociación realiza además ayuda a domicilio en 6 de los munic ipios más importantes de la Región Cántabra (España).

En su ya dilatada historia, AMICA ha participado en el programa Helios II de la Unión Europea (1993-96) profundizando en soluciones de alojamiento. Y desde 
1.992 a 1.999 desarrolló 4 proyectos dentro de la Iniciativa Empleo-Horizon ensayando la conveniencia y la eficacia de producir una continuidad entre formación y empleo protegido, para dar oportunidades a personas con distinto grado de limitaciones (Ca stillo, 2010).

Desde 1997 tomó parte, en colaboración con la Organización Mundial de la Salud, en todo el proceso de revisión y elaboración de la Clasificación Intemacional del Funcionamiento, la discapacidad y de la salud (CIF) que fue aprobada en la Asamblea Mundial de la OMS en mayo de 2001. En 2002 inició un proyecto EQUAL de la Unión Europea para ensayar la creación de oportunidades de empleo conjuntamente con otras personas en riesgo de exclusión social "Generando Empleo en Medio Ambiente" (GEMA), como se denominó la iniciativa (Ca stillo, 2010).

AMICA se plantea en el futuro ser una Asociación con amplia presencia social, basada en los principios de calidad y de marcado carácter innovador, que desarrolle actuaciones flexibles, en alianza con otros agentes públic os o privados, que eviten la dependencia institucional y favorezcan la imagen de las personas y el ejercicio de sus derechos (AMICA, 2010b).

\subsection{Cultura y valores de AMICA}

AMICA en su III Plan estratégico 2010-2012 (AMICA, 2010b) señala los diez valores que marcan su filosofía y cultura. Para complementar cada uno de los valores, y ofrecer una evidencia de cómo se despliegan en la organización, se señalan breves extractos recogidos del libro "Descubriendo capacidades" que ilustran, de forma concisa, cómo dicho valor está inmerso en el día a día de 
AMICA, en su organización y en su forma de ver el potencial que tiene cada persona.

Diez son los valores que marc an la filosofía del Grupo AMICA.

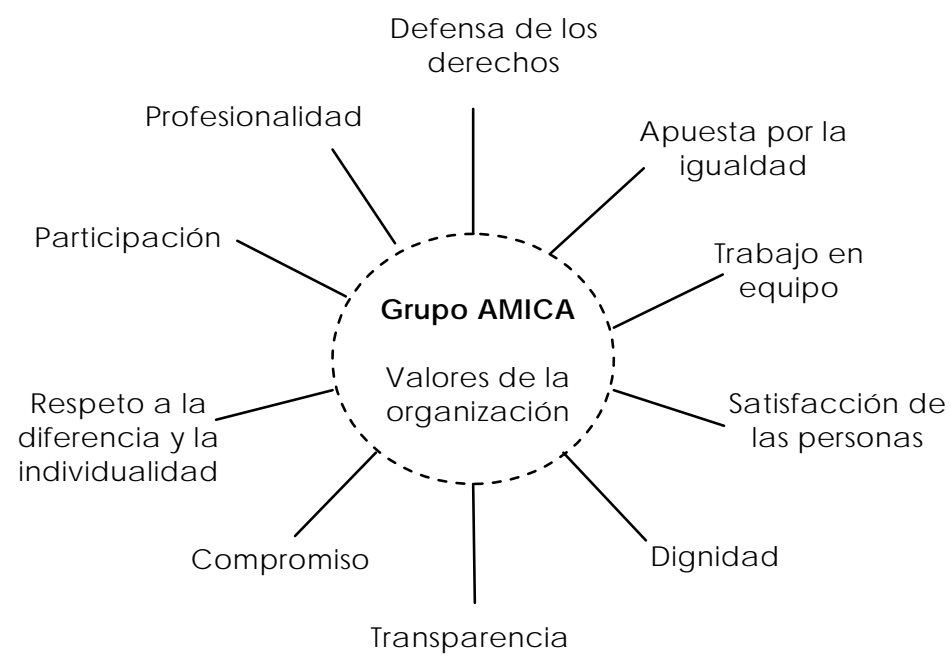

FIG URA 26. VALORES QUE MARCAN LA FILOSOFÍA AMICA (AMICA, 2010B)

1. Defensa de los derechos. Los centros deben defender los derechos fundamentales de las personas porque son la razón de ser del centro; y para ello, deben plasmar en sus valores el compromiso que adquieren sobre la defensa de los mismos (AMICA, 2010b).

AMICA (2009)

Dignificar implica reconocer los derechos de la persona, pero sobre todo potenciar todas sus capacidades, su autonomía, ya que la consideración social viene muy determinada por la posibilidad de valemos por nosotros mismos. Es clave desarrollar una imagen de valía, para demostrar todas las posibilidades individua les. (p.33) 
2. Apuesta por la igualdad. Los centros deben apostar por la igualdad entendida como el derecho y la necesidad de vivir en la comunidad y utilizar los mismos servicios y entomos que el resto de la ciudadanía (AMICA, 2010b).

Los centros deben defender la idea de que la persona con discapacidad tiene iguales derechos que el resto. Para hacerlos efectivos debe desarrollar las mismas actividades que las demás personas con los apoyos precisos, en su comunidad, su ba mio, su colegio, su trabajo. Además, desde los centros, se debe velar por la igualdad entre todas las personas que lo constituyen.

AMICA (2009)

Tener la normalización como pauta básica, posibilita la participación real de las personas y su reconocimiento como ciudadanos de pleno derecho. (p.47)

3. Trabajo en equipo. Los centros deben apostar por un estilo de trabajo basado en la participación activa de todas las personas involuc radas, teniendo en cuenta sus opiniones y posibilidades, buscando el consenso como método imprescindible para avanzar juntos, promoviendo el diálogo y compromiso con los grupos de interés (AMICA, 2010b).

AMICA (2009)

El trabajo y las ideas salen mejor generalmente cuando hay una participación colegiada, cuando se trabaja en equipo, buscando que cada cual aporte sus conocimientos, su especialización en eso 
que llamamos multiprofesionalidad, lo que permite la participación y complementariedad de diferentes especialidades. ( $p .85$ )

4. Satisfacción de las personas. Uno de los objetivos de los centros debe ser la satisfacción de las personas. Para ello deberán ser capaces de mirar con ellas hacia el futuro, centrar los esfuerzos en la búsqueda de la mejora de la calidad de vida de las personas y de sus familias, dirigir las actuaciones a la potenciación de las capacidades de las personas y a su aprobación permanente (AMICA, 2010b).

AMICA (2009)

Intentamos que el centro sea vivido como un entomo cercano, de confianza, donde cada miembro juega un papel importante, siendo primordial la satisfacción personal y la mejora en la calidad de vida. Tratamos de evitar así la despersonalización y la instituciona liza ción de los grandes centros, y de crear un ambiente familiar que favorezca la calidez, el tra to personalizado y la mayor implicación de los profesionales. (p.21)

5. Dignidad. Desde los centros se deberán desarrollar siempre acciones regidas por la dignidad, lo cual va a implicar mantenerla en cualquier circunstancia, independientemente de las limitaciones y proyectando siempre las capacidades. Del mismo modo, conlleva mejorar la imagen de las personas con discapacidad, promover la ciudadanía ejerciendo derec hos (AMICA, 2010b).

AMICA (2009) 
Proponemos continuamente la superación de expresiones de lástima hacia la "desgracia ajena", defendiendo que la discapacidad, lejos de ser una desgracia, es una manifestación de la diversidad humana, que no limita la dignidad personal. (p.36)

6. Transparencia. La transparencia en la gestión de los recursos y la demostración de su eficiencia. Todo el mundo en el centro debe tener acceso a la información relevante que se genera en la organización de manera compartida. Los dirigentes deben basar su gestión en la honradez, la claridad económica y la eficiencia, optimizando los recursos (AMICA, 2010b).

AMICA (2009)

\begin{abstract}
Nuestro compromiso de lealtad ha sido siempre el de gestionar con el máximo rigor los recursos públicos, entendiendo que con el dinero que es de todos estamos especialmente comprometidos con la transparencia y la austeridad, al mismo nivel que la propia Administración. (p.125)
\end{abstract}

7. Compromiso social. Los centros deben perseguir el compromiso social buscando lo mejor no solo para sus miembros sino para todas las personas que se encuentran en dificultad por sus limitaciones. De la misma manera, deben colaborar en la construcción, mejora y transformación de esta sociedad desde el ejercicio de la solidaridad y de la accesibilidad, donde todas las personas puedan participar plenamente y en condiciones de igualdad (AMICA, 2010b). 
AMICA (2009)

Otra de las grandes vocaciones que han ido surgiendo a lo largo de estos años es la del compromiso con las personas más necesitadas que nacen en países en los que no disponen de las posibilidades que hay para las personas con discapacidad en nuestro entomo. (p.169)

8. Respeto a la diferencia y la individualidad. El respeto a la diferencia y la individualidad es un componente fundamental de la diversidad del ser humano que supone considerar que cada persona es única, con proyectos de vida, con ilusiones, con necesidad de que se crea en sus capacidades como ser cargado de posibilidades si se le aportan oportunidades (AMICA, 2010b).

AMICA (2009)

El acompañamiento, eje de este modelo, viene marcado por el respeto a la individualidad y a la propia voluntad, desarrollando una intervención flexible adaptada a los intereses, ritmos y necesidades personales. (p.30)

9. Participación. La participación de todos, ya sean voluntarios, profesionales o personas usuarias, desde sus responsabilidades, contribuyen al proyecto común, para conseguir una mayor motivación y un mayor acierto en los servicios, compartiendo ideas, opiniones y experiencias. No hay movimiento asocia tivo sin la participación de todos (AMICA, 2010b).

AMICA (2009) 
Nuestro Código de buenas Prácticas recoge que "AMICA considera la participación como el valor fundamental de su organización y eje básico de su desarrollo, ya que sin ella no hay asociacionismo, ni transparencia, ni comunicación... Así mismo es básica la implicación en la marcha de los procesos y por tanto en los resultados finales. $(p .81)$

10. Profesionalidad. La profesionalidad debe ser entendida en los centros como la vocación por hacer bien el oficio al que se dedican los diferentes profesionales y voluntarios, con una adecuada cualificación (AMICA, 2010b).

AMICA (2009)

La profesionalización de AMICA, la búsqueda de una alta cualificación, mediante la formación continua, ha sido otra de las claves para el desarrollo de una entidad que ha procurado tener ideas claras y consensuadas de lo que había que hacer. (p.87)

AMICA ha ido evolucionado a lo largo de los años pero siempre manteniéndose fiel a sus valores que, como nos señala Castillo (2009), "han permitido construir ladrillo a la drillo esta enome inic iativa social". (p.4)

\subsection{Polític as organizativas en AMICA}

AMICA ha fundamentado su sistema de gestión en la participación. Para ello, ha desarrolla do una estructura que permite, como nos señala Castillo (2009)"la implicación del conjunto de la organización en las grandes tomas de decisiones, 
desde el Plan Estratégico que se realiza cada tres años, a la planificación anual, aprobación de presupuestos, modificaciones estatutarias, etc." (p.4)

Castillo (2009) nos señala el modelo de organización.

La Asamblea de Socios es soberana, elige cada tres años a la Junta Directiva, y ésta a su vez a la Comisión Ejecutiva. Los 140 profesionales cuentan con un órgano de participación y toma de decisiones, el Claustro, que se reúne quincenalmente, y elige al Director-Gerente, así como al Equipo de Dirección. El capital de AMICA lo constituyen las personas, sus socios, con igualdad de poder. Cada persona es un voto. (p.4)

Como base de su política organizativa, además de los valores que la sustentan, podemos encontrar seis líneas básicas de actuación que marcan la toma de decisiones en la organización.

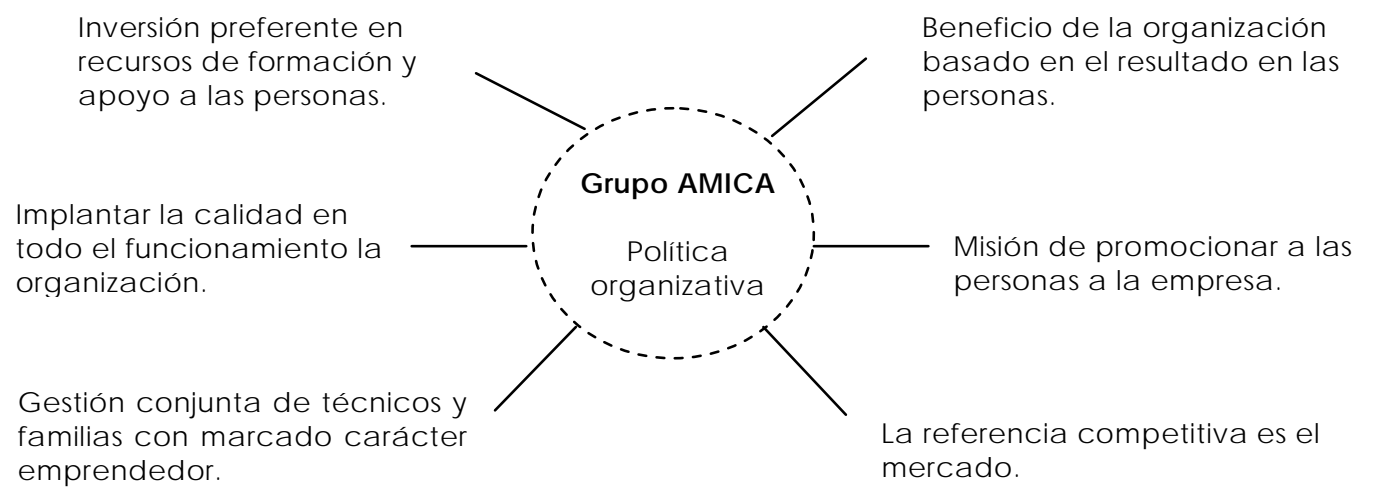

FIG URA 27. POLITICA ORG ANIZATIVA DE AMICA (ELABORACIÓN PROPIA) 
En primer lugar, se ha cambiado el beneficio industrial por los resultados en las personas. Línea de actuación que se refleja en las sociedades SOEMCA S.L y SAEMA S.L. Entre las dos organizaciones un total de 308 personas, con todo tipo de limitaciones de las cuales 43 personas tienen reconocidas discapacidades superiores al $65 \%$, cuentan con un puesto de trabajo en a mbos centros. Como nos señala Castillo (2009) la unión de las capacidades de las personas ha permitido la creación de equipos de producción que hacen viable cada uno de los proyectos iniciados.

AMICA (2010)

La meta principal del proyecto que se desarrolla es acompañar a la persona en el logro de sus objetivos, proporcionándole los apoyos necesarios, y luchando por el disfrute de iguales oportunidades. (p.13)

En segundo lugar, se mantiene constante, a lo largo de los años y de las a c tua ciones, la misión de promocionara las personas a la empresa. El objetivo fina I es que las personas se incomoren a empresas ordinarias en el mercado de trabajo. AMICA hasta la actualidad ha conseguido este objetivo con 119 personas.

AMICA (2010)

Supone sustituir el viejo esquema de que las personas tienen que acudir a centros especializados donde tratan mejor "su problema", por otro en el que son los profesionales y los servicios quienes se acercan a ellas, a sus escuelas, a sus bamios, a sus centros de trabajo, a su hogar. (p.59) 
En tercer lugar, AMICA tiene como referencia competitiva al mercado y no tiene como referente a otras entidades que trabajan para y por personas con discapacidad. Esta política organizativa hace que tengan que, como nos señala Castillo (2009) "acudir directamente al mercado con marca propia, mantener y fidelizar una amplia cartera de clientes que proporcionen estabilidad a las empresas, han constituido una práctica desde los inicios de Centro Especial de Empleo". (p.5.)

AMICA (2010)

La a puesta por la innovación supone asumir el riesgo a la crítica, a la incomprensión como consecuencia a quedar fuera de las protecciones institucionales o pertenencia a federaciones. AMICA ha tenido, y tiene, una singladura en ocasiones difícil, por no crear centros al uso como los ocupacionales, lo que ha dificultado su financiación; y en otras para pertenecer a alguna federación, por defender el trabajo conjunto con todas las discapacidades. (p.132)

La cuarta línea de actuación, que marca el buen hacer de la a sociación, se basa en la necesidad de una gestión conjunta de técnic os y familias con marcado carácter emprendedor. Este sistema de gestión se ha llevado a cabo hasta sus últimas consecuencias manteniendo el carácter democrático en la toma de decisiones en el conjunto de los servicios de AMICA, que funciona en forma de red organizada en base a un mapa de procesos, ya que la entidad tiene implantada la gestión por proc esos (Ca stillo, 2009).

AMICA (2010)

Hemos trabajado conjuntamente profesionales, familia res y personas con discapacidad. Gestión conjunta que no podría existir sin un componente de confianza excepcional. Cuando nos planteamos 
esta idea, no había organizaciones en este país de padres y de profesionales que trabajaran de esta forma. Sí existían asociaciones de padres que contrataban profesionales, o cooperativas, pero no era conocido este modelo de gestión común, en el que cada cual ejerce un papel importante: los profesionales tienen la tarea de buscar nuevas soluciones para las personas, las familias la de defender la calidad, y las personas usuarias de participar activamente en lo que atañe a su vida. (p.64)

La quinta línea que nos da la pauta de los niveles de excelencia existentes en la organización, es la de implantar la calidad en todo el funcionamiento la organización. Desde AMICA (Castillo, 2009) se entiende que la calidad es una guía, una herramienta que permite la mejora continúa de su funcionamiento, en la que todas las personas de la organización tienen que estar comprometidas con esta cultura de orientación al cliente que da sentido a todo su trabajo.

AMICA (2010)

AMICA ha a postado tradic ionalmente por la calidad de los servicios que presta, contando continuamente con la opinión de los usuarios para lograr su satisfacción, y como un valor que favorece los comporta mientos étic os en el quehacer cotidiano. (p.73)

La sexta y última línea que señalamos, está basada en la inversión preferente en recursos de fomación y apoyo a las personas. Para ello desde AMICA se apuesta por compartir el conocimiento realizando una permanente labor de intercambio entre profesionales y con otras organizaciones, haciendo de la transferencia de experiencias un método permanente de trabajo que ha constituido nuestra mejor herramienta de gestión del conocimiento. 
AMICA (2010)

El trabajo y las ideas salen mejor generalmente cuando hay una participación colegiada, cuando se trabaja en equipo, buscando que cada cual aporte sus conocimientos, su especialización en eso que llamamos multiprofesionalidad, lo que permite la participación y complementariedad de diferentes especialidades. ( $p .85$ )

\subsection{La participación como eje de la gestión}

La Asociación, formada por familiares, personas con discapacidad y profesionales, representa un modelo de gestión directa y participación de las personas afectadas, tanto en los órganos de gobiemo, como en las actividades de mantenimiento y mejora de los centros, persiguiendo así el principio de solidaridad y a poyo mutuo entre las familias a fectadas (AMICA, 2010a).

Con cada una de las personas se intenta llevara cabo un itinerario personal ajustado a sus intereses, necesidades y capacidades con el objetivo de favorecer su promoción personal e integración social. Este itinerario personal se fundamenta en un modelo de intervención basado en una atención global e individua liza da de las personas, procurando el acercamiento de estos recursos a su entomo y la impresc indible colaboración familiar.

AMICA, acorde a su sistema de gestión y su política de calidad y en pro de de su misión, visión y valores, despliega procesos estratégicos, de prestación de servicios y de a poyo.

Dentro de la organización, destaca la implicación de los profesionales. En el Claustro, que mantiene dos reuniones mensuales, participan 135 profesionales. Se cuenta con una dirección-gerencia común a la Asociación y sus entidades 
participadas que coordina los procesos estratégicos y garantiza el buen funcionamiento de los procesos de a poyo. La Asociación cuenta asimismo con una dirección técnica, al igual que cada una de las entidades participadas en func ionamiento, que forman parte del equipo de gestión junto con los responsables de los procesos de AMICA y de los centros (AMICA, 2010a).

Este equipo se rige por las responsabilidades definidas en el Mapa de Procesos, cuyo funcionamiento es guia do por un sistema de Gestión por medio del cual los responsables de proceso toman las decisiones. La definición del alcance de cada proceso, así como los objetivos e indicadores, ha permitido que, a pesar del crecimiento de la entidad, no se haya perdido la implicación y el sentimiento de pertenencia de los responsables. La Gestión diaria de los Procesos cuyo eje y motivo de existencia es el apoyo a la persona con discapacidad y su familia, queda recogido en el proceso de Dirección Técnica.

Mensualmente, se realizan dos reuniones de seguimiento y coordinación de los programas una con los responsables de los Procesos de Prestación de Servic io y otra con los Directores de centros (AMICA, 2010a).

En 2009 se establece un nuevo sistema de reuniones y despachos de temas ejec utivos entre los distintos miembros del Equipo de Procesos que permite, a gilizar la toma de decisiones, una mejor gestión del tiempo por parte de todos sus integrantes, así como mantener informado al resto del equipo a través del acta mensual únic a (AMICA, 2010a). Este sistema facilita el establecimiento de tiempos y responsables para la ejecución de las acciones y permite realizar despachos virtuales.

Cada tres años, se procede a la elección de cargos, tanto de la Junta Directiva como del equipo de procesos y representantes de las personas usuarias. En ambos casos, se cuenta con la participación de todas las personas de la entidad. El equipo de procesos rea liza un análisis de su funcionamiento, previo a la 
convocatoria electoral, así como de las acciones de mejora necesarias (AMICA, 2010a). Con carácter anual, la J unta Directiva expone en la Asamblea de socioslos resultados de la memoria de actividades y de la memoria económica, haciendo un balance de los resultados obtenidos y un a nálisis de las causas y consecuencias de los aspectos que han revestido mayor dificultad. Siguiendo el principio de transparencia en el que se basa la entidad desde su creación, AMICA realiza desde 1996 auditorias económic as externas en cada ejercicio.

Los líderes han propiciado, desde 2004, la realización del Informe de Transparencia y Buenas Prácticas promovido por la Fundación Lealtad. Han demostrado la accesibilidad de la entidad y facilitado la información necesaria para las auditorias oficiales (AMICA, 2010a).

\subsection{Rec ursos de AMICA}

El Grupo AMICA cuenta con diversos centros en la Comunidad Autónoma de Cantabria (Torrelavega, Reinosa, Viveda, Santander y Maliano) y en Bolivia a demás de prestar sus servic ios a otra s entida des y rea liza r a c tivida des diversa s.

\subsubsection{Centro de recursos Agustín Bárcena Cruz}

Desde 2002, el Centro de recursos Agustín Bárcena Cruz, ubicado en Torrelavega, es la sede social y el centro de referencia para el conjunto de la entidad: familias, personas con discapacidad, profesionales y socios. En él se desarrollan las actividades propias de Sede Social: reuniones de los Órganos de Gobiemo y la coordinación de la actividad asociativa. Asimismo es la sede de la Dirección de AMICA, SOEMCA y SAEMA, y de varios procesos de prestación de servicios de apoyo. Es centro de referencia del resto de los centros y servicios, y el lugar donde se coordinan el conjunto de profesionales. Cuenta con un amplio Tesis Doctoral 
espacio dedicado tanto a las actividades formativas, como lúdicas y de apoyo mutuo (AMICA, 2007).

\subsubsection{Centro agnupado de atención de día}

Centro Agrupado de Atención de Día se compone de trescentros: La Barca, La Vega y Sotileza (AMICA, 2007).

Centro de día La Barca. Este centro es el pionero de la red de AMICA y está ubica do en Viveda. Inició su actividad en 1984 como respuesta a un colectivo de personas con deficiencia mental grave que, habiendo teminado su proceso de escolarización, requerían de recursos que les permitieran convivir con sus familias $y$, al mismo tiempo, promocionar en su desarrollo personal. El centro tiene una capacidad de 15 plazas.

Centro de día la Vega. El centro esta situa do en Torrelavega y tiene una capacidad máxima de 20 plazas lo cual permite una atención personalizada. Está destinado a un grupo de personas que por sus caracteństicas físicas y psíquicas necesitan desarrollar una serie de habilidades. Se trata de personas con lesiones cerebrales, daño cerebral sobrevenid o y enfermeda des degenera tivas.

Centro de día Sotileza. El centro se encuentra en Santander y se estructura como un grupo familiar. Dispone de 20 plazas para personas a dultas afectadas por disc a pacidades físic as graves y psíquic as a socia das, que necesitan desarrollar, rehabilitar y/o mantener habilidades de autonomía personal y social (AMICA, 2007). 


\subsubsection{Centro Horizón}

Horizón es un centro creado en Torrelavega para buscar experiencias innovadoras en el área de la integración social de las personas con discapacidad, programa en el que AMICA ha participado desarrollando con éxito acciones de formación para el empleo.

El Centro dispone de aulas para la realización de: Formación Básica y Prelaboral, Programa de Garantía Social de Lavandeńa, cursos de formación laboral en: lavandería y confección industrial, a poyo personal a trabajadores y alumnos, acciones de formación continua de trabajadores, formación, asesoramiento y apoyo familiar, rehabilitación en logopedia y fisioterapia y ocio, deporte y acceso a la cultura. Este centro cuenta con dos núcleos de actividad productiva: Confecciones Albor y Lavandería Alba 2.

Pretende la continuidad de la formación de las personas usuarias en un centro especial de empleo, con una estructura con diseño empresarial, en el área de confección, alquiler y lavado de ropa, especializado en hostelería, hospitales y residencias. La integración de los trabajadores en el medio ordinario de trabajo culmina el proceso formativo y de integración laboral del Proyecto.

\subsubsection{Centro Entomo}

"Entomo" es un Centro Especial de Empleo, situado en Santander, integrado en el modelo de gestión de residuos del Gobiemo de Cantabria y gestionado por SOEMCA para la formación en el trabajo como paso previo a la incorporación en el empleo ordinario de personas con discapacidad (AMICA, 2007). 
En este centro existe una zona de prestaciones genera les que cuenta con servicios de valoración y atención social para la población de la zona de Santander. Asimismo, se desarrollan diversas acciones formativas y de apoyo: Programa de Garantía Social, Formación Básica y Prelaboral, Rehabilitación Laboral del Proyecto Inicia, Formación Laboral en recuperación y selección de residuos urbanos y recuperación paisajística, apoyo personal, acciones de orientación laboral, formación de familias, ocio, fisioterapia y logopedia (AMICA, 2007).

\subsubsection{Centro de formación y empleo Marisma}

El Centro de formación y empleo Marisma está en Maliaño y dispone de un área destinada a la realización de actividades formativas de Formación Básica, Apoyo Personal a trabajadores y alumnos, acciones de forma ción continua de trabajadores y a sesoramiento y a poyo familiar.

En el mismo Centro se encuentra la Lavandería Alba 3, que está diseñada específicamente para el tratamiento e higienización de ropa hospita la ria así como de ropa hotelera (AMICA, 2007).

El proyecto empresarial permite emplear a personascon todo tipo de discapacidades, lo que convierte a esta actividad en idónea para dar oportunidades de empleo a un gran número de personas que previamente han sido formadas en los programas de integración social y laboral de AMICA (AMICA, 2007). 


\subsubsection{Viviendas}

\section{Casa Helios}

La Vivienda Helios está situada en Torrelavega y forma parte del proyecto de Vida Autónoma que AMICA desarrolla para la atención a personas con grave discapacidad. Son personas con necesidades de alojamiento y apoyo en las actividades de la vida diaria. Combina sus servicios con los de atención de día, ofreciendo de esta manera un modelo innovador de atención globalizada durante 24 h, los 365 días y cuenta con 16 plazas. Las personas que viven en la Casa pasan por un proceso de valoración y seguimiento continuo y desarrollan programas terapéuticos ind ividua liza dos (AMICA, 2007).

\section{Vivienda de "Matías Sainz"}

Situada en Santander, fue puesta en marcha en 2005 para dar alternativas de alojamiento a personas que presentan problemas graves de movilidad. Cuenta con 10 plazas para personas que acuden habitualmente a los centros de día de AMICA (La Vega y Sotileza) (AMICA, 2007).

\section{Vivienda de formación para la vida independiente}

El objetivo de esta vivienda, ubic ada en Torrelavega, es responder a los deseos de Vida Independiente que plantean personascon discapacidad y sus fa milias.

El programa a desa rrollar persigue dar oportunidades para aprender a vivir de manera independiente. Apoyar y acompañar a la persona en este proceso, dotándola de estrategias para resolver situaciones cotidianas, tomar sus propias decisiones, organizarse y aprender a llevar una casa (AMICA, 2007). 
Participan un grupo de ocho personas, apoyados por un equipo de profesionales. De esta manera, se favorece el mejor conocimiento de cada persona y el establecimiento de relaciones más cercanas entre todos los miembros.

\subsection{Conc lusiones del capítulo}

AMICA es más que un Grupo asociativo, es más que las personas que forman parte de ella, es una comunidad que se construye día a día mediante la participación en una práctica compartida y cuyos miembros comparten una historia común. Una historia que no ha sido fácil pero que tiene resultados con nombres y apellidos que hace que todo haya tenido sentido.

El trabajo realizado en AMICA a lo largo de sus veinticinco años de existencia ha hecho posible que en la actualidad exista una comunidad de personas que luchan por los derechos de las personas con algún tipo de limitación, que luchan porque las personas con limitaciones y, con muchas capacidades, puedan ocupar el lugarque les corresponde en la sociedad; luchan porque AMICA pueda apoyar a las personas en los contextos ordinarios para que puedan llevara cabo su proyecto de vida.

Los elementos clave de la inclusión: presencia, aprendizaje y participación están presentes en la cultura, política y prácticas que se llevan a cabo en todos los centros del grupo. Como se ha visto a lo largo del capítulo, en AMICA se reflejan las características de una organización inclusiva, que según Ainscow (1999) son la ausencia de toda forma de discriminación, la justicia social, la equidad, los derechos humanos y la no discriminación (Barton, 2009; Meza, 2010). 
Los valores inclusivos que caracterizan a AMICA van más allá de los propuestos por Booth (2005) y, a unque alguno de ellos coinciden, como su apuesta por los derechos de la persona, la igualdad o la participación, los valores de la Asociación han ido evolucionando junto con la cultura y el momento que vive la comunidad y se han ido ajustado a una filosofía de trabajo cada más centrada en la defensa de los derechos, la calidad y la mejora continua.

Las políticas que se promueven desde AMICA reflejan los valores y la cultura que sustenta a la organización y se elaboran desde una participación plena de todos los órganos de la Asociación. 

SEG UNDA PARIE.

INVESTIGACIÓN EMPÍRICA 

CAPITLLO 5.

Adaptación del INDEX para la inc lusión para centros para personas con discapacidad

(Fase I y Fase II) 


\subsection{Presentación}

Como hemos venido señalando en la fundamentación teórica de la presente Tesis Doctoral, las orga nizaciones inclusivas constituyen un entra mado en el que tres dimensiones: cultura, políticas y prácticas están interrelaciona das para garantizar que las personas con algún tipo de limitación puedan descubrir todas sus capacidades, a lcanzar las máximas cuotas de autonomía que sean posibles y formar parte de una comunidad en la que compartan compromiso e identidad (Blair, 2010; González, 2008; Booth y Ainsc ow, 2002).

También hemos a na liza do cómo la utilización de instrumentos como el Index para la inclusión puede ayudar a las organizaciones a poner en marcha un proceso de autoevaluación (Booth y Ainscow, 2002) de las tres dimensiones señaladas y facilitar de este modo el desarrollo de procesos de planificación y colaboración, acordes a los valores y contextos, que sean sostenibles en el tiempo (Rustemier y Booth, 2005).

Partiendo de estas premisas nos planteamos la realización de una investigación que tenga como objetivos (1) adaptar el Index para la Inclusión (Booth y Ainscow, 2002) para su aplicación en centros que prestan servicios a personas con discapacidad (2) construir un Cuestionario de Evaluación de los Indicadores del Index con adecuadas propiedades psicométricas que nos proporcione evidencias de la adecuación de la adaptación y de la pertinencia de los cambios que se han realizado, y finalmente (3) evaluar la inclusión en un centro que presta servicios a personas con discapacidad partiendo de un instrumento elaborado desde losindic adores del Index adaptado. 
CAPITULO 5. Adaptación del Index para la inclusión para centros para personas con disc apacidad (Fase I y Fase II)

Varias razones justifican este trabajo; en primer lugar, existe un escaso desarrollo de instrumentos que permitan a las organizaciones poder evaluar la situación en la que se encuentran respecto a los valores y procesos inclusivos, y en segundo lugar, las herramientas de trabajo y de evaluación existentes se centran únic a mente en contextos educativos.

Los objetivos marcados para la presente Tesis Doctoral nos han llevado a diseñar un proceso investigador basado en cuatro fases.

En la primera fase, abordando el primer objetivo de la investigación, se ha realizado una adaptación del Index para centros que prestan servicios a personas adultas con algún tipo de discapacidad, partiendo de los fundamentos teóricos señalados en la primera parte de la Tesis.

La segunda fase, acorde con el segundo objetivo, se inicia con un proceso para la elaboración de un instrumento, Cuestionario de Evaluación de los Indic a dores del Index (versión preliminar) que nos permita someter a la adaptación del Index realizada en la fase anterior a un proceso de validación de su contenido porparte de Jueces Extemos.

En la tercera fase y, partiendo de los resultados de la fase anterior se diseña un segundo proceso de adaptación del Cuestionario de Evaluación de los Indic adores del Index (versión definitiva) para pasar posteriomente a realizar un a nálisis de las propieda des psic ométric as del mismo.

En la cuarta y última fase, alineándonos con el tercer objetivo de la investigación, se diseña un instrumento de evaluación de la inclusión elaborado desde los indicadores del Index adaptado, Cuestionario de Indicadores de Inclusión, que nos servirá para evaluar la inclusión en un centro que presta servicios a personas con discapacidad como es AMICA, centro de referencia de la presente investigación. 
Este quinto capítulo comienza con la descripción de los objetivos (apartado 5.2) e hipótesis (apartado 5.3) que orientan la investigación. Posteriomente, en el apartado de metodología (5.4) se presentan de modo descriptivo las características de la investigación y se incluyen apartados correspondientes al diseño de la investigación y al procedimiento seguido en las dos primeras fases y, se exponen las características de los participantes del estudio en el proceso de validación de la Fa se II. Habiendo descrito la investigación y los instrumentos que se han utilizado en estos primeros momentos de la investiga ción, el último a partado (5.5) se dedica a los resultados obtenidos en ambas fases. En él se incluyen, los a ná lisis sobre la validez de contenid o y de construc to, y el a nálisis sobre la fiabilidad del Cuestionario de Evalua ción de los Indic a dores del Index elaborado en la Fase II.

Las Fases III y IV de la investigación se reflejan en el capitulo 6.

\subsection{Objetivos de la investigación}

En el presente estudio empírico se han pretendido tres cuestiones fundamentales: (1) adaptar el Index para la Inclusión, diseñado origina Imente para el ámbito escolar (Ainscow y Booth, 2000), para su aplicación en centros que prestan servicios a personas con discapacidad, (2) construir un Cuestionario de Evaluación de los Indicadores del Index con adecuadas propiedades psic ométric as que nos proporcione evidencias de la adecuación de la adaptación y de la pertinencia de los cambios realizados partiendo de una base teóric a sólida, y (3) evaluar la inclusión un centro que presta servicios a personas con discapacidad determinando el posible impacto de variables sociodemográficas en 
CAPITULO 5. Adaptación del Index para la inclusión para centros para personas con disc apacidad (Fase I y Fase II)

la percepción de la inclusión. Estos objetivos generales se concretan en los siguientes objetivos específic os:

a. Adecuar el Index para la inclusión (enfoque, teminología, etc.) al contexto socio-educativo de los centros que prestan servicios a personas con discapacidad.

b. Someter a la adaptación del Index a un proceso de validación de su contenido (validez aparente) por parte de jueces expertos, profesionales, personas usuarias y familia res de personas con disca pacidad.

c. Recoger las valoraciones a portadas por los distintos informa ntes para conformarla estructura final del Index.

d. Recoger valoraciones de los jueces que nos pemitan valorar la fiabilidad de las Dimensiones, secciones, indicadores y preguntas que aparecen en el anexo del Index.

e. Evaluar la percepción de la inclusión en un centro que presta servicios a personas con discapacidad utilizando un cuestionario elaborado partiendo de los indic adores del Index.

f. Analizar las valoraciones de los miembros de un centro que presta servicios a personas con discapacidad sobre la inclusión utilizando un cuestionario elaborado partiendo de los indicadores del Index.

\subsection{Hipótesis de la investigación}

En la presente investigación, partiendo de los objetivos definidos, se esperan validar las hipótesis que se reflejan a continuación.

Las hipótesis de investiga ción para las Fases I y II son: 
- Hipótesis 1. El Index para Inclusión presentará un elevado porcentaje de contenidos y preguntas susceptibles de ser empleados en centros de personas con disc apacidad.

- Hipótesis 2. El Index para Inclusión adaptado para centros de personas con discapacidad presentará adecuados niveles de fiabilidad, entendida como concordancia entre jueces, respecto a la pertenencia de contenidos del Index a sus respectivas categońas.

- Hipótesis 3. El Cuestionario de Evaluación de los Indicadores del Index (CEII) (versión preliminar) presentará adecuados niveles de fiabilidad entre jueces pertenecientes a diferentes grupos de la comunidad a nalizada (profesiona les, familias, usua rios, equipo).

Las hipótesis de investigación para las Fases III y IV son:

- Hipótesis 4. El Cuestionario de Evaluación de los Indicadores del Index (versión definitiva) mostrará adecuadas propiedades psicométricas de fiabilidad (acuerdo entre jueces, consistencia intema) y validez (va lidez a parente y validez de construc to).

- Hipótesis 5. El Cuestiona rio de Indica dores de Inc lusión, a plic ado en el centro de referencia seleccionado para la presente Tesis, obtendrá eleva das puntuaciones en las tres dimensiones en las que se basa el instrumento: cultura (comunidad y valores), políticas y prácticas.

- Hipótesis 6. Los resultados obtenidos con el Cuestionario de Indicadores de Inclusión, en el centro de referencia, no mostrarán diferencias signific ativas en las puntuaciones obtenidas en función del género o la edad, o el rol que se desempeñe en el centro. 
- Hipótesis 7. Los resultados obtenidos con el Cuestionario de Indicadores de Inclusión, en el centro de referencia, no mostrarán diferencias signific ativas en las puntuaciones obtenidas en función del centro con el que se tenga relación y con los años de vincula ción con la Asociación.

\subsection{Método}

Como ya se ha señalado, la presente investigación se desarrolla a través de cuatro fases a través de las cuales se realizará una adaptación del Index para la Inclusión para centros de atención a personas con discapacidad (Fase I), se elaborará un cuestionario que nos pemita someter a la adaptación del Index a un proceso de validación de su contenido por parte de Jueces Extemos (Fase II). Con los resultados obtenidos en la segunda fase se pasará a la Fase III en la que realizará una readaptación del instrumento y se analizarán las propiedades psicométricas del Cuestionario de Evaluación de los Indicadores del Index (CEII), para obtener la versión definitiva. En la cuarta fase, y partiendo de los indic adores definitivos, se elaborará el Cuestionario de Indicadores de Inclusión (CII) y se aplic ará a AMICA.

En la Figura 28 se exponen las diferentes actividades realiza das a lo la rgo del proceso. En el presente capítulo nos centra remos en la exposición de las Fases I y II. En el ca pítulo posterior detalla remos los resulta dos derivados de las Fases III y IV. 
Fase I. Adaptación del Index para la Inclusión

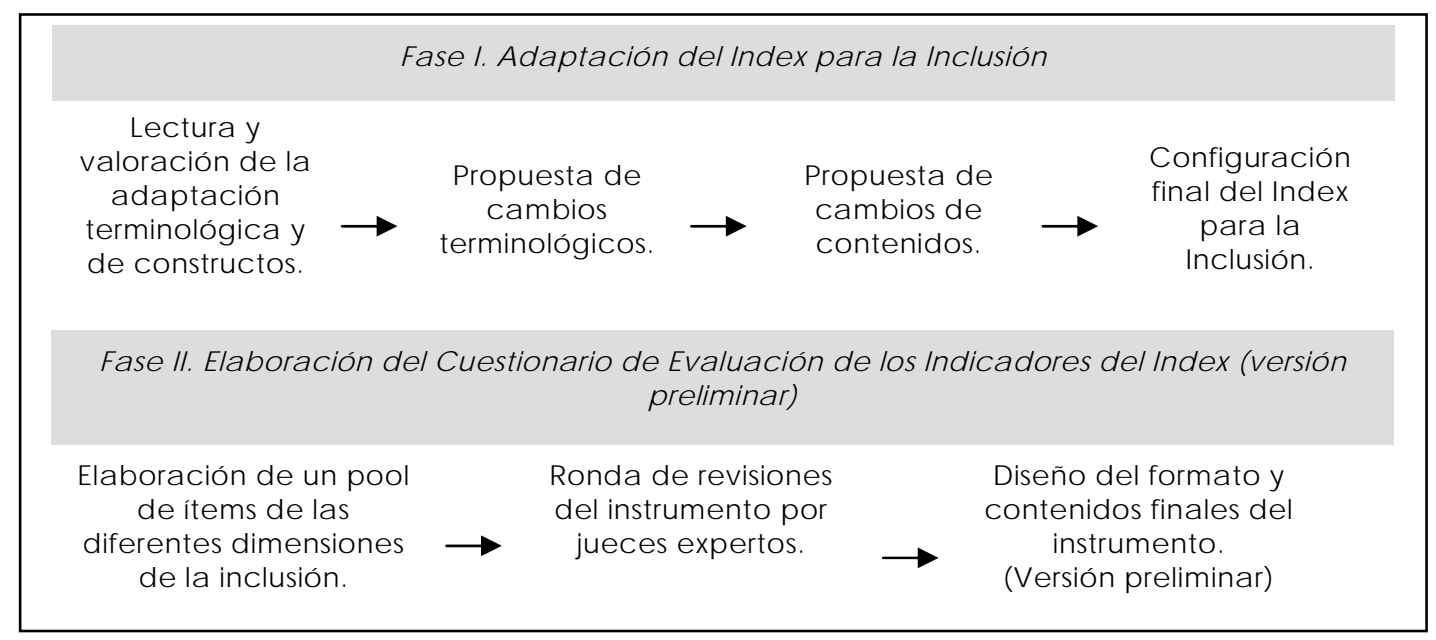

Fase III. Adaptación y a nálisis de propiedades psic ométric as del Cuestiona rio de Evaluación de los Indic a dores del Index (versión definitiva)

Reelaboración
de la versión
preliminardel
Cuestionario $\rightarrow \begin{gathered}\text { Valoración del } \\ \text { instrumento por } \\ \text { parte de jueces } \\ \text { extemos. }\end{gathered} \rightarrow \begin{gathered}\text { Análisis de } \\ \text { fiabilidad y } \\ \text { validez. }\end{gathered} \rightarrow \begin{gathered}\text { Cuestionario de } \\ \text { Evaluación de los }\end{gathered}$ Indicadores del Index.

Fase IV. Diseño y a plic a ción del Cuestionario de Indic a dores de Inclusión

\begin{tabular}{|c|c|c|c|}
\hline $\begin{array}{l}\text { Diseño y } \\
\text { aplicación del } \\
\text { cuestionario. }\end{array}$ & $\longrightarrow \quad \begin{array}{c}\text { Análisis de los } \\
\text { datos } \\
\text { recogidos. }\end{array}$ & $\longrightarrow \quad \begin{array}{r}\text { Resultadosy } \\
\text { conclusiones. }\end{array}$ & $\longrightarrow \quad \begin{array}{c}\text { Sugerencias } \\
\text { para la } \\
\text { investigación. }\end{array}$ \\
\hline
\end{tabular}

FIGURA 28. PROCESO EMPÍRICO PARA LA ADAPTACIÓN DEL INDEX PARA LA INCLUSIÓN Y PARA LA CONSTRUCCIÓN DE UN INSTRUMENTO DE EVALUACIÓN DE LA INCLUSIÓN

\subsubsection{Diseño y procedimiento}

El estudio parte de un diseño de tipo descriptivo, centrado en el proceso de adaptación del Index (Fase I) y en la construcción de un instrumento con propiedades psic ométric as adecuadas (Fase II). Para ello se han empleado jueces, a ná lisis descriptivos y a ná lisis de las propieda des de un instrumento de medida.

La investigación de esta primera parte, fases I y II se llevó a cabo desde Octubre de 2009 a J unio de 2010. 
La primera fase del estudio se ha centrado en la adaptación del Index para la inclusión de Booth y Ainscow (2002) en su versión en castellano. En primer lugar se ha realizado una exploración teórica centrada en tres áreas: la inclusión y el instrumento sobre el que pivota el estudio, las tres dimensiones que propone el Index: cultura, política y prácticas y, por último, las Comunidades de Prác tic a como altemativa al proceso de trabajo que propone el Index original. Todo ello se ha realizado con el objetivo de realizar una adaptación teminológica y de constructos.

Una vez elaborado el marco teórico-conceptual sobre el que se basa el estudio se ha realizado una propuesta de cambios terminológicos y de contenidos para a daptar el instrumento al nuevo contexto de a plic ación.

La investigación teórica se ha complementado con visitas a los diferentes centros de AMICA que han servido de referente para el presente estudio y se han realizado diferentes encuentros con miembros del equipo directivo, profesionales de la organización y personas usua rias de diferentes centros y viviendas.

Para finalizar esta fase se ha modificado el Index para la inclusión para poder aplicarse a los centros que proporcionan servicios a personas con disca pacidad (ver apartado 5.4.4.1).

La realización de la adaptación del instrumento se llevó a cabo íntegramente por la autora de la presente Tesis Doctoral, en coordinación con las directoras de la misma.

En la segunda fase del estudio, y partiendo de la adaptación del Index para la inclusión realizada, se ha elaborado un pool de ítems de las diferentes dimensiones que propone el Index: cultura, políticas y prácticas, que ha servido de base para la elaboración del Cuestionario de Evaluación de los Indicadores del Index. 
Una vez realizados los cambios que se han considerado oportunos para la adaptación, se ha llevado a cabo un proceso iterativo de revisiones del instrumento por parte de jueces expertos, tanto miembros de la Universidad de Salamanca como de AMICA.

Con las aportaciones realizadas desde el mundo académico y desde la práctica directa, se han realizado los ajustes pertinentes consistentes principalmente en simplificar algunos conceptos, indicadores y preguntas, tanto del Index como del cuestionario.

La consulta a jueces requirió un contacto previo con el coordinador del proceso en AMICA, con el que se acordó el momento más adecuado para la validación, así como sobre la selecc ión de los participantes y el proceso a seguir en las sesiones con las personas enc uestadas.

Para la validación intema de la adaptación del instrumento se ha contado con 14 encuestados o jueces extemos, de los cuales 12 pertenecen a la comunidad de AMICA y 2 son profesionales extemos a la asociación. En la Tabla 06 se indic an los centros a los que están vinculados los participantes de AMICA.

\begin{tabular}{|l|c|}
\hline Centro & Partic ipantes \\
\hline Centro de Recursos Agustín Barcena & 7 \\
\hline Centro Horizon & 2 \\
\hline Centro de día La Vega & 1 \\
\hline Centro de día La Barca & 1 \\
\hline Centro Entomo & 1 \\
\hline
\end{tabular}

TABLA 06. CENTROSDE AMICA PARTICIPANTES.

Concretamente, el Cuestionario de Evaluación de los Indicadores del Index (CEII) se aplicó en Torrelavega (Cantabria) en el Centro de Recursos de AMICA el 19 de marzo de 2010. Se realizaron cuatro sesiones para los cuatro colectivos que 
CAPITULO 5. Adaptación del Index para la inclusión para centros para personas con disc apacidad (Fase I y Fase II)

iban a participar en la validación. En la primera sesión participaron tres trabajadores de AMICA y en la segunda, los familiares; en la tercera las personas usuarias y en la última, los miembros del equipo directivo. Cada sesión, de una duración aproximada de dos horas, se inició con una explicación breve de la investigación de la que se deriva el cuestionario, y posteriomente, se procedió a presentar el instrumento y el proceso para su cumplimentación.

En el caso de las sesiones con las familias y las personas usuarias, fue necesario ir leyendo cada indicador y aña dir una explicación basándonos en los enunciados que se incluyen en el cuestionario. Posteriomente cada persona señalaba su valoración en el cuestionario. En la sesión con las personas usuarias, a modo de apoyo, participó un miembro del equipo directivo de AMICA, para dar, en unos casos, los apoyos físic os necesarios para cumplimentar el cuestionario a una de las personas participantes $y$, en otros, pautas de referencia que relacionasen el indicador que se estaba presentando con aspectos relacionados con la vida diaria en los centros de AMICA.

\subsubsection{Participantes}

El estudio que se presenta se ha realizado de forma integra en la Asociación AMICA que trabaja para promover el pleno ejercicio de los derechos de las personas con discapacidad y sus familias. Se constituyó el 12 de junio de 1984 y fue declarada de Utilidad Pública el 26 de marzo de 1993 (AMICA, 2010a, 2010b). Cuenta actualmente con 1.060 socios, 26 centros y núc leos de actividad repartidos por toda la Comunidad Autónoma de Cantabria (España) y presta apoyo a una media de 950 personas a nua Imente.

El grupo AMICA cuenta con una plantilla (véase Tabla 07), en el momento de la realización de la investigación, de 527 trabajadores, 106 en Asociación 
AMICA, 295 en SOEMCA y 126 en SAEMA, de los cuales 350 son personas con disc a pacidad (PCD).

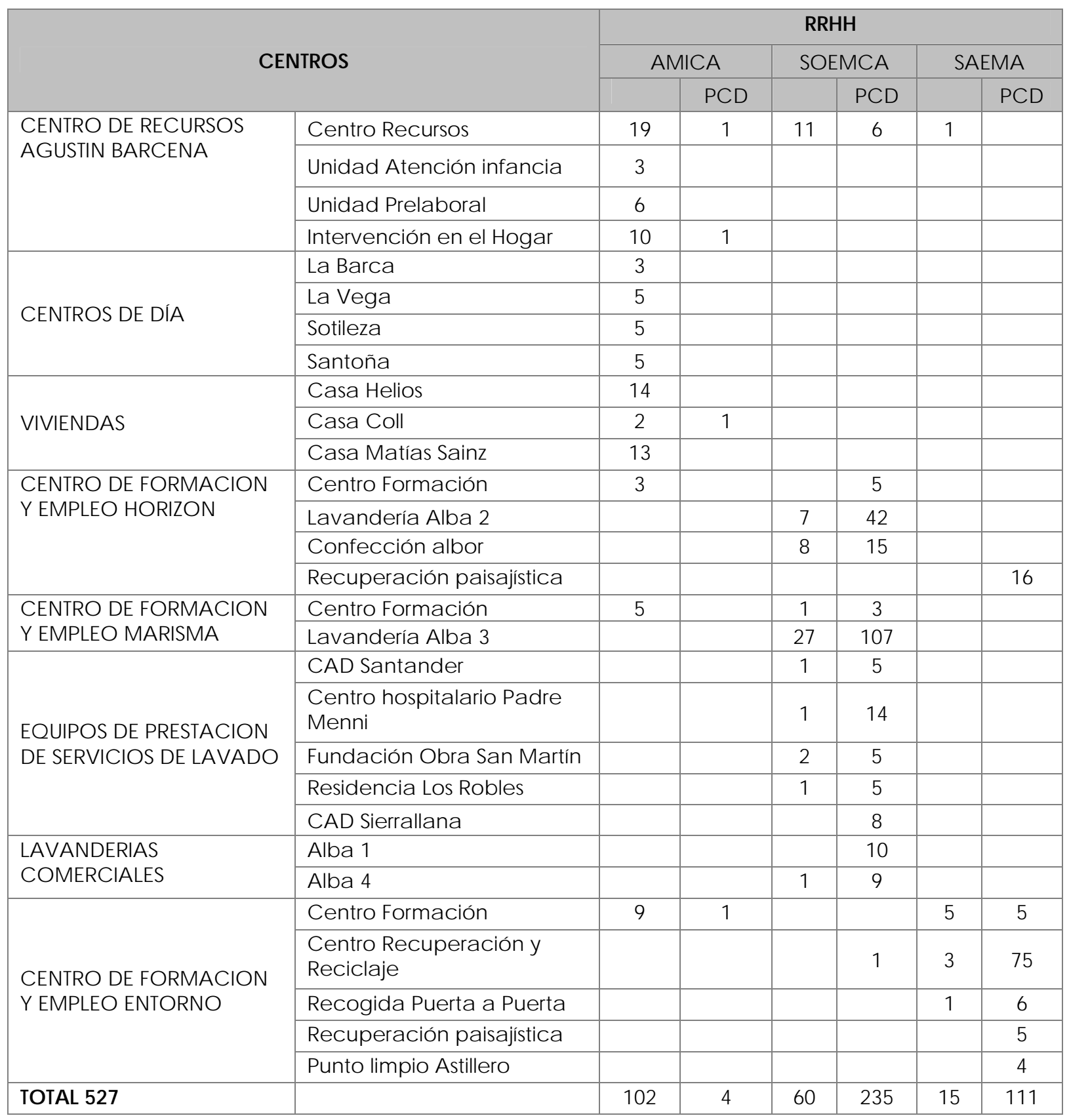

TABLA 07. PRO FESIO NALES Q UE TRABAJ AN EN LOS DIFERENTES C ENTROS DE AMICA.

En el cuarto capítulo de la presente tesis se ha expuesto con mayor detalle tanto la situación actual como futura de la Asociación (apartado 4.2), la cultura y 198 Tesis Doc tora I 
CAPITULO 5. Adaptación del Index para la inclusión para centros para personas con disc apacidad (Fase I y Fase II)

valores de AMICA que marcan su filosofía (apartado 4.3), las polític as orga nizativas de AMICA (apartado 4.4.) apoyadas en su apuesta por la participación (apartado 4.5.), y los centros con los que cuenta la asociación en la Comunidad Autónoma de Cantabria (Torrelavega, Reinosa, Viveda, Santander y Maliano) desde dónde ofrece sus servicios (aparta do 4.6).

Una vez que se estableció contacto con AMICA y accedió a participar en la investigación se continuó con la selección de los participantes para la validación intema de la adaptación del instrumento.

Los criterios para la selección de los participantes fueron que tuvieran relación directa con el centro en el momento del desa rollo de la investigación y que estuvieran dispuestos a partic ipar de forma volunta ria.

Otro aspecto, de especial relevancia para la investigación es que los participantes, por la filosofía del Index para inclusión, debían representar a toda la comunidad de AMICA. Por ello, la muestra que se debía seleccionar debía estar formada por representantes del equipo directivo, de los profesionales del centro, de las personas usuarias y de las familias.

La investigación se complementó con la colaboración de dos profesionales extemos a AMICA miembros de la Universidad de Salamanca y con fuerte relación con el ámbito de estudio. El recluta miento de los participantes se realizó desde la dirección del centro que se encargó de invitara los potencialesparticipantes.

La investigación contó con un total de 14 participantes, de los cuales 12 pertenecen a la comunidad de AMICA y 2 son profesionales extemos a la asociación. De las personas de AMICA han participado tres miembros del equipo directivo, tres profesionales de atención directa, tres familiares y tres personas usuarias de los servicios de la asociación. Los profesionales estaban adscritos a cinco centros de la asociación: Centro de Recursos Agustín Barcena, Centro 
Horizon, Centro de día La Vega, Centro de día La Barca y Centro Entomo, para garantizar la representatividad de la información recogida.

\subsubsection{Instrumentos}

En la presente investigación se han adaptado el Index para la inclusión (Booth y Ainsc ow, 2002) y partiendo de los indicadores del mismo se ha elaborado en las fases II y III el Cuestionario de Evaluación de los Indicadores del Index (CEII) (véa se Anexo I y II) y que será el que se valide en el presente estudio.

Como veremos en el capitulo 6, del Cuestionario de Evaluación de los Indicadores del Index se desarrollará el Cuestionario de Indic adores de Inclusión (CII) (véase Anexo III) que se aplicará a la comunidad de AMICA.

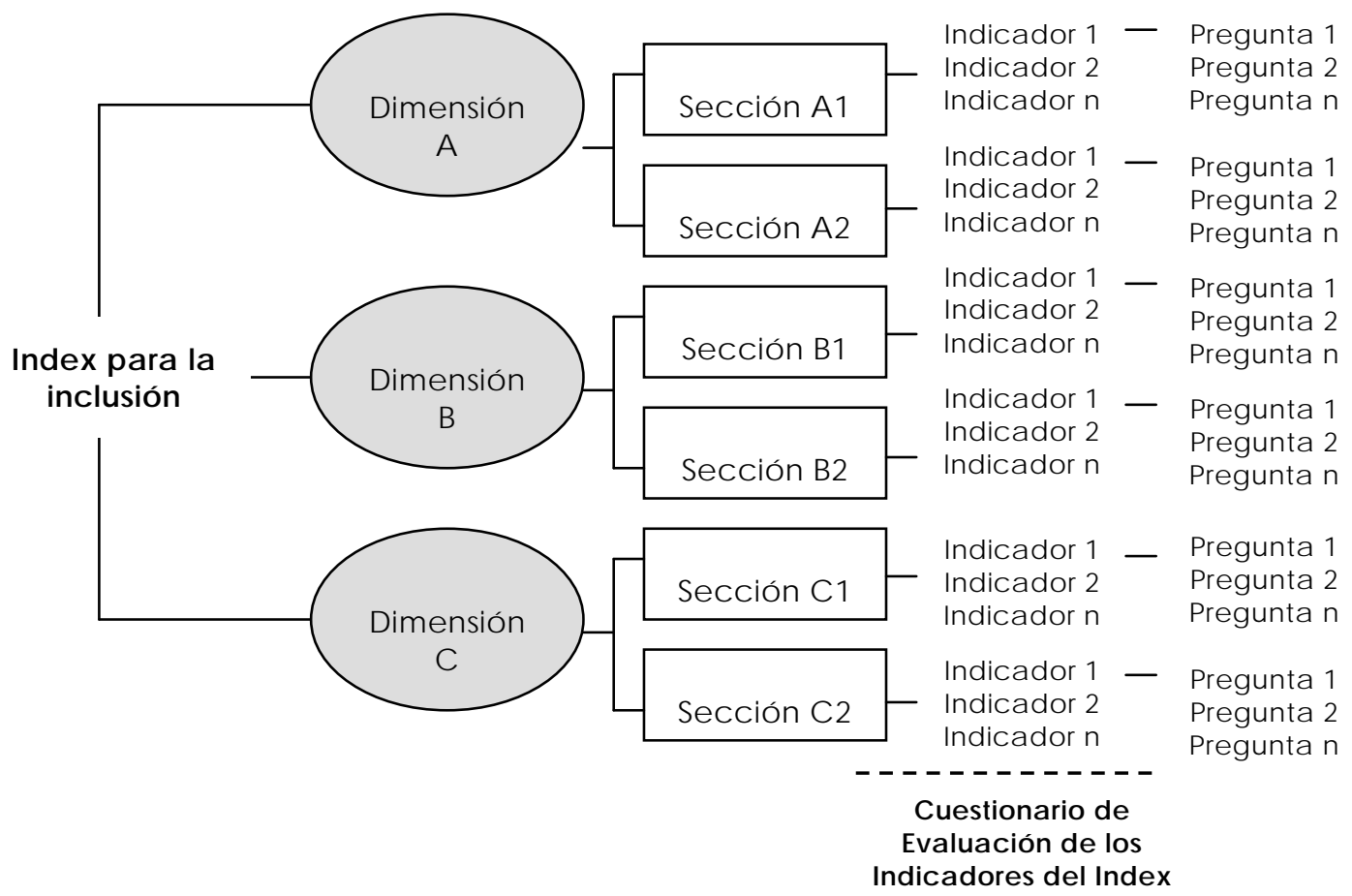

Index para la inclusión

FIGURA 29. ELEMENTOS QUE FO RMAN PARTE DEL INDEX Y DEL CUESTIONARIO DE EVALUACIÓN DE LOS INDICADORES DEL INDEX (CEII). 
CAPITULO 5. Adaptación del Index para la inclusión para centros para personas con disc apacidad (Fase I y Fase II)

\subsubsection{Index para la Inclusión: características y proceso de adaptación}

Como se ha señalado en el primer capítulo de la tesis, el Index para la inclusión fue desarrollado en el Centro de Estudios sobre Educación Inclusiva (CSIE) y representa el producto obtenido tras tres años de trabajo experimental y de su aplic ación en 25 escuelas de Ingla terra (Rustemier y Booth, 2005).

El Indexpara la inclusión se publicó por primera vez en el año 2000 (Booth y Ainsc ow, 2000) y fue revisado en 2002 (Booth y Ainsc ow, 2002). En la actualidad, el Index para la inclusión se ha posicionado a nivel internacional como un instrumento que promueve prácticas más inc lusivas en las esc uelas (Vislie, 2003)

El instrumento constituye un medio para explorar un enfoque inclusivo que se puede aplicar en todos los niveles de la organización (Mittler, 2000). Está compuesto por tres dimensiones que se desarrollan a través de 45 indicadores (ver apartado 1.3) que se agrupan como se muestra en la Tabla 08.

\begin{tabular}{|c|l|c|}
\hline Dimensión A & Crear CULTURAS inclusivas & Indicadores \\
\hline Sección A.1. & Construir comunidad. & 7 \\
\hline Sección A.2. & Establecervalores inc lusivos. & 6 \\
\hline Dimensión B & Elaborar POÚtTCAS inclusivas & Indicadores \\
\hline Sección B.1. & Desarrollar una escuela para todos. & 6 \\
\hline Sección B.2. & Organizar la atención a la diversidad. & 9 \\
\hline Dimensión C & Desa rrollar PRÁCTICAS inclusivas & Indicadores \\
\hline Sección C.1. & Orquestar el proceso de aprendizaje. & 12 \\
\hline Sección C.2. & Movilizar recursos. & 5 \\
\hline
\end{tabular}

TABLA 08. DIMENSIO NES, SECCIONESE INDICADORES DEL INDEX PARA LA INCLUSIÓN (ELABORACIÓN PROPIA) 
Booth y Ainscow (2002, p.21) nos proponen una descripción de las tres dimensiones. Se reseñan a continuación porque son la base sobre la que pivotan todos los cambios realizados en el proceso de adaptación que se presenta.

La primera dimensión, Crear Culturas inclusivas, está orientada hacia la creación de una comunidad escolar segura, acogedora, colaboradora y estimulante en la que cada uno es valorado como el fundamento primordial para que todo el alumnado tenga mayores niveles de logro. Pretende desa rollar valores inclusivos, compartidos por todo el profesorado, los estudiantes, los miembros del consejo escolar y las familias, de forma que se transmitan a todos los nuevos miembros de la comunidad escolar.

La segunda dimensión, Elaborar políticas inclusivas, pretende a segurar que la inclusión esté en el corazón del proceso de innovación, empapando todas las políticas, para que mejore el aprendizaje y la participación de todos los estudiantes.

La tercera y última dimensión, Desarrollar Prácticas inclusivas, pretende que las prácticas de los centros reflejen la cultura y las políticas inclusivas. Intenta a segurar que las actividades en el aula y las activida des extra escola res motiven la participación de todo el alumnado y tengan en cuenta el conocimiento y la experiencia de los estudiantes fuera del entomo escolar.

Este instrumento, como se ha expuesto ampliamente en la parte teórica, ha sido investigado a nivel intemacional (Dyson, 2001; Norwich et al., 2001; Corbett, 2001; Vaughan, 2002; Rose, 2002; Vislie, 2003; Channon, 2003; Hick, 2005; Rustemier y Booth, 2005; Heung, 2006; Ainscow, 2007; Booth, 2008) y se ha adaptado a diferentes idiomas y contextos, por ejemplo podemos destacar el ajuste a las características de un país como Noruega por Vaughan (2002) y Vislie (2003), al contexto de Entrea por Channon (2005) o la adaptación conforme a la cultura y a 
CAPITULO 5. Adaptación del Index para la inclusión para centros para personas con disc apacidad (Fase I y Fase II)

los estándares de calidad de Hong Kong por Heung (2006). También existen versiones para diferentes niveles educativos como Educación Infantil (Booth, Ainsc ow y Kingston, 2006) que ha sido adaptado al contexto español por el Instituto Universitario de Integración en la Comunidad (INICO), denominado "Index para la Inclusión. Desarrollo del juego, el aprendizaje y la participación en Educación Infantil" (Booth y Ainsc ow, 2006), y Educación Primaria (Booth y Ainscow, 2002).

El proceso de adaptación del Index para los contextos socio-educativos de los centros que prestan servicios a personas con discapacidad constó de las siguientes etapas:

1. Lectura y valoración de la adecuación terminológica y de constructos.

2. Propuesta de cambios terminológicos.

3. Propuesta de cambios de contenidos: inclusión, eliminación o modific ación en su caso.

4. Configuración final del Indexpara la inclusión.

Para la adaptación de las secciones, indicadores y preguntas a los centros que prestan servicios a las personas con algún tipo de limitación, se ha analizado diversa información recogida sobre la asociación que se ha tomado de referencia para el presente trabajo, AMICA. La documentación ha sido tanto comorativa (AMICA, 2007, 2008, 2010a, 2010b), como divulgativa como pueden ser las revistas o los libros public a dos por la Asociación (AMICA, 2009; Castillo, 2007, 2009, 2010).

Dicha información ha sido complementada con la documentación técnica analizada sobre inclusión (FEAPS, 2009; Villa lobos y Zalakain, 2010; Echeita, 2007; Meza, 2010; Ainscow, 2010; Norwich, 2008; OMS, 2001; Ainscow, Booth y Dyson, 2006), sobre las características de las organizaciones inclusivas: cultura (Wilkins y 
Ouchi, 1983; Aiman-Smith, 2004; Shein, 1996, 2004; Priante, 2003; Partson, 2010; Cox y Cox, 2001; Hamburger, 2008), sobre las polític as inclusivas (Cameiro, 2002; Strully y Broderick, 2010; AMICA, 2009; Booth, 2008; Bla ir, 2010; UN ESCAP, 2010; Craig, 2010) y sobre las prácticas inclusivas (AMICA, 2009; EUSE, 2005, ONU, 2006; Iso-Ahola y St.Clair, 2000; Carver, 1998; McMillen, Zuravin y Rideout, 1995; Deci y Ryan, 1980, 1985, 1991; Wehmeyer, 2005, 2009; C sikszentmihalyi, 1996,1998).

Debido a que el Index es un instrumento reconocido a nivel intemacional se estableció desde un primer momento, como norma que guiara a la investigación en la Fase Il, el realizar una adaptación y no una modifica ción del mismo. Por ello, aunque los cambios realizados son múltiples por la diferencia del contexto de a plic ación las ca tegorías, indic a dores y preguntas son fieles al original.

En todo momento, se ha optado por la eliminación o modificación de indicadores que pudiesen conllevar un alto grado de subjetividad. Una vez eliminada la subjetividad se ha adaptado el indicador al tipo de centro para el que se está desarrollando y se ha orientado sobre el aspecto clave sobre el que se quiere incidir el instrumento, la inclusión.

En otros casos, se han eliminado directamente indicadores o preguntas por no ser pertinentes para este tipo de centros, por ejemplo, se ha eliminado entre otros los indicadores C.1.11 "Los "deberes para casa" contribuyen al a prendizaje de todos" y el B.2.5 “El apoyo de los alumnos que aprenden Euskara/castellano como segunda lengua se coordina con otros tipos de apoyo pedagógico". Y se han adaptado y/o modificado prácticamente la totalidad de las preguntas para adaptarlas al objeto del instrumento. 
CAPITULO 5. Adaptación del Index para la inclusión para centros para personas con disc apacidad (Fase I y Fa se II)

\begin{tabular}{|l|c|c|c|c|c|}
\hline & Mantenido & Adaptado & Modificado & Eliminado & Añadido \\
\hline Dimensiones & 3 & 0 & 0 & 0 & 0 \\
\hline Secciones & 1 & 3 & 2 & 0 & 0 \\
\hline Indicadores & 2 & 30 & 8 & 4 & 2 \\
\hline Preguntas & 46 & 335 & 67 & 74 & 27 \\
\hline
\end{tabular}

TABLA 09. CAMBIOS REA UZADOS EN EL INDEX PARA LA INCLUSIÓN.

En la Tabla 09 se puede ver el número total de cambios realizados en las dimensiones, secciones, indic adores y preguntas del Indexpara la inc lusión.

Los cambios más significativos son los realizados en los indicadores y preguntas. En las Tablas 10 y 11 se puede ver el número de indicadores y preguntas mantenidas (son las que aparecen en la versión original), adaptadas (en ellas se han realizado cambios para adecuarlas al nuevo contexto de aplicación), modificadas (son aquellas que se han cambiado considerablemente y no representan la misma idea o filosofía de trabajo), eliminadas (aquellas que se han descartado porque no se ajustan al nuevo contexto) y añadidas (son nuevos elementos que proporcionan nueva información sobre el contexto de aplicación). Tal y como predecíamos en nuestra primera hipótesis, los cambios realizados pa ra la adaptación de los contenidos del Index han sido escasos. En otras palabras, el Index es susceptible de ser empleado en centros de personas con discapacidad más allá de centros educativos. 


\begin{tabular}{|c|c|c|c|c|c|c|}
\hline Dimensión & Sección & $\begin{array}{l}\text { Indicadores } \\
\text { mantenidos }\end{array}$ & $\begin{array}{l}\text { Indicadores } \\
\text { adaptados }\end{array}$ & $\begin{array}{l}\text { Indicadores } \\
\text { modificados }\end{array}$ & $\begin{array}{l}\text { Indic a dores } \\
\text { elimina dos }\end{array}$ & $\begin{array}{c}\text { Indic adores } \\
\text { añadidos }\end{array}$ \\
\hline \multirow{2}{*}{$\begin{array}{c}\text { Crear } \\
\text { CULTURAS } \\
\text { inc lusivas }\end{array}$} & A.1. & 1 & 5 & 1 & 0 & 0 \\
\hline & A. 2 . & 0 & 0 & 6 & 0 & 0 \\
\hline \multirow{2}{*}{$\begin{array}{l}\text { Elaborar } \\
\text { PO LíTICAS } \\
\text { inc lusivas }\end{array}$} & B.1. & 0 & 5 & 1 & 0 & 0 \\
\hline & B.2. & 0 & 6 & 0 & 2 & 2 \\
\hline \multirow{2}{*}{$\begin{array}{c}\text { Desa rrollar } \\
\text { PRÁC TICAS } \\
\text { inc lusivas }\end{array}$} & C.1. & 0 & 10 & 0 & 2 & 0 \\
\hline & C.2. & 1 & 4 & 0 & 0 & 0 \\
\hline \multicolumn{2}{|c|}{ Total } & 2 & 30 & 8 & 4 & 2 \\
\hline
\end{tabular}

TABLA 10. CAMBIOS REALIZADOS EN LOS INDICADORES PARA LA ADAPTACIÓN DEL INDEX.

\begin{tabular}{|c|c|c|c|c|c|c|}
\hline Dimensión & Sección & $\begin{array}{l}\text { Preguntas } \\
\text { mantenidas }\end{array}$ & $\begin{array}{l}\text { Preguntas } \\
\text { adaptadas }\end{array}$ & $\begin{array}{l}\text { Preguntas } \\
\text { modificadas }\end{array}$ & $\begin{array}{l}\text { Preguntas } \\
\text { eliminadas }\end{array}$ & $\begin{array}{l}\text { Preguntas } \\
\text { añadidas }\end{array}$ \\
\hline \multirow{2}{*}{$\begin{array}{c}\text { Crear } \\
\text { CULTURAS } \\
\text { inclusivas }\end{array}$} & A.1. & 13 & 62 & 1 & 4 & 13 \\
\hline & A. 2 . & 3 & 49 & 15 & 7 & 4 \\
\hline \multirow{2}{*}{$\begin{array}{l}\text { Elaborar } \\
\text { POLíTICAS } \\
\text { inclusivas }\end{array}$} & B.1. & 7 & 37 & 7 & 11 & 5 \\
\hline & B.2. & 13 & 52 & 21 & 18 & 1 \\
\hline \multirow{2}{*}{$\begin{array}{l}\text { Desa rrollar } \\
\text { PRÁCTICAS } \\
\text { inc lusivas }\end{array}$} & C.1. & 8 & 103 & 12 & 29 & 4 \\
\hline & C.2. & 2 & 32 & 11 & 5 & 0 \\
\hline \multicolumn{2}{|c|}{ Total } & 46 & 335 & 67 & 74 & 27 \\
\hline
\end{tabular}

TABLA 11. CAMBIOS REALIZADOS EN LAS PREG UNTAS PARA LA ADAPTACIÓN DEL INDEX.

5.4.4.3. Cuestionario de Evaluación de los Indicadores del Index (CEI): característic as y proceso de elaboración

Una vez adaptado el Index para la inclusión, se seleccionaron sus indicadores y con ellos se construyó el Cuestionario de Evaluación de los Indicadores del Index (CEII). A continuación procedimos a valorar la pertinencia o intensidad, es decir, adecuación de cada ítem para medir los diferentes 
CAPITULO 5. Adaptación del Index para la inclusión para centros para personas con disc apacidad (Fase I y Fase II)

constructos o conceptos incluidos en el Index, así como la dimensión a la que podría pertenecercada uno de los ítems seleccionados.

El cuestionario elaborado contiene un total de 42 ítems que se corresponden con los indicadores del Index adaptado a los centros que prestan servicios a personas con discapacidad. En la Tabla 12 que se muestra a continuación se presentan el número de ítems por cada una seis secciones del Index adaptado.

\begin{tabular}{|c|c|c|}
\hline \multicolumn{2}{|c|}{ Dimensión A C rear CULTURAS inclusivas } & $\begin{array}{l}\text { Ítems/ } \\
\text { Indic adores }\end{array}$ \\
\hline A.1. & Desa rrollo de una comunidad inclusiva. & 7 \\
\hline A.2. & Esta blec imiento de valores inclusivos. & 6 \\
\hline \multicolumn{2}{|c|}{ Dimensión B Ela borar POĹTCCAS inclusivas } & $\begin{array}{l}\text { Ítems/ } \\
\text { Indicadores }\end{array}$ \\
\hline B.1. & Desa rrollo un centro para todos. & 6 \\
\hline B.2. & $\begin{array}{l}\text { Organización de la actividad del centro para promover } \\
\text { la vida independiente de las personas usuarias. }\end{array}$ & 8 \\
\hline \multicolumn{2}{|c|}{ Dimensión C Desarrollar PRÁC TICAS inclusivas } & $\begin{array}{l}\text { Ítems/ } \\
\text { Indic adores }\end{array}$ \\
\hline C.1. & $\begin{array}{l}\text { Dirección del proceso de aprendizaje para promover la } \\
\text { vida independiente. }\end{array}$ & 10 \\
\hline C.2. & Movilización de recursos. & 5 \\
\hline
\end{tabular}

TABLA 12. ÍTEMS DEL CEII Y SU RELACIÓN CON LAS DIMENSIO NESY SECCIONES DEL INDEX ADAPTADO (VERSIÓN PRELIMINAR)

La primera dimensión, Crear CULTURAS inclusivas, contiene dos secciones y trece ítems orientados a obtener información sobre la comunidad de AMICA y los valores inclusivos que están presentes en ella. A través de esta dimensión se pretende obtener información sobre si la asociación está orientada hacia la creación de una comunidad segura, acogedora y colaboradora; y si tiene entre sus objetivos desa rrollar va lores inclusivos, compartid os por todos los profesionales, las personas usuarias, los miembros de la dirección de la organización y las familias, de forma que se transmitan a todos los nuevos miembros de la asociación. La 
información se obtiene a través de preguntas que van desde el clima del centro o la colaboración entre todos los miembros de la comunidad hasta la valoración de la diversidad de las personas.

La segunda dimensión, Elaborar POLíTICAS inclusivas, contiene dos secciones y catorce ítems orientados a obtener información sobre si los principios que se derivan de la cultura de inclusión de la asociación se concretan en las políticas de cada centro.

La tercera dimensión, Desarrollar PRÁCTICAS inclusivas, contiene dos secciones y quince ítems destinados a obtener información sobre si las actuaciones que se llevan a cabo en la organización reflejan la cultura y las políticas inc lusivas. Los indicadores se centran tanto en las actividades y actuaciones profesionales como en la movilización de recursos ya sea de la asociación o de entidades extemas.

Para la elaboración del cuestionario se ha alterado el orden de los indicadores del Index para que no se puedan identific ar por su lugar de aparición con la dimensión y sección que tienen asignada.

El cuestionario va precedido de una página introductoria, a modo de presentación y guía para su cumplimentación. La página introductoria se compone del título del cuestionario, una recogida básica de datos sobre el centro al que pertenece la persona que va a participar en la investigación y su relación con él y unas breves instrucc iones para partic ipar como juez extemo.

En primer lugar se les indic a que, desde su punto de vista, señalen la sección (en el cuestionario se denomina categoría) a la que pertenece cada indicador (en el cuestionario se denomina ítem) teniendo en cuenta las seis secciones que se muestran. En el cuestionario se señala una breve descripción de cada sección para darles mayor información sobre las mismas. En segundo lugar, se señala que una vez valorada la sección a la que pertenece cada indicador, valoren la pertinencia 
CAPITULO 5. Adaptación del Index para la inclusión para centros para personas con disc apacidad (Fase I y Fase II)

o grado en que el ítem mide o representa dicha categoría, en una escala de " 1 " a "4", teniendo en cuenta que el " 1 " indica una muy baja relevancia y el "4" indica una pertenencia o relevancia muy alta. En este momento se indica que se han añadido unos enunciados asociados a cada indicador para facilitar el entendimiento de los mismos.

Valoración del instrumento porparte de jueces expertos

El cuestionario fue inicialmente valorado a través de unas entrevistas no estructura das por jueces expertos de AMICA con el objetivo de recoger opiniones sobre la redacción y presentación del cuestionario. Obtenidos los datos, se procedió a modificar el cuestionario para adecuarlo a las diferentes limitaciones que pudiesen presentar los entrevistados.

Así, desde la Asociación, se señaló la posibilidad de modificar las descripciones de las secciones y, por otra parte, se indicó que si fuera posible se incluyeran elementos de apoyo en los indicadores para que fueran accesibles a personas con cua lquier tipo de limitación.

Valoradas las a portaciones realizadas se procedió a realizar los dos ca mbios propuestos. El primer cambio, en las descripciones de las seis secciones, se realizó porque, efectivamente, la información que se había extraído de forma literal del documento original de la versión en castellano (p.21) encerraba una complejidad que podría conllevar el no entendimiento de las mismas por parte de los encuestados.

En la Tabla 13 se presenta la versión final de las categorías y su definición.

\begin{tabular}{|l|l|}
\hline Nombre & Descripción \\
\hline Desarrollo de una & Todaslas personas que están en contacto con el centro se \\
\hline
\end{tabular}




\begin{tabular}{|c|c|}
\hline comunidad inclusiva. & $\begin{array}{l}\text { sienten partícipes de el. Los miembros de la comunidad } \\
\text { (profesionales, familias y personas usuarias) se ayudan, se } \\
\text { a poyan y colaboran para que to do el mund o se sienta } \\
\text { acogido, respetado y valorado. }\end{array}$ \\
\hline $\begin{array}{l}\text { Esta blec imiento de } \\
\text { va lores inclusivos. }\end{array}$ & $\begin{array}{l}\text { En el centro se comparten los valores centradosen la } \\
\text { persona y en suscapacidades. Se considera a la } \\
\text { individualidad, como componente fundamental de la } \\
\text { diversidad del ser humano que supone considerar que } \\
\text { cada persona es única, con proyectos de vida, con } \\
\text { ilusiones y con la necesidad de que se crea en sus } \\
\text { capacidades, como ser cargado de posibilidades se le } \\
\text { aportan oportunidades. }\end{array}$ \\
\hline $\begin{array}{l}\text { Desa rrollo un centro } \\
\text { para todos. }\end{array}$ & $\begin{array}{l}\text { El centro tiene políticas y procesos encaminados a que } \\
\text { tanto las personas usuarias, sus familias y los profesionales } \\
\text { que trabajan en el se sientan acogidos y valorados. }\end{array}$ \\
\hline $\begin{array}{l}\text { Organización de la } \\
\text { actividad del centro } \\
\text { para promover la vida } \\
\text { independiente de las } \\
\text { personas usuarias. }\end{array}$ & $\begin{array}{l}\text { En el centro se ponen en marcha todos los mecanismos y } \\
\text { esfuerzos en la búsqueda de la mejora de la calidad de } \\
\text { vida de las personas y de sus familias, dirigiendo sus } \\
\text { actuaciones a la potenciación de lascapacidades. Para } \\
\text { ello, se centrará en las potencialidades de las personas, en } \\
\text { sus intereses y necesidades y coordina rá sus a poyos para } \\
\text { conseguir los mejores resultados. }\end{array}$ \\
\hline $\begin{array}{l}\text { Dirección del proceso } \\
\text { de aprendizaje para } \\
\text { promover la vida } \\
\text { independiente. }\end{array}$ & $\begin{array}{l}\text { Las actividades del centro esta rán dirigidas a a poyar la } \\
\text { partic ipación de las personas; haciendo realidad el } \\
\text { derecho de acceso a los servic ios comunitarios, y } \\
\text { contando con los apoyos que posibiliten el ejercic io del } \\
\text { derecho a gobemarse a sí mismas y promocionen su } \\
\text { condición de plena ciudadanía. }\end{array}$ \\
\hline $\begin{array}{l}\text { Moviliza c ión de } \\
\text { recursos. }\end{array}$ & $\begin{array}{l}\text { El centro para conseguir sus objetivos optimizará los } \\
\text { recursos humanos, económicos y materiales de que } \\
\text { dispone, logrando una efica cia y eficiencia de los mismos. } \\
\text { Y buscará recursos y a poyos externos en la sociedad. }\end{array}$ \\
\hline
\end{tabular}

TABLA 13. CATEG ORÍASY DESCRIPCIÓN VERSIÓN FINAL.

El segundo cambio que se realizó sobre el cuestionario fue elegir un par de preguntas representativas de cada indicador que servirán de guía y de apoyo para poder valorar la pertinencia del mismo. Las preguntas se convirtieron en enunciados explic a tivos del indic ador.

Indicador B.1.2. El centro tiene una política de acogida de las personas usuarias.

- El centro tiene un programa de acogida. 
- Se han establecido programas para facilitar la transición entre la anterior situación de la persona y la nueva en el centro.

Las actividades que se llevan a cabo en el centro contribuyen a una mayor comprensión de la diversidad.

- Se motiva a las personas a que conozcan opiniones diferentes a las suyas.

- Se proporcionan oportunidades para que las personas trabajen con otros que son diferentes a ellos por su contexto, etnia, capacidad o género.

El resultado del proceso de adaptación y revisión de esta fase se puede ver en el Anexo I.

Diseño del formato y contenidos finales del instrumento (versión preliminar).

El siguiente paso consistió en el análisis cuantitativo (i.e. a través de cuestionario) de la fiabilidad del instrumento por parte de jueces extemos. La fiabilidad entre jueces es un componente crítico del análisis de contenido y que, aunque ello no asegura la validez, si se carece de fiabilidad, los datos no se pueden considerar válidos (Neuendorf, 2002). Existen docenas de medidas o índices de fiabilidad entre jueces. Popping (1988) identificó 39 “índices de acuerdo" diferentes para categorías nominales, que incluye varias técnicas para calcular la fiabilidad con datos de variables a nivel de intervalo o razón. Sin embargo, habitualmente se emplean unas pocas téc nicas. Las más comunes son: porcentaje de acuerdo, método de Holsti, pi de Scott, kappa de Cohen y alfa de Krippendorff. En la actualidad no existe consenso a la hora de indicar "el mejor" índice. Por ejemplo, varios autores recomiendan el empleo de kappa de Cohen (p.ej. Dewey, 1983) especialmente en investigadores que se basan en codificar 
conductas (Bakeman, 2000), otros autores (p.ej. Krippendorff, 1978, 1987) indican que sus características lo hacen inapropiado para medir el acuerdo entre codificadores. El porcentaje de acuerdo es fácil de calcular pero tiende a so brestimar el acuerdo real entre codific adores, al menos para variables nomina les. El Alfa de Krippendorff suele ser aceptado y es muy flexible, pues puede ser empleado con múltiples codificadores, distintos tamaños de muestra y datos perdidos, y puede ser empleado con variables ordinales, de intervalo y de razón, pero requiere largos cálculos o el empleo de software no muy conocido.

Existe un consenso general en la literatura que indic a que los índic es que no tienen en cuenta el acuerdo que puede ocumir por azar (como sucede con los procedimiento de porcentaje de acuerdo y el método Holsti) son demasiado libera les (es decir, tienden a sobreestimar el acuerdo verdadero), mientras que los procedimientos que lo tienen en cuenta pueden ser demasiado conservadores. También existe consenso de que a veces se emplean algunos índices de modo inadecuado. Por ejemplo, el alfa de Cronbach está diseñado para medir tan sólo la consistencia intema a través de la correlación, estandarizando las medias y varianza de los datos de diferentes codificadores y midiendo tan sólo la covariación (Hughes y Garrett, 1990), y que ji cuadrado produce elevados valores tanto de acuerdo como de desacuerdo, desviándose por tanto del acuerdo esperable por azar (los "valores esperados" en la fómula de ji cuadrado) (Lombard, Snyder-Duch y Bracken, 2008).

Es posible emplear software especializado que permite calcular uno o más índices de fiabilidad. Entre ellos, destacamos:

a) ReCal: sistema online que permite calcular varios índices para variables nominales: porcentaje de acuerdo, porcentaje de acuerdo entre dos observadores (o para tres o más codificadores), Pi de Scott, Kappa de Cohen, Kappa de Fleiss, Alfa de Krippendorff. 
CAPITULO 5. Adaptación del Index para la inclusión para centros para personas con disc apacidad (Fase I y Fase II)

b) Macros de distribución gratuita para SPSS que permiten calcular el porcentaje de acuerdo y el alfa de Krippendorf para datos de intervalo.

Teniendo en cuenta todas estas consideraciones, a la hora de calcular la fiabilidad entre jueces hemos seguido las directrices de Lombard, Snyder-Duch y Bracken (2002, 2003), que se concretan en los siguientes pasos:

a. Selección de uno o más índices, en función de las caracteństicas de las variables, incluyendo sus niveles de medida, distribuciones esperadas entre categorías, y número de codificadores. En nuestro caso hemos optado por seleccionar el porcentaje de acuerdo (aunque no sea el más recomendable), junto con otros índic es que tienen en cuenta el porcentaje de acuerdo esperable por azar, como es el coeficiente alfa de Krippendorff (Krippendorff, 1990, 2004). El índice perfecto valdría 1 y el nulo 0. Krippendorff (1990) señala que puntuaciones inferiores al 0,70 suelen poseer baja significación estadística. Además, para el cálculo de la fiabilidad en cuanto a la pertinencia de los ítems hemos empleado adicionalmente el coeficiente Alfa de Cronbach, que mide la covariación entre valoraciones de jueces.

b. Obtener las herramientas necesarias para calcular los índices seleccionados. Concreta mente, hemos empleado el SPSS para el cálculo de varios índices de fiabilidad y la a plic ación online para otros índices.

c. Seleccionar un nivel de fiabilidad mínimo aceptable para el índice o índices a emplear. Los coeficientes de 0,90 o mayores son casi siempre aceptables, los de 0,80 son a ceptables en la mayoría de las situa ciones y los de 0,70 pueden ser apropiados en algunos estudios exploratorios y para algunos índices. Se deben emplear criterios más restric tivos con índic es que son menos exigentes (p.ej. porcentaje de acuerdo) y criterios menos 
restrictivos con índices muy exigentes (p.ej. kappa de Cohen, pi de Scott, y alfa de Krippendorff).

A los 14 participantes se les explicó el objetivo del estudio y se les instó a que valoraran los siguientes aspectos para cada uno de losítems:

(1) Pertinencia o Intensidad, es decir, adecuación del ítem para medir dicho constructo, en una escala de " 1 " a " 4 ", teniendo en cuenta que el " 1 " indica una muy baja relevancia y el "4" indica una pertenencia o relevancia muy alta.

(2) Dimensión a la que podría pertenecercada uno de losítems.

Se ofrecieron seis dimensiones: 1) Desarrollo de una comunidad inclusiva; 2) Establecimiento de valores inclusivos; 3) Desarrollo un centro para todos; 4) Organización de la actividad del centro para promover la vida independiente de las personas usuarias; 5) Dirección del proceso de aprendizaje para promover la vida independiente; 6) Movilización de recursos. Cada categońa iba a compañada de una breve descripción.

Las indicaciones, que se han incluido para evitar fallos u omisiones en el proceso, permiten que el cuestionario sea administrado sin la presencia del encuestador. Sin embargo, por la complejidad de los conceptos que se están valorando se optó por apoyar el proceso con la presencia del encuestador en todo momento.

\subsection{Resultados}

Antes de pasar a la codificación de la información recopilada, se realizó un recuento y revisión de los 14 cuestionarios recibidos, asignándoles un número de identificación. Después se procedió a la codificación del cuestionario para 
CAPITULO 5. Adaptación del Index para la inclusión para centros para personas con disc apacidad (Fase I y Fase II)

posibilitar su procesamiento informático mediante diferentes métodos, con objeto de determinar la fiabilidad entre jueces.

Una vez devueltas las valoraciones de los jueces, los resultados se volcaron en una matriz, sobre la que se rea lizaron a nálisis cuantitativos de la concordancia entre los jueces (entre pares y global) respecto a las valoraciones sobre la c a tegoría; estos a ná lisis fueron rea liza dos con el fin de va lorar el gra do de a cuerdo o concordancia entre los jueces que valoraron el conjunto inicial de ítems, tanto por pares como acuerdo global. Presentamos a continuación un resumen de los índic es obtenidos.

\begin{tabular}{|l|c|c|c|c|c|}
\hline & $\begin{array}{c}\text { Kappa } \\
\text { de Fleiss }\end{array}$ & $\begin{array}{c}\text { Alfa de } \\
\text { Krippendorf }\end{array}$ & $\begin{array}{c}\text { Porcentaje } \\
\text { promedio } \\
\text { de acuerdo }\end{array}$ & $\begin{array}{c}\text { Kappa de } \\
\text { Cohen } \\
\text { promedio }\end{array}$ & $\begin{array}{c}\text { Alfa de } \\
\text { Cronbach }\end{array}$ \\
\hline Categoría & 0,213 & 0,214 & $35,111 \%$ & 0,217 & \\
\hline Pertinencia & & 0,041 & $54,146 \%$ & & 0,49 \\
\hline
\end{tabular}

TABLA 14. RESUMEN ÍNDICES.

\begin{tabular}{|c|c|c|c|c|c|c|}
\hline Jueces & $\begin{array}{c}\text { Kappa } \\
\text { de Fleiss }\end{array}$ & $\begin{array}{c}\text { Alfa de } \\
\text { Krippendorf }\end{array}$ & $\begin{array}{c}\text { Porcentaje } \\
\text { promedio } \\
\text { de acuerdo }\end{array}$ & $\begin{array}{c}\text { Kappa de } \\
\text { Cohen } \\
\text { promedio }\end{array}$ & $\begin{array}{c}\text { Alfa de } \\
\text { Cronbach }\end{array}$ & $\begin{array}{c}\text { Pi de } \\
\text { Scott }\end{array}$ \\
\hline Profesionales & 0.198 & 0.204 & $34.146 \%$ & 0.2 & & \\
\hline Familia & 0.958 & 0.958 & $96.748 \%$ & 0.958 & & \\
\hline Directivos & 0.159 & 0.166 & $30.081 \%$ & 0.164 & & \\
\hline $\begin{array}{c}\text { Personas } \\
\text { usuarias }\end{array}$ & 0.739 & 0.741 & $78.862 \%$ & 0.74 & & 0.171 \\
\hline $\begin{array}{c}\text { Personal } \\
\text { extemo }\end{array}$ & 0.181 & $34.1 \%$ & 0.181 & & \\
\hline
\end{tabular}

TABLA 15. RESUMEN ÍNDICES POR G RUPOS DE J UECES. 
En las Tablas 14 y 15 se observa cómo los índices de acuerdo obtenidos respecto a la categoría y a la pertenencia fueron bajos. Tan sólo los jueces pertenecientes a las familias y los usuarios, realizaron estimaciones similares. Teniendo en cuenta los resultados obtenidos por los otros grupos, creemos que la elevada concordancia entre los dos grupos mencionados pudiera deberse a que unos se influenciaron a otros, pese a que indicáramos la conveniencia de rellenar los da tos individua Imente.

\subsection{Conclusiones}

En este capítulo hemos abordado el proceso seguido en la adaptación del Index para centros que prestan servicios a personas con discapacidad. Para ello hemos seguido los siguientes pasos: (1) Adaptación del Index para la inclusión (Fase I); (2) Elaboración del Cuestionario de Evaluación de los Indicadores del Index (versión preliminar) (Fase II).

Las conclusiones del presente capítulo se van a presentar a partir de las hipótesis que se plantearon para las fases I y II de la parte empírica.

Hipótesis 1. El Index para Inclusión presentará un elevado porcentaje de contenidos y preguntas susceptibles de ser empleados en centros de personas con disc a pacidad.

Tal y como predecíamos, en nuestra primera hipótesis, esperábamos encontrar en el Index para la inclusión un elevado porcentaje de contenidos y preguntas susceptibles de ser aplicados en los centros que prestan servicios a personas con discapacidad. Pues bien, en este sentido como se ha señalado en el apartado 5.4.4.1, los cambios que se han realizado han 
estado más orientados hacia una adaptación al nuevo contexto de aplicación que a una modificación sustancial del instrumento. Por ello, podemosconcluir que se corrobora la hipótesis.

Por otro lado, hemos encontrado varios aspectos susceptibles de mejora que procedemosa señalara continuación.

La dimensión A "Crear culturas inc lusivas" y sus secciones ofrec en un enfoque claro que está en la línea de las aportaciones realizadas por la comunidad científica (Aiman-Smith, 2004; Shein, 1996, 2004; Priante, 2003; Partson, 2010; Cox y Cox, 2001; Hamburger, 2008).

La dimensión B "Elaborar políticas inclusivas" se entremezcla con otras secciones, principalmente con la A.1 y la A.2. Por la documentación científica analizada para la presente tesis creemos que esta dimensión debería estar más enfocada a provocar la reflexión en los centros sobre la promoción de políticas, sistemas de gestión y entomos de trabajo que permitan el ejercicio de derechos de ciudadanía, la adaptación a los cambios constantes de la sociedad, la excelencia y la creación entomos en los que todos sus miembros se sientan bien acogidos y partícipes de un proyecto común (Cameiro, 2002; Strully y Broderick, 2010; AMICA, 2009; Booth, 2008; Bla ir, 2010; UN ESCAP, 2010; Craig, 2010 ).

La dimensión C “Desarrollar prácticas inclusivas” en su sec ción C 1 se entremezcla con la dimensión $A$ y $B$ ya que, aunque tiene un enfoque orientado a las prácticas, los indicadores y preguntas que engloba se pueden confundir muy fácilmente con aspectos relacionados con la gestión, más propios de la dimensión B o los valores o la concepción de comunidad, correspondientes a la dimensión A. Por ello, y como aportación de cara a una mejora del instrumento y basándonos en la revisión documental realizada en la parte teórica de la presente tesis, creemos que 
esta dimensión debería estar enfocada a potenciar en los centros prácticas inclusivas en las que el eje de la misma sean las personas y no los profesionales del centro y las actuaciones que ellos realizan (AMICA, 2009; ONU, 2006; Deci y Ryan, 1980, 1985, 1991; Wehmeyer, 2005, 2009; C sikszentmiha lyi, 1996,1998).

Hipótesis 2. El Index para Inclusión adaptado para centros de personas con discapacidad presentará adecuados niveles de fiabilidad, entendida como concordancia entre jueces, respecto a la pertenencia de contenidos del Index a sus respec tiva s c a teg orías.

En segundo lugary en contra de nuestra segunda predicción según la cual, esperábamos encontrar adecuados niveles de fiabilidad, entendida como concordancia entre jueces, respecto a la pertenencia de contenidos del Index a sus respectivas categorías, tanto generalmente considerados como atendiendo a los diferentes subgrupos analizados, los niveles obtenidos han sido bastante bajos.

En cuanto a posibles explic aciones sobre tales resultados, es posible concluir que las categorías del Index para la inclusión tal y como estaban definidas inicialmente, no presentaban las características diferenciadoras necesarias para que los jueces pudieran asignar correctamente los indicadores a cada una de ellas. En el gráfico que se presenta a continuación puede verse la dispersión de opiniones que existen en todas las categorías.

Si analizamos los procesos de asignación de ítems a las categonas (secciones del Index) podemos ver que los jueces sitúan indicadores pertenecientes a la sección 1 "Desarrollo de una comunidad inclusiva" en 
CAPITULO 5. Adaptación del Index para la inclusión para centros para personas con disc apacidad (Fase I y Fase II)

otras secciones, principalmente a la 3 y 4 . En la sección 2, la asignación de indica dores ha sido mayorita riamente correcta pero sin embargo hay jueces que vinculan los indica dores a las secciones 1,3 y 4 .

Esto es especialmente evidente en la sección 5 "Dirección del proceso de aprendizaje para promover la vida independiente" dónde hay una gran dispersión de las a signaciones entre todas las secciones y en la 6 "Movilización de recursos" dónde se asignan casi tantos indicadores a la sección correcta como a la 5.

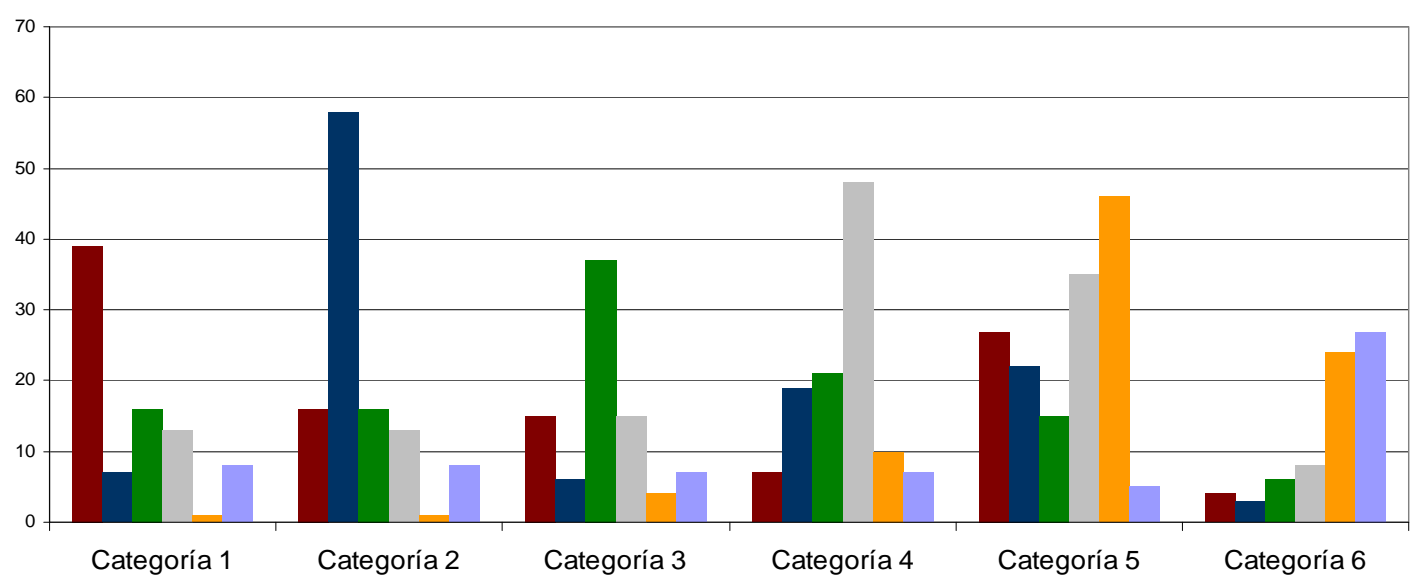

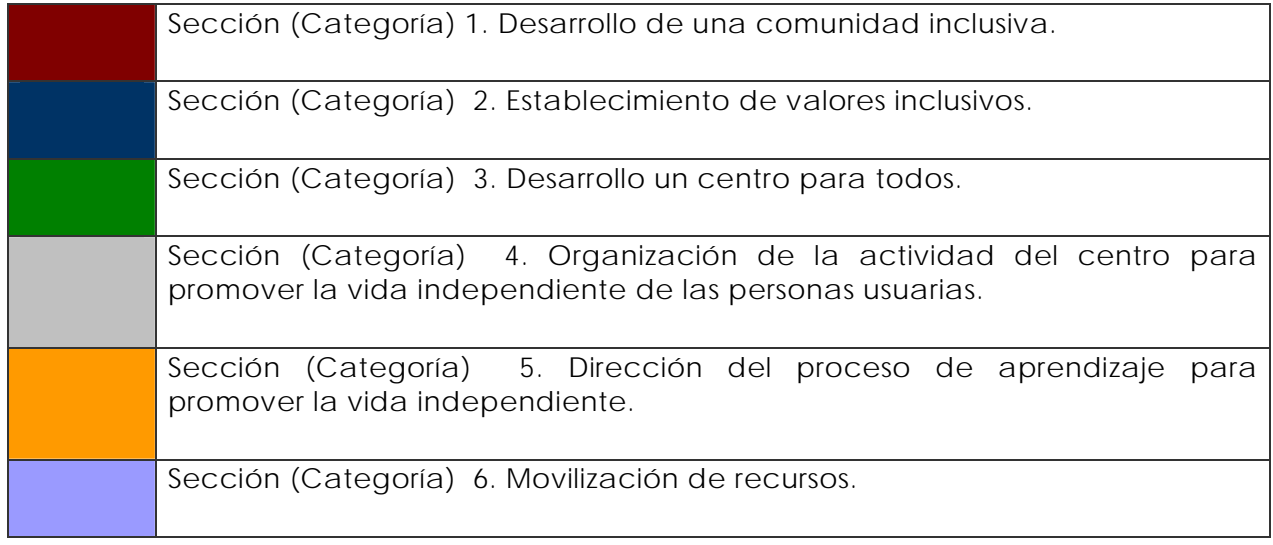

FIG URA 30. RESUMEN POR SEC CIONES (CATEG ORIAS) DE ASIG NACIÓN DE INDIC ADO RES A CADA UNA DE ELLAS. 
Otra de las conclusiones a las que se llega tras analizar los resultados obtenidos en el proceso de validación y, por tanto, en los procesos de categorización que se ponían en marcha en dicho proceso, es la dificultad de realizar una diferenciación entre secciones (por ejemplo, nuestra concepción de la sección "Desarrollo de una comunidad inclusiva") y conceptos (por ejemplo, los significados asignados al concepto "comunidad").

Creemos además que los participantes, en unos casos, no tenían conocimiento suficiente sobre las propiedades que formaban parte de los conceptos con los que se estaba trabajando y, en otros casos, las representaciones mentales del concepto estaban a sociadas directamente a sus vivencias en AMICA y no se llegaba a abstraer el concepto de la situa ción vivida.

Hipótesis 3. El Cuestionario de Evaluación de los Indicadores del Index (versión preliminar) presentará adecuados niveles de fiabilidad entre jueces pertenecientes a diferentes grupos de la comunidad analizada (profesionales, fa milias, usua rios, equipo).

En contra de lo que se preveía en la hipótesis, tras las sencillas modific aciones y adaptaciones rea lizadas en la Fase II, el cuestionario no ha presentado adecuadas propiedades psicométricas lo cual se refleja en los resultados obtenidos por los diferentes estadístic os utilizados tanto a nivel general (Alfa de Cronbach con un valor de 0,49 ) como los aplicados para determinar la fiabilidad entre observadores (Kappa de Cohen promedio con un valor de 0,217; Kappa de Fleiss con un valor de 0,213; Alfa de Krippendorff con valores de 0,214 y de 0,041). La validez de contenido se 
CAPITULO 5. Adaptación del Index para la inclusión para centros para personas con disc apacidad (Fase I y Fase II)

evaluó mediante consulta a jueces expertos a través un procedimiento estructurado en el que se les pidió emparejar los ítems con la categoría/indicador.

Por todo, y según los resultados obtenidos tanto en el a nálisis estadístico realizado como en el proceso de observación llevado a cabo en las diferentes sesiones con los participantes, el principal problema que se produce es que las secciones del instrumento poseen características comunes, lo cual hace que un indicador pueda vincularse a más de una sección.

Por los resultados obtenidos, las propuestas de adaptación que se establecen para la fase III están directamente relacionadascon la modificación de las secciones del Index, simplificándolas y haciendo que las carac terístic as que las definen no se entremezclen. Por otra parte, en dicha fase, la definición de los indicadores deberá ser también revisada para no producir confusión en el proceso de categorización.

En el siguiente capítulo expondremos el proceso de readaptación de los indica dores y los a nálisis adicionales realizados al CEll para llegar a conseguir una versión con adecuadas propiedades psicométricas y que se ajuste a este tipo de centros. 
CAPITLO 6.

Evaluación de la inclusión en los centros

para personas con discapacidad (Fase III

y Fase IV) 


\subsection{Presentación}

En el capítulo anterior hemos presentado el trabajo realizado en tomo a la adaptación (Fase I) y valoración de la a decuación del Index para la inclusión para la aplicación del mismo en los centros que prestan servicios a personas con discapacidad (Fase II). Tras la realización de diversos a nálisis hemos comprobado cómo los jueces consideran que es un instrumento susceptible de ser empleado en este tipo de centros, aunque señalan que para ello se deben realizar algunas adaptaciones. Como se indic aba en las conclusiones, se ha comprobado cómo las definiciones de las categorías (secciones del Index para la Inclusión) suscitan problemas a la hora de lograr un acuerdo sobre pertenencia de los indicadores a una u otra categoría.

Todo ello nos lleva a plantear en este capítulo la necesidad de realizar una nueva evaluación de las Dimensiones, Secciones (categorías) e Indicadores y Preguntas, incluidos en el Index para la Inclusión (ver Anexo IV). Para ello, procederemos en la Fase III a revisar las definiciones de las diferentes Dimensiones y Secciones, lo cual supond rá rea liza r un cambio en los Indic a dores y Preguntas.

Una vez realizada la adaptación siguiendo las recomendaciones extraídas en el capitulo 5, se adaptará el Cuestionario de Evaluación de los Indicadores del Index (CEII) (ver Anexo II) y se analizarán sus propiedades psicométricas tanto de fiabilidad como de validez.

Partiendo de los indicadores adaptados en la Fase III se elaborará un Cuestionario de Indicadores de Inclusión (CII) (ver Anexo III) que se aplicará en la comunidad de AMICA en un proceso de recogida de información en el que participarán 93 de sus miembros. Será en esta última fase cuando abordaremos el tercer objetivo de la investigación y valoraremos el posible impacto que puedan tener deteminadas variables sociodemográficas sobre la percepción de la 
inclusión en un centro que presta servicios a personas con discapacidad como es AMICA.

El capitulo 6 se inicia recogiendo las hipótesis (apartado 6.2) y objetivos (apartado 6.2) a alcanzar en las fases III y IV de la presente investigación para pasar posteriomente a describir el método (apartado 6.4) y los instrumentos de evaluación que se han utilizado en estos momentos de la Tesis Doctoral (a partado 6.5). Descrito el proceso, se presentan los resultados relativos a la aplicación tanto de la versión definitiva del Cuestionario de Evaluación de los Indica dores del Index (CEII) (véase Anexo II) y del Cuestionario de Indicadores de Inclusión (CII) (véase Anexo III)como del análisis factorial (apartado 6.7). El capitulo finaliza con la presentación del contraste de hipótesis asignadas a las Fases III y IV (apartado 6.8) y las conc lusiones (a partado 6.9).

\subsection{Objetivos}

Los objetivos que se abordan en este momento de la investigación (Fase III y IV) se centran principalmente, en primer lugar, en continuar c on la adaptación del Index para la Inclusión para centros que prestan servicios a personas con discapacidad y con la elaboración un Cuestionario de Evaluación de de los Indicadores del Index (CEEI) con adecuadas propiedades psicométricas. En segundo lugar, se pretende evaluar la inclusión en un centro de personas con discapacidad y deteminar el posible impacto de variables sociodemográficas en la percepción de la inclusión. Como ya se ha señalado anteriomente el centro de referencia para la presente investigación es la Asociación AMICA. 


\subsection{Hipótesis}

Como se ha señalado en el capitulo 5, las hipótesis de las fases III y IV son:

- Hipótesis 4. El Cuestionario de Evaluación de los Indicadores del Index (versión definitiva) mostrará adecuadas propiedades psicométricas de fiabilidad (acuerdo entre jueces, consistencia intema) y validez (validez a pa rente y validez de construc to).

- Hipótesis 5. El Cuestionario de Indic a dores de Inc lusión, a plic a do en el centro de referencia seleccionado para la presente Tesis, obtend rá elevadas puntua ciones en las tres dimensiones en las que se basa el instrumento: cultura (comunidad y valores), políticas y prácticas.

- Hipótesis 6. Los resultados obtenidos con el Cuestionario de Indicadores de Inclusión, en el centro de referencia, no mostrarán diferencias signific ativas en las puntuaciones obtenidas en función del género o la edad, o el rol que se desempeñe en el centro.

- Hipótesis 7. Los resultados obtenidos con el Cuestionario de Indicadores de Inclusión, en el centro de referencia, no mostrarán diferencias signific ativas en las puntuaciones obtenidas en función del centro con el que se tenga relación y con los años de vinculación con la Asociación.

\subsection{Método}

En el presente capítulo se abordan las fa ses II y IV. En ellas hemos empleado estadísticos de tests para la contrastación de la primera hipótesis. Además, el estudio es de tipo correlacional, ex post facto, para el contraste de las hipótesis 
relacionadas con la evaluación de la inclusión. Hemos utilizado estadístic os descriptivos, así como inferenciales bivariados (Anova), para el contraste de hipótesis. Previamente constatamos el cumplimiento de los supuestos paramétric os de normalidad de las distribuciones y homogeneidad de las varianzas. El nivel de signific a ción establecido para los a ná lisis fue de alfa =0,05.

\subsection{Instrumentos}

En la fase III se ha empleado la versión definitiva del Cuestionario de Evaluación de los Indicadores del Index (CEII), construido para la presente Tesis Doctoral y cuya versión preliminar se expuso con detalle en el capítulo previo (Fase II). Para esta fase de la investigación, procedimos a realizar varias mejoras con objeto de incrementar la a decuación del instrumento. Estas fueron:

(1) Redefinir las categońas incluidas o evaluadas a través del cuestionario. Así, como expusimos en el capítulo precedente, los jueces encontraban difícil la distinción de categorías, por lo que finalmente quedaron definidas como aparece en la Tabla 16.

\begin{tabular}{|l|l|l|}
\hline \multicolumn{2}{|c|}{ Sección (Categona) } & \multicolumn{1}{c|}{ Descripción } \\
\hline 1. & $\begin{array}{l}\text { Desa rrollar una comunidad } \\
\text { inclusiva }\end{array}$ & $\begin{array}{l}\text { El centro es una comunidad en la que todo el mundo se } \\
\text { siente acogido y en la que predomina un sentimiento } \\
\text { de compromiso y pertenencia. }\end{array}$ \\
\hline 2. & Establecervalores inclusivos & $\begin{array}{l}\text { En el centro se comparten los va lores centra dos en } \\
\text { considerar que ca da persona es única, con sus } \\
\text { proyectos de vida, ilusiones, etc }\end{array}$ \\
\hline 3. & $\begin{array}{l}\text { Fomentar estrategiasy } \\
\text { políticas inclusivas }\end{array}$ & $\begin{array}{l}\text { En el centro se desa rrollan unas políticas y estrategias } \\
\text { que tienen en cuenta a todas las personas. }\end{array}$ \\
\hline 4. & $\begin{array}{l}\text { Promover una gestión } \\
\text { organizativa inclusiva }\end{array}$ & $\begin{array}{l}\text { El centro pone en marcha procesos organizativos } \\
\text { acordes con sus valores inclusivos. }\end{array}$ \\
\hline
\end{tabular}




\begin{tabular}{|l|l|l|}
\hline 5. & Planificar prácticas inclusivas & $\begin{array}{l}\text { En centro pla nifica todas sus actividades teniendo en } \\
\text { cuenta que cada persona tiene derecho a tener un } \\
\text { proyecto personal, a alca nzar sus a spirac iones y metas } \\
\text { y a poder decidir so bre su futuro. }\end{array}$ \\
\hline 6. & Desa rollar prácticas inclusivas & $\begin{array}{l}\text { El centro a la hora de poner en marc ha todas sus } \\
\text { actividades se adapta a cada persona. }\end{array}$ \\
\hline
\end{tabular}

TABLA 16. DENOMINACIÓN DE CATEG ORÍAS Y DESCRIPCIÓN DE LAS MISMAS

(2) Revisar y redefinir los indicadores incluidos en cada categoría con un objetivo doble, por un lado, realizar los ajustes necesarios para que existieran las correspondencias necesarias con las nuevas categorías y, por otro, recoger las a portaciones realizadas por los jueces y los miembros de AMICA en la fase anterior basadas en su experiencia como comunidad basada en el aprendizaje y la participación.

(3) Elaborar el instrumento final y realizar los ajustes necesarios entre las diferentes categońas.

El instrumento, previo a su aplicación piloto, estaba compuesto por 42 indicadores (ítems) (ver apartado 5.4.4.1). Con las adaptaciones realizadas en la Fase III se redujeron a 40, agrupados según se presenta a continuación:

\begin{tabular}{|c|c|}
\hline \multicolumn{2}{|c|}{ CULTURA inclusiva } \\
\hline A.1. & Desamollar una comunidad inclusiva \\
\hline A.1.1. & Todas las personas que tienen rela ción c on el centro se sienten parte de él. \\
\hline A.1.2. & Existe un compromiso entre to dos los miembros que forman parte del centro. \\
\hline A.1.3. & $\begin{array}{l}\text { Entre los profesiona les del centro existen unas relaciones basadas en el } \\
\text { compromiso, la responsabilidad y la comprensión. }\end{array}$ \\
\hline A.1.4. & $\begin{array}{l}\text { Todos en el centro sienten que son parte de un proyecto al que pueden aportar } \\
\text { algo. }\end{array}$ \\
\hline A.1.5. & Los nuevos miembros se sienten bien acogidos en el centro. \\
\hline A.1.6 & El centro hace partícipe de su proyecto a la sociedad. \\
\hline A.2. & Establecer valores inc lusivos \\
\hline A.2.1. & $\begin{array}{l}\text { En el centro se valora la capacidad de todas las personas para desarrollar su } \\
\text { potencial. }\end{array}$ \\
\hline A.2.2. & $\begin{array}{l}\text { Las personas usuarias, las familias, los profesionales y el equipo directivo } \\
\text { comparten una filosofía de inclusión. }\end{array}$ \\
\hline
\end{tabular}




\begin{tabular}{|c|c|}
\hline A.2.3. & $\begin{array}{l}\text { En el centro se valora la diversidad, la individualidad y el potencial de cada } \\
\text { persona. }\end{array}$ \\
\hline A.2.4. & En el centro se respetan los derec hos de las personas. \\
\hline A.2.5. & $\begin{array}{l}\text { En el centro se considera que las barreras al a prendizaje y a la participación } \\
\text { están en los contextos y no en las personas. }\end{array}$ \\
\hline A.2.6. & $\begin{array}{l}\text { En el centro se reconoce la igualdad de las personas independientemente de } \\
\text { factores personales, socialesy culturales. }\end{array}$ \\
\hline A.2.7. & El respeto y la aceptación de todos son c lave para que nadie se sienta excluido \\
\hline \multicolumn{2}{|r|}{ POப́TाCAS inc lusivas } \\
\hline B.1. & Fomentar estra tegias y polític as inclusivas \\
\hline B.1.1. & $\begin{array}{l}\text { Las polític as del centro favorecen el ejercicio de derechos de los miembros de } \\
\text { la comunidad. }\end{array}$ \\
\hline B.1.2. & $\begin{array}{l}\text { Las polític as del centro están orientadas a fomentar la participación de las } \\
\text { personas en la sociedad. }\end{array}$ \\
\hline B.1.3. & $\begin{array}{l}\text { El centro tiene una estrategia de comunic ación para que se conozca su filosofía } \\
\text { de inclusión. }\end{array}$ \\
\hline B.1.4. & $\begin{array}{l}\text { La política de recursos humanos se basa en el mérito, la capacidad y la } \\
\text { igua ldad. }\end{array}$ \\
\hline B.1.5. & $\begin{array}{l}\text { El centro tiene una estrategia orientada a que to do el mundo tenga la } \\
\text { información y los apoyosnecesarios para tener una vida independiente. }\end{array}$ \\
\hline B.1.6. & $\begin{array}{l}\text { El centro tiene una política de mejora continua orientada a solucionarlos } \\
\text { problemas que la discapacidad plantea. }\end{array}$ \\
\hline B.1.7. & $\begin{array}{l}\text { La estrategia de formación de los profesionales del centro está diseñada para } \\
\text { ayudarlesa dar respuesta a la diversidad de laspersonas usuarias. }\end{array}$ \\
\hline B.2. & Promover una gestión inclusiva \\
\hline B.2.1. & El modelo organizativo del centro promueve la inclusión. \\
\hline B.2.2. & En los procesos y proyectos del centro se ve refleja da la filosofía de inclusión. \\
\hline B.2.3. & $\begin{array}{l}\text { Los procesos de trabajo están orientados a que las personas puedan desa mollar } \\
\text { su potencial. }\end{array}$ \\
\hline B.2.4. & $\begin{array}{l}\text { La gestión del centro implica a todos en la toma de decisiones, conciliando } \\
\text { intereses y repartiendo tareas. }\end{array}$ \\
\hline B.2.5. & $\begin{array}{l}\text { La gestión del c entro se a poya en las a lia nzas, en la cooperación institucional y } \\
\text { en los recursos existentes en la soc iedad. }\end{array}$ \\
\hline B.2.6. & $\begin{array}{l}\text { Los recursos del centro se distribuyen de forma que promuevan la autonomía y } \\
\text { la vida independiente de todas las personas. }\end{array}$ \\
\hline B.2.7. & $\begin{array}{l}\text { El centro intenta mejorar sus procesos de trabajo responder a las nec esidades } \\
\text { de cada persona. }\end{array}$ \\
\hline \multicolumn{2}{|c|}{ PRÁCTICAS inc lusivas } \\
\hline C.1. & Pla nific ar práctic as inc lusivas \\
\hline C.1.1. & $\begin{array}{l}\text { Las actividades que se planific an implic an hacer con cada persona algo } \\
\text { diferente porque cada individuo tiene sus propias aspiracionese ilusiones. }\end{array}$ \\
\hline C.1.2. & $\begin{array}{l}\text { Lasactividades se planifican para que las personaspuedan tomar decisiones } \\
\text { sobre su propia vida y participarplenamente en la sociedad. }\end{array}$ \\
\hline C.1.3. & $\begin{array}{l}\text { Los profesionales del centro diseñan actividadespara promover la } \\
\text { participación, el aprendizaje, la felic idad y el bienestar de todas las personas. }\end{array}$ \\
\hline C.1.4. & $\begin{array}{l}\text { La evaluación de las diferentes actividades que se rea lizan motiva a todos a } \\
\text { mejorar. }\end{array}$ \\
\hline
\end{tabular}




\begin{tabular}{|c|c|}
\hline C.1.5. & $\begin{array}{l}\text { Las actividadesse diseñan para fomentar la participación de laspersonas en la } \\
\text { sociedad. }\end{array}$ \\
\hline C.1.6. & $\begin{array}{l}\text { Lasactividades se planifican para que las personas se relacionen y a prendan } \\
\text { juntas. }\end{array}$ \\
\hline C.1.7. & $\begin{array}{l}\text { Las ac tividades se planific an por equipos multidisciplinares donde cada persona } \\
\text { aporta lo mejor de sus cualidades personalesy profesionales. }\end{array}$ \\
\hline C. 2 . & Desa rrollar práctic as inclusivas \\
\hline C.2.1. & $\begin{array}{l}\text { Todas laspersonas en el centro pueden participar en aquellas activida des que } \\
\text { les interesan porque tienen los a poyos nec esarios. }\end{array}$ \\
\hline C.2.2. & $\begin{array}{l}\text { A la hora de realizar una actividad los pensa mientos, sentimientos, capacidades } \\
\text { y emociones de cada persona se tienen en cuenta y son importantes. }\end{array}$ \\
\hline C.2.3. & $\begin{array}{l}\text { Las actividadesque se ponen en marcha en el centro son accesibles para } \\
\text { todos. }\end{array}$ \\
\hline C.2.4. & $\begin{array}{l}\text { Las actividades promueven la igualdad de oportunidades y el derecho a poder } \\
\text { elegir. }\end{array}$ \\
\hline C.2.5. & $\begin{array}{l}\text { Las actividadesque se rea lizan en el centro implic an de forma activa a todas las } \\
\text { personasfavoreciendo su autonomía personal y la vida independiente. }\end{array}$ \\
\hline C.2.6. & $\begin{array}{l}\text { Las actividades que se rea lizan en el centro utilizan to dos los recursos que existen } \\
\text { en la sociedad (espacios de ocio, asociaciones, empresas, servicios públic os, } \\
\text { etc.) }\end{array}$ \\
\hline
\end{tabular}

TABLA 17. CATEG ORIAS E INDICADORES DEL INDEX PARA LA INCLUSIÓN (VERSIÓN DEFINITIVA)

La adaptación de la versión definitiva del Index para la Inclusión se puede vercon detalle en el Anexo IV.

\subsubsection{Procedimiento}

La segunda parte del proceso empírico, Fases III y IV, llevado a cabo para la presente tesis se realizó en Torrelavega (Cantabria), durante los meses de julio de 2010 a Enero de 2011. 
Fase I. Adaptación del Index para la Inclusión

\begin{tabular}{|c|c|c|c|}
\hline $\begin{array}{l}\text { Lectura y } \\
\text { valoración de la } \\
\text { adaptación } \\
\text { teminológica y } \\
\text { de constructos. }\end{array}$ & $\begin{array}{l}\text { Propuesta de } \\
\text { cambios } \\
\text { terminológicos. }\end{array}$ & $\begin{array}{l}\text { Propuesta de } \\
\text { cambios de } \\
\text { contenidos. }\end{array}$ & $\begin{array}{c}\text { Configuración } \\
\text { final del Index } \\
\text { para la } \\
\text { Inclusión. }\end{array}$ \\
\hline \multicolumn{4}{|c|}{$\begin{array}{l}\text { Fase II. Elaboración del Cuestionario de Evalua ción de los Indic a dores del Index (versión } \\
\text { preliminar) }\end{array}$} \\
\hline $\begin{array}{l}\text { Elaboración de un pool } \\
\text { de ítems de las } \\
\text { diferentes dimensiones } \\
\text { de la inclusión. }\end{array}$ & \multicolumn{2}{|c|}{$\begin{array}{l}\text { Ronda de revisiones } \\
\text { del instrumento por } \\
\text { jueces expertos. }\end{array}$} & $\begin{array}{l}\text { Diseño del forma to y } \\
\text { contenidos finales del } \\
\text { instrumento. } \\
\text { (Versión preliminar) }\end{array}$ \\
\hline \multicolumn{4}{|c|}{$\begin{array}{l}\text { Fase III. Adaptación y a ná lisis de propieda des psic ométric as del Cuestiona rio de } \\
\text { Evaluación de los Indic a dores del Index (versión definitiva) }\end{array}$} \\
\hline $\begin{array}{l}\text { Reelaboración } \\
\text { de la versión } \\
\text { preliminardel } \\
\text { Cuestionario }\end{array}$ & $\begin{array}{c}\text { Valoración del } \\
\text { instrumento por } \\
\text { parte de jueces } \\
\text { externos. }\end{array}$ & $\begin{array}{c}\text { Análisis de } \\
\text { fiabilidad y } \\
\text { validez. }\end{array}$ & $\begin{array}{c}\text { Cuestionario de } \\
\text { Evaluación de los } \\
\rightarrow \text { Indicadores del Index. } \\
\text { (Versión definitiva) }\end{array}$ \\
\hline \multicolumn{4}{|c|}{ Fase IV. Diseño y a plic a ción del Cuestiona rio de Indic a dores de Inclusión } \\
\hline $\begin{array}{l}\text { Diseño y } \\
\text { aplicación del } \\
\text { cuestionario. }\end{array}$ & $\begin{array}{l}\text { Análisis de los } \\
\text { datos } \\
\text { recogidos. }\end{array}$ & $\begin{array}{r}\text { Resultadosy } \\
\rightarrow \quad \text { conclusiones. }\end{array}$ & $\begin{array}{l}\text { Sugerencias } \\
\text { para la } \\
\text { investigación. }\end{array}$ \\
\hline
\end{tabular}

FIG URA 31. PROCESO EMPÍRICO PARA LA ADAPTACIÓN DEL INDEX PARA LA INCLUSIÓN Y PARA LA CONSTRUCCIÓN DE UN INSTRUMENTO BREVE DE EVALUACIÓN DE LA INCLUSIÓN

En la tercera fase, se realizaron las adaptaciones oportunas en los ítems del CEll, se obtuvieron datos y se analizaron las propiedades psicométricas del Cuestionario de Evaluación de los Indicadores del Index (versión definitiva) (véase Anexo II), para ello, se contó con jueces externos pertenecientes a AMICA. La consulta a jueces requirió un contacto previo con el coordinador del proceso en la asociación, con el que se acordó el momento más adecuado para la validación, así como sobre la selección de los participantes y el proceso a seguir en las sesiones con las personas encuestadas. 
En esta fase se analizaron los datos obtenidos en las valoraciones de los jueces extemos tanto sobre la pertinencia o intensidad, es decir, la adecuación del ítem para medir dicho constructo y sobre la dimensión a la que podría pertenecer cada uno de los ítems seleccionados. De todo ello informaremos con más detalle en páginas posteriores.

En la cuarta fase, se diseñó y se aplicó el Cuestionario de Indicadores de Inclusión (CII) y se recogieron datos que pemitieran contrastar nuestra segunda hipótesis, esto es, deteminar posibles semejanzas y/o diferencias en la percepción de la inclusión en función de variables sociodemográficas. Los partic ipantes fueron personas pertenecientes a la comunidad de AMICA que participaron de forma voluntaria, tras ofrecemos su consentimiento informado. La recogida de datos se realizó partiendo del Cuestionario de Indicadores de Inclusión (CII) elaborado a partir de la versión definitiva de los indicadores del Index para la Inclusión adaptados (véase Anexo III).

\subsubsection{Participantes}

La muestra estaba compuesta por 93 personas, de las cuales, un 51,6\% $(n=48)$ eran profesionales, un $20,4 \%$ eran usuarios o familiares $(n=19$, respectivamente), y un $7,5 \%(n=7)$ era n profesionales del equipo directivo. Del total de la muestra un $68,8 \%(n=64)$ eran mujeres y un $31,2 \%(n=29)$ hombres.

En la Tabla 18 se ofrece la distribución de frecuencias de grupos de edad de los participantes. Se puede observar el predominio de personas entre los 22 y los 30 años (31,2\%), seguido de personas entre 31 y $40(25,8 \%)$.

\begin{tabular}{|l|c|c|c|}
\hline Edad & Frecuencia & Porcentaje & Porcentaje acumulado \\
\hline $16-21$ & 3 & 3,2 & 3,3 \\
\hline $22-30$ & 29 & 31,2 & 34,8 \\
\hline $31-40$ & 24 & 25,8 & 60,9 \\
\hline $41-50$ & 18 & 19,4 & 80,4 \\
\hline
\end{tabular}


CAPITULO 6. Evaluación de la inclusión en los centros para personascon discapacidad (Fase III y Fase IV)

\begin{tabular}{|l|c|c|c|}
\hline $51-60$ & 10 & 10,8 & 91,3 \\
\hline Mayorde 60 & 8 & 8,6 & 100 \\
\hline NC & 1 & 1,1 & \\
\hline Total & 93 & 100 & \\
\hline
\end{tabular}

TABLA 18. FREC UENCIA Y DISTRIBUCIÓN SEG ÚN GRUPO DE EDAD DE LOS PARTICIPANTES

En la Tabla 19 se ofrece la distribución de respuestas en cuanto al tiempo de relación con la asociación, por parte de los participantes. Se puede observar cómo existe una importante dispersión de las puntuaciones, con un predominio de quienes llevan relacionándose con la a sociación entre uno y cuatro años (32,3\%).

\begin{tabular}{|l|c|c|c|c|}
\hline & Frecuencia & Porcentaje & $\begin{array}{c}\text { Porcentaje } \\
\text { válido }\end{array}$ & $\begin{array}{c}\text { Porcentaje } \\
\text { acumulado }\end{array}$ \\
\hline Menos 1 año & 8 & 8,6 & 8,6 & 8,6 \\
\hline $1-4$ años & 30 & 32,3 & 32,3 & 40,9 \\
\hline 5 años - 8 años & 16 & 17,2 & 17,2 & 58,1 \\
\hline $9-12$ años & 11 & 11,8 & 11,8 & 69,9 \\
\hline $13-16$ años & 11 & 11,8 & 11,8 & 81,7 \\
\hline Más de 16 años & 17 & 18,3 & 18,3 & 100 \\
\hline Total & 93 & 100 & 100 & \\
\hline
\end{tabular}

TABLA 19. FREC UENCIA Y DISTRIBUCIÓN DE LOS PARTICIPANTES, DE AC UERDO AL TIEMPO DE RELACIÓN CON AMICA

En la Tabla 20 se ofrece información sobre el centro al que pertenecen los participantes. Se puede observar el predominio de personas del Centro de Recursos Agustín Bárcena Cruz (33,3\%), seguido de los pertenecientes al centro Horizon (21,5\%).

\begin{tabular}{|l|c|c|c|}
\hline Centro & Frecuencia & Porcentaje & Porcentaje acumula do \\
\hline Centro de Recursos Agustín Bárcena Cruz & 31 & 33,3 & 33,7 \\
\hline Centro de día La Vega & 12 & 12,9 & 46,7 \\
\hline Centro Horizon & 20 & 21,5 & 68,5 \\
\hline Casa Helios & 1 & 1,1 & 69,6 \\
\hline
\end{tabular}




\begin{tabular}{|l|c|c|c|}
\hline Centro Entomo & 14 & 15,1 & 84,8 \\
\hline Centro Sotileza & 5 & 5,4 & 90,2 \\
\hline Centro Marisma & 3 & 3,2 & 93,5 \\
\hline Centro La Barca & 3 & 3,2 & 96,7 \\
\hline Centro de día Santoña & 3 & 3,2 & 100 \\
\hline NC & 1 & 1,1 & \\
\hline Total & 93 & 100 & \\
\hline
\end{tabular}

TABLA 20. FREC UENCIA Y DISTRIBUCIÓN DE LOS PARTICIPANTES, DE ACUERDO AL CENTRO DE PERTENENCIA

\subsubsection{Análisis de datos}

En el presente estudio hemos utilizado en diferentes fases del análisis el paquete esta dístico SPSS $®$ Versión 11.5 .0 (SPSS, 2000). Pa ra la configura ción de los gráfic os hemos utiliza do el programa Microsoft Excel Versión 2007 para PC.

\subsection{Resultados}

Comenzamos exponiendo en este apartado los resultados relativos a la elaboración del Cuestionario de Evaluación de los Indicadores del Index y del Cuestionario de Indicadores de Inclusión para, en segundo lugar, exponer los resultados derivados del contraste de hipótesis relacionadas con la valoración de la inc lusión.

\subsubsection{Análisis de los ítems}

Con esta fase pretendíamos asegurar que la configuración definitiva de la escala presentara unas características psicométricas suficientemente sólidas. El proceso seguido se basó en el análisis de la fiabilidad de las sucesivas iteraciones, 
eliminando, si fuera necesario y salvo excepciones que comentaremos en cada caso, los ítems cuya homogeneidad corregida no fuera aceptable. El criterio fija do para su inclusión fue que el ítem alcanzara un valor mínimo de homogeneidad corregida de 0,30 (salvo excepciones). Tras los sucesivos a nálisis que exponemos a continuación, la escala redujo su configuración inicial de 40 ítems a 24 que sivieron de base para los posteriores a nálisis.

\subsubsection{Estadístic os desc riptivos}

Una vez tabuladas las puntuaciones se realizó un recuento de frecuencias de las 3.720 respuestas obtenidas, a fin de comprobar cómo se distribuían cada una de las puntuaciones en el conjunto de los 40 ítems por parte de los 94 participantes. La Figura 32 muestra dicha distribución. Puede apreciarse una a simetría izquierda de las puntuaciones, lo que sugiere que las valoraciones de la inclusión son bastante favorables en el grupo a nalizado.

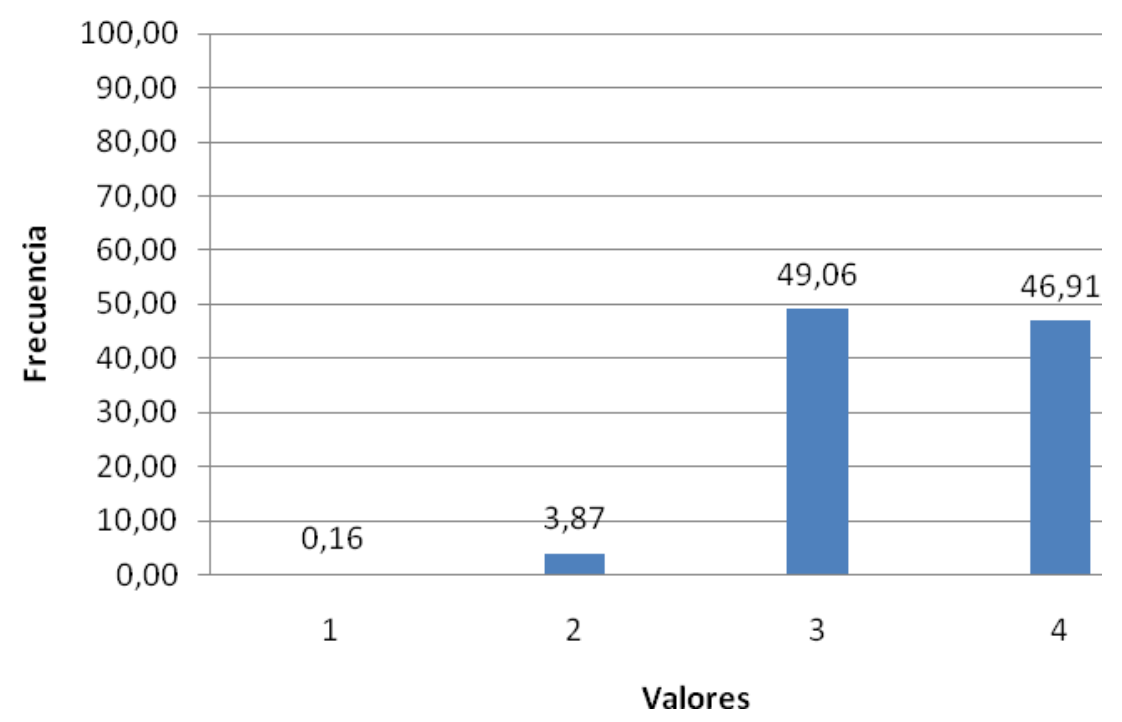

FIG URA 32. DISTRIBUCIÓN DE LAS RESPUESTAS A LOS ITEMS EN EL CUESTIONARIO DE INDICADORES DE INCLUSIÓN (CII) 
Esta asimetría a la izquierda queda también constatada en la gráfica siguiente (véase Figura 33), en la que aparece indicado para cada ítem la media y más-menos una desviación típica.

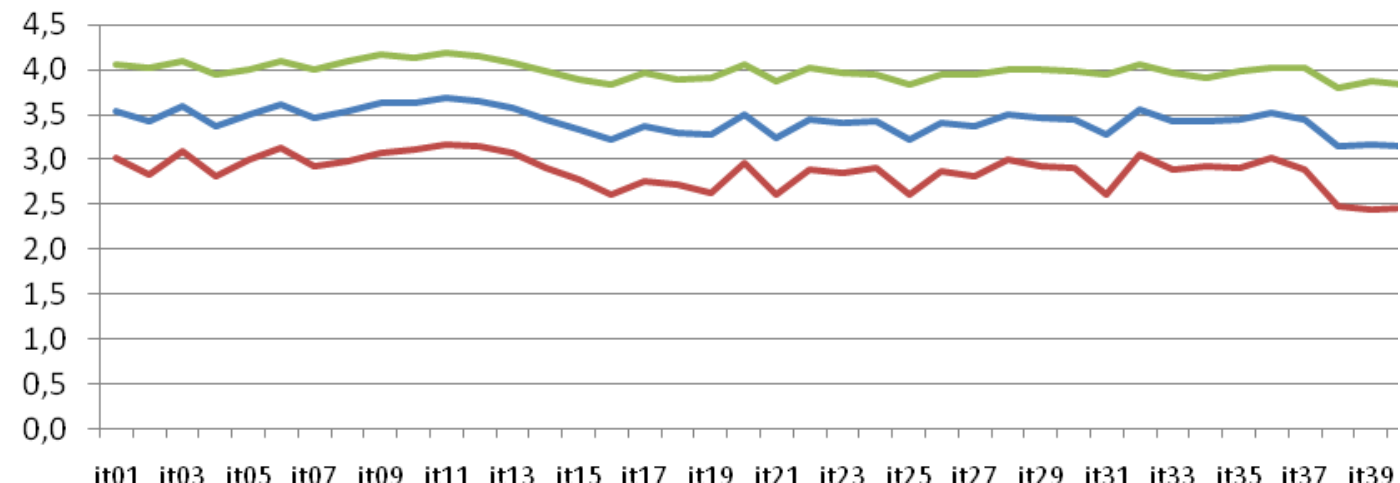

FIG URA 33. MEDIA Y DESVIACIO NES TÍPICAS DE LOS ITEMS DEL CUESTIONARIO DE INDICADORES DE INCLUSIÓN (CII).

Tras este análisis gráfico ofrecemos (véanse Tabla 21 y Tabla 22) las puntua ciones medias y más-menos una desviación típica, así como las frecuencias totales de la distribución de respuesta de los ítems. Puede observarse cómo los ítems que han supuesto una valoración más a lta son los ítems $11,3,6,9,10,11,12$ y 13. Queda también constatado cómo los ítems 38, 16, 21, 25, 39 y 40 suponen una valoración inferior. No obstante, a la vista de los resultados puede decirse que la escala posee una variabilidad razonable.

\begin{tabular}{|c|c|c|c|c|}
\hline Ítem & Media & Desv. típ. & m+1dt & M-1DT \\
\hline it01 & 3,5 & 0,5 & 4,1 & 3,0 \\
\hline it02 & 3,4 & 0,6 & 4,0 & 2,8 \\
\hline it03 & 3,6 & 0,5 & 4,1 & 3,1 \\
\hline it04 & 3,4 & 0,6 & 3,9 & 2,8 \\
\hline it05 & 3,5 & 0,5 & 4,0 & 3,0 \\
\hline it06 & 3,6 & 0,5 & 4,1 & 3,1 \\
\hline it07 & 3,5 & 0,5 & 4,0 & 2,9 \\
\hline it08 & 3,5 & 0,6 & 4,1 & 3,0 \\
\hline it09 & 3,6 & 0,5 & 4,2 & 3,1 \\
\hline it10 & 3,6 & 0,5 & 4,1 & 3,1 \\
\hline it11 & 3,7 & 0,5 & 4,2 & 3,2 \\
\hline it12 & 3,6 & 0,5 & 4,1 & 3,1 \\
\hline it13 & 3,6 & 0,5 & 4,1 & 3,1 \\
\hline it14 & 3,4 & 0,5 & 4,0 & 2,9 \\
\hline
\end{tabular}


CAPITULO 6. Evaluación de la inclusión en los centros para personascon discapacidad (Fase III y Fase IV)

\begin{tabular}{|r|l|l|l|l|}
\hline it15 & 3,3 & 0,6 & 3,9 & 2,8 \\
\hline it16 & 3,2 & 0,6 & 3,8 & 2,6 \\
\hline it17 & 3,4 & 0,6 & 4,0 & 2,8 \\
\hline it18 & 3,3 & 0,6 & 3,9 & 2,7 \\
\hline it19 & 3,3 & 0,6 & 3,9 & 2,6 \\
\hline it20 & 3,5 & 0,5 & 4,0 & 3,0 \\
\hline it21 & 3,2 & 0,6 & 3,9 & 2,6 \\
\hline it22 & 3,5 & 0,6 & 4,0 & 2,9 \\
\hline it23 & 3,4 & 0,6 & 4,0 & 2,9 \\
\hline it24 & 3,4 & 0,5 & 3,9 & 2,9 \\
\hline it25 & 3,2 & 0,6 & 3,8 & 2,6 \\
\hline it26 & 3,4 & 0,5 & 3,9 & 2,9 \\
\hline it27 & 3,4 & 0,6 & 3,9 & 2,8 \\
\hline it28 & 3,5 & 0,5 & 4,0 & 3,0 \\
\hline it29 & 3,5 & 0,5 & 4,0 & 2,9 \\
\hline it30 & 3,4 & 0,5 & 4,0 & 2,9 \\
\hline it31 & 3,3 & 0,7 & 3,9 & 2,6 \\
\hline it32 & 3,5 & 0,5 & 4,0 & 3,0 \\
\hline it33 & 3,4 & 0,5 & 4,0 & 2,9 \\
\hline it34 & 3,4 & 0,5 & 3,9 & 2,9 \\
\hline it35 & 3,4 & 0,5 & 4,0 & 2,9 \\
\hline it36 & 3,5 & 0,5 & 4,0 & 3,0 \\
\hline it37 & 3,5 & 0,6 & 4,0 & 2,9 \\
\hline it38 & 3,1 & 0,7 & 3,8 & 2,5 \\
\hline it39 & 3,2 & 0,7 & 3,9 & 2,4 \\
\hline it40 & 3,2 & 0,7 & 3,8 & 2,5 \\
\hline & & & & \\
\hline
\end{tabular}

TABLA 21. MEDIA MÁS-MENOS UNA DESVIACIÓN TÍPICA DE LOS ITEMS DEL C UESTIONARIO DE INDICADORES DE INCLUSIÓN (CII)

\begin{tabular}{|l|l|l|l|l|}
\hline ítem & frec_1 & frec_2 & frec_3 & frec_4 \\
\hline it01 & $0(0,0)$ & $1(1,1)$ & $41(44,1)$ & $51(54,8)$ \\
\hline it02 & $1(1,1)$ & $2(2,2)$ & $47(50,5)$ & $43(46,2)$ \\
\hline it03 & $0(0,0)$ & $0(0,0)$ & $38(40,9)$ & $55(59,1)$ \\
\hline it04 & $0(0,0)$ & $4(4,3)$ & $50(53,8)$ & $39(41,9)$ \\
\hline it05 & $0(0,0)$ & $0(0,0)$ & $47(50,5)$ & $46(49,5)$ \\
\hline it06 & $0(0,0)$ & $0(0,0)$ & $36(38,7)$ & $57(61,3)$ \\
\hline it07 & $0(0,0)$ & $2(2,2)$ & $46(49,5)$ & $45(48,4)$ \\
\hline it08 & $0(0,0)$ & $3(3,2)$ & $37(39,8)$ & $53(57,0)$ \\
\hline it09 & $0(0,0)$ & $3(3,2)$ & $29(31,2)$ & $61(65,6)$ \\
\hline it10 & $0(0,0)$ & $1(1,1)$ & $33(35,5)$ & $59(63,4)$ \\
\hline it11 & $0(0,0)$ & $2(2,2)$ & $26(28,0)$ & $65(69,9)$ \\
\hline it12 & $0(0,0)$ & $1(1,1)$ & $31(33,3)$ & $61(65,6)$ \\
\hline it13 & $0(0,0)$ & $0(0,0)$ & $40(43,0)$ & $53(57,0)$ \\
\hline it14 & $0(0,0)$ & $2(2,2)$ & $48(51,6)$ & $43(46,2)$ \\
\hline it15 & $0(0,0)$ & $4(4,3)$ & $54(58,1)$ & $35(37,6)$ \\
\hline it16 & $0(0,0)$ & $9(9,7)$ & $54(58,1)$ & $30(32,3)$ \\
\hline it17 & $0(0,0)$ & $6(6,5)$ & $47(50,5)$ & $40(43,0)$ \\
\hline
\end{tabular}




\begin{tabular}{|l|l|l|l|l|}
\hline it18 & $0(0,0)$ & $6(6,5)$ & $53(57,0)$ & $34(36,6)$ \\
\hline it19 & $1(1,1)$ & $7(7,5)$ & $51(54,8)$ & $34(36,6)$ \\
\hline it20 & $0(0,0)$ & $2(2,2)$ & $42(45,2)$ & $49(52,7)$ \\
\hline it21 & $2(2,2)$ & $4(4,3)$ & $57(61,3)$ & $30(32,3)$ \\
\hline it22 & $0(0,0)$ & $3(3,2)$ & $45(48,4)$ & $45(48,4)$ \\
\hline it23 & $0(0,0)$ & $3(3,2)$ & $49(52,7)$ & $41(44,1)$ \\
\hline it24 & $0(0,0)$ & $1(1,1)$ & $51(54,8)$ & $41(44,1)$ \\
\hline it25 & $0(0,0)$ & $9(9,7)$ & $54(58,1)$ & $30(32,3)$ \\
\hline it26 & $0(0,0)$ & $2(2,2)$ & $51(54,8)$ & $40(43,0)$ \\
\hline it27 & $0(0,0)$ & $4(4,3)$ & $50(53,8)$ & $39(41,9)$ \\
\hline it28 & $0(0,0)$ & $0(0,0)$ & $47(50,5)$ & $46(49,5)$ \\
\hline it29 & $0(0,0)$ & $2(2,2)$ & $46(49,5)$ & $45(48,4)$ \\
\hline it30 & $0(0,0)$ & $2(2,2)$ & $48(51,6)$ & $43(46,2)$ \\
\hline it31 & $0(0,0)$ & $11(11,8)$ & $45(48,4)$ & $37(39,8)$ \\
\hline it32 & $0(0,0)$ & $0(0,0)$ & $42(45,2)$ & $51(54,8)$ \\
\hline it33 & $0(0,0)$ & $2(2,2)$ & $50(53,8)$ & $41(44,1)$ \\
\hline it34 & $0(0,0)$ & $0(0,0)$ & $54(58,1)$ & $39(41,9)$ \\
\hline it35 & $0(0,0)$ & $2(2,2)$ & $48(51,6)$ & $43(46,2)$ \\
\hline it36 & $0(0,0)$ & $0(0,0)$ & $44(47,3)$ & $49(52,7)$ \\
\hline it37 & $0(0,0)$ & $3(3,2)$ & $45(48,4)$ & $45(48,4)$ \\
\hline it38 & $1(1,1)$ & $11(11,8)$ & $55(59,1)$ & $26(28,0)$ \\
\hline it39 & $0(0,0)$ & $17(18,3)$ & $44(47,3)$ & $32(34,4)$ \\
\hline it40 & $1(1,1)$ & $13(14,0)$ & $50(53,8)$ & $29(31,2)$ \\
\hline & & & & \\
\hline
\end{tabular}

TABLA 22. FREC UENCIASY PORCENTAJ E DE LA DISTRIBUC IÓN DE RESPUESTAS DE LOS ITEMS DEL CUESTIONARIO DE INDICADORES DE INCLUSIÓN (C II)

\subsubsection{Disc riminación de los ítems}

Calculamos el poder discriminativo de los ítems aislando las puntuaciones tota les de los sujetos por encima del centil $75(\mathrm{~N}=24)$ y por debajo del Centil $25(\mathrm{~N}=$ 25), realizando posteriomente un contraste de la diferencia entre las medias de ambos grupos, mediante la prueba t para grupos independientes (véase Tabla 23). Los puntos de corte se encontraban en las puntuaciones 124 y 148 (Centiles 25 y 75 , respec tiva mente). 
Puede observarse cómo en todos los ítems se superó el nivel de confianza de 1 por $1000(\alpha \varangle 0,001)$ por lo que optamos por retener todos los ítems para el posterior análisis. El rango de las diferencias en valores absolutos oscila entre 1,42 (ítem 39) y 0,98(ítem 06).

\begin{tabular}{|c|c|c|c|c|c|c|c|c|}
\hline \multirow[b]{2}{*}{ ítems } & \multicolumn{2}{|c|}{ G. Bajo } & \multicolumn{2}{|c|}{ G.Alto } & \multirow[b]{2}{*}{ dif } & \multirow[b]{2}{*}{$\mathrm{t}$} & \multirow[b]{2}{*}{ gl } & \multirow[b]{2}{*}{$\mathrm{p}$} \\
\hline & M & DT & M & DT & & & & \\
\hline it01 & 3,20 & 0,50 & 3,92 & 0,28 & 1,05 & 6,21 & 38,19 & 0,000 \\
\hline it02 & 3,12 & 0,44 & 3,75 & 0,53 & 1,19 & 4,51 & 44,67 & 0,000 \\
\hline it03 & 3,20 & 0,41 & 3,88 & 0,34 & 0,99 & 6,32 & 46,02 & 0,000 \\
\hline it04 & 2,96 & 0,45 & 3,83 & 0,38 & 1,14 & 7,30 & 46,16 & 0,000 \\
\hline it05 & 3,00 & 0,00 & 3,92 & 0,28 & 1,01 & 15,91 & 23,00 & 0,000 \\
\hline it06 & 3,24 & 0,44 & 3,88 & 0,34 & 0,98 & 5,71 & 45,03 & 0,000 \\
\hline it07 & 3,00 & 0,41 & 3,92 & 0,28 & 1,09 & 9,17 & 42,79 & 0,000 \\
\hline it08 & 3,20 & 0,50 & 3,88 & 0,45 & 1,13 & 4,98 & 46,79 & 0,000 \\
\hline it09 & 3,28 & 0,61 & 3,92 & 0,41 & 1,10 & 4,29 & 41,93 & 0,000 \\
\hline it10 & 3,24 & 0,44 & 4,00 & 0,00 & 1,02 & 8,72 & 24,00 & 0,000 \\
\hline it11 & 3,20 & 0,41 & 4,00 & 0,00 & 1,03 & 9,80 & 24,00 & 0,000 \\
\hline it12 & 3,16 & 0,47 & 4,00 & 0,00 & 1,01 & 8,89 & 24,00 & 0,000 \\
\hline it13 & 3,20 & 0,41 & 4,00 & 0,00 & 1,00 & 9,80 & 24,00 & 0,000 \\
\hline it14 & 3,04 & 0,35 & 3,92 & 0,28 & 1,08 & 9,65 & 45,62 & 0,000 \\
\hline it15 & 2,96 & 0,35 & 3,79 & 0,51 & 1,12 & 6,63 & 40,68 & 0,000 \\
\hline it16 & 2,76 & 0,44 & 3,83 & 0,38 & 1,22 & 9,19 & 46,60 & 0,000 \\
\hline it17 & 2,88 & 0,44 & 3,92 & 0,28 & 1,21 & 9,86 & 41,13 & 0,000 \\
\hline it18 & 2,88 & 0,44 & 3,83 & 0,38 & 1,17 & 8,12 & 46,52 & 0,000 \\
\hline it19 & 2,76 & 0,60 & 3,79 & 0,41 & 1,29 & 7,05 & 42,88 & 0,000 \\
\hline it20 & 3,08 & 0,49 & 3,88 & 0,34 & 1,09 & 6,60 & 42,58 & 0,000 \\
\hline it21 & 2,76 & 0,66 & 3,88 & 0,34 & 1,26 & 7,46 & 35,98 & 0,000 \\
\hline it22 & 2,96 & 0,45 & 3,92 & 0,28 & 1,12 & 8,89 & 40,36 & 0,000 \\
\hline it23 & 2,96 & 0,35 & 3,92 & 0,28 & 1,11 & 10,53 & 45,62 & 0,000 \\
\hline it24 & 3,04 & 0,35 & 3,88 & 0,34 & 1,04 & 8,48 & 47,00 & 0,000 \\
\hline it25 & 2,76 & 0,44 & 3,71 & 0,46 & 1,22 & 7,36 & 46,49 & 0,000 \\
\hline it26 & 3,00 & 0,29 & 3,96 & 0,20 & 1,07 & 13,46 & 43,26 & 0,000 \\
\hline it27 & 3,00 & 0,50 & 3,96 & 0,20 & 1,14 & 8,85 & 32,05 & 0,000 \\
\hline it28 & 3,08 & 0,28 & 3,96 & 0,20 & 1,01 & 12,67 & 44,11 & 0,000 \\
\hline it29 & 3,08 & 0,40 & 3,92 & 0,28 & 1,09 & 8,49 & 43,23 & 0,000 \\
\hline it30 & 3,04 & 0,45 & 3,88 & 0,34 & 1,08 & 7,32 & 44,27 & 0,000 \\
\hline it31 & 2,64 & 0,49 & 3,96 & 0,20 & 1,33 & 12,38 & 32,36 & 0,000 \\
\hline it32 & 3,20 & 0,41 & 3,96 & 0,20 & 1,00 & 8,27 & 35,61 & 0,000 \\
\hline it33 & 2,96 & 0,35 & 3,96 & 0,20 & 1,08 & 12,22 & 38,84 & 0,000 \\
\hline it34 & 3,16 & 0,37 & 3,88 & 0,34 & 0,99 & 7,03 & 46,83 & 0,000 \\
\hline it35 & 3,00 & 0,41 & 3,96 & 0,20 & 1,08 & 10,45 & 35,61 & 0,000 \\
\hline it36 & 3,08 & 0,28 & 4,00 & 0,00 & 1,00 & 16,61 & 24,00 & 0,000 \\
\hline it37 & 2,96 & 0,35 & 4,00 & 0,00 & 1,12 & 14,81 & 24,00 & 0,000 \\
\hline it38 & 2,68 & 0,63 & 3,71 & 0,46 & 1,31 & 6,54 & 44,20 & 0,000 \\
\hline it39 & 2,60 & 0,50 & 3,71 & 0,46 & 1,42 & 8,04 & 46,95 & 0,000 \\
\hline it40 & 2,72 & 0,46 & 3,67 & 0,70 & 1,38 & 5,57 & 39,36 & 0,000 \\
\hline
\end{tabular}

TABLA 23. DISC RIMINACIÓN DE LOS ITEMS DEL CUESTIONARIO DE INDIC ADO RES DE INCLUSIÓN (CII): RESULTADO DEL CONTRASTE ENTRE MEDIAS (PRUEBA T. DIFERENCIAS EN VALORES ABSOLUTOS) 
En la Figura 34 se presentan gráficamente las puntuaciones medias en cada ítem obtenidas por el grupo a lto y bajo, respectivamente,

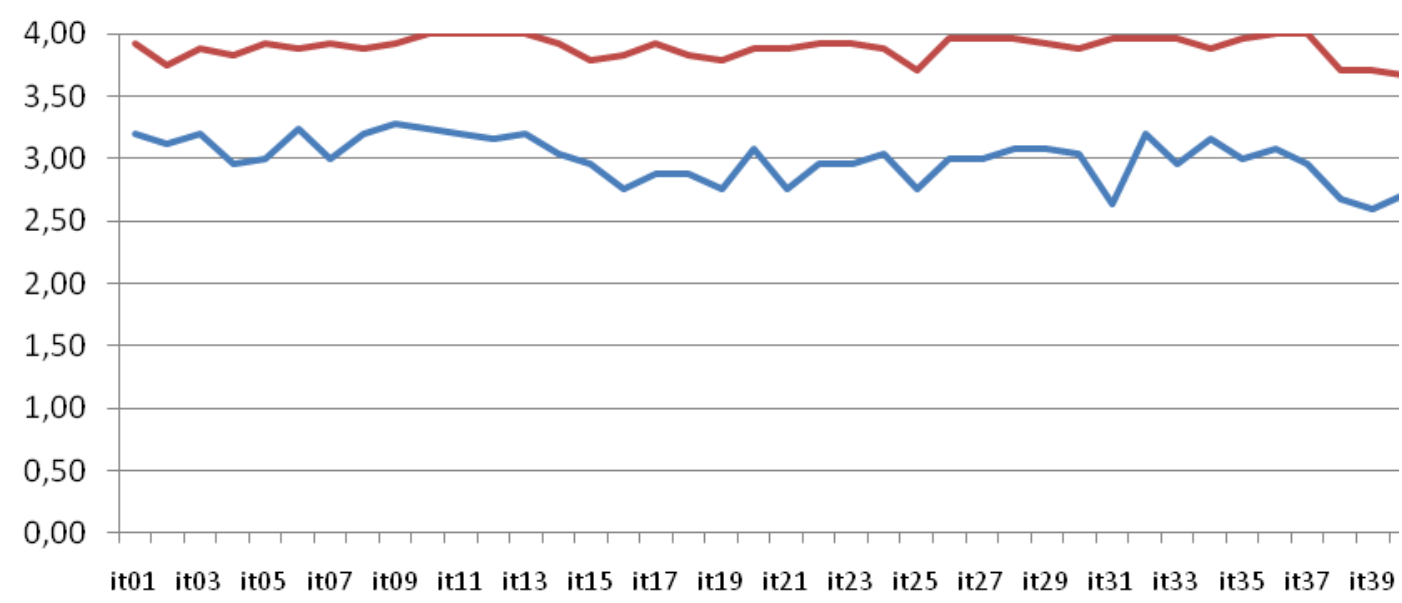

-G_Alto -G_Bajo

FIGURA 34. DISCRIMINACIÓN DE LOS ITEMS -MEDIAS GRUPO ALTO-BAJO, EN CADA ITEM DEL CUESTIONARIO DE INDICADORES DE INCLUSION (CII)

Podemos decir que todos los ítems de la configuración inicial de la escala han demostrado una potencia discriminativa suficiente entre sujetos altos y bajos en cuanto a madurez hacia el empleo.

\subsubsection{Fiabilidad de los ítems}

Hemos obtenido los coeficientes de correlación producto-momento de Parson entre cada ítem y la puntuación total. Puede observarse (véase Tabla 24) cómo todas las correlaciones fueron significativas a un nivel de confianza de 1 por $100(\alpha<0,01)$, lo que nos condujo a retener todos los ítems pa ra el posterior a ná lisis. 
CAPITULO 6. Evaluación de la inclusión en los centros para personascon discapacidad (Fase III y Fase IV)

\begin{tabular}{|l|l|l|l|l|l|}
\hline Ítems & \multicolumn{1}{|c|}{ Rxy } & Ítems & \multicolumn{1}{c|}{ Rxy } & Ítems & \multicolumn{1}{c|}{ Rxy } \\
\hline it01 &, $546^{* *}$ & it15 &, $592^{* *}$ & it29 &, $669^{* *}$ \\
\hline it02 &, $406^{* *}$ & it16 &, $701^{* *}$ & it30 &, $636^{* *}$ \\
\hline it03 &, $569^{* *}$ & it17 &, $658^{* *}$ & it31 &, $757^{* *}$ \\
\hline it04 &, $650^{* *}$ & it18 &, $636^{* *}$ & it32 &, $641^{* *}$ \\
\hline it05 &, $698^{* *}$ & it19 &, $621^{* *}$ & it33 &, $717^{* *}$ \\
\hline it06 &, $524^{* *}$ & it20 &, $567^{* *}$ & it34 &, $514^{* *}$ \\
\hline it07 &, $668^{* *}$ & it21 &, $698^{* *}$ & it35 &, $665^{* *}$ \\
\hline it08 &, $445^{* *}$ & it22 &, $693^{* *}$ & it36 &, $683^{* *}$ \\
\hline it09 &, $485^{* *}$ & it23 &, $698^{* *}$ & it37 &, $640^{* *}$ \\
\hline it10 &, $541^{* *}$ & it24 &, $702^{* *}$ & it38 &, $626^{* *}$ \\
\hline it11 &, $500^{* *}$ & it25 &, $619^{* *}$ & it39 &, $608^{* *}$ \\
\hline it12 &, $630^{* *}$ & it26 &, $678^{* *}$ & it40 &, $479^{* *}$ \\
\hline it13 &, $603^{* *}$ & it27 &, $696^{* *}$ & & \\
\hline it14 &, $658^{* *}$ & it28 &, $696^{* *}$ & & \\
\hline & & & & & \\
\hline
\end{tabular}

** La correlación es signific ativa al nivel 0,01 (bila teral).

TABLA 24. COEFICIENTES DE CORRELACIÓN DE PEARSON ENTRE LOS ITEMS Y LA PUNTUACIÓN TOTAL DEL CUESTIONARIO DE INDICADORES DE INCLUSIÓN (C II)

\subsubsection{Análisis de la escala}

\subsubsection{Fiabilidad de la Escala}

Para realizar este análisis nos basamos en la fiabilidad entendida como la consistencia intema, utilizando dos métodos: el índice Alfa de Cronbach y el método de correlación entre dos mitades (Split-Half) con la corrección de Spearman-Brown. Además, hemos estima do la fiabilidad mediante juicios de jueces expertos.

Así pues, por lo que se refiere a la fiabilidad de la escala considerada globalmente, hemos obteniendo un Índice Alfa de Cronbach=0,96. En cuanto a la 
correlación entre dos mitades, hemos obtenido un Coeficiente de Correlación Spea man-Brown $=0,91$.

Por lo que se refiere al juicio de jueces expertos, elegimos a seis jueces expertos a quienes se les pidió señalar la categońa a la que pertenecían cada uno de los ítems. En la Tabla 25 se presentan los resultados obtenidos. Se puede observar cómo en 34 de los 40 ítems, la moda coincide con la categoría a la que teóricamente pertenecía el ítem, lo que indica que todos o la mayoría de los jueces coincidieron en adscribir el ítem a la categońa correcta. Los resultados obtenidos en los ítems $8,10,12,18,22,27$, y 37 ind ic an que los juec es a dscribieron mayoritariamente los ítems a una categoría distinta a la de pertenencia teóricamente hablando.

\begin{tabular}{|l|c|c|c|c|c|c|c|c|}
\hline & j01 & j02 & j03 & j04 & j05 & j06 & MODA & Dimensión \\
\hline it01 & 6 & 5 & 6 & 6 & 6 & 6 & 6 & 6 \\
\hline it02 & 3 & 1 & 3 & 1 & 1 & 1 & 1 & 1 \\
\hline it03 & 4 & 3 & 4 & 5 & 5 & 4 & 4 & 4 \\
\hline it04 & 3 & 4 & 1 & 4 & 3 & 2 & 3 & 3 \\
\hline it05 & 3 & 5 & 3 & 3 & 3 & 3 & 3 & 3 \\
\hline it06 & 3 & 4 & 3 & 3 & 3 & 3 & 3 & 3 \\
\hline it07 & 4 & 3 & 4 & 4 & 4 & 4 & 4 & 4 \\
\hline it08 & 1 & 2 & 2 & 1 & 2 & 1 & 1 & 2 \\
\hline it09 & 2 & 2 & 2 & 3 & 1 & 2 & 2 & 2 \\
\hline it10 & 1 & 2 & 2 & 2 & 1 & 1 & 1 & 2 \\
\hline it11 & 1 & 5 & 2 & 4 & 2 & 2 & 2 & 2 \\
\hline it12 & 2 & 2 & 4 & 2 & 2 & 2 & 2 & 1 \\
\hline it13 & 2 & 2 & 4 & 4 & 2 & 2 & 2 & 2 \\
\hline it14 & 3 & 4 & 4 & 4 & 4 & 6 & 4 & 4 \\
\hline it15 & 2 & 1 & 1 & 1 & 1 & 4 & 1 & 1 \\
\hline it16 & 1 & 1 & 1 & 1 & 1 & 1 & 1 & 1 \\
\hline it17 & 3 & 3 & 4 & 3 & 3 & 4 & 3 & 3 \\
\hline it18 & 4 & 1 & 6 & 6 & 6 & 4 & 6 & 2 \\
\hline it19 & 4 & 4 & 1 & 1 & 4 & 4 & 4 & 4 \\
\hline it20 & 4 & 4 & 3 & 4 & 4 & 4 & 4 & 4 \\
\hline it21 & 3 & 4 & 1 & 3 & 3 & 3 & 3 & 3 \\
\hline it22 & 5 & 6 & 5 & 5 & 5 & 5 & 5 & 6 \\
\hline it23 & 5 & 5 & 6 & 5 & 6 & 6 & 5 & 5 \\
\hline it24 & 6 & 5 & 5 & 5 & 5 & 6 & 5 & 6 \\
\hline it25 & 6 & 6 & 6 & 6 & 6 & 6 & 6 & 6 \\
\hline it26 & 6 & 5 & 6 & 6 & 6 & 6 & 6 & 6 \\
\hline it27 & 6 & 5 & 6 & 6 & 6 & 1 & 6 & 5 \\
\hline it28 & 5 & 5 & 5 & 5 & 5 & 5 & 5 & 5 \\
\hline it29 & 1 & 5 & 5 & 5 & 5 & 5 & 5 & 5 \\
\hline it30 & 3 & 5 & 1 & 5 & 5 & 5 & 5 & 5 \\
\hline it31 & 2 & 2 & 2 & 1 & 1 & 2 & 2 & 2 \\
\hline it32 & 3 & 3 & 3 & 3 & 3 & 3 & 3 & 3 \\
\hline it33 & 3 & 3 & 3 & 3 & 3 & 3 & 3 & 3 \\
\hline & & & & & & & \\
\hline
\end{tabular}


CAPITULO 6. Evaluación de la inclusión en los centros para personascon discapacidad (Fase III y Fase IV)

\begin{tabular}{|l|l|l|l|l|l|l|l|l|}
\hline it34 & 1 & 1 & 1 & 1 & 1 & 1 & 1 & 1 \\
\hline it35 & 4 & 4 & 4 & 5 & 3 & 4 & 4 & 4 \\
\hline it36 & 5 & 5 & 5 & 5 & 5 & 5 & 5 & 5 \\
\hline it37 & 2 & 6 & 5 & 5 & 4 & 4 & 5 & 4 \\
\hline it38 & 6 & 5 & 6 & 6 & 3 & 6 & 6 & 6 \\
\hline it39 & 1 & 1 & 1 & 1 & 1 & 1 & 1 & 1 \\
\hline it40 & 1 & 1 & 1 & 1 & 1 & 1 & 1 & 1 \\
\hline
\end{tabular}

TABLA 25. VALORACIONES DE LOSJ UECES RESPECTO A LA CATEG ORÍA DE PERTENENCIA DE LOS ITEMS DEL CUESTIONARIO DE EVALUACIÓN DE LOS INDICADORES DEL INDEX

De modo complementario, empleamos varios estadístic os para deteminar la fiabilidad entre obsenadores para datos nominales. En la Tabla 26 se ofrece el resumen del porcentaje de acuerdo entre jueces. Se puede observar cómo el acuerdo promedio es de $58 \%$. Los acuerdos más elevados se alcanzan entre los jueces 1 y 6, así como entre los jueces 4 y 5. Los menores acuerdos se obtienen entre los jueces 1 y 2 y los jueces 2 y 3 . Estos datos son corroborados por los obtenidos con el estadístico Kappa de Cohen en el que se obtienen valores entre 0,34 y 0,67. Por otro lado, el estadístico Kappa de Fleiss a rrojó un valor de 0,491 (acuerdo observado=0,58; Acuerdo esperado=0,17). Finalmente, cabe destacar que con el estadístico Alfa de Krippendorff se obtuvo un valor $=0,50$.

\begin{tabular}{|c|c|c|}
\hline Acuerdo entre pares & Porcentaje & Kappa de Cohen \\
\hline Jueces 1 y 6 & $72.5 \%$ & 0,67 \\
\hline Jueces 1 y 5 & $60.0 \%$ & 0,52 \\
\hline Jueces 1 y 4 & $57.5 \%$ & 0,49 \\
\hline Jueces 1 y 3 & $55.0 \%$ & 0,46 \\
\hline Jueces 1 y 2 & $45.0 \%$ & 0,35 \\
\hline Jueces 2 y 6 & $47.5 \%$ & 0,37 \\
\hline Jueces 2 y 5 & $52.5 \%$ & 0,43 \\
\hline Jueces 2 y 4 & $52.5 \%$ & 0,42 \\
\hline Jueces 2 y 3 & $45.0 \%$ & 0,34 \\
\hline Jueces 3 y 6 & $60.0 \%$ & 0,52 \\
\hline Jueces 3 y 5 & $60.0 \%$ & 0,52 \\
\hline Jueces 3 y 4 & $65.0 \%$ & 0,58 \\
\hline Jueces 4 y 6 & $57.5 \%$ & 0,49 \\
\hline Jueces 4 y 5 & $72.5 \%$ & 0,67 \\
\hline Jueces 5 y 6 & $67.5 \%$ & 0,61 \\
\hline Promedio de acuerdo & $58.0 \%$ & 0,50 \\
\hline
\end{tabular}

TABLA 26. PORCENTAJ E DE AC UERDO ENTRE PARES DE J UECESY ESTADÍSTICO KAPPA DE COHEN EN EL CUESTIONARIO DE EVALUACIÓN DE LOS INDICADORES DEL INDEX. 
En la Tabla 27 se presenta n los resultados obtenidos tras a na liza r la fiabilidad de la escala considerada globalmente. Se puede observar cómo todos los ítems muestran una elevada correlación corregida con el total de la escala, superior a 0,35 en todos los casos, lo que avala la consistencia intema del instrumento.

\begin{tabular}{|c|c|c|c|c|}
\hline Ítem & $\begin{array}{c}\text { Media } \\
\text { corregida }\end{array}$ & $\begin{array}{l}\text { Varianza } \\
\text { corregida }\end{array}$ & $\begin{array}{c}\text { Correlación } \\
\text { corregida }\end{array}$ & $\begin{array}{c}\text { Alfa de } \\
\text { Cronbach } \\
\text { corregida }\end{array}$ \\
\hline it01 & 133,55 & 185,163 &, 519 & ,958 \\
\hline it02 & 133,67 & 186,464 & ,369 & ,959 \\
\hline it03 & 133,49 & 185,253 &, 544 & ,958 \\
\hline it04 & 133,71 & 182,860 & ,626 &, 957 \\
\hline it05 & 133,59 & 183,331 & ,678 & ,957 \\
\hline it06 & 133,47 & 185,926 & ,498 &, 958 \\
\hline it07 & 133,62 & 183,042 & ,645 &, 957 \\
\hline it08 & 133,55 & 186,185 & ,411 & ,958 \\
\hline it09 & 133,46 & 185,708 & ,454 & ,958 \\
\hline it10 & 133,46 & 185,425 &, 515 & ,958 \\
\hline it11 & 133,41 & 185,940 & ,472 & ,958 \\
\hline it12 & 133,44 & 184,271 & ,607 & ,957 \\
\hline it13 & 133,52 & 184,731 & ,579 & ,957 \\
\hline it14 & 133,65 & 183,231 & ,635 & ,957 \\
\hline it15 & 133,75 & 183,949 &, 565 &, 958 \\
\hline it16 & 133,86 & 181,317 & 677 & ,957 \\
\hline it17 & 133,72 & 182,138 & ,633 & ,957 \\
\hline it18 & 133,78 & 182,823 & ,609 & ,957 \\
\hline it19 & 133,82 & 182,108 &, 591 & ,957 \\
\hline it20 & 133,58 & 184,550 &, 539 & ,958 \\
\hline it21 & 133,85 & 180,955 & 674 & ,957 \\
\hline it22 & 133,63 & 182,321 & 671 & ,957 \\
\hline it23 & 133,68 & 182,351 & ,676 & ,957 \\
\hline it24 & 133,66 & 182,967 & ,682 & ,957 \\
\hline it25 & 133,86 & 182,709 &, 590 & ,957 \\
\hline it26 & 133,68 & 183,004 & ,656 & ,957 \\
\hline it27 & 133,71 & 182,143 & ,674 & ,957 \\
\hline it28 & 133,59 & 183,353 & ,677 & ,957 \\
\hline it29 & 133,62 & 183,020 & ,647 & ,957 \\
\hline it30 & 133,65 & 183,558 & ,612 & ,957 \\
\hline it31 & 133,81 & 179,266 & ,736 & ,956 \\
\hline it32 & 133,54 & 184,164 & ,619 & ,957 \\
\hline it33 & 133,67 & 182,399 & ,697 &, 957 \\
\hline it34 & 133,67 & 185,986 & ,487 &, 958 \\
\hline it35 & 133,65 & 183,123 & ,642 &, 957 \\
\hline it36 & 133,56 & 183,554 & ,663 & ,957 \\
\hline it37 & 133,63 & 183,147 & ,615 & ,957 \\
\hline it38 & 133,95 & 181,899 &, 596 & ,957 \\
\hline it39 & 133,92 & 181,309 &, 574 &, 958 \\
\hline it40 & 133,94 & 184,104 & ,439 &, 959 \\
\hline
\end{tabular}

TABLA 27. RESULTADOSDEL ANÁLISIS DE FIABILIDAD DE LA ESCALA CONSIDERADA GLOBALMENTE 
CAPITULO 6. Evaluación de la inclusión en los centros para personas con discapacidad (Fase III y Fase IV)

Esto s a ná lisis so bre la consistencia intema se complementa rán c on el a ná lisis de las dimensiones resultantes del a ná lisis factorial, en pá gina s posteriores.

\subsubsection{Validez de la Escala}

A continuación presentamos cada uno de los tipos de validez y los procedimientos seguidos para deteminarlos, especialmente la validez de contenido, la validez referida a un criterio (validez concurrente y predictiva) y la validez de constructo.

Para determinar la validez de contenido hemos optado por tres vías: la revisión de contenidos en la literatura, los datos de validez de contenido efectuados con esta escala y la consulta a expertos y el a nálisis de contenido de cada uno de los ítems.

En cuanto a la primera y como expusimos en la parte teórica, hemos selec cionado términos que se relacionan con los factores clave de la inclusión.

Este hec ho queda constata do en el a nálisis factorial rea lizado con la escala y que expondremos seguidamente con más detalle, sin embargo, podemos adelantar que en dicho análisis se obtienen cuatro factores denominados: Prácticas, Comunidad, Políticas, y Valores. Además, como ya expusimos, los jueces consultados consideraron que esta escala medía dichos constructos, mostrando una elevada uniformidad en sus valoraciones.

\subsection{Análisis fac torial}

Los datos se sometieron a análisis factorial por el método de componentes principales. Además, dado que los factores se encuentran estrechamente relacionados tanto desde el punto de vista de los datos, como desde el punto de 
vista conceptual, procedimos a emplear un a nálisis fac to rial empleando el método de rotación Oblimin. Los a nálisis confimaron la existencia de un único factor en el que se distribuyen los diferentes ítems del cuestiona rio, la inclusión.

A la vista de los resultados obtenidos, procedimos a realizar de nuevo un a nálisis factorial, en este c aso con rota ción Varimax y normalización de Kaiser, para tratar de obtener factores lo más independientes posible, que nos permitieran contar con una herramienta de screening sobre áreas de mejora a trabajar en los diferentes centros. El a nálisis puso de manifiesto la existencia de algunos ítems que saturaban con claridad en un factor, mientras que otros ítems saturaban en varios factores. Estos últimos fueron eliminados, lo que permitió finalmente obtener una escala abreviada, compuesta por cuatro factores, que se detalla a continuación. En la Tabla 28 se puede observar cómo las saturaciones factoriales son superiores a 0,60. Las sa tura ciones inferiores aparecen en blanco.

\begin{tabular}{|l|l|l|l|l|}
\hline & Factor 1 & Factor 2 & Factor 3 & Factor 4 \\
\hline it02 & & & 0,76 & \\
\hline it03 & & & 0,61 & \\
\hline it05 & & & 0,55 & \\
\hline it06 & & & 0,69 & \\
\hline it07 & & & 0,67 & \\
\hline it08 & & & & 0,79 \\
\hline it10 & & & & 0,66 \\
\hline it11 & & & & 0,65 \\
\hline it12 & & & & 0,73 \\
\hline it13 & & & & 0,65 \\
\hline it14 & & & 0,67 & \\
\hline it17 & 0,73 & & & \\
\hline it18 & & 0,66 & & \\
\hline it19 & & 0,60 & & \\
\hline it25 & & 0,67 & & \\
\hline it26 & 0,67 & & & \\
\hline it27 & 0,67 & & & \\
\hline it28 & 0,64 & & & \\
\hline it31 & 0,66 & & & \\
\hline it32 & 0,79 & & & \\
\hline
\end{tabular}


CAPITULO 6. Evaluación de la inclusión en loscentros para personascon discapacidad (Fase III y Fase IV)

\begin{tabular}{|l|l|l|l|l|}
\hline it33 & 0,64 & & & \\
\hline it38 & & 0,74 & & \\
\hline it39 & & 0,79 & & \\
\hline it40 & & 0,74 & & \\
\hline
\end{tabular}

TABLA 28. MATRIZFACTORIAL ROTADA DEL C UESTIONARIO INDICADORES DE INCLUSIÓN

Las Ta blas siguientes (Tablas 29, 30, 31, 32, 33) recogen respectivamente los valores propios y la proporción de varianza explicada. Como puede observarse en la Tabla 29 , el conjunto de los cuatro factores extraídos explican un $62,5 \%$ de la va rianza total.

\begin{tabular}{|l|l|l|l|}
\hline & \multicolumn{3}{|l|}{ Autovalores iniciales } \\
\hline Componente & Total & $\%$ de la varianza & $\%$ acumula do \\
\hline Factor 1 & 9,468 & 39,449 & 39,449 \\
\hline Factor 2 & 2,476 & 10,317 & 49,767 \\
\hline Factor 3 & 1,569 & 6,538 & 56,305 \\
\hline Factor 4 & 1,467 & 6,110 & 62,415 \\
\hline
\end{tabular}

Método de extracción: Análisis de Componentes principales.

TABLA 29. VARIANZA TOTALEXPLICADA (C UESTIONARIO DE INDICADORES DE INCLUSIÓN)

El Factor 1 con un valor propio de 9,47 explica el $39,5 \%$ de la varianza total. Lo integran los ítems no $17,26,27,28,31,32,33$ de la escala original. Todos ellos se relacionan con actuaciones que tienen como principio la idea de que cada persona tiene derecho a tener un proyecto personal, a alcanzar sus aspiraciones y metas y a poder decidir sobre su futuro. Lo hemos denominado Prácticas. Es el factor predominante de la escala. Los ítems incluidos en este Factor son los siguientes: 
17. La estrategia de formación de los profesiona les de AMICA está diseñada para ayudarles a dar respuesta a la diversidad de las persona s usuarias.

26. Las actividades que se realizan en AMICA implican de forma activa a todaslas personas favoreciend o su a utonomía personal y la vida independiente.

27. Las activida des que se realizan en AMICA utilizan to dos los recursos que existen en la sociedad (espacios de ocio, a socia ciones, empresas, servic ios públic os, etc.)

28. Las actividades se diseñan para fomentar la participación de las personas en la sociedad.

31. Las persona susuarias, la s familias, los profesiona les y el equipo directivo comparten una filosofía de inclusión.

32. Las políticas de AMICA están orienta das a fomentar la partic ipación de las personas en la sociedad.

33. Las polític as de AMICA favorecen el ejercicio de derechos de los miembros de la comunidad.

Además, el a nálisis de la consistencia interna de los ítems y de la subescala pusieron de manifiesto una elevada fiabilidad (véase Tabla 30). El alfa de Cronbach para la subesc ala fue $=0,89$.

\begin{tabular}{|l|c|c|c|c|}
\hline item & $\begin{array}{c}\text { Media } \\
\text { corregida }\end{array}$ & $\begin{array}{c}\text { Varianza } \\
\text { corregida }\end{array}$ & $\begin{array}{c}\text { Correlación } \\
\text { elemento-total } \\
\text { corregida }\end{array}$ & $\begin{array}{c}\text { Alfa de Cronbach } \\
\text { corregido }\end{array}$ \\
\hline it17 & 20,53 & 6,948 &, 676 &, 881 \\
\hline it26 & 20,48 & 7,252 &, 667 &, 882 \\
\hline it27 & 20,52 & 6,992 &, 714 &, 876 \\
\hline it28 & 20,40 & 7,264 &, 720 &, 876 \\
\hline it31 & 20,61 & 6,544 &, 728 &, 876 \\
\hline it32 & 20,34 & 7,359 &, 684 &, 880 \\
\hline it33 & 20,47 & 7,187 &, 690 &, 879 \\
\hline
\end{tabular}

TABLA 30. ESTADÍSTICOS TOTAL-ELEMENTO (SUBESCALA 1: PRÁCTICAS) 
CAPITULO 6. Evaluación de la inclusión en los centros para personascon discapacidad (Fase III y Fase IV)

El Factor 2, con un valor propio de 2,48 , explica el $10,32 \%$ de la varianza total. Está compuesto por los ítems no $18,19,25,38,39,40$ de la escala original. Todos ellos hacen referencia a sentirse parte de un equipo o de un grupo en el que todos son tenidos en cuenta. Así pues lo hemos denominado Comunidad. Es el segundo factor más importante del instrumento en cuanto a su peso.

Los ítems inc luidos en este Factor son los siguientes:

18. La evaluación de las diferentes actividades que se realizan motiva a todos a mejorar.

19. La gestión de AMICA implica a todosen la toma de decisiones, conciliando intereses y repartiendo ta reas.

25. Las actividades que se ponen en marcha en AMICA son accesibles para todos.

38. Todas las personas en AMICA pueden partic ipar en aquellas actividades que les interesan porque tienen los apoyos necesarios.

39. Todas las personas que tienen relación con AMICA se sienten parte de ella.

40. Todosen AMICA sienten que son parte de un proyec to al que pueden a portaralgo.

El análisis de la consistencia intema de los ítems y de la subescala pusieron también de manifiesto una elevada fiabilidad (véase Tabla 31). El alfa de Cronbach para la subesc ala fue $=0,86$.

\begin{tabular}{|l|c|c|c|c|}
\hline \multicolumn{1}{|c|}{ Ítem } & Media corregida & $\begin{array}{c}\text { Varianza } \\
\text { corregida }\end{array}$ & $\begin{array}{c}\text { Correlación } \\
\text { elemento-total } \\
\text { corregida }\end{array}$ & $\begin{array}{c}\text { Alfa de } \\
\text { Cronbach } \\
\text { corregido }\end{array}$ \\
\hline it18 & 15,95 & 6,573 &, 648 &, 832 \\
\hline it19 & 15,98 & 6,413 &, 622 &, 836 \\
\hline it25 & 16,02 & 6,456 &, 656 &, 830 \\
\hline it38 & 16,11 & 6,271 &, 662 &, 828 \\
\hline it39 & 16,09 & 5,927 &, 701 &, 821 \\
\hline it40 & 16,10 & 6,349 &, 585 &, 844 \\
\hline
\end{tabular}

TABLA 31. ESTADÍSTICOS TOTAL-ELEMENTO (SUBESCALA 2: COMUNIDAD) 
El Factor 3 con un valor propio de 1,57 explica el $6,54 \%$ de la varianza total y está compuesto por los ítems no 2, 3, 5, 6, 7 y 14 de la escala original. Todos ellos hacen referencia a la existencia de políticas y estrategias que promueven la defensa de los derechos de todas las personas, la diversidad, la igualdad y la promoción de las personas como individuos únicos. En consecuencia, lo hemos denominado, Políticas. Está compuesto por los ítems:

2. AMICA hace partíc ipe de su proyecto a la sociedad.

3. AMICA intenta mejorar sus procesos de trabajo respondera las necesidades de cada persona.

5. AMICA tiene una estrategia orienta da a que todo el mundo tenga la información y los a poyos necesarios para tener una vida independiente.

6. AMICA tiene una política de mejora continua orientada a solucionar los problemas que la discapacidad plantea.

7. El modelo organizativo de AMICA promueve la inclusión.

14. En los procesos y proyectos de AMICA se ve reflejada la filosofía de inclusión.

Por su parte, el análisis de la consistencia intema de los ítems y de la subesc ala pusieron también de manifiesto una elevada fiabilidad (véase Tabla 32). El alfa de Cronbach para la subesc ala fue $=0,85$.

\begin{tabular}{|l|c|c|c|c|}
\hline Ítem & $\begin{array}{c}\text { Media } \\
\text { corregida }\end{array}$ & $\begin{array}{c}\text { Varianza } \\
\text { corregida o }\end{array}$ & $\begin{array}{c}\text { Correlación } \\
\text { elemento-total } \\
\text { corregida }\end{array}$ & $\begin{array}{c}\text { Alfa de } \\
\text { Cronbach } \\
\text { corregido }\end{array}$ \\
\hline it02 & 17,60 & 4,112 &, 536 &, 847 \\
\hline it03 & 17,43 & 4,313 &, 586 &, 834 \\
\hline it05 & 17,53 & 4,122 &, 679 &, 817 \\
\hline it06 & 17,41 & 4,266 &, 620 &, 811 \\
\hline it07 & 17,56 & 3,945 &, 705 &, 813 \\
\hline it14 & 17,58 & 3,964 &, 698 & \\
\hline
\end{tabular}

TABLA 32. ESTADÍSTICOS TOTAL-ELEMENTO (SUBESCALA 3: POLITICAS) 
CAPITULO 6. Evaluación de la inclusión en los centros para personascon discapacidad (Fase III y Fase IV)

El Factor 4, con un valor propio de 1,47 explica el $6,11 \%$ de la varianza total y está compuesto por los ítems no $8,10,11,12$ y 13 de la escala original. Todos ellos hacen referencia a la existencia de valores que se centran en la persona y en sus potencialidades. Se considera que cada persona es única, con sus proyectos de vida, con sus ilusiones y con la necesidad de que se crea en sus capacidades. Por ello, lo hemos denominado, Valores. Está compuesto por los ítems:

8. El respeto y la aceptación de todos son clave para que nadie se sienta excluido.

10. En AMICA se reconoce la igualdad de laspersonas independientemente de factores personales, sociales y culturales.

11. En AMICA se respetan los derechos de laspersonas.

12. En AMICA se valora la capacidad de todas laspersonas para desarrollar su potencial.

13. En AMICA se valora la diversidad, la individualidad y el potencial de cada persona.

El a nálisis de la consistencia intema de los ítems y de la subescala pusieron también de manifiesto una elevada fiabilidad (véase Tabla 33). El alfa de Cronbach para la subesc ala fue $=0,83$.

\begin{tabular}{|l|c|c|c|c|}
\hline Ítem & Media corregida & $\begin{array}{c}\text { Varianza } \\
\text { corregida }\end{array}$ & $\begin{array}{c}\text { Correlación } \\
\text { elemento-total } \\
\text { corregida }\end{array}$ & $\begin{array}{c}\text { Alfa de } \\
\text { Cronbach } \\
\text { corregido }\end{array}$ \\
\hline it08 & 14,52 & 2,557 &, 594 &, 799 \\
\hline it10 & 14,43 & 2,683 &, 601 &, 796 \\
\hline it11 & 14,38 & 2,716 &, 568 &, 805 \\
\hline it12 & 14,41 & 2,614 &, 661 &, 779 \\
\hline it13 & 14,48 & 2,600 &, 682 &, 773 \\
\hline
\end{tabular}

TABLA 33. ESTADÍSTIC OS TOTAL-ELEMENTO (SUBESCALA 3: PO LITTCAS)

En la Tabla 34 puede observarse además cómo los factores encontrados correlacionan a niveles medios entre sí y en un grado moderado-alto con el total. 


\begin{tabular}{|l|c|c|c|c|}
\hline & Comunidad & Políticas & Valores & Total Escala Breve \\
\hline Prácticas &, $624^{* *}$ &, $608^{* *}$ &, $485^{* *}$ &, $853^{* *}$ \\
\hline Comunidad & &, $454^{* *}$ &, $375^{* *}$ &, $792^{* *}$ \\
\hline Políticas & & &, $597^{* *}$ &, $813^{* *}$ \\
\hline Valores & & & &, $745^{* *}$ \\
\hline
\end{tabular}

** La correla c ión es signific a tiva al nivel 0,01 (bila teral).

TABLA 34. MATRIZDE CORRELACIONES ENTRE FACTORES DE PRIMER ORDEN

\subsubsection{Baremos}

A continuación (véase Tabla 35) ofrecemos los baremos correspondientes a los 93 sujetos c on que contamos para la validación de la escala.

\begin{tabular}{|c|c|c|c|c|c|}
\multicolumn{7}{|c|}{ Puntuaciones directas } \\
\hline Percentiles & Prácticas & Comunidad & Políticas & Valores & Total \\
\hline 5 & 2,86 & 2,45 & 2,95 & 3,00 & 2,95 \\
\hline 10 & 3,00 & 2,57 & 3,00 & 3,00 & 3,00 \\
\hline 25 & 3,00 & 3,00 & 3,17 & 3,20 & 3,12 \\
\hline 50 & 3,29 & 3,17 & 3,50 & 3,60 & 3,45 \\
\hline 75 & 3,86 & 3,50 & 4,00 & 4,00 & 3,69 \\
\hline 90 & 4,00 & 4,00 & 4,00 & 4,00 & 3,96 \\
\hline 95 & 4,00 & 4,00 & 4,00 & 4,00 & 4,00 \\
\hline
\end{tabular}

TABLA 35. BAREMOS DE LA ESC A LA BREVE DE INCLUSIÓN

A continuación en la Tabla 36 presentamos la configuración definitiva de la escala compuesta por un total de 24 ítems. En la columna derecha se indica el factoral que pertenece cada ítem.

\begin{tabular}{|l|l|l|}
\hline Num. & ítem & Factor \\
\hline 01. & AMICA hace partícipe de su proyecto a la sociedad. & $\mathrm{f3}$ \\
\hline 02. & $\begin{array}{l}\text { AMICA intenta mejorar sus procesos de trabajo responder a las necesidades } \\
\text { de cada persona. }\end{array}$ & $\mathrm{f3}$ \\
\hline 03. & $\begin{array}{l}\text { AMICA tiene una estrategia orientada a que todo el mundo tenga la } \\
\text { información y los apoyos necesarios para tener una vida independiente. }\end{array}$ & $\mathrm{f3}$ \\
\hline
\end{tabular}




\begin{tabular}{|c|c|c|}
\hline 04. & $\begin{array}{l}\text { AMICA tiene una polític a de mejora continua orientada a solucionar los } \\
\text { problemas que la discapacidad plantea. }\end{array}$ & f3 \\
\hline 05. & El modelo organizativo de AMICA promueve la inclusión. & f3 \\
\hline 06. & $\begin{array}{l}\text { El respeto y la aceptación de todos son clave para que nadie se sienta } \\
\text { excluido. }\end{array}$ & f4 \\
\hline 07. & $\begin{array}{l}\text { En AMICA se reconoce la igualdad de las personas independientemente de } \\
\text { factores personales, sociales y culturales. }\end{array}$ & f4 \\
\hline 08. & En AMICA se respetan los derechos de laspersonas. & f4 \\
\hline 09. & $\begin{array}{l}\text { En AMICA se valora la capacidad de todas las personas para desa rollar su } \\
\text { potencial. }\end{array}$ & f4 \\
\hline 10. & $\begin{array}{l}\text { En AMICA se valora la diversidad, la individualidad y el potencial de cada } \\
\text { persona. }\end{array}$ & f4 \\
\hline 11. & En los procesos y proyectos de AMICA se ve reflejada la filosofía de inclusión. & f3 \\
\hline 12. & $\begin{array}{l}\text { La estrategia de formación de los profesionales de AMICA está diseñada } \\
\text { para ayudarles a darrespuesta a la diversidad de las personas usuarias. }\end{array}$ & f1 \\
\hline 13. & $\begin{array}{l}\text { La evaluación de las diferentes actividades que se realizan motiva a todos a } \\
\text { mejorar. }\end{array}$ & f2 \\
\hline 14. & $\begin{array}{l}\text { La gestión de AMICA implica a todos en la toma de decisiones, conciliando } \\
\text { intereses y repartiendo tareas. }\end{array}$ & f2 \\
\hline 15. & $\begin{array}{l}\text { Las actividades que se ponen en marcha en AMICA son accesiblespara } \\
\text { todos. }\end{array}$ & f2 \\
\hline 16. & $\begin{array}{l}\text { Las actividades que se rea lizan en AMICA implic an de forma activa a todas } \\
\text { las personas favoreciendo su autonomía personal y la vida independiente. }\end{array}$ & f1 \\
\hline 17. & $\begin{array}{l}\text { Las actividades que se realizan en AMICA utilizan todos los recursos que } \\
\text { existen en la sociedad (espacios de ocio, a sociaciones, empresas, servicios } \\
\text { públic os, etc.) }\end{array}$ & f1 \\
\hline 18. & $\begin{array}{l}\text { Las actividades se diseñan para fomentar la participación de las personas en } \\
\text { la sociedad. }\end{array}$ & f1 \\
\hline 19. & $\begin{array}{l}\text { Las personas usuarias, las fa milias, los profesionales y el equipo direc tivo } \\
\text { comparten una filosofía de inclusión. }\end{array}$ & f1 \\
\hline 20. & $\begin{array}{l}\text { Las polític as de AMICA están orientadas a fomentar la participación de las } \\
\text { personas en la sociedad. }\end{array}$ & f1 \\
\hline 21. & $\begin{array}{l}\text { Las polític as de AMICA favorecen el ejercicio de derechos de los miembros } \\
\text { de la comunidad. }\end{array}$ & f1 \\
\hline 22. & $\begin{array}{l}\text { Todas las personas en AMICA pueden participar en aquellas actividades que } \\
\text { les interesan porque tienen los a poyos necesarios. }\end{array}$ & f2 \\
\hline 23. & Todas las personas que tienen relación con AMICA se sienten parte de ella. & f2 \\
\hline 24. & $\begin{array}{l}\text { Todos en AMICA sienten que son parte de un proyecto al que pueden } \\
\text { aportaralgo. }\end{array}$ & f2 \\
\hline
\end{tabular}

TABLA 36. CONFIG URACIÓN DEFINITIVA DE LA ESCALA

En definitiva, el instrumento en su configuración definitiva, ha demostrado poseer adecuadas propiedades de fiabilidad y validez, tanto considerado globalmente como en sus diferentes subescalas. Todo ello ofrece apoyo a nuestra primera hipótesis. 
A continuación hemos procedido a realizar el contraste de hipótesis relacionado con la valoración de la inclusión. De todo ello ofrecemos información a continuación.

\subsection{Contraste de hipótesis sobre valoraciones de las dimensiones de la inclusión}

Nuestra segunda hipótesis predecía que se obtendrían valoraciones elevadas en cuanto a inclusión. En este sentido, a demás de las valora c iones ítem a ítem antes expuestas, que denotan la existencia de valoraciones elevadas, presentamos a continuación los resulta dos obtenidos en los diferentes factores. Así, como se puede observar en la Tabla 37, todos los factores obtienen puntuaciones superiores a tres puntos. Destaca la valoración relativamente más elevada obtenida en el factor "Valores", seguido de las obtenidas en "Polític as", "Prácticas" y "Comunidad".

\begin{tabular}{|l|l|l|l|l|l|}
\hline & N & Mínimo & Máximo & Media & Desv. típ. \\
\hline Práctic as & 93 & 2,43 & 4,00 & 3,41 &, 44 \\
\hline Comunidad & 93 & 1,83 & 4,00 & 3,21 &, 50 \\
\hline Polític as & 93 & 2,67 & 4,00 & 3,50 &, 40 \\
\hline Valores & 93 & 2,60 & 4,00 & 3,61 &, 40 \\
\hline Total & 93 & 2,57 & 4,00 & 3,43 &, 35 \\
\hline N válido (según lista ) & 93 & & & & \\
\hline
\end{tabular}

TABLA 37. ESTADÍSTIC OS DESC RIPTIVOSY DISPERSIÓN DE LAS PUNTUACIONES OBTENIDAS POR LOS PARTICIPANTES EN LA ESCALA BREVE DE INCLUSIÓN.

Por otro lado, hemos procedido a emplear la prueba $Z$ de KolmogorovSmimov para determinar si la muestra se distribuye nomalmente en el cuestionario globalmente considerado y en sus diferentes factores. Hemos obtenido valores de 
signific ación superiores a 0,05 en el total de la escala y en el factor "participacióncomunidad"; así como valores superiores a 0,01 en los factores "Prácticas" y "Políticas". Finalmente, hemos obtenido valores inferiores a 0,01 en el factor "Valores". Pese a estas desviaciones de la nomalidad, los histogramas reflejaron una dispersión adecuada de las puntuaciones. Esto se vio corroborado con la inspec ción visual de las gráfic as Q-Q nomal y Q-Q normal sin tendencia. Por ta nto, para el posterior contraste de hipótesis emplearemos pruebas pa ra métricas.

Así pues, en tercer lugar, procedimos al contraste de hipótesis que predecía una ausencia de diferencias en las percepciones sobre la inclusión del centro, en función del género de los participantes. En la Tabla 38 se exponen los resultados obtenidos, tras haber realizado un contraste de medias (Anova). Se puede observar cómo, de acuerdo con nuestras predicciones, no existen diferencias significativas en las valoraciones sobre la inclusión en función del género del respondiente.

\begin{tabular}{|c|c|c|c|c|c|c|c|c|}
\hline & & $\mathrm{N}$ & Media & DT & Mínimo & Máximo & $F$ & Sig. \\
\hline \multirow[t]{3}{*}{ Practicas } & & & & & & &, 514 & ,475 \\
\hline & Mujer & 64 & 3,44 & ,42 & 2,86 & 4,00 & & \\
\hline & Hombre & 29 & 3,36 & ,48 & 2,43 & 4,00 & & \\
\hline \multirow[t]{3}{*}{ Comunidad } & & & & & & & ,703 & ,404 \\
\hline & Mujer & 64 & 3,24 & ,49 & 2,00 & 4,00 & & \\
\hline & Hombre & 29 & 3,14 &, 52 & 1,83 & 4,00 & & \\
\hline \multirow[t]{3}{*}{ Políticas } & & & & & & & ,379 &, 540 \\
\hline & Mujer & 64 & 3,52 & ,40 & 2,67 & 4,00 & & \\
\hline & Hombre & 29 & 3,47 & ,40 & 2,67 & 4,00 & & \\
\hline \multirow[t]{3}{*}{ Valores } & & & & & & & , 149 & ,700 \\
\hline & Mujer & 64 & & & & 4,00 & & \\
\hline & Hombre & 29 & & & & 4,00 & & \\
\hline \multirow[t]{3}{*}{ Total } & & & & & & & 351 &, 555 \\
\hline & Mujer & 64 & 3,45 & ,35 & 2,80 & 4,00 & & \\
\hline & Hombre & 29 & 3,40 & ,34 & 2,57 & 4,00 & & \\
\hline
\end{tabular}

TABLA 38. PUNTUACIONES MEDIASY SIG NIFICACIÓN DE LAS DIFERENCIAS EN LA ESCALA BREVE DE INCLUSIÓN, EN FUNCIÓN DEL GÉNERO 
Continuando con nuestra tercera hipótesis, planteábamos también la ausencia de diferencias en las valoraciones sobre la inclusión en función de la edad del respondiente. Se puede observar en la Tabla 39 cómo tampoco existen diferencias signific ativas en función de esta variable. Así pues, es posible afimar que nuestra tercera hipótesis se ha visto confimada.

\begin{tabular}{|c|c|c|c|c|c|c|c|c|}
\hline & & $\mathrm{N}$ & Media & DT & Mínimo & Máximo & $\mathrm{F}$ & Sig. \\
\hline \multirow[t]{7}{*}{ Prácticas } & & & & & & & ,610 & ,693 \\
\hline & $16-21$ & 3 & 3,7619 & ,41239 & 3,29 & 4,00 & & \\
\hline & $22-30$ & 29 & 3,4039 & ,44863 & 2,57 & 4,00 & & \\
\hline & $31-40$ & 24 & 3,4464 & ,46590 & 2,43 & 4,00 & & \\
\hline & $41-50$ & 18 & 3,4127 & , 41255 & 2,71 & 4,00 & & \\
\hline & $51-60$ & 10 & 3,4143 & ,50597 & 3,00 & 4,00 & & \\
\hline & Mayorde 60 & 8 & 3,2500 & ,36422 & 3,00 & 4,00 & & \\
\hline \multirow[t]{7}{*}{ Comunidad } & & & & & & & 2,172 & ,065 \\
\hline & $16-21$ & 3 & 3,40 & ,45 & 3,67 & 4,00 & & \\
\hline & $22-30$ & 29 & 3,45 & ,47 & 1,83 & 4,00 & & \\
\hline & $31-40$ & 24 & 3,41 & ,41 & 2,50 & 4,00 & & \\
\hline & $41-50$ & 18 & 3,41 & ,51 & 2,00 & 3,50 & & \\
\hline & $51-60$ & 10 & 3,25 & , 36 & 2,33 & 3,83 & & \\
\hline & Mayorde 60 & 8 & 3,42 & 44 & 3,00 & 4,00 & & \\
\hline \multirow[t]{7}{*}{ Polític as } & & & & & & & 1,335 & 257 \\
\hline & $16-21$ & 3 & 3,18 & ,57 & 3,50 & 4,00 & & \\
\hline & $22-30$ & 29 & 3,30 &, 50 & 2,67 & 4,00 & & \\
\hline & $31-40$ & 24 & 3,00 & ,40 & 3,00 & 4,00 & & \\
\hline & $41-50$ & 18 & 3,17 &, 43 & 2,83 & 4,00 & & \\
\hline & $51-60$ & 10 & 3,33 & , 36 & 2,83 & 4,00 & & \\
\hline & Mayorde 60 & 8 & 3,21 &, 50 & 3,00 & 4,00 & & \\
\hline \multirow[t]{7}{*}{ Valores } & & & & & & & 1,869 & ,108 \\
\hline & $16-21$ & 3 & 3,58 & ,44 & 3,60 & 4,00 & & \\
\hline & $22-30$ & 29 & 3,56 & ,39 & 3,00 & 4,00 & & \\
\hline & $31-40$ & 24 & 3,42 & ,36 & 2,60 & 4,00 & & \\
\hline & $41-50$ & 18 & 3,47 & ,39 & 3,00 & 4,00 & & \\
\hline & $51-60$ & 10 & 3,27 & ,38 & 3,00 & 4,00 & & \\
\hline & Mayorde 60 & 8 & 3,51 &, 40 & 3,00 & 4,00 & & \\
\hline \multirow[t]{5}{*}{ Total } & & & & & & & ,910 & , 478 \\
\hline & $16-21$ & 3 & 3,50 & ,36 & 3,00 & 4,00 & & \\
\hline & $22-30$ & 29 & 3,47 & ,34 & 2,80 & 4,00 & & \\
\hline & $31-40$ & 24 & 3,33 & ,36 & 2,57 & 4,00 & & \\
\hline & $41-50$ & 18 & 3,29 &, 35 & 2,94 & 4,00 & & \\
\hline
\end{tabular}


CAPITULO 6. Evaluación de la inclusión en los centros para personascon discapacidad (Fase III y Fase IV)

\begin{tabular}{|l|l|r|r|r|r|r|r|r|}
\hline & N & Media & DT & Mínimo & Máximo & F & Sig. \\
\hline $51-60$ & 10 & 3,52 &, 34 & 3,05 & 4,00 & & \\
\hline Mayorde 60 & 8 & 3,48 &, 34 & 2,97 & 3,96 & & \\
\hline
\end{tabular}

TABLA 39. PUNTUACIONES MEDIASY SIG NIFICACIÓN DE LAS DIFERENCIAS EN LA ESCALA BREVE DE INCLUSIÓN, EN FUNCIÓN DE LA EDAD DE LOS RESPONDIENTES

Nuestra cuarta hipótesis no predecía la existencia de diferencias signific ativas en función de la tipología de usuario y del tiempo de relación con el centro. Así pues, en primer lugar, ofrecemos los resultados del contraste de medias en función de la tipología. En la Tabla 40 se puede observar cómo existen diferencias significativas en el total de la escala y en los diferentes subfactores, salvo en la subescala "Valores". Los a nálisis post-hoc (Duncan y Scheffé) pusieron de manifiesto que las personas usuarias puntuaban significativamente más alto en "prácticas", “comunidad" y total de la escala. En cuanto a "polític as", los fa milia res puntuaban signific ativamente más bajo que los otros grupos. Por tanto, es posible afimar que la tipología de respondiente está asociada a percepciones significativamente distintas sobre la inclusión, al menos en los términos que acabamos de exponer.

\begin{tabular}{|c|c|c|c|c|c|c|c|c|}
\hline & & $\mathrm{N}$ & Media & DT & Mínimo & Máximo & $\mathrm{F}$ & \\
\hline \multirow[t]{5}{*}{ Prácticas } & & & & & & & 7,487 & , 000 \\
\hline & Usua rio & 19 & 3,80 & ,40 & 2,43 & 4,00 & & \\
\hline & Familiar & 19 & 3,32 & ,37 & 3,00 & 4,00 & & \\
\hline & Profesional & 48 & 3,33 & ,41 & 2,57 & 4,00 & & \\
\hline & Equipo direc tivo & 7 & 3,22 & ,41 & 2,71 & 4,00 & & \\
\hline \multirow[t]{5}{*}{ Comunidad } & & & & & & & 18,505 & ,000 \\
\hline & Usua rio & 19 & 3,74 & ,35 & 3,00 & 4,00 & & \\
\hline & Familiar & 19 & 3,32 & ,28 & 3,00 & 4,00 & & \\
\hline & Profesional & 48 & 3,02 & ,46 & 1,83 & 4,00 & & \\
\hline & Equipo direc tivo & 7 & 2,74 & ,27 & 2,33 & 3,17 & & \\
\hline \multirow[t]{2}{*}{ Polític as } & & & & & & & 4,206 & ,008 \\
\hline & Usuario & 19 & 3,75 &, 32 & 2,83 & 4,00 & & \\
\hline
\end{tabular}




\begin{tabular}{|l|l|l|l|l|l|l|l|l|}
\hline & Familiar & 19 & 3,32 &, 33 & 2,83 & 4,00 & & \\
\hline & Profesional & 48 & 3,49 &, 43 & 2,67 & 4,00 & & \\
\hline & Equipo direc tivo & 7 & 3,43 &, 29 & 3,00 & 3,83 & & \\
\hline Valores & & & & & & & 1,544 &, 209 \\
\hline & Usuario & 19 & 3,68 &, 40 & 2,60 & 4,00 & & \\
\hline & Familiar & 19 & 3,44 &, 34 & 3,00 & 4,00 & & \\
\hline & Profesional & 48 & 3,65 &, 42 & 2,80 & 4,00 & & \\
\hline & Equipo direc tivo & 7 & 3,60 &, 28 & 3,20 & 4,00 & & \\
\hline Total & & & & & & & 7,969 &, 000 \\
\hline & Usuario & 19 & 3,61 & 0,40 & 2,60 & 4,00 & & \\
\hline & Familiar & 19 & 3,74 & 0,27 & 3,20 & 4,00 & & \\
\hline & Profesional & 48 & 3,35 & 0,28 & 3,00 & 4,00 & & \\
\hline & Equipo direc tivo & 7 & 3,37 & 0,35 & 2,57 & 4,00 & & \\
\hline
\end{tabular}

TABLA 40. PUNTUACIONES MEDIAS Y SIG NIFICACIÓN DE LAS DIFERENCIAS EN LA ESCALA BREVE DE INCLUSIÓN, EN FUNCIÓN DE LA TIPOLOGÍA DE LOS RESPONDIENTES

Por otro lado, presentamos los resultados relativos al análisis de posibles diferencias en función del tiempo de relación con la asociación. En la Tabla 41 se observa cómo no existen diferencias significativas en función de esta variable en las diferentes subesc alas ni en el total de la misma.

\begin{tabular}{|c|c|c|c|c|c|c|c|c|}
\hline & & $\mathrm{N}$ & Media & DT & Mínimo & Máximo & $\mathrm{F}$ & Sig \\
\hline \multirow[t]{7}{*}{ Prácticas } & & & & & & & ,754 & ,585 \\
\hline & Menos 1 año & 8 & 3,34 & ,43 & 3,00 & 4,00 & & \\
\hline & 1- 4 años & 30 & 3,45 & ,43 & 2,86 & 4,00 & & \\
\hline & 5 años - 8 años & 16 & 3,29 & ,46 & 2,57 & 4,00 & & \\
\hline & $9-12$ años & 11 & 3,31 & ,38 & 2,86 & 4,00 & & \\
\hline & $13-16$ años & 11 & 3,55 & ,44 & 2,71 & 4,00 & & \\
\hline & Más de 16 años & 17 & 3,49 &, 49 & 2,43 & 4,00 & & \\
\hline \multirow[t]{7}{*}{ Comunidad } & & & & & & & 1,384 & ,238 \\
\hline & Menos 1 año & 8 & 3,35 & ,38 & 3,00 & 4,00 & & \\
\hline & 1- 4 años & 30 & 3,28 &, 50 & 2,33 & 4,00 & & \\
\hline & 5 años - 8 años & 16 & 3,05 & ,57 & 1,83 & 4,00 & & \\
\hline & $9-12$ años & 11 & 2,94 & ,49 & 2,50 & 4,00 & & \\
\hline & $13-16$ años & 11 & 3,27 & ,44 & 2,67 & 4,00 & & \\
\hline & Más de 16 años & 17 & 3,28 &, 48 & 2,33 & 4,00 & & \\
\hline \multirow[t]{4}{*}{ Polític as } & & & & & & & ,239 & ,944 \\
\hline & Menos 1 año & 8 & 3,54 & ,44 & 3,00 & 4,00 & & \\
\hline & 1- 4 años & 30 & 3,51 &, 42 & 2,67 & 4,00 & & \\
\hline & 5 años - 8 años & 16 & 3,47 & ,45 & 2,67 & 4,00 & & \\
\hline
\end{tabular}


CAPITULO 6. Evaluación de la inclusión en los centros para personascon discapacidad (Fase III y Fase IV)

\begin{tabular}{|c|c|c|c|c|c|c|c|c|}
\hline & $9-12$ años & 11 & 3,45 & ,41 & 3,00 & 4,00 & & \\
\hline & $13-16$ años & 11 & 3,44 & 45 & 2,83 & 4,00 & & \\
\hline & Más de 16 años & 17 & 3,58 & ,28 & 3,00 & 4,00 & & \\
\hline \multirow[t]{7}{*}{ Valores } & & & & & & & 1,280 & ,280 \\
\hline & Menos 1 año & 8 & 3,75 & ,46 & 3,00 & 4,00 & & \\
\hline & 1- 4 años & 30 & 3,62 & ,37 & 3,00 & 4,00 & & \\
\hline & 5 años - 8 años & 16 & 3,53 & ,36 & 3,00 & 4,00 & & \\
\hline & $9-12$ años & 11 & 3,47 & ,44 & 2,80 & 4,00 & & \\
\hline & $13-16$ años & 11 & 3,82 &, 26 & 3,20 & 4,00 & & \\
\hline & Más de 16 años & 17 & 3,56 & 47 & 2,60 & 4,00 & & \\
\hline \multirow[t]{7}{*}{ totbrev } & & & & & & & ,910 & ,478 \\
\hline & Menos 1 año & 8 & 3,50 & ,36 & 3,00 & 4,00 & & \\
\hline & 1- 4 años & 30 & 3,47 & ,34 & 2,80 & 4,00 & & \\
\hline & 5 años - 8 años & 16 & 3,33 & ,36 & 2,57 & 4,00 & & \\
\hline & $9-12$ años & 11 & 3,29 & ,35 & 2,94 & 4,00 & & \\
\hline & $13-16$ años & 11 & 3,52 & ,34 & 3,05 & 4,00 & & \\
\hline & Más de 16 años & 17 & 3,48 & ,34 & 2,97 & 3,96 & & \\
\hline
\end{tabular}

TABLA 41. PUNTUACIONES MEDIASY SIG NIFICACIÓN DE LAS DIFERENCIAS EN LA ESCALA BREVE DE INCLUSIÓN, EN FUNCIÓN DEL TIEMPO DE RELACIÓN CON LA ASOCIACIÓN

De modo complementario, hemos procedido a determinar las puntuaciones medias obtenidas por los participantes en función del centro de pertenencia. Dada la disparidad en el tamaño de los grupos, no es posible realizar un contraste de medias. Es posible no obstante identificar centros con puntuaciones más elevadas en varios factores o en el total de la escala, como sucede con la Casa Helios, el Centro Horizon, o el Centro de día la Vega. También en términos relativos, el Centro de día Santoña ocupa posiciones que denotan una inferior valoración de la inc lusión.

\begin{tabular}{|c|c|c|c|c|c|}
\hline \multirow[t]{2}{*}{ Centro } & \multicolumn{2}{|c|}{ Cultura } & \multirow[t]{2}{*}{ Políticas } & \multirow[t]{2}{*}{ Prácticas } & \multirow[t]{2}{*}{ totbrev } \\
\hline & Comunidad & Valores & & & \\
\hline \multicolumn{6}{|l|}{ Centro de recursos } \\
\hline Media & 3,18 & 3,61 & 3,52 & 3,42 & 3,43 \\
\hline Desv. típ. &, 59 & ,39 & ,43 & ,47 & ,41 \\
\hline \multicolumn{6}{|c|}{ Centro de día La Vega } \\
\hline Media & 3,28 & 3,60 & 3,57 & 3,45 & 3,47 \\
\hline Desv. típ. &, 45 & ,46 &, 43 &, 51 &, 33 \\
\hline
\end{tabular}




\begin{tabular}{|c|c|c|c|c|c|}
\hline \multicolumn{6}{|l|}{ Centro Horizón } \\
\hline Media & 3,44 & 3,61 & 3,54 & 3,56 & 3,54 \\
\hline Desv. típ. & 43 & ,38 & ,39 &, 45 & ,31 \\
\hline \multicolumn{6}{|l|}{ Casa Helios } \\
\hline Media & 3,00 & 4,00 & 4,00 & 3,57 & 3,64 \\
\hline Desv. típ. &. &. & . &. &. \\
\hline \multicolumn{6}{|l|}{ Centro Entomo } \\
\hline Media & 3,13 & 3,74 & 3,52 & 3,30 & 3,42 \\
\hline Desv. típ. &, 44 & ,32 & ,35 & ,37 & ,29 \\
\hline \multicolumn{6}{|l|}{ Centro Sotileza } \\
\hline Media & 2,87 & 3,60 & 3,40 & 3,43 & 3,32 \\
\hline Desv. típ. & ,18 & ,47 & ,38 & ,35 & ,25 \\
\hline \multicolumn{6}{|l|}{ Centro Marisma } \\
\hline Media & 3,39 & 3,53 & 3,44 & 3,10 & 3,37 \\
\hline Desv. típ. & ,35 &, 50 & ,42 & 08 & ,32 \\
\hline \multicolumn{6}{|l|}{ Centro La Barca } \\
\hline Media & 3,11 & 3,33 & 3,33 & 3,33 & 3,28 \\
\hline Desv. típ. & ,19 &, 58 &, 58 &, 58 &, 48 \\
\hline \multicolumn{6}{|c|}{ Centro de día Santoña } \\
\hline Media & 3,00 & 3,40 & 3,06 & 3,24 & 3,17 \\
\hline Desv. típ. & ,29 &, 53 & 10 & ,22 & 18 \\
\hline
\end{tabular}

TABLA 42. PUNTUACIONES MEDIAS OBTENIDAS POR LOS PARTICIPANTES EN FUNCIÓN DEL CENTRO DE PERTENENCIA.

A la vista de los resultados, podemos decir que nuestra cuarta hipótesis ha recibido una confirmación parcial.

\subsection{Conclusiones}

Las conclusiones del presente capítulo se van a presentar a partir de las hipótesis que se plantearon para las fases III y IV de la parte empírica.

Hipótesis 4. El Cuestionario de Evaluación de los Indicadores del Index (versión definitiva) mostrará adecuadas propiedades psicométricas de fiabilidad (acuerdo entre jueces, consistencia intema) y validez (validez a parente y validez de constructo). 
CAPITULO 6. Evaluación de la inclusión en los centros para personascon discapacidad (Fase III y Fase IV)

Tal y cómo se preveía en la hipótesis, tras las modificaciones y adaptaciones realizadas en estas últimas fases, el cuestionario ha presentado adecuadas propiedades psicométricas que se reflejan en los resultados obtenidos por los diferentes estadístic os utilizados tanto a nivel general (Alfa de Cronbach con un valor de 0,96 y Correlación SpearmanBrown con un índice de 0,91 ) como los aplicados para deteminar la fiabilidad entre observadores (Kappa de Cohen con valores entre 0,34 y 0,67; Kappa de Fleiss con un valor de 0,491; Alfa de Krippendorff con un valor de 0,50). Todos los ítems tuvieron elevada correlación corregida, superior a 0,35 , en todos los casos lo que avala la consistencia intema del instrumento.

La validez de contenido se evaluó mediante consulta a jueces expertos a través un procedimiento estructurado en el que se les pidió emparejar los ítems con la categoría/indicador. De modo complementario, se empleó el análisis factorial para verificar la validez de constructo. Concretamente, los ítems se sometieron en primer lugar a análisis factoria I por el método de componentes principales y rotación Oblimin, lo cual nos permitió concluir que había un único factor en el que se distribuyen los diferentes ítems del cuestionario. Dicho de otro modo, todos los ítems miden un concepto como es el de la inclusión. En segundo lugar se aplicó una rotación Varimax a los ítems, para obtener factores lo más independientes posible, y se utilizó el criterio de noma liza ción de Ka iser. Este a nálisis permitió la obtención de cuatro factores independientes relaciona dos directamente con la propuesta inicial del Index para la inclusión: Prácticas, Comunidad, Políticas y Valores. Hay que destacar que tanto el segundo factor como el cuarto son las dos secciones de la Dimensión Cultura Inclusiva. 
Respecto a la fiabilidad de dichosfactores, la consistencia interna de los ítems de los cuatro factores ofreció valores elevados en todos ellos (factor $1=0,89$; factor $2=0,86$; factor $3=0,85$; factor $4=0,83$ ). Además podemos concluir diciendo que los factores encontrados correlacionan a niveles medios entre sí y en un grado moderado-alto con el total; confimando la multidimensionalidad del cuestionario, y por tanto, su validez de constructo.

Hipótesis 5. El Cuestionario de Indicadores de Inclusión, aplicado en el centro de referencia seleccionado para la presente Tesis, obtendrá elevadas puntuaciones en las tres dimensiones en las que se basa el instrumento: cultura (comunidad y valores), políticas y prácticas.

Tal y cómo se preveía por las características de la Asociación de referencia y de los participantes, se han obtenido puntuaciones elevadas con una media superior a tres puntos. La Dimensión "Cultura Inclusiva" ha obtenido una media de 3,61 en el factor "Valores" y 3,21 en el factor "Comunidad"; la Dimensión "Políticas Inclusivas" ha obtenido una puntua ción de 3,50 y la Dimensión “Prácticas Inclusivas" 3,41 de media.

Por los resultados arrojados por el análisis estadístico podemos concluir que la hipótesis se ha corroborado.

Hipótesis 6. Los resultados obtenidos con el Cuestiona rio de Indic a dores de Inclusión, en el centro de referencia, no mostrarán diferencias significativas en las puntuaciones obtenidas en función del género, la edad o el rol que se desempeñe en el centro.

La hipótesis, como era de prever por la cultura de la Asociación, ha quedado comoborada por los datos obtenidos. No se han encontrado 
CAPITULO 6. Evaluación de la inclusión en los centros para personas con discapacidad (Fase III y Fase IV)

diferencias signific ativas entre las valoraciones sobre la inclusión en AMICA ni en función del género ( $\operatorname{Sig}=0,555)$, ni de la edad $(\operatorname{Sig}=0,478)$, ni en relación con el rol que se desempeñe en la organización (tipología del respondiente): persona usuaria, familiar, profesional o equipo directivo $(\mathrm{Sig}=0,555)$.

Hipótesis 7. Los resulta dos obtenidos con el Cuestionario de Indicadores de Inclusión, en el centro de referencia, no mostrarán diferencias significativas en las puntuaciones obtenidas en función del centro con el que se tenga relación y con los años de vinculación con la Asociación.

La hipótesis se ha corroborado parcialmente ya que se han detectado diferencias entre las puntuaciones obtenidas entre los diferentes centros. Aunque existe una gran disparidad en el número de participantes en la investigación por centro, se puede concluir diciendo que hay centros que obtienen puntuaciones más altas que otros en todos los factores ana liza dos; estos son los centros situados en Torrelavega (Cantabria): Casa Helios, Centro Horizon, Centro de día la Vega y el Centro de Recursos. El centro que ha obtenido una media más baja es el situado en Santoña. A pesar de ello, to dos los centros obtienen puntuaciones igua les o superiores a tres en los cua tro factores a na liza dos.

Por otra parte, se han analizado las puntuaciones obtenidas centrándonos en los años de vinculación con el centro, en este caso no existen evidencias significativas ni a nivel global ni en cada uno de los factores.

Una vez expuestos los resultados derivados del contraste de hipótesis, en el capítulo final ofreceremos una reflexión de los hallazgos teóricos y empíricos de 
esta Tesis Doctoral, así como de sus implicaciones para la mejora de los procesos de inclusión en los centros que prestan servicios a personas con discapacidad. 


\subsection{Desc ripción general}

Este último capítulo tiene como objetivos principa les (1) disc utir los resultados obtenidos a lo largo de la presente Tesis Doctoral y ofrecer una síntesis de las conclusiones que se pueden obtener del estudio realizado, (2) resaltar las limita ciones de dichos resultados y, a partir de ello, proponer a lgunas líneas futuras de investigación. La intención principal de esta discusión es analizar hasta qué punto se ha alcanzado cada uno de los objetivos y cuáles son las evidencias, teóricas o empíricas dependiendo el caso, que lo a valan.

\subsection{Disc usión de los resultados y conclusiones}

En la presente investigación hemos pretendido tres cuestiones fundamentales: (1) adaptar el Index para la Inclusión, diseñado originalmente para el ámbito escolar (Booth y Ainscow, 2000), para su aplicación en centros que prestan servicios a personas con discapacidad, (2) construir un Cuestionario de Evaluación de los Indicadores del Index con adecuadas propiedades psicométricas que nos proporcione evidencias de la adecuación de la adaptación y de la pertinencia de los cambios realizados partiendo de una base teórica sólida, y (3) evaluar la inclusión un centro que presta servicios a personas con discapacidad determinando el posible impacto de variables sociodemográficas en la percepción de la inclusión.

\subsubsection{Disc usión y conclusiones del primer objetivo de la investigación}

Para el cumplimiento del primer objetivo se ha realizado un análisis exhaustivo, que se ha presentado en la primera parte de la tesis, centrado en cuatro aspectos: la inclusión y el Index para la inclusión, las características de las 
CAPITULO 7. Conc lusiones, disc usión, limitaciones y líneas futuras de investigación

organiza ciones inclusivas, las comunida des de práctica y AMICA, como centro de referencia para la presente investigación.

El a nálisis teórico realizado en torno al tema de la inclusión y la situación actual del Index para la Inclusión permite concluir que la inclusión (Ainsc ow, 2000) se puede entender como un proceso que tiene como objetivo la búsqueda interminable de formas positivas de responder a la diversidad. Dicho proceso está centrado en la identific ación y eliminación de barreras y no en la búsqueda de deficiencias en la persona. Esta visión de la inclusión tiene repercusiones organizativas para los centros que prestan servicios a personas con algún tipo de limitación, ya que requiere que mejoren sus políticas y prácticas para prestar el apoyo que la persona necesite y en el lugar que lo precise. También supone fomentar la participación de todos los miembros de la organización y mejorar las prácticas para obtener mejores resultados orientados a la vida independiente de las personas con discapacidad.

En la presente Tesis Doctoral hemos analizado el Index para la inclusión (Booth y Ainscow, 2000), tanto en su propuesta ideológica como en su vertiente metodológica.

Respecto a la primera, tanto los a nálisis realizados por la autora del presente trabajo como por los jueces expertos han constatado que el instrumento se centra en promover la inclusión únicamente en el contexto de la escuela ya que no presenta ningún indicador que relacione al alumnado con actividades que se realicen en la comunidad. Por otra parte, aunque en la Dimensión "Construir una comunidad" se hace referencia a la colaboración con las familias y a la importancia de compartir valores inclusivos (Indic adores A.1.5 y A.2.2) no se vuelve a hacer referencia a las mismas a lo largo de todo el instrumento. Creemos que ello constituye una cierta limitación del Index, pues la promoción de una vida 
independiente requiere que los apoyos no se supediten únicamente y exc lusiva mente al contexto educativo.

Respecto a la propuesta metodológica sugerida porloscreadores del Index, pensamos que mientras en la propuesta original no se tiene en cuenta el contexto organizacional en el que se está promoviendo el cambio, en la adaptación realizada en esta investigación se supera esta limitación. Y ello porque como hemos expuesto, en este trabajo proponemos un enfoque metodológico basado en la práctica y, por lo tanto, consistente en la utilización de las Comunidades de Práctica en vez del trabajo en equipos ad hoc como escenario para desplegar la filosofía de inclusión en los centros tanto educativos como socio-educativos. Esta recomendación está empezando a ser difundida también por los autores del instrumento (Ainsc ow y Sandill, 2010), como veremos con mayor profundidad más adelante.

El análisis sobre las características de las organizaciones inclusivas en relación con las dimensiones que propone el Index para la Inclusión permite conc luir que las tres dimensiones del instrumento: cultura, polític as y práctic as, son adecuadas para analizar la situación de una organización ante la inclusión. Por ello, en el presente estudio hemos profundizado sobre los diferentes aspectos que deben formarparte del instrumento.

Concretamente, la revisión bibliográfica, en primer lugar, sobre la dimensión "Culturas inclusivas" pone de manifiesto la importancia de la comunidad y de los valores que la sustentan. El sentimiento de comunidad, como nos señalan diferentes autores (Sarason, 1974; Sánchez Vidal, 2001; McMillan y Chavis, 1986; Maya Jariego, 2004), va a hacerque todos los miembros que forman parte de ella, desde el equipo directivo a los aliados estratégicos del centro, compartan un 
sentimiento de pertenencia, unos valores y unos principios de actuación y una conexión emocional.

Consideramos que los valores inclusivos, de acuerdo con la propuesta original del Index para Inclusión, son el componente más importante de la cultura (Pasmore, 1988; O'Reilly, Chatman, y Caldwell, 1991; Schein, 2004) ya que éstos se utilizan para juzgar no sólo las propias acciones sino también las de los demás (Dewey, 1939; Rokeach, 1973) y las de la propia organización (Seiler, 1967). Por tanto, estos valores inclusivos, van a ser el prisma desde el que se enfoquen las polític as y las prácticas que se lleven a cabo en el centro.

Si bien la investigación ha partido de los valores señalados por Booth (2005) y que se encuentran en la filosofía del Index (ver apartado 2.2.5), hemos a naliza do además los valores de AMICA, organización de referencia para el presente estudio. De este análisis es posible concluir que a unque a lgunos valores coinciden, como su apuesta por los derechos de la persona, la igualdad o la participación, nos decantamos por los señalados por AMICA ya que aportan una visión más ajustada a la adaptación que se ha realizado del Index para centros que prestan servicios para personas con discapacidad (véase apartado 4.3).

En segundo lugar, sobre la dimensión "Políticas inclusivas" podemos concluir que tras la revisión teóric a efectuada, hemos modificado el enfoque propuesto por el Index. Concretamente, tras el trabajo teórico y empírico realiza do, creemos que las políticas del centro no deben pivotar sobre la creación de un centro para todos o en la organización del apoyo para atender a la diversidad sino sobre los derechos de las personas con discapacidad. Este aspecto se apoya directamente en la "Convención de Derechos de las personas con Discapacidad" (2008). Partiendo de esta premisa hemos analizado cómo deberían ser los procesos de gestión y las políticas en las organizaciones inclusivas. Tras el análisis hemos 
concluido que para mantener una cultura de inclusión y unas políticas inclusivas activas en los centros que prestan servicios a personas con discapacidad, los procesos de gestión han de ser transparentes e inclusivos (Bla ir, 2010). Así mismo, los procesos de toma de decisiones deben involucrar a todos los miembros de la comunidad; los líderes deben estar abiertos al cambio y deben saber inspirar y apoyar a las personas que forman parte de la comunidad. Por su parte, los procesos de gestión deben estar basados en el Buen Gobiemo (UN ESCAP, 2010) por lo que deben apostar por la participación, la legalidad, la transparencia, la responsabilidad, el consenso, la equidad, la efic acia y la eficiencia. Por último, los centros deben acentuar un enfoque basado en la gestión de las emociones positivas, las formas efectivas de afrontamiento de situaciones conflictivas, la resistencia psicológica, la autenticidad en las relaciones sociales, la a utoeficacia y la autodeterminación (Salanova y Schaufeli, 2004).

En tercer lugar, de la revisión realizada sobre "Práctic as inclusivas" se extrae una primera conclusión: la persona debe ser eje de las prácticas. En consecuencia, éstas deben ser diseñadas para atender a las necesidades, aspiraciones y expectativas de cada persona (AMICA, 2009) y para fomentar el aprendizaje y la participación (EUSE, 2005; ONU, 2006).

Las prác tic as deben estar centra das en los múltiples a spec tos positivos de la persona, y no en la acomodación y la adaptación a lo ya existente. Partiendo de esta premisa, hemos analizado aspectos relacionados con la motivación y la autodeteminación (véase apartado 2.4.2), la implicación de la persona (véase apartado 2.4.3) o la resiliencia (véase apartado 2.4.4). Todo ello nos permite concluir que las prácticas en los centros deben estar orientadas al desarrollo de competencias que fortalezcan a las personas y no solamente al desarrollo de habilidades instrumentales que no se pueden extrapolar a otros contextos de la 
CAPITULO 7. Conc lusiones, disc usión, limitaciones y líneas futuras de investigación

vida cotidiana. Además, los centros que promuevan procesos inclusivos deben poner en marcha modelos basados en el ciudadano y en sus derechos y no en los objetivos del sistema en el que está inmerso.

En definitiva, y tras el análisis de las características de las organizaciones inc lusivas podemos concluir que la cultura, política y las prácticas forman parte de un entramado que está en la base de todas lasorganizaciones; las tres dimensiones están íntimamente relacionadas y no se pueden analizar por separado ya que las tres dimensiones deben girar en tomo a la persona con discapacidad y la defensa de sus derechos.

El a ná lisis de las característic as de las Comunidades de Práctica, su relación con las organizaciones inclusivas y la aplicación del Index para la inclusión nos permite concluir que las culturas, políticas y prácticas inclusivas, como indican Ainsc ow, Booth y Dyson (2006), no se producen en el vacío sino que están inmersas en los procesos de aprendizaje social que se desa rollan en los contextos laborales. Dichos contextos tienen el poder de influir en las personas que las ponen en marcha y, portanto, en su forma de pensar (Ainsc ow y Sandill, 2010).

Como hemos venido exponiendo a lo largo de estas páginas, Wenger (1991) ofrece un marco susceptible de ser utiliza do para analizar el desa rollo de prácticas en contextos sociales: las Comunidades de Práctica (CoPs). De acuerdo con Wenger y sus colaboradores (Wenger, Mc Dermott et al., 2002) las CoPs constituyen grupos de personas que comparten un interés, un conjunto de problemas o una pasión sobre un tema. A lo largo de las interacciones que se producen en sus encuentros discuten sus vivencias, aspiraciones y necesidades a la vez que comparten un lenguaje común (Huberman, 1993; Little y McLaughlin, 1993), tiempo, 
información, consejos y se ayudan entre sí a resolver problemas que se producen en los contextos laborales.

A través de tales experiencias compartidas los profesionales de los centros que prestan servicios a las personas con discapacidad pueden ayudarse a expresar lo que hacen en el día a día y definir lo que les gustana hacer para mejorar y adaptarse a los cambios que se producen en la sociedad (Hiebert, Gallimore y Stigler, 2002; Ainsc ow y Sandill, 2010).

Si se analiza cómo introducen los centros nuevos enfoques inclusivos, podemos ver cómo las prácticas que permanecen estables y se integran en la cultura de la organización no surgen de un proceso mecánico implementado a través de una reestructuración organizativa específic a o a través de la introducción de un conjunto de técnicas innovadoras. Más bien, se generan a través de un incremento de los niveles de participación de la comunidad en la que se llevan a cabo.

En las CoPs, la práctica en sí misma involucra aspectos explíc itos e implícitos que son desarrollados, negociados y compartidos. Asimismo el proceso de participar en una práctica implica a toda la persona, actuando y conociendo al mismo tiempo. Es así como la noción de práctica es desarrollada por Wenger (2001) en diferentes sentidos, como: significado, comunidad, aprendizaje, límite, situación y conocer en la práctica.

Las Comunidades de Práctic a ayudan por tanto a desarrollar una cultura de apoyo que se puede extender más allá de las acciones que se desarrollen dentro de la comunidad. Más importante aún, estudios realizados por Davenport y Hall (2002) han demostrado que los miembros de las Comunidades de Práctica han llegado a confiar en los demás, por lo menos, a nivel profesional, como consecuencia de la participación en las mismas. 
En definitiva, las Comunidades de Práctica son un instrumento que tienen a su alcance las organizaciones que prestan servicios a las personas con algún tipo de limitación para impulsar la aplic ación del Index para la Inclusión.

En relación con la organización que ha servido de referencia para la presente investigación, es posible concluir que la Asociación AMICA, como se señala ampliamente en el capítulo 4, cumple con todas las características de una organización inclusiva y que a lo largo de los años ha constituido una Comunidad de Práctica a través de la cual ha creado una empresa conjunta, un repertorio compartido y un compromiso mutuo.

Sobre el primer aspecto, tras analizar los diferentes centros a través de las visitas y entrevistas con diferentes miembros de la organiza ción (equipo directivo, profesionales, familias y personas usuarias) podemos concluir que su cultura es muy fuerte y está a rra iga da en unos valores orga nizativos compartid os por los miembros de la organización. Sus valores transcienden a los señalados por Booth (2005) y se centran en: la defensa de los derechos, la apuesta por la igualdad, el trabajo en equipo, la satisfacción de las personas, la dignidad, la transparencia, el compromiso social, el respeto a la diferencia y la individualidad, la participación y la profesionalidad (AMICA, 2010B). Estos valores se ven reflejados en las diferentes polític as y práctic as que se realizan en los diferentes centros y en todas las personas que forman parte de la Asociación.

Si ana lizamos las políticas inclusivas en AMICA y aplicamos lo a na liza do a nivel teórico podemos constatar que, en la Asociación, los derechos de las personas con discapacidad están en la base de todas sus políticas y ello se ve reflejado en su sistema de gestión basado en el Modelo EFQM y en los resultados que van obteniendo, que cada año se sitúan en AMICA en puntuaciones superiores a los 400 puntos. 
Como prueba de la relación de los valores organizativos de la asociación con las políticas implantadas en el centro podemos ver que el valor transparencia se refleja en una política basada en la confianza, en la honestidad y la transparencia en la gestión. AMICA se somete a los principios de transparencia y buenas prácticas de gestión de la Fundación Libertad. Otro ejemplo claro de cómo se aplica a la Asociación lo analizado el capitulo 2, es cómo se ponen en marcha políticas inclusivas saludables basadas en el trabajo en equipo, el compromiso compartido, la participación de todas las personas implicadas y un liderazgo compartido centrado en que liderar es compartir ideas e inquietudes para que todo el mundo trabaje en la misma dirección.

Respecto al desarrollo de prácticas inclusivas, y como no podía ser de otra manera por el despliegue de la cultura y las políticas, en AMICA las prácticas están centradas en la persona como protagonista de su proyecto personal, en sus derechos como ciudadano y en la defensa de la individualidad.

Todo ello nos lleva a concluir que AMICA, es una organización inclusiva que puede ser referente para todos aquellos centros que desarrollen servicios para personas con discapacidad. Los resultados de la parte empíica de la presente investiga c ión a va la n esta conclusión.

En la parte empírica de la presente Tesis Doctoral, hemos realizado una adaptación del Index para la inclusión al contexto socio-educativo de los centros que prestan servicios a personas con discapacidad. En primer lugar, hemos corroborado que el Index para la inclusión se puede adaptar a centros que prestan servicios a las personas con discapacidad.

En segundo lugar, las dimensiones que presenta el Index para la Inclusión para el ámbito educativo son válidas para los centros para personas con discapacidad. Sin embargo, existen dificultades a la hora de adscribir los indicadores y preguntas del Anexo del Index en su versión original, a unas u otras 
categorías. Concreta mente, la versión preliminar del Cuestiona rio de Evaluación de los Indic a dores del Index (CEII) que se realizó en la Fase II (véase Capítulo 5) mostró muchas limitaciones, ya que sus índic es de validez de contenido y de constructo y de fiabilidad no fueron adecuados.

Sin embargo, tras las actuaciones llevadas a cabo en las Fases III y IV (Capítulo 6) hemos comprobado que, tras rea lizar modific ac iones en las Secciones, los Indicadores y las Preguntas del Index para Inclusión, es posible utilizarlo para fomentar la inclusión en centros que prestan servic ios a personas con discapacidad (véase Anexo IV).

Por todo ello, y a modo de conclusión final sobre el primer objetivo general de este estudio, podemos decir que es posible adaptar el Index para la Inclusión (Booth y Ainscow, 2000) para su aplicación en centros que prestan servicios a personascon discapacidad.

\subsubsection{Discusión y conclusiones del segundo objetivo de la} investigación

El segundo objetivo que se planteaba para la presente investigación es construir un Cuestionario de Evaluación de los indicadores del Index (CEII) para la inc lusión con a dec ua das propiedades psic ométric as.

Como se puede observar en el Capítulo 6, el Cuestionario de Evaluación de los Indicadores del Index (CEII) elaborado, muestra adecuadas propiedades psicométricas de fiabilidad (acuerdo entre jueces, consistencia intema) y validez (validez a parente, validez de constructo) tras las a daptaciones rea liza das, por lo que podemos concluir diciendo que los cambios que se han realizado en la secciones del Index han resultado adecuados y reflejan la realidad de un centro que presta serviciosa personascon discapacidad de un modo más ajustado que el Index original (véase conclusiones capítulo 5). 
Si a nalizamos los resulta dos obtenidos en el análisis factorial podemos ver cómo los cuatro factores que se han obtenido son los mismos que los que presenta el Index para la Inclusión para centros escolares aunque es de destacar que la Dimensión Cultura Inclusiva se desdobla en dos factores: comunidad y valores. Este aspecto es coherente con la investigación documental realizada que permite concluir que estos dos elementos son la base sobre la que se construyen tanto las polític as como las prácticas.

Otro aspecto a destacar es que en cada uno de los factores se entremezclan los indicadores del Index para la inclusión, lo cual demuestra que las tres dimensiones no son espacios estancos y que en la vida diaria de los centros, lejos de los aspec tos teóricos, la sinfluencias son múltiples y muy va ria das.

\subsubsection{Disc usión y conc lusiones del tercer objetivo de la investigac ión}

Si nos centramos en las altas puntuaciones obtenidas en AMICA sobre los indic a dores del Cuestionario de Indic a dores de Inclusión (CII), en ningún factor, en una escala de 1 a 4, se obtienen resultados inferiores a tres. Estos resultados no se ven afectados aunque varíen las características de los participantes: la edad, el género, el rol que se desempeñe en el centro o el tiempo de relación con él. Por ello, podemos concluir que un centro que presente un compromiso compartido con una filosofía inclusiva obtendrá eleva das puntuaciones en las tres dimensiones del Index. Y que si existe una filosofía inclusiva no habrá diferencias de opinión entre los diferentes miembros de la comunidad en torno a los temas relacionados con la cultura, las polític a s y las prác tic as inc lusivas.

Para finalizar este a partado, nos gustaría resaltar que el factor prácticas es el que mayores puntuaciones ha obtenido, lo cual es coherente tanto con lo analiza do a nivel teórico como con las obsenvaciones y entrevistas realizadas en 
CAPITULO 7. Conc lusiones, disc usión, limitaciones y líneas futuras de investigación

AMICA, ya que en las prácticas del centro se reflejan claramente los otros tres factores. Por ello, podemos concluir diciendo que las prácticas inclusivas son el factor sobre el que un centro debe poner especial a tención en el día a día.

\subsection{Limitac iones y líneas futuras de investigac ión}

Una vez que se han discutido cada uno de los objetivos planteados en esta investiga ción, es necesario resaltar sus limitaciones y ofrecer a lgunas líneas futuras de investigación que pueden enriquecer los logros conseguidos hasta a hora.

Teniendo en cuenta las áreas que mayores limitaciones presentaron y aquellas donde futuras investigaciones son más importantes, en el presente a parta do se comentan las limitaciones y líneas futuras con respecto a las revisiones teóric as y los instrumentos.

La revisión teórica con respecto a la inclusión en los centros que prestan servicios a personas con discapacidad y a las tres dimensiones que presenta el instrumento nos ha mostrado que existen múltiples temas a analizar en cada una de las tres dimensiones y que existen escasas publicaciones que abarquen la inclusión como un concepto global que puede ser aplicado fuera de la escuela. Por ello, seguir profundizando en las tres dimensiones desde el punto teórico se perfila como un área interesante de investigación futura.

Respecto a la propuesta de incluir las Comunidades de Práctica como metodología de apoyo a la aplicación del Index sería una línea de investigación que proporcionaría resultados muy interesantes ya que permitiría conocer cómo a través de una Comunidad de Práctic a se pueden introducir cambios culturales en una organiza ción y cómo se organizan las Comunidades de Práctica en los centros.

Con respecto a los instrumentos que se han adaptado y elaborado en la presente tesis, señalar que el Index para la inclusión adaptado ha mostrado ser un 
instrumento que nos permite trabajar los temas relacionados con la inclusión en los centros que prestan servicios a personas con discapacidad, por lo que en investigaciones futuras sería recomendable aplic arlo en otros centros más allá de la Asociación AMICA que se ha utilizado como centro de referencia en este estudio. Señalar también que el Cuestionario de Indicadores de Inclusión (CII) mostró ser un instrumento con adecuados niveles de validez de constructo y contenido y de fiabilidad para la muestra que participó en la investigación. Debido a esto se puede proponer como un instrumento a perfeccionar con análisis psicométricos posteriores y también en muestras más amplias y en centros no pertenecientes a AMICA. 
Bib liogra fía

\section{BIBUOGRAF́A}


Abravanel, H., Alla ire, Y., Firsirotu, M., y otros. (1992). Cultura organizacional. Colombia: Legis.

Adams, E. C., y Freeman, C. (2000). Communities of practice: bridging technology and knowledge assessment. Joumal of Knowledge Management, 4(1), 38 44.

Aiman-Smith, L. (2004). What Do We Know about Organizational Culture. Recupera do de http://www4.nc su.edu/ hp/LAS_overview.pdf

Ainsc ow, M. (1991). Effective Schools for All. London: Fulton.

Ainsc ow, M. (1998). Exploring links between special needs and school improvement. Support for lea ming, 13(2), 70-75.

Ainsc ow, M. (1999). Understanding the Development of Inclusive Education. London: Fa Imer Press.

Ainsc ow, M. (2001). Desa rrollo de esc uelas inclusivas. Madrid: Narcea.

Ainsc ow, M. (2003). Toward s Inc lusive Sc hooling. British J oumal of Special, 24(1), 3-6.

Ainscow, M. (2005). La mejora de la escuela inclusiva. Cuademos de Pedagogía (349), 78-83.

Ainsc ow, M. (2005). Para comprender el desa rollo del sistema educativo inclusivo. Electronic J oumal of Research in Educational Psychology, 3.

Ainscow, M. (2007). Taking an inclusive tum. Joumal of Research in Special Educational Needs, 7(1), 3-7.

Ainsc ow, M., Booth, T., y Dyson, A. (2004). Understanding and developing inclusive practices in schools: a collaborative action research network. Intemational jo umal of inclusive education, 8(2), 125-139.

Ainsc ow, M., Booth, T., y Dyson, A. (2006). Improving schools, developing inclusion. Londres: Routledge.

Ainscow, M., Booth, T., y Dyson, A. (2006). Inclusion and the standards agenda: negotiating policy pressures in England. Intemational Joumal of Inclusive Education, 295-308.

Ainscow, M., y Kaplan, I. (2004). Using evidence to encourage inclusive school development: possibilities and challenges. Ponencia presentada en Australian Association of Research in Education Annual Conference, Melboume.

Ainsc ow, M., y Sandill, A. (2010). Developing inclusive education systems: the role of organisational cultures and leadership Intemational Joumal of Inclusive Educ ation, 14(4), 401-416

Ainsc ow, M., y West, M. (2008). Mejorando las escuela s urbanas. Madrid: Narcea.

Alberic io Huerta, J . J . (1991). Educar en la diversida d. Madrid: Bruño.

Allen, J. B. (2003). Social motivation in youth sport. Joumal of Sport and Exercise Psychology, 25 (4).

Alonso, J. R., \& Sánc hez Gómez, M. C. (2011). Neurociencia.Pla sticidad neuronal y educación. Educadores: Revista de renovación pedagógica, 8-20.

Amabile, T. M. (1993). What Does a Theory of Creativity Require? Psychological Inquiry, 4(2), 179-181.

Ames, C. (1992b). Achievement goals, motivational climate and motivational processes. En G. C. Roberts (Ed.), Motivational in sport and exercise (pp. 161176). Champaign, IL: Human Kinetic s.

Ames, C. (1992a). Classroom: goal, structures, and student motivation. Joumal of Educ a tional Psychology, 84, 261-271.

Ames, C. (1987). The enhacement of student motivation. En D. Kleiber y M. Maehr (Coords.), Advances in motivation and achievement (pp. 123-148). Greenwich, CT: J AI Press. 
AMICA. (2009). Descubriendo capacidades. Principios y valores que unen volunta des. Torrela vega (Cantabria): AMICA.

AMICA. (2010a). Memoria Asociación AMICA. Sello de Excelencia Europea 400+ Año 2010. Torrelavega (Cantabria): AMICA.

AMICA. (2007). Plan Estratégico. Asociación AMICA 2007-2009. Torrelavega (Cantabria): AMICA.

AMICA. (2010b). Plan Estratégico. Asociación AMICA 2010-2012. Torrelavega (Cantabria): AMICA.

AMICA. (2008). Resumen plan de actividades 2009. Torrelavega (Cantabria): AMICA.

Anand, V., Ashforth, B. E., y J oshi, M. (2004). Business as usual: the acceptance and perpetuation of comuption in organizations. Academy of Management Exec utive, 18(2), 39-53.

Andrés, M. D., y Sarto, P. (2009). Escuela inclusiva: Valores, a cogida y convivencia Aspectos clave de la Educación Inclusiva. Salamanca: Publicaciones del INICO, Colección Investigación.

Arbea, L., y Tamarit, J . (2003). De la capacitación a la autorrealiza ción: Hacia una nueva conciencia profesional. Ponencia presentada en Educación CREENA, Pamplona.

Ardichvili, A., Page, V., y Wentling, T. (2002). Virtual Knowledge-Sharing Communities of Practice at Caterpillar: Success Factors and Barriers. Performance Improvement Quarterly, 15, 94 - 113.

Argyris, C., y Schön, D. A. (1974). Theory in practice: Increasing professional effectiveness. San Fra ncisc o: J ossey-Bass.

Amáiz, P. (1999a). Atención a la diversidad en contextos inclusivos. Ponencia presentada en el Congreso Intemacional: Reto Social para el próximo milenio: Educación para la diversidad. 25 Aniversario de AEDES., Madrid.

Amáiz, P. (1999b). Cumíc ulum y atención a la diversidad. En M. A. Verdugo y F. B. Jordán de Umíes (Coords.), Hacia una nueva concepción de la discapacidad (pp. 39-61). Salamanca: Amanú.

Amáiz, P. (1997). Integración, segregación e inclusión. En P. Amáiz y R. De Ha ro (Coords.), 10 años de integración en España (pp. 313-353). Murcia: Servicio de Publicaciones de la Universidad.

Bakeman, R. (2000). Behavioral observation and coding. En H. T. Reis y C. M. Judge (Coords.), Handbook of research methods in social and personality psychology ( pp. 138-159). New York: Cambridge University Press.

Band ura, A. (1977). Social Lea ming Theory: New J ersey: Prentice Hall.

Banfield, E. G. (1958). The moral basis of a blackward society. New York: Free Press.

Baquero, R. (2002). Del experimento escolar a la experiencia educativa. La transmisión educativa desde una perspectiva psicológica situacional. Perfiles Educativos, 24 (97-98), 57-75.

Barab, S. A., MaKinster, J. G., y Scheckler, R. (2004). Designing System Dualities. Characterizing an Online Professional Development Community. Designing for Virtual Communities in the Service of Leaming, 53 - 90.

Barab, S. A., y Plucker, J. A. (2002). Smart people or smart contexts? Cognition, ability, and talent development in an age of situated approaches to knowing and leaming. Educ ational Psyc hologist, 37 (3), 165-182.

Barley, S. R., Meyer, G. W., y Gash, D. C. (1988). Cultures of culture: Academics, practitioners and the pragmatics of normative control. Administrative Sc ience Quarterly, 33, 24-60.

Bamey, J. B. (1986). Organizational Culture: Can it be a source of sustained competitive advantage? Ac ademy of Management Review, 11(3), 656-665.

Barton, L. (2009). Estudios sobre discapacidad y la búsqueda de la inclusividad. Observaciones. Revista de Educación, 349 (Ma yo-a gosto 2009), 137-152. 
Becker, G. S. (1976). The economic approach to human behavior. Chicago: University of Chic ago Press.

Becker, H. S. (1982). Culture: A Sociologic al View. Yale Review, 4, 513-527.

Beers, R. L. (2003). Organizational leaming in multidisciplinary teams: Knowledge brokering across communities of practice: Alliant Intemational University, San Francisc o Campus, San Francisco, CA.

Bell, D. (1974). The Coming of the Post Industrial Society: A Venture in Social Forecasting: Heinemann.

Bellah, R. H., Madsen, R., Sullivan, W., Swindler, A., y Tipton, S. (1985). Habits of the heart: Individualism and commitment in American life. Berkeley, CA: University of Ca lifomia Press.

Bellah, R. N., Madsen, R., Sullivan, W. M., Swidler, A., y Tipton, S. M. (1985). Habits of the heart. Berkeley, CA: University of Califomia Press.

Benner, C. (2003). Learning Communities in a Leaming Region: The Soft Infra structure of Cross-Firm Leaming Networks in Silic on Valley. Environment and Planning A, 35, $1809-1830$.

Bereiter, C. (1997). Situated cognition and how to overc ome it. En D. Kirshner y J. A. Whitson (Coords.), Situated cognition. Social, semiotic and psychological perspectives (pp. 281-300). Mahwah, NJ : Lawrence Erlbaum.

Blair, K. (2010). Creating an Inclusive Organization. Recuperado de http://maytree.com/fgi/2005/5-2.html

BOE. (2008). Instrumento de Ratificación de la Convención sobre los derechos de las personas con discapacidad, hecho en Nueva York el 13 de diciembre de 2006. Madrid: BOE. Recuperado de http:// www.convenciondisc a pacidad.es/ConvencionEspana/Texto \%20Conv encion\%20BOE\%20abril\%202008.pdf.

Boggs, W. B. (2004). TQM and organizational culture: A case study. The Quality Management J oumal, 11(2), 42-52.

Bonanno, G. A., y Kaltman, S. (2001). The varieties of grief experience. Clinical Psychology Review, 21, 705-734.

Bonanno, G. A., Wortman, C. B., Lehman, D. R., Tweed, R. G., Haring, M., Sonnega, J . (2002). Resilience to loss and chronic grief: A prospective study from preloss to 18 months post-loss. J oumal of Personality and Social Psychology, 83, 11501164.

Booth, T. (1996). A Perspective on Inclusion from England. Cambridge J oumal of Educ ation, 26(1), 87-99.

Booth, T. (2005). Keeping the future a live: putting inclusive values into a ction. Forum, $47(2 / 3), 151-158$.

Booth, T. (2006). Manteniendo el futuro con vida; convirtiendo los valores de la inclusión en acciones. En M. A. Verdugo y F. B. Jordán de Umées (Coords.), Rompiendo inercias. Claves para avanzar. VI Jomadas Científicas de Investigación sobre Personas con Discapacidad. Salamanca: Amanu.

Booth, T. (2008). Valores inclusivos y el indice de la inclusión. Ponencia presentada en Valores, políticas y prácticas para una educación inclusiva, Buenos Aires, Argentina.

Booth, T., y Ainscow, M. (2002). Guía para la evaluación y mejora de la educación inclusiva. Index for inclusión. Madrid: Consorcio Universitario para la Educ ación Inclusiva.

Booth, T., y Ainsc ow, M. (2000, 2002). The Index for Inclusion; Developing Leaming and Participation in Schools. Bristol: CSIE. 15.

Booth, T., Ainscow, M., y Kingston, D. (2006). The Index for Inclusion, Developing Play Leaming and Participation in Early Years and Childcare. Bristol: CSIE [Tra ducción y a daptación al castellano de F. Gonzá lez-Gil, M. Gómez-Vela y C. Jenaro. (2007). Index para la Inclusión: Desarrollo del juego, el 
aprendizaje y la participación en Educación Infantil. Universidad de Salamanca].

Booth, T., y Black Hawkins, K. (2005). Developing Leaming and Participation in Countries of the South; the Role of an Index for Inclusion. Paris: UNESCO.

Booth, T., Nes, K., y Stromstad, M. (2003). Developing inclusive teacher education. Lond res: Routledge Falmer.

Bourdieu, P. (1984). La délégation et le fetic hisme politique. Actes de Recherche en Sciences Soc ia les, 52-53, 49-65.

Bozu, Z, y Imbemon Muñoz, F. (2009). Creando comunidades de práctica y conocimiento en la Universidad: una experiencia de trabajo entre las universidades de lengua catalana. Revista de Universidad y Sociedad del Conocimiento, 6(I).

Bradley, V. J. (1994b). Evolution of a new service paradigm. En V. J. Bradley, J. W. Ashbaugh y B. C. Blaney (Coords.), Creating individual supports for people with developmental disa bilities (pp. 11-32). Ba Itimore: P.H. Brookes.

Bradley, V. J. (1994a). Introduction. En V. J. Bradley, J. W. Ashbaugh y B. C. Blaney (Coords.), Creating individual supports for people with developmental disa bilities (pp. 3-9). Ba ltimo re: P.H. Brookes.

Bronfenbrenner, U. (1979). The ecology of Human Development. Cambridge: Ha va rd University Press.

Brown, J., Caston, M., y Bernard, B. (2001). Resilience in Education. Califomia, EE. UU.: Corwin Press, Inc.

Brown, J. S., Collins, A., y Duguid, P. (1989). Situated cognition and the culture of leaming. Educational Researcher, 18, 10-12.

Brown, J. S., y Duguid, P. (1991). Organizational Leaming and Communities of Practice: Toward a unified view of working, leaming, and innovation. Orga nization Science, 2(1), 40 - 57.

Brown, J. S., y Duguid, P. (2000). The social life of information. Boston, MA: Harvard Business Sc hool Press.

Brown, J. S., y Duguid, P. (2001). Knowledge and Organization: a Social-Practice Perspective. Organization Science, 12(2), 198-213.

Buber, M. (1970). ¿Qué es el hombre?. México: Fondo de Cultura Económica.

Buber, M. (1998). Yo y Tú. Madrid: Ca pa rós Editores.

Buchanan, A. (2001). Towards an inclusive organizational culture: Applying a 'diversity lens (Vol. April): Canadian Council for International Co-operation Organiza tional Development Team.

C.E. (2001). UBRO VERDE. Fomentar un marco europeo para la responsabilidad social de las empresas. Bruselas: Comisión de las Comunidades Europeas.

Careaga, A. (2003). La resiliencia desde la escuela: resistir y reconstruirse. Recuperado $\mathrm{de}$ http://cecap.anep.edu.uy/Foro \%20Inc l/Doc umento s/Foro\%20II/La \%20resilien cia\%20desde\%20la \%20esc uela point.pdf

Carneiro Caneda, M. (2002). Reducción de desigualdades en los procesos de inserción organizativa: Un acercamiento al concepto de responsabilidad social intema. Revista de trabajo y seguridad social, 237, 195-264.

Carneiro Caneda, M. (2004). La responsabilidad social corporativa intema. Madrid: ESIC Editorial.

Camington, S., y Robinson, R. (2006). Inclusive school community: why is it so complex? Intemational I oumal of Inclusive Education, 10(4-5), 323-334.

Carver, C. S. (1998). Generalization, adverse events, and development of depressive symptoms. J oumal of Persona lity, 66, 607-619.

Castaño, R. (2009). La a tención a la diversidad en el marco de la LOE. Las etapas de la educación infantil y primaria. Revista de investigación, técnica y educ a tiva (J ulio). 
Castaño, R. (2010). El Curriculum y la atención a la diversidad en las etapas de la educación básica, primaria y secundaria obligatoria, en el marco de la Ley Orgánica de Educación. Hekademos. Revista educativa digital, 6, 5-26.

Castaño, R. (2010). El reconocimiento de las lenguas de signos españolas como instrumento de comunicación para la comunidad de personas sordas. Hekademos. Revista educativa digital, 5, 23-44.

Castaño, R. (2010). La atención educ ativa integral a los alumnos con necesidades específic as de apoyo educativo: actitudes, valores y nomas. Hekademos. Revista educa tiva digita I, 7, 23-42.

Castaño, R., Flores, N., G onzález-Gil, F., y J enaro, C. (2011). El cambio de actitudes hacia los alumnos con discapacidad en padres, compañeros y profesores (Enviado para su public ación). Siglo Cero

Castillo, T. (2007). Déjame intentarlo. La discapacidad: hacia una visión creativa de la s limita c iones humanas. Madrid: CEAC.

Castillo, T. (2009). Aprendiendo a vivir. La enfermedad: descubrir las posibilidades que hay en mí. Madrid: CEAC.

Castillo, T. (2010). Grupo AMICA: motor de economía social en Cantabria. CIES.

Cawrse, S., y D'Arcy Walsh, I. (2005). Cultivating communities of practice to build organisational capacity: a case study of the Philippines-Australia Basic Education Assistance for Mindanao (BEAM) Project. Evaluation Joumal of Australa sia, 4(1-2), 22-26.

Centre, Y., Ward, J., y Ferguson, C. (1991). Towards an index to evaluate the integration of children with disabilities into regular classes. Sydney, Australia: Centro de Educación Especial Mcquaire.

CERMI. (2010). Una Convención para la Discapacidad, Recuperado de http://www.convenciondiscapacidad.es/

Cervelló, E. (2002). Abandono deportivo: Propuestas para favorecer la adherencia a la práctica deportiva. En J. Dosil (Ed.), Psicología y rendimiento deportivo (pp. 175-187). Ourense: GERSAM.

Clancey, W. J. (1995). A tutorial on situated leaming. Ponencia presentada en Intemational Conference on Computers and Education, Taiwan.

Clancey, W. J. (1997). Situated cognition: On human knowledge and computer representations. Cambridge: Cambridge University Press.

Clark, A. (1997). Being there. Putting brain, body, and world together again. Cambridge, MA: MIT Press.

Cobb, P. (1994). Where is the mind? Constructivist and soc ioc ultural perspectives on mathematic al development. Educational Researcher, 23, 13 - 20.

Cobb, P., y Yackel, E. (1996). Constructivist, emergent, and sociocultural perspectives in the context of development research. Educational Psychologist, 31, 175 - 190.

Cohendet, P., Creplet, F., y Dupouët, O. (2000). Communities of Practice and Epistemic Communities: A Renewed Approach of Organisational Leaming within the Firm. Ponencia presentada en el 5th Workshop on Economics with Heterogeneous Interacting Agents (WEHIA). Recuperada de http:// www.marsouin.org/IMG/pdf/dupouet.pdf

Contu, A., y Willmott, H. (2003). Re-embedding situatedness: the importance of power relations in lea ming theory. Organization Science, 14, 283 - 296.

Cooke, R. A., y Rousseau, D. M. (1988). Behavioral norms and expectations: A quantitative approach to the assessment of organizational culture. Group y Organization Studies, 13(3), 245-273.

Corbett, J. (2001). Teaching approaches which support inclusive education: a connective pedagogy. British J oumal of Special Education, 28(2), 55-59.

Corkill, D. D. (1991). Blackboard Systems. AI Expert, 6, 40-47.

Cortese, H. E. (2006). Comunidades de Práctica, Recuperado de 
www.nexic onsultores.com.ar/ download/comunidades.pdf

Cox, A. (2005). What are communities of practice? A comparative review of four seminal works. J oumal of Informa tion Sc ience, 31(6), 527 - 540.

Cox, T., y Cox, T. J. (2001). Creating the Multic ultural Organization; A Strategy for Capturing the Power of Diversity. San Francisc o: J ossey-Bass.

Craig, D. (2010). Qualities of an Inclusive Organization. Recuperado de http:// www.ehow.com/ list_6324626_qualities-inc lusive-orga nization.html

Csikszentmihalyi, M. (1975). Beyond boredom and anxiety. San Francisco: JosseyBass.

Csikszentmihalyi, M. (1988). The flow experience and its significance for human psychology. En M. Csikszentmihalyi y I. S. C sikszentmihalyi (Coords.), Optimal Experience: Psychological Studies of Flow in Consciousness. Cambridge, United Kingdom: Cambridge University Press.

Csikszentmihalyi, M. (1990). Flow: The psychology of optimal experience. Nueva York: Harper Parennial.

Csikszentmihalyi, M. (1992). Flow. The Psychology of Happiness. London: Rider.

Csikszentmihalyi, M. (1993). The evolving self. New York: Harper Collins.

Csikszentmihalyi, M. (1996). Fluir: Una psic ología de la felicidad. Barcelona Ka iros.

Csikszentmihalyi, M. (1998). Optimal experience: foundation for effective disaster rec overy. The Australian J oumal of Emergency Mana gement, 19, 6-15.

Csikszentmihalyi, M., y Csikszentmihalyi, I. S. (1998). Experiencia óptima: Estudios psicológic os del flujo en la conciencia. Bilba o Descleé de Brouwer.

Cyrulnik, B. (2001). Los patitos feos. La resiliencia: Una infancia infeliz no determina la vida. Madrid: Gedisa.

Channon, H. (2003). An Index for Inclusive Education at ATEl: Ra ising a wareness and enabling participation. Lancaster.

Chua, A. Y. K. (2006). The rise and fall of a community of practice: A descriptive case study. Knowledge and Process Management, 13, 120-128.

D'Amato, C., Hoag, P., Crocker, E., Neville, D., Carpenter-Barbee, C., y Bartell, L. (2002). Society for Clinical Coding comes around as CoP (Communities of Practice). J ournal of A hima, 73(6), 64 - 65.

Daniels, H. (2003). Vygotsky y la pedagogía. Barcelona: Paidós.

Davenport, E., y Hall, H. (2002). Organizational knowledge and communities of practice. Annual Review of Information Science y Technology, 36(1), 170227.

De la Cuesta González, M. (2004). El porqué de la responsabilidad social corporativa. Boletín económico de ICE 2813.

Deal, T. E., y Kennedy, A. A. (1982). Corporate Cultures: The Rites and Rituals of Corporate Life. Reading, MA: Addison-Wesley.

Deal, T. E., y Kennedy, A. A. (1983). Culture: A New Look Through Old Lenses. J ournal of Applied Behavioral Science, 501-513.

Deal, T. E., y Kennedy, A. A. (1985). Corpora tive cultures. USA: Addison-Wesley.

Deci, E. L. (1975). Intrinsic motivation. New York: Plenum.

Deci, E. L., y Ryan, R. M. (1980). The empirical exploration of intrinsic motivational processes. En L. Berkowitz (Ed.), Advances in experimental social psychology (Vol. 13, pp. 39-80). Nueva York: Academic Press.

Deci, E. L., y Ryan, R. M. (1985). Intrinsic motivation and self-determination in human behavior. Nueva York: Plenum Press.

Deci, E. L., y Ryan, R. M. (1991). A motivational approach to self: Integration in personality. En R. Dienstbier (Ed.), Nebraska symposium on motivation, Vol. 38: Perspectives on motivation (pp. 237-288). Lincoln, NE: University of Nebraska Press.

Deci, E. L., y Ryan, R. M. (2000). The "what" and "why" of goal pursuits: Human needs and the self-determination of behaviour. Psychological Inquiry, 11, 
227-268.

Denison, D. R. (1990). Corporate culture and organizational effectiveness. Nueva York: Wiley

Denison, D. R., y Mishra, A. K. (1995). Toward a theory of organizational culture and effectiveness. Organization Sc ience, 6(2), 204-215.

Derry, S., Levin, J., y Schauble, L. (1995). Stimulating statistical thinking through situated simulations. Teaching of Psychology, 22 (1), 51-57.

Dewey, J . (1938). Experience y education. New York: Collier Ma cmillan.

Dewey, J . (1939). Theory of valuation. Chic ago University of Chic ago Press.

Dewey, M. E. (1983). Coefficients of agreement. British J oumal of Psychiatry, 143, 487-489.

Dhiman, S. K. (2007). Running successful organizations humanly: Lessons from the trenches. J oumal of G lobal Business Issues, 1(1), 53.

Diener, E., Suh, E. M., Lucas, R. E., y Smith, H. L. (1999). Subjective well-being. Three decades of progress. Psychologic al Bulletin, 125, 276 - 302.

Do Nascimento João, B. (2005). Estrategias de valor para la creación de conocimiento en organizaciones intensivas en conocimiento. Revista Galega de Economía, 14(2), 1-19.

Donnan, R. (2008). Critical Analysis of the Research on Communities of Practice. Recuperado http://www.blog.klpnow.com/2008/01/critical a nalysis of the resea.html

Duda, J. L. (1992). Sport and exercise motivation: A goal perspective analysis. En G. C. Roberts (Ed.), Motivation in sport and exercise (pp. 57-91). Champaign, IL: Human Kinetics.

Duk, C. (2009). El enfoque de la educación inclusiva. Recuperado de http://redinclusion. googlepa ges.com/EL_ENFOQUE_DE_LA_EDUCACI_N_.PDF

Durán, D., Echeita, G., Giné, C., López, A. L., Miguel, E., y Sañdoval, M.'(2003). Promover la inclusión educativa. Cuademos de Pedagogía, 325.

Durán, D., Echeita, G., Giné, C., Miguel, E., Ruiz, C., y Sandoval, M. (2005). Primeras experiencias de uso de la Guía para la evaluación y mejora de la educación inclusiva (Index for Inclusión) en el Esta do Español. REICE: Revista Electrónica Iberoamericana sobre Calidad, Eficacia y Cambio en la Educa ción, 3(1), 464-467.

Dweck, C. S. (1986). Motivational processes affecting learning. American Psychologist, 41, 1040-1048.

Dyson, A. (2001). Special needs education as the way to equity: an altemative approach? Support for leaming, 16(3), 99-104.

Dyson, A., Gallannaugh, F., y Millward, A. (2003). Making space in the Standards agenda: developing inclusive practices in schools. European Educational Research J oumal, 2, 228-244.

Echeita, G. (2004). La situación educativa del alumnado con NEE asociadas a disc a pacidad en la CAM. Psicología Educativa, 10(1), 19-44.

Echeita, G. (2006). Educación para la inclusión o educación sin exclusiones. Madrid: Narcea.

Echeita, G. (2007). Ya no, pero todavía tampoco. Entre los procesos de integración escolar y las aspiraciones de una educación más inclusiva. Un a nálisis psicosocial. Ponencia presentada en el Congreso Intemacional: Integración escolare inclusión educativa, Puebla

Echeita, G., Parrilla, A., y Carbonell, F. (2008). Hacia un marco de referencia compartido para la educación del alumnado en desventaja. La educación especial a debate. Ponencia presentada en las XXV Jomadas de Universidades y Educa ción Especial.

Echeita, G., y Sandoval, M. (2002). Educa ción inc lusiva o educ ación sin exclusiones. Revista de Educación, 327, 31-48. 
Echeita, G., Simón, C., Verdugo, M. A., Sandoval, M., López, M., González-Gil, F. (2009). Paradojas y dilemas en el proceso de inclusión educativa en España. Revista de Educación, 349 (Mayo-Agosto), 153-178.

Echeita, G., y Verdugo, M. A. (2004). La declaración de Salamanca sobre necesidades educativas especiales 10 años después: Valoración y prospectiva. Salamanca: INICO

Ec heita, G., Verdugo, M. A., Sandoval, M., Simón, C., López, M., González-Gil, F. (2009). La opinión de FEAPS sobre el proceso de inclusión educativa. Siglo Cero, 39(4), 26-50.

Echeita, G., Verdugo, M. A., Simón, C., González-Gil, F., Sandoval, M., Calvo, I. (2009). La opinión de las organizaciones de personas con discapacidad sobre el proceso de inclusión educativa en España. En M. A. Casanova, M. Carballeda y M. A. Cabra de Luna (Coords.), Educación y personas con disc a pacidad: presente y futuro (pp. 66-95).

Eichinger, J., Meyer, L. H., y D'Aquanni, M. (1996). Evolving best practices for lea mers with severe disabilities. Special Education Leadership Review, 1-13.

Ellul, J . (1964). The Technologic al Soc iety: Rand om House.

Engeström, E. (1987). Leaming by expanding: an activity-theoretical approach to developmental research. Helsinki: Orienta-Konsultit

Engeström, Y., y Cole, M. (1997). Situated cognition in search of an agenda. En D. Kirshner y J. A. Whitson (Coords.), Situated cognition. Social, semiotic and psychologic al perspectives (pp. 301-309). Mahwah, NJ : Lawrence Erlbaum.

Ep stein, J . (1988). Effec tive schools or effective students? Dealing with diversity. En R. Haskins y B. MacRae (Coords.), Policies for America's public schools. Norwood, NJ : Ablex.

Epstein, J. (1989). Family structures and student motivation: A developmental perspective. En C. Ames y R. Ames (Coords.), Research on motivation in education: Vol 3 (pp. 259-295). New York: Academic Press.

Era ut, M. (1999). Non-formal learning, implic it leaming and tac it knowledge. Informal learning.

Etxeberná, X. (2008). La condición de ciudadanía de las personas con disc a pacidad intelectual. Bilbao: Universidad de Deusto.

EUSE (2005). [Folleto informativo "Values, Standards and Principles of Supported Employment"].

Eysenbach, G., Powell, J., Englesakis, M., Rizo, C., y Stem, A. (2004). Health related virtual communities and electronic support groups: systematic review of the effects of online peer to peer interactions. BMJ , 328, 1166 - 1160.

FEAPS. (2000). Manual de Buena Práctic a de Educación. Madrid: FEAPS.

FEAPS. (2002). Indic a dores de c alidad para la integrac ión escolar. Madrid: FEAPS.

FEAPS. (2004). Código ético. Recuperado de http://www.feaps.org/confederacion/ documentos/codigo_etico.pdf

FEAPS. (2008). Guía REINE. C̄uadernos de Buenas Prácticas Retrieved 05/01/2010, Recuperado http://www.feaps.org/biblioteca/libros/documentos/guia_reine.pdf

FEAPS. (2009). La educación que queremos. Situación actual de la inclusión educativa en España. Madrid: FEAPS.

FED. (2009). Educación inclusiva: pasar de las palabras a los hechos. Recuperado de www.edf-feph.org

Fischer, G. (2001). Communities of interest: Leaming through the interaction of multiple knowledge systems. 1 - 14.

Flanagan, P. (1995). The abc's of changing corporate culture. Management Review, 84(7), 57-62.

Flores, N., J enaro, C., González-Gil, F., y García, P. M. (2010). Análisis de la calidad de vida laboral en trabajadores con discapacidad. Zerbitzuan: Gizarte 
zerb itzueta rako aldizka ria = Revista de servicios sociales, 2010(47), 95-107.

Foster, W. P. (2004). The decline of the local: a Challenger to educational Leadership. Educational Administration Quartely, 40, 176-191.

Frost, P. J ., Moore, L. F., Louis, M. R., Lundberg, C. C., y Martin, J. (1991). Reframing Organizational Culture. Newbury Park: Sage.

Fuentes Blanco, J. M. (2001). Funda mentos de psic ometría. Salamanca: Ama rú.

Furman, G. C. (2003). Moral Leadership and the Ethic of Community. Values and Ethic s in Educational Administration, 2(1).

Gabbay, J., y le May, A. (2004). Evidence based guidelines or collectively constructed "mindlines"? Ethnographic study of knowledge management in primary care. BMJ , 329(7473), 1013.

Gabbay, J., le May, A., J efferson, H., Webb, D., Lovelock, R., y Powell, J. (2003). A case study of knowledge management in multi-agency consumer-informed 'communities of practice': implications for evidence-based policy development in health and social services. Health (London), $283-310$.

Gagné, E. D., Yekovich, C. W., y Yekovich, F. R. (1993). The cognitive psychology of school leaming. New York: Longman.

Galvis, A. H., Tobón, M. I., y Salazar, P. (2008). Hacia una Gestión Efectiva de Comunidades Virtuales. Antología. Bogotá: Ministerio de Educación Nacional de Colombia.

Gannon-Leary, P. M., y Fontainha, E. (2007). Communities of Practice and virtual leaming communities: benefits, barriers and success factors. elearning Papers, 5.

Garber, D. (2004). Growing virtual communities. International Review of Research in Open and Distance Learning.

García Femández, J. A., Sánchez Delgado, P., Moreno Herrero, I., y Goenechea Permisán, C. (2010). Estudio del sistema y funcionamiento de las aulas de enlace de la Comunidad de Madrid: de la nomativa institucional a la realidad cotidiana. Revista de educa ción, 352, 473-493

Gillett, E., y Stenfer-Kroese, B. (2003). Investigating organizational culture: a comparison of a 'high'-and a 'low'-performing residential unit for people with intellectual disabilities. Joumal of Applied Research in Intellectual Disa bilities, 16(4), 279-283.

Giné, C. (2004). La Declaración de Salamanca sobre necesidades educativas especiales 10 años después. Valoración y prospectiva desde Catalunya. En G. Echeita y M. A. Verdugo (Coords.), La declaración de Salamanca sobre necesida des educativa sespecial. Salamanca: INICO.

Glisson, C., y James, L. R. (2002). The cross-level effects of culture and climate in human service teams. J oumal of Orga nizational Behavior, 76, 776-794.

González, M. T. (2008). Diversida d e inclusión educativa: a lgunas reflexiones sobre el liderazgo en el centro escolar. REICE: Revista Electrónica Iberoamericana sobre Calidad, Efic acia y Cambio en la Educación, 6(002), 82-99.

González-Gil, F. (2009). Formación del profesorado y a poyos. En M. P. Sarto Martín y M. E. Venegas Renauld (Coords.), Aspectos clave de la Educación Inclusiva. Salamanca: Universidad de Salamaca (INICO).

González-Gil, F., Gómez, M., y J enaro, C. (2009). Traducción y adaptación al castellano del Index para la inclusión: desarrollo del juego, el aprendizaje y la participación en educación infantil

Ponencia presentada en Mejorando resultados personales para una vida de calidad: VII Jomadas Científicas de Investigación sobre Personas con Disc a pacidad.

Gordon, G., y DiTomaso, N. (1992). Predicting corporate performance from orga nizational culture. J ournal of Management Studies, 29, 783-798.

Graves, L. N. (1992). Cooperative leaming communities: Context for a new vision of 
education and society. J oumal of Education, 174, 57 - 79.

Greeno, J. (1998). The situativity of knowing, leaming, and research. American Psychologist, 53, 5-26.

Gros Salvat, B. (2008). Las comunida des virtuales para la formación permanente del profesorado. REIRE, 1( Noviembre), 1-10.

Grotberg, E. (1995). A guide to promoting resilience in children: strenghening the human spirit, The Intemational Resilience Project. La Haya, Holanda: Bemard Van Leer Foundation.

Grotberg, E. H. (2002). Nuevas tendencias en resiliencia. En A. Melillo y E. Suarez (Coords.), Resiliencia. Buenos Aires: Paidós.

Haas, R., Aulbur, W., y Thakar, S. (2003). Enabling Communities of Practice at EADS Airbus. Sharing expertise: Beyond knowledge management 2003, 179 - 198.

Hamburger, F. A. (2008). Los valores comporativos en la empresa. Bogotá, Colombia: Ed ic iones Paulinas.

Hampton, J., y Dubois, D. (1993). Psychologic al models of concepts: introduction. En I. Van Mechelen, J. Hampton, R. S. Michalski y P. Theuns (Coords.), Categories and concepts. Theorical view and inductive data analysis. London: Academic Press.

Handley, K., Sturdy, A., Fincham, R., y Clark, T. (2006). Within and Beyond Communities of Practice: Making Sense of Leaming Through Participation, Identity and Practic **. J ournal of Management Studies, 43, 641 - 653.

Hanges, P. J., y Dickson, M. W. (2004). The development and validation of the GLOBE culture and leadership scales. En R. J. House, P. J. Hanges, M. Javidan, P. W. Dorfman y V. Gupta (Coords.), Culture, Leadership, and Organizations: The GLOBE Study of 62 Soc ieties (pp. 122-151). Thousand Oaks, CA: Sage Publications.

Hara, N. (2009). Communities of Practice. Fostering Peer-to-Peer Leaming and Informal Knowledge Sharing in the Work Place. Bloomington: Springer.

Hara, N., y Hew, K. F. (2007). Knowledge sharing in an online community of healthcare professiona Is. Information Tec hnology y People, 20(3), 235-261.

Hargreaves, A. (1996). Profesorado, cultura y postmodemidad. (Cambian los tiempos, cambia el profesorado). Madrid: Morata.

Harris, L. C., y Ogbonna, E. (2002). The unintended consequences of culture interventions: A study of unexpected outcomes. British Joumal of Management, 13(1), 31-49.

Hart, S., Dixon, A., Drummond, M., y Mc Intyre, D. (2004). Leaming without limits. Maidenhead: Open University Press.

Hatch, M. (1997). Organization Theory, modem, symbolic, and postmodem perspectives. Oxford: University press.

Hayes, B. C. (2010). Moving From Diversity Management to Creating Inclusive Organizations Recuperado de http:// events.kenexa.com/newsletter/oldver/ 09052.a sp? uid =1ytbl=test

Helliwell, J. F., y Putnam, R. D. (1995). Economic growth and social capital in Italy. Ea stem Ec onomic J ournal 21(3), 295-307.

Henderson, N., y Milststein, M. (1996). Resiliency in schools: making it happen for students and educators. Thousand Oaks, Califomia: Corvin Press.

Heung, V. (2006). Can the introduction of an inclusion index move a system forward?. Intemational J oumal of Inc lusive Education, 10 (4-5), 309-322.

Heung, V., y Ainsc ow, M. (2004). Inclusive education a framework for reform. Hong Kong: Hong Kong Institute of Education.

Hick, P. (2005). Supporting the development of more inclusive practices using the Index for Inclusion. Educ ational Psychology in Practice, 21 (2), 117-122.

Hild reth, P., Kimble, C., y Wright, P. (2000). Communities of Practice in the Distributed Intemational Environment. J oumal of Knowled ge Mana gement 4(1), 27 - 38. 
Hild reth, P., Wright, P., y Kimble, C. (1999). Knowledge Management: Are We Missing Something? Ponencia presentada en 4th UKAIS Conference: Information Systems - The Next Generation, University of York.

Hild reth, P. M. (2004). Going virtual: Distributed communities of practice. Hershey, PA: Idea Group.

Hild reth, P. M., Kimble, C., y Wright, P. (1998, March 1998). Computer Mediated Communications and Communities of Practice. Ponencia presentada en Ethic omp'98, Era smus University, The Netherlands.

Hiltz, S. R., y Turoff, M. (1978). The Network Nation: Humman Communication Vai Computers. Cambridge, MA: MITPress.

Hodson, P., Baddaley, A., Laycock, S., y Williams, S. (2005). Helping secondary schools to be more inclusive of year 7 pupils with SEN. Educational Psychology in Practice, 21 (1), 53-67.

Honeyman, A. (2002). Communities of practice. British J ournal of General Practice, $52,621-622$.

House, R. J., Javidan, M., Hanges, P. J., y Dorfman, P. W. (2002). Understanding cultures and implic it leadership theories across the globe: an introduction to Project GLOBE. J oumal of World Business, 37, 3-10.

Howard, R. W. (1992). Classifying types of concepts and conceptual structure: some taxonomics. European J oumal of Cognitive Psychology, 4(2), 81-111.

Huberman, M., Little, J. W., y McLaughlin, M. W. (1993). The model of the independent artisan in teachers' professional relationships. Teachers' work: Individuals, colleagues and contexts Teachers' work: Individuals, colleagues and contexts ( $p$ p. 11-50). New York: Teachers College Press.

Hughes, M. A., y Garrett, D. E. (1990). Interc oder relia bility estimation-Approa ches in marketing: A Genera liza bility Theory fra mework for qua ntita tive data. J oumal of Marketing Research, 27 (May), 185-195.

Huntington, S. (2003). Resiliencia: un nuevo enfoque de la terapéutica. En J. P. Schust, M. Contreras, M. Bersten, P. Carrara y J. Parral (Coords.), Redes, vínculos y subjetividad (pp. 115-124). Buenos Aires: Lugar.

Huysman, M. (2003). Knowledge sharing in practice. Recuperado de http:// www.sapdesignguild.org/ ed itions/ edition5/ km_mh.asp

Infante, F. (2002). La resiliencia como proceso: Una revisión de la literatura reciente. En A. Melillo y E. Suarez (Coords.), Resiliencia: Descubriendo las propias fortalezas (pp. 41-53). Buenos Aires: Paidós.

Iso-Ahola, S. E., y St.Clair, B. (2000). Toward a theory of exercise motivation. Quest, $52,131-147$.

J a ckson, A. S., y C sikszentmiha lyi, M. (2002). Fluir en el Deporte. Barc elona.

Jeffries, J. (2001). Members test drive communities of practice. Joumal of Ahima, $72(6), 51$.

Jenaro, C. (2000). Inclusión, Cambio Organizacional, Planific ación Centrada en la Persona y Apoyos Naturales. Recuperado de http://www.usal.es/invesinic o/inc lusion.htm

Jiménez, R. (2004). Motivación, trato de igualdad, comportamientos de disciplina y estilos de vida saludables en estudiantes de Educación Física en Secundaria. Tesis doctoral, Universidad de Extrema dura, Cáceres.

Johnson, C. M. (2001). A Survey of Current Research on Online Communities of Practice. Intemet and Higher Educ ation, 45 - 60.

Kanfer, R. (1994). Motivation. En N. Nicholson (Ed.), The Blackwell dictionary of organizational behavior. Oxford: Blackwell publishers.

Kemo, S. J., y Mace, S. L. (2010). Communities of Practice: Beyond Teams. Advances in Developing Human Resources, 12(1), 78-92.

Kimble, C. (2006). Communities of Practice: Never Knowingly Undersold. Ponencia presentada en Innovative Approaches for Leaming and Knowledge Sharing, 
EC-TEL 2006 Workshops Proceedings.

Kimble, C., y Hildreth, P. (2004). Communities of Practice: Going One Step Too Far? Ponencia presentada en Proceedings 9e colloque de l'AIM, Evry, France.

Kirshner, D., y Whitson, J. A. (1997). Situated Cognition: Social, semiotic, and psychological perspectives Mahwah, New Jersey: Lawrence Erlbaum Associates.

Klein, A. S., Bigley, G. A., y Roberts, K. H. (1995). Organizational culture in high reliability orga nizations: An extension. Human Relations, 48 (7), 771-793.

Kling, R. (1996). Social relationships in electronic forums: Hangouts, salons, workplaces, and communities. En R. Kling (Ed.), Computerization and controversy: Value conflicts and social choices, (2nd ed.). San Diego: Academic Press.

Kling, R., y Coutright, C. (2004). Group Behavior and Leaming in Electronic Forums: A Socio-Technical Approach. Designing for Virtual Communities in the Service of Leaming, 91 - 119.

Knapp, A. G., y Anderson, J. A. (1984). Theory of categorization ba sed on distributed memory storage. J oumal of Experimental Psychology: Learning, Memory and Cognition, 10(4), 616-637.

Kose, B. W., y Shields, C. M. (2010). Ecologic al and Social J ustice: A Leadership Framework for Susta ina bility. Intema tional J oumal of Environmental, Cultural, Ec onomic and Social Susta inability, 6(3), 275-288.

Kotter, J. P., y Heskett, J . L. (1992). Corporate culture and performance. Nueva York: Free Press.

Krippendorff, K. (1978). Relia bility of binary attribute data. Biometric s, 34, 142-144.

Krippendorff, K. (1987). Association, a greement, and equity. Quality and Quantity, $21,109-123$.

Krippendorff, K. (1990). Metodología de análisis de contenido. Teoría y práctica. Barcelona: Paidós Comunic a ción.

Krippendorff, K. (2004). Content analysis: An introduction to its methodology. Thousand Oaks, CA: Sage.

Kujala, J., y Lillrank, P. (2004). Tota I qua lity management as a c ultural phenomenon. The Quality Management J oumal, 11(4), 43-55.

Kull, T. J., y Narasimhan, R. (2010). Quality Management and Cooperative Values: Investigation of Multilevel Influences on Workgroup Performance. Decision Sciences, 41(1), 81-113.

Lacasta, J. J. (2010). La inclusión como objetivo de los movimientos sociales de la discapacidad. En CERMI (Ed.), La inclusión como objetivo de los movimientos sociales de la disc a pacidad. Madrid: CERMI.

Lathlean, J., y le May, A. (2002). Communities of practice: an opportunity for interagency working. J oumal of Clinic al Nursing, 11, 394 - 398.

Lave, J. (1991). Situated learning in a community of practice. En L. B. Resnick, J. M. Levine y S. D. Teasley (Coords.), Perspectives on socially shared cognition. Washington: American Psychological Association.

Lave, J. (1997). The culture of acquisition and the practice of understanding. En D. Kirshner y J. A. Whitson (Coords.), Situated cognition. Social, semiotic and psychologic al perspectives (pp. 17-35). Mahwah, NJ : La wrence Erlbaum.

Lave, J., y Wenger, E. (1991). Situated leaming: legitimate peripheral participation. Cambridge: Cambridge University Press.

Lawler, E. E. (1996). From the Ground Up: Six Principles for Creating the New Logic Corporation. San Francisc o, CA.: J ossey-Bass Publishers.

Leal, D. E., y Galvis, A. H. (2010). Criterios de evaluación de herramientas de apoyo a comunidades virtuales., Recuperado de http://www.diegoleal.org/social/blog/blogs/media/blogs/_EduTTC/LEALGALVIS-EvaluacionHerra mientasC o munid a des.pdf 
Ledema, R., Meyerkort, S., y White, L. (2005). Emergent modes of work and communities of practice. Health Services Management Research, 18(1), 13 24.

Leontiev, A. (1978). Actividad, conciencia y personalidad. Buenos Aires: Ciencias del Hombre.

Lesser, E. L. y Storck, J. (2001). Communities of practice and organizational performance. IBM Systems J oumal, 40(4).

Li, L., Grimshaw, J., Graham, I., Neilsen, C., J udd, M., y Coyte, P. (2007). Knowledge translation in health care communities: Use of communities of practice for the dissemination and uptake of best practices. A research synthesis project. Canadian Institute of Hea lth Research.

L, L., Grimshaw, J., Nielsen, C., J udd, M., C oyte, P., y Graham, I. (2009). Evolution of Wenger's concept of community of practice. Implementation Science, 4(1), 11.

Liedtka, J. (1999). Linking Competitive Advantage with Communities of Practice. J ournal of Mana gement Inquiry, 8(1), 5 - 16.

Little, J. W., y McLaughlin, M. W. (1993). Tea cher's work: Individuals, colleagues and contexts. New York: Tea chers College Press.

Litzky, B. E., Eddleston, K. A., y Kidder, D. L. (2006). The good, the bad, and the misguided: how managers inadvertently encourage deviant behaviors. Aca demy of Management Perspectives, 20(1), 91-103.

Lobato, X. (2001). Importancia de la cultura escolar para el desarrollo de escuelas inclusivas. Tesis Doctoral inédita, Universidad de Salamanca, Salamanca.

Lombard, M., Snyder-Duch, J., y Bracken, C. C. (2002). Content analysis in mass communication: Assessment and reporting of intercoder reliability. Human Communic ation Research, 28, 587-604.

Lombard, M., Snyder-Duch, J., y Bracken, C. C. (2003). Correction. Human Communic ation Research, 29, 469-472.

Lo mbard, M., y Snyder-Duch, J. B., C.C. (2008). Practic al resources for assessing and reporting intercoder reliability in content analysis research projects. Recuperado de http://a stro .temple.edu/ -lo mb a rd/relia bility/\#What\%20is\%20interc oder\%20rel iability.

López, M. (2008). Redes de Apoyo para Promover la Inclusión Educativa. Revista Electrónica Iberoamericana sobre Calidad, Eficacia y Cambio en Educación, 6(2), 200-211. Recuperado de http://www.rinace.net/arts/vol6num2/art14.pdf

López Noguero, F., y Reyes Santana, M. (2002). Dinámica de grupos en contextos forma tivos. Huelva: XYZ

Louis, K. S., Marks, H. M., y Kruse, S. (1996). Teachers' professional community in restructuring schools. Americ an Educational Research J oumal, 33(4), 757-798.

Luria, A. R. (1987). Desa rrollo históric o de los procesos cognitivos. Madrid: Akal.

Luthar, S., y Zngler, E. (1991). Vulnerability and competent: a review of research on resilience in child hood. Americ a $\mathrm{n}$ J oumal of orthopsychia try.

M.A., K., Cáceres, I., y Fontecilla, M. (1997). Estado de arte en resiliencia. Wa shington D.C: Organización Panamericana de la Salud.

Maehr, M. L. (1974). Culture and achievement motivation. American Psychologist, 29, 887-896.

Maehr, M. L. (1984). Meaning and motivation: toward a theory of personal investiment. En R. Ames y C. Ames (Coords.), Research on motivation in education: Vol. 1. Student Motivation (pp. 144). New York: Academic Press.

Maher, M. L. y Braskamp, L. A. (1986). The motivation factor. A theory of personal investiment. Lexinton: Lexinton Books.

Manciaux, M., Vanistendael, S., Lecomte, J., y Cyrulnik, B. (2001). La resiliencia: 
estado de la cuestión. En M. Manciaux (Ed.), La resiliencia: resistir y rehacerse. Madrid: Gedisa.

Mancia ux, M. C. (2003). La resiliencia: resistir y rehacerse. Barcelona: Gedisa.

Maya Jariego, I. (2004). Sentido de comunidad y potenciación comunitaria. Apuntes de Psic ología, 22(2), 187-211.

McDermott, C. M., y Stock, G. N. (1999). Organizational culture and advanced manufacturing technology implementation. Joumal of Operations Management, 17(5), 521-533.

McDermott, R. (2004). How to Avoid a Mid Life Crisis in Your Cops. KM Review, 7, 10 13.

McLuhan, M. (1964). Understanding Media: The Extensions of Man. New York: McGraw-Hill.

McLuhan, M., y Powers, B. R. (1989). The Global Village: Transformations in World Life and Media in the 21st Century. New York: Oxford University Press.

McMillan, B., y Chavis, D. M. (1986). Sense of community: a definit ion and theory. J oumal of Community Psychology, 14, 6-23.

McMillen, C., Zuravin, S., y Rideout, G. (1995). Perceived benefit Recuperado de child sexual abuse. Journal of Consulting and Clinical Psychology, 63(6), 1037-1043.

Medin, D. L. (1989). Concepts and conceptual structure. Americ an Psychologist, 44, $1469-1481$.

Mendía, R. (2004). Paso a paso hacia una escuela inclusiva en el País Vasco. En G. Echeita y M. A. Verdugo (Coords.), La declaración de Salamanca sobre necesidades educativas especiales 10 años después: Valoración y prospectiva. Salamanca: INICO.

Merriam, S., y Caffarella, S. (1999). Leaming in adulthood. San Francisco: J osseyBass.

Meyerson, D., y Martin, J. (1987). Cultural Change. An Integration of Three Different Views. J oumal of Management Studies, 623-647.

Meza García, C. L. (2010). Cultura escolar inclusiva en educación infantil: percepciones de profesionales y padres. Universidad de Salamanca, Salamanca.

Miller, F. A. (1998). Strategic culture change: The door to achieving high performance and inclusion. Public Personnel Management, 27(2), 151-161.

Mills, C. W. (1940). Situated actions and vocabularies of motive. American Soc io logic al review, 5, 904-913.

Miron, E., Erez, M., y Naveh, E. (2004). Do personal characteristic s and cultural values that promote innovation, quality, and efficiency compete or complement ea ch other. J oumal of O rga nizational Behavior, 25(2), 175-199.

Mitroff, I., y Kilmann, R. (1984). Corporate Tra gedies. Nueva York: Praeger.

Mittler, P. (2000). Working towards inclusive education: social contexts. London: David FultonPublishers Ltd.

Moreno, M., Giménez Plano, F., y García, S. (2009). La empresa con sentido: construir una comunidad consciente. Harward Deusto Business Review, 4756.

Morin, E. (1999). Los 7 saberes necesarios para la educación del futuro. Paris: UNESC O.

Muijs, D., Ha ris, A., Chapman, C., Stoll, L, y Russ, J. (2004). Improving Schools in Socioeconomically Disadvantaged Areas A Review of Research Evidence. Sc hool Effectiveness and Sc hool Improvement, 15(2), 149-175.

Napier, R., y McDaniel, R. (2006). Measuring what matters. USA: Editorial DaviesBlack.

Naveh, E., y Erez, M. (2004). Innovation and attention to detail in the quality improvement paradigm. Management Science, 50(11), 1576-1586. 
Neuend orf, K. A. (2002). The content a nalysis guidebook. Thousa nd Oa ks, CA: Sage. Nicholls, J. G. (1984a). Achievement motivation: Conceptions of ability, subjective experience, task choice and performance. Psychological Review, 91, 328346.

Nicholls, J. G. (1989). The Competitive Ethos and Democratic Education. Cambridge: Harvard University Press.

Nicholls, J. G. (1984b). Conceptions of ability and achievement motivation. En R. Ames y C. Ames (Coords.), Research on motivation in education: Vol. 1. Student motivation (pp. 39-73). New York: Academic Press.

Nicholls, J. G. (1978). The development of the concepts of effort and ability, perceptions of attainment and the understanding that diffic ult tasks require more ability. Child development, 49, 800-814.

Nicholls, J. G. (1992). The general and the especific in the development and expression of achievement motivation. En G. C. Roberts (Ed.), Motivation in sport and exercise (pp. 57-91). Champaign, IL: Human Kinetics.

Nicholls, J. G., Patashnick, M., y Nolen, S. B. (1985). Adolescent's theories of educ ation. J oumal of Educ ational Psyc hology, 77, 683-692.

Nonaka, I., y Takeuchi, H. (1995). The knowledge creation company: how Japanese companies create the dyna mic s of innovation: New York: Oxford.

Noman, C., y Huerta, T. (2006). Knowledge transfer y exchange through social networks: building foundations for a community of practice within tobacco control. Implementation Science, 1, 20.

Norwich, B. (2002). Education, inclusion and individual difference. British J oumal of Educ a tional Studies, 50 (4), 482-502.

Norwich, B. (2008). What future for special schools and inclusion? Conceptual and professional perspec tives. British J ournal of Special Ed uc ation, 35(3), 136-143.

Norwich, B., Goodchild, L., y Lloyd, S. (2001). Some aspects of the Inclusion Index in operation. Support for leaming, 16(4), 156-161.

Ntoumanis, N. (2001). A self-determination approach to the understanding of motivation in physical education. British Joumal of Educational Psychology, $71,225-242$.

Ntoumanis, N. (2002). Motivational clusters in a sample of British physical education classes. Psychology of Sport and Exerc ise, 3, 177-194.

O'Leary, M., Orlikowski, W., y Yates, J. (2002). Distributed work over the centuries: trust and control in the Hudson's Bay Company, 1670-1826. En P. Hinds y S. Kiesler (Coords.), Distributed work (pp. 27-54). Cambridge MA The MIT Press.

Ogbonna, E., y Hamis, L. C. (1998). Managing organizational culture: Compliance or genuine change. British J oumal of Mana gement, 9(4), 273-289.

Oishi, S. (2000). Goals as Comerstones of subjective well-being: Linking individuals and cultures. En E. Dienery E. M. Suh (Coords.), Culture and Subjective Wellbeing (pp. 87-112). Cambridge, MA: MITPress.

OMS. (2001). Clasific ación Intemacional del Funcionamiento, de la Discapacidad y de la Salud «CIF». Madrid: Ministerio de Trabajo y Asuntos Sociales.

ONU. (2006). Convención de la ONU sobre los derechos de las personas con disc a pacidad. New York: ONU.

O'Reilly, C. A., Chatman, J., y Caldwell, D. F. (1991). People and organizational culture: A profile comparison approach to assessing person-organization fit. Aca demy of Management J oumal, 34(3), 487-516.

Orr, J. (1987a). Narratives at Work: Story Telling as Cooperative Diagnostic Activity. Field Servic Manager, 47-60.

Orr, J. (1990a). Sha ring Knowledge, Celebrating Identity: War Stories and Community Memory in a Service Culture. En D. S. Middleton y D. Edwards (Coords.), Collective Remembering: Memory in Society. Beverley Hills: Sage Public ations. 
Or, J . (1990). Ta lking a bout ma chines: An ethnogra phy of a modem job. Itha ca, NY: Comell University Press.

Orr, J. (1987b). Talking about Machines: Social Aspects of Expertise. Report for the Intelligent Systems Laboratory. Palo Alto, CA.: Xerox Palo Alto Research Center.

Ott, J . E. (1989). The organizational c ulture perspective. Chic ago: The Dorsey Press.

Ouchi, W. G., y Price, R. L. (1978). Hierachies, Clans and Theory Z: A new Perspective on Organizational Development. En J. R. Hackman y Otros (Coords.), Perspectives on Behavior in Organizations (pp. 564-577). New York: McGraw Hill.

Owens, R. G. (1987). Organizational theory Organizatioanl behaviour in education (3a ed., pp. 37-52). Englewood Cliffs: Prentice-Hall.

Palacios, A. (2008). El modelo social de discapacidad: orígenes, caracterización y plasmación en la Convención Intemacional sobre los Derechos de las Personas con Disca pacidad. Madrid: CERMI.

Palacios, A., y Bariffi, F. (2007). La disc apacidad como una cuestión de derechos humanos. Una aproximación a la Convención Intemacional sobre los derechos de las personascon discapacidad. Madrid.

Palincsar, A. S., Magnusson, S. J., Marano, N., Ford, D., y Brown, N. (1998). Designing a community of practice: principles and practices of the GISML community. Teaching and Teacher Education, 14, 5 - 19.

Palys, T. S., y Little, B. R. (1983). Perceived life satisfaction and the organization of personal projects systems. Joumal of Personality and Social Psychology, 44, 1221-1230.

Parboosingh, J. T. (2000). Continuing education and professional development for hospital doctors and dentists. Med Educ, 34, 421 - 423.

Parboosingh, J. T. (2002). Physician communities of practice: where learning and practice are inseparable. Joumal of Continuing Education in the Health Professions, 22, 230 - 236.

Partson, M. P. (2010). Inclusive practic es within cultures of educ ational orga niza tions; the implications of implementing inclusive policies on educational organizations. Recuperado de http://onlinecollegeworld.com/inclusivepractic es-within-c ultures-of-e duc a tiona l-orga niza tions-the-implic a tions-ofimplementing-inc lusive-polic ies-on-ed uc a tiona l-orga nizations

Pascale, R. (1985). The paradox of corporate culture: Reconciling ourselves to socia lization. Califomia Management Review, XXVII(2), 26-41.

Pasmore, W. (1988). Designing effective organizations: The socio-technic al systems perspective. New York: Wiley.

Pereles, L., Lockyer, J., y Fidler, H. (2002). Permanent small groups: group dynamics, leaming, and change. Joumal of Continuing Education in the Health Professions, 22, 205 - 213.

Peters, T. J., y Waterman, R. H. (1982). In search of excellence: Lessons from America's best run companies. Nueva York: Harpery Row.

Pierre, A., Balthazard, P. A., Cooke, R. A., y Potter, R. E. (2006). Dysfunctional culture, dysfunctional organization. Capturing the behavioral noms that form organizational culture and drive performance. Joumal of Managerial Psychology, 21(8), 709-732.

Poole, M. (2002). Developing Online Communities of Practice in Preservice Teacher Education. Ponencia presentada en CSCL Conference, Boulder.

Popping, R. (1988). On agreement indices for nominal data. En W. E. Saris y I. N. Gallhofer (Coords.), Sociometric research: Volume 1, data collection and scaling (pp. 90-105). New York: St. Martin's Press.

Poy Castro, R., y Blanco, A. I. (2009). Inclusión educativa y tecnologías de apoyo en discapacidad intelectual. Bordón: Revista de Orientación Pedagógica, 
61(4).

Poy Castro, R. (2010). Efec tos del c redenc ia lismo y las expectativas soc ia les so bre el abandono escolar. Revista de Educación, número extraordinario 2010, 147169.

Priante Bretón, C. M. (2003). Mejoras en organizaciones de México y España mediante el desarrollo de una estrategia inclusiva. Universidad de Salamanca, Salamanca.

Putnam, R. D. (1993). Making democracy work: Civic traditions in Modem Italy. Princ eton: Princeton University Press.

Putnam, R. D. (1995). Bowling a lone: America's declining social capital. J oumal of Democracy, 6, 65-78.

Putnam, R. D. (2000). Bowling alone: The collapse and revival of American community. New York: Simon y Schuster.

Revuelta Domínguez, F. I., y Sánchez Gómez, M. C. (2003). Programas de a nálisis cualitativo para la investigación en espacios virtuales de formación. Teoría de la Educación: Educación y Cultura en la Sociedad de la Información, 4.

Resnick, L. B. (1989). Knowing, leaming and instruction - Essa ys in Honour of Robert Gla ser. Hilsda le, New J ersey: La wrence Erlbaum Associates, Inc.

Reyes Santana, M. (2001). Calidad e innovación en las instituciones educativas. En M. Monescillo, J. L. Gómez de Benito, J. C. González y J. Ca millo (Coords.), Bases psic opedagógicaspara la formación inicial del profesor de Educación Secundaria ( $p p$. 541-574): Hergué.

Reyes Santana, M. (2001). Aspectos educativos de la discapacidad motórica Huelva: $X Y Z$

Richardson, A. J. (1996). The production of institucionalization theory in Organiza tional Ana lysis. J oumal of Administra tive Sciences, 304-316.

Richardson, B., y Cooper, N. (2003). Developing a virtual interdisciplinary research community in higher education. J oumal of Interprofessional Care, 17, 173182.

Riel, M., y Polin, L. (2004). Online Leaming Communities: Common Ground and Critic al Differences in Designing Technical Environments. Designing for Virtual Communities in the Service of Leaming, 16-52.

Robbins, S. (1999). Comporta miento Organiza cional. México: Prentice Hall.

Roberts, G. C. (1992). Motivation in sport and exercise: Conceptual constraints and conceptual convergence. En G. C. Roberts (Ed.), Motivation in sport and exercise (pp. 3-30). Champaign, IL: Human Kinetic s.

Roberts, J. (2006). Limits to Communities of Practice. Journal of Management Studies, 43(3), 623-639.

Rodrigo, A., González-Gil, F., Ortiz, M. C., Sa rto, M. P., Lecuona, M. P., y Calvo, I. (1998). Análisis de la Evolución de la Educación Especial en el Ámbito Universitario: perspectivas y actuaciones desde el área de Didáctica y Organización Escolar. Ponencia presentada en Educación y diversidad: XV J omadas Nacionales de Universidad y Educación Especial.

Rodríguez Aguilella, A., Verdugo Alonso, M. A., y Sánchez Gómez, M. C. (2008). Calidad de vida familiar y apoyos para los progenitores de personas con discapacidad intelectual en proceso de envejecimiento. Siglo Cero: Revista Española sobre Disc a pacidad Intelectual, 39(227), 19-34.

Rogoff, B. (1990). Apprenticeship in thinking. Cognitive development in social context. New York: Oxford University Press.

Rogoff, B. (1993). Aprendices del pensamiento. El desarrollo cognitivo en el contexto social. Barcelona: Paidós.

Rokeach, M. (1973). The nature of human values. New York: Free Press.

Rosch, E., Mervis, C. B., Gray, W. D., Johnson, M. D., y Boyes-Bra em, P. (1976). Basic objects in natural categories. Cognitive Psychology, 8, 382-439. 
Rosch, E. R. (1978). Principles of categorization. En E. R. Rosch y B. B. Loyd (Coords.), Cognition and Categorization. Hillsd ale, N. J.: LEA.

Rose, R. (2002). Including pupils with special educational needs: beyond rhetoric and towards an understanding of effective classroom practic e. Westminster Studies in Educ ation, 25 (1), 67-76.

Ruhleder, K., Jordan, B., y Elmes, M. B. (1996). Wiring the "new organization": Integrating collaborative technologies and team-based work. Ponencia presentada en Annual Meeting of the Aca demy of Management.

Russell, J., Greenhalgh, T., Boynton, P., y Rigby, M. (2004). Soft networks for bridging the gap between research and practice: illuminative evaluation of CHAIN. BMJ , 328, 1174.

Rustemier, S., y Booth, T. (2005). Leaming about the Index in use; a study of the Index for Inclusion in schools and LEAs in England. Bristol CSIE.

Ryan, R. M. (1982). Control and information in the interpersonal sphere: An extension of cognitive evaluation theory. J oumal of Personality and Social Psychology, 43, 450-461.

Ryan, R. M., y Deci, E. L. (2000). The darker and brighter sides of human existence: Basic psychological needs as a unifying concept. Psychological Inquiry, 11, 319-338.

Ryan, R. M., y Deci, E. L. (2000). Self-determination theory and the facilitation of intrinsic motivation, social development and well-being. American Psychologist, 55, 68-78.

Saavedra, E. (2004). El Enfoque Cognitivo Procesal Sistémico, como posibilidad de intervenir educativa mente en la formación de sujetos Resilientes: Estudio de Casos. Tesis Doctoral Universidad Vallad olid, Valla dolid.

Saffold, G. S. (1988). Culture traits, strength and orga nizational performance: Moving beyond "strong" culture. Ac ademy of Management Review, 13(4), 546-558.

Sage, G. (1977). Introduction to motor behavior: A neuropsychological approach (2nd ed.). Reading MA: Addison-Wesley.

Saint-Onge, H., y Wallace, D. (2004). Innoversity Network Space. Leveraging communities of practice for strategic advantage.

Sánchez Delgado, P. (Ed.). (2005). Enseñar y a prender: Edic iones Témpora.

Sánchez Delgado, P. (2002). Atención a la diversidad cultural en los centros educativos: propuestas de reflexión y acción sobre el Proyecto Educativo, el Proyecto Cumicular y la práctica en el aula. Revista complutense de educación, 13(2), 677-706.

Sánc hez Q uirós, I. (2009). Ha cia unos va lores cultura les más efic a ces: el papel de la estrategia en la consecución de mejores resultados. Investigaciones Europeas de Dirección y Economía de la Empresa, 15(2), 159-182.

Sánchez, T., Fuentes, J. M., Sánchez, J. F., Delgado, M. C., Quevedo, M. P., y Salgado, A. (1999). Relación entre despersonalización (bumout), trastomos psic ofisiológicos, clima laboral y tácticas de afrontamiento en una muestra de docentes. Estudios de psicología, 63-64, 87-108.

Sánchez-Vidal, A. (2001). Medida y estructura intema del sentimiento de comunidad: un estudio empíico. Revista de Psicología Social, 16(2), 157-175.

Sandoval, M., López, M. L., Miquel, E., Durán, D., G iné, C., y Ec heita, G. (2002). Index for inclusion. Una Guía para la Evaluación y mejora de la educación inc lusiva. Contexto educ a tivos, 5, 227-238.

Santos Guerra, M. A. (2002). Organizar la diversidad. Cuademos de Pedagogía, 311, 76-80.

Santos Guerra, M. Á. (1993). Agrupamientos flexibles. Un claustro investiga. Sevilla: Díada.

Sanz Martos, S. (2005). Comunidades de práctica virtuales: acceso y uso de contenidos. Revista de Universidad y Sociedad del Conocimiento (RUSC), 
2(2), 26-35.

Sanz Martos, S., y Pérez Montoro, M. (2009). Conocimiento colaborativo: las comunidades de práctica y otras estrategias organizacionales. Ponencia presentada en Congreso ISKO España, Valencia.

Sarason, S. B. (1974). The psychological sense of community: prospects for a community psychology. San Fransc isc o: J ossey Bass.

Sarrazin, P., Vallerand, R., Guillet, E., Pelletier, L., y Cury, F. (2002). Motivation and dropout in female handballers: A 21-month prospective study. European J oumal of Social Psychology, 32, 395-418.

Sarto, P. (1997). Proyecto Docente de Educación Especial. Inédito: Universidad de Salamanca.

Sathe, V. (1983). Some action implic ations of corporate culture: A manager's guide to action. Orga nizational Dynamic s, 12, 4-23.

Schalock, R. L., y Verdugo, M. A. (2003). Calidad de vida. Manual para profesionales de la educa ción, salud y servic ios sociales. Madrid: Alianza.

Scheier, M. F., y Carver, C. S. (1985). Optimism, coping and health:Assesment and implications of generalized outcome expectancies. Health Psychology, 4, 219-247.

Schein, E. H. (1983). The Role of the Founder in Creating Organizational Culture. Organizational Dynamics, 13-28.

Schein, E. H. (1985). Organizational culture and leadership. San Francisco: J ossey Bass.

Schein, E. H. (1986). Are You Corporate Cultured? Personnel J ournal, November, 8396.

Schein, E. H. (1990). Organizational Culture. Americ an Psychologist, Februa ry, 116.

Schein, E. H. (1996). Culture: The missing concept in organization studies. Administrative Science Quarterly, 41, 229-240.

Schein, E. H. (2004). Organizational Culture and Leadership. San Francisco: John Wiley and Sons.

Schwier, R. (2001). Catalysts, Emphases, and Elements of Virtual Leaming Communities: implications for research and practice. Quarterly Review of Distance Education, 2(1), 5-18.

Seiler, J. A. (1967). Systems analysis in organizational behavior. Homewood, IL.: R.D.Inwin.

Shields, C. M. (2003). Good intentions a re not enough: Transformative leadership for Communities of Difference. Lanham, Maryland: Scarecrow Press.

Shields, C. M. (2004). Creating a community of difference. Educ ational Leadership, $61(7), 38-41$.

Shields, C. M. (2006). Creating spaces for value-based conversations: the role of school lea ders in the 21st century. ISEA, 34(2), 62-81.

Shields, C. M. (2009). Democratizing practice: Courageous leadership for transforming schools. Norwood, MA: Christopher-Gordon.

Shields, C. M. (2009). Leveling the playing field in racialised contexts: Leaders speaking out about difficult issues. International Joumal of Educational Administration, 37(3), 55-70.

Siehl, C., y Martin, J. (1990). Organizational culture: A key to financial performance? In Sc hneider (Ed.), Organizational cliante and culture. San Francisco: J osseyBass.

Skrtic, T. (1991). Behind special education: A critical a nalysis of professional culture and school organization. Denver, CO: Love.

Smith, E. E., y Medin, D. L. (1981). Categories and concepts. M. A.: Cambridge.

Snyder, W. M. (1997). Communities of practice: Combining organizational leaming and strategy insights to create a bridge to the 21st century. Recuperado de http://www.co-i-l.com/coil/knowledge-garden/cop/cols.shtml 
Snyder, W. M., y Briggs, X. d. S. (2003). Communities of Practice: A New Tool for Govemment Managers. Arlington: The IBM Center for The Business of Govemment.

Snyder, W. M., Wenger, E., y Briggs, X. d. S. (2003). Communities of Practice in Govemment: Leveraging Knowledge for Performance. The Public Manager, 32(4), 17 - 21.

Sorensen, J. B. (2002). The strength of corporate culture and the reliability of firm performance. Administrative Sc ience Quarterly, 47(marzo), 57-81.

Spagnolo, G. (1999). Social relations and cooperation in organizations. Journal of Ec onomic Behaviory Organization, 38 1-25.

Stamps, D. (1997). Communities of practic e: Leaming is social. Tra ining is irrelevant? Training, 34(2), 34-42.

Stewart, T. A. (1996). The invisible key to success. Fortune, 134(3), 173-176.

Strully, J., y Broderick, L. (2010). Thoughts on Leadership. Recuperado de http:// www.inclusion.com/artleadership.html

Suchman, L. (1987). Plans and Situated Actions: The problem of human-machine communic ation: Cambridge University Press.

Theis, A. (2003). La resiliencia en la literatura científica. En M. Manciaux (Ed.), La resiliencia: resistir y rehacerse (pp. 45-59). Ba rcelona: Gedisa.

Thomas, R. R. (1990). From Affirmative Action to affirming diversity. Harvard Business Review, 90, 107-117.

Toffler, A. (1972). The Futurists: Random House.

Toffler, A. (1980). The Third Wave: Pan.

Tönnies, F. (1887). Community and society. (Gemeinschaft and Gesellschaft) ( . Samplesed.). New Brunswick, N. J.: Transaction Books.

Triandis, H. C., Kurowski, L. L., y Gelfand, M. J . (1994). Workplace diversity. En H. C. Triandis, M. Dunnette y L. M. Hough (Coords.), Handbook of industrial and organizational psychology ( $p$ p. 770-827). Palo Alto, CA: Consulting Psychologists Press.

Tschennan-Moran, M. (2004). Trust matters: Leadership for successful schools. San Francisc o, CA: J osey-Bass.

Tschennan-Moran, M., y Hoy, W. K. (2000). A multidisciplina ry a nalysis of the nature, meaning and measurement of trust. Review of Educational Research, 70, 547-593.

UN ESCAP. (2010). ¿Qué es gobemanza? ¿Y buen gobiemo?. Recuperado de http:// www.casaasia.es/govemasia/boletin2/3.pdf

UNESCO. (2008a). La educación inclusiva: el camino hacia el futuro. Declaración final. Ginebra: UNESCO.

UNESC O. (2008b). La educación inclusiva: el ca mino hacia el futuro. Documento de referencia. Recuperado de http:// www.ibe.unesco.org/fileadmin/user_upload/Polic y_Dialogue/ 48th_ICE/CONFINTED_48-3_Spa nish.pdf

Usoro, A., Sharratt, M. W., Tsui, E., y Shekhar, S. (2007). Trust as an antecedent to knowledge sharing in virtual communities of practice. Knowledge Management Research y Practice, 5, 199-212.

Uttal, B. (1983). The corporate culture vultures. Fortune Magazine, Oct 17.

Van Mechelen, I., y Mic ha Iski, R. S. (1993). General intro duction: purpose, underlying ideas, and scope of the book. En I. Van Mechelen, J. Hampton, R. S. Mic halski y P. Theuns (Coords.), Categories and concepts.

Theorical view and inductive data analysis. London: Academic Press.

Vanistendael, S. (1996). Cómo crecer superando los percances: Resiliencia. Ginebra: BICE, Ofic ina Intemacional Católica de la Infancia.

Vanistendael, S. (2005). La Resiliencia: Desde una inspiración hacia cambios prácticos. Ponencia presentada en 2 o Congreso Intemacional de los 
trastomos del comporta miento en niños y a dolescentes.

Vanistendael, S., y Lecomte, J . (2002). La felic idad es posible. Barcelona: Gedisa.

Vann, K., y Bowker, G. (2001). Instrumentalizing the Truth of Practice. Social Ep istemology, 15(3), 247-262.

Varela, A. H., Thompson, E., y Rosch, E. (1991). The embodied mind: Cognitive Science and human experience. Cambridge, MA.: MIT Press.

Vasquez Bronfman, S. (2007). The Launching of a Knowledge Management Project in a Public Administration. Ponencia presentada en 8th EDINEB Conference., Viena.

Vaughan, M. (2002). An Index for Inclusion. European Joumal of Special Needs Education, 17(2), 197-201.

Velásquez de Naime, Y., Nuñez Botini, M., y Rodríguez Monroy, C. (2009). La Productividad y los Valores Organizacionales. Ponencia presentada en 7th Latin Americ an and Caribbean Conference for Engineering and Technology, San Cristóbal, Venezuela.

Vera Poseck, B., Carbelo Baquero, B., y Vecina Jiménez, M. L. (2006). La experiencia traumática desde la psicología positiva: resiliencia y crecimiento postra umátic o Pa peles del Psicólogo, 27(1), 40-49.

Verdugo, A. (2003). De la segregación a la inclusión escolar. Salamanca: Universidad de Sa la manca.

Verdugo, M. A., y Rodríguez, A. (2008). Valoración de la inclusión educativa desde diferentes perspectivas. Revista Española sobre Discapacidad Intelectual, 39(4).

Villa lobos, E., y Za laka in, J. (2010). Delimita ción conceptual de la inclusión social. En L. C. Pérez Bueno (Ed.), Discapacidad, Tercer Sector e Inclusión Social. Madrid: CERMI.

Vislie, L. (2003). Recupera do de integration to inclusion: focusing global trends and changes in the westem European societies. European Joumal of Special Needs Educ ation, 18(1), 17-35.

Vygotsky, L. (1988). El desarrollo de los procesos psicológicos superiores. México: G rija lbo.

Vygotsky, L. S. (1978). Mind in society: The development of higher psychological processes. Cambridge: Harvard University Press.

Vygotsky, L. S. (1986). Pensamiento y lenguaje. Buenos Aires: La Pléyade.

Wamier, J. P. (2002). La mundialización de la cultura. Barcelona: Editorial Gedisa, S.A.

Wehmeyer, M. L. (2005). Self-determination and individuals with severe disabilities: Reexamining meanings and misinterpretations. Research and Practice in Severe Disa bilities, 30, 113-120.

Wehmeyer, M. L. (2006). Autodeterminación y personas con discapacidades severas. En M. A. Verdugo y F. B. Jordán de Uríes (Coords.), En Rompiendo inercias. Claves para avanzar (pp. 89-100). Salamanca: Amarú.

Wehmeyer, M. L. (2009). Autodeterminación y la tercera generación de prácticas de inclusión. Revista de Educación, 349, 45-67.

Wehmeyer, M. L., Abery, B., Mithaug, D. E., y Stancliffe, R. J. (2003). Theory in selfdetermination: Foundations for educational practice. Springfield, IL: Charles C. Thomas.

Wehmeyer, M. L., y Schalock, R. L. (2001). Self-Determination and Quality of Life: Implications for Special Education Services and Supports. Focus on Exc eptional Child ren, 33(8), 1-16.

Weick, K. (1985). Sources of Order in Underorganized Systems: Themes in Recent Organizational Theory. En Y. S. Lincoln (Ed.), Organizational Theory and Inquiry. The paradigm revolution (pp. 106-135). London: Sage.

Weiner, Y. (1988). Forms of value systems: A focus on organizational effectiveness 
and culture change and maintenance. Academy of Management Review, 13, 534-545.

Wenger, E. (1987). Artificial intelligence and tutoring systems: computational and cognitive approaches to the communic ation of knowledge. Los Altos, Calif.: Morgan Kaufmann Publishers.

Wenger, E. (1998a). Communities of practice: leaming, meaning, and identity. Cambridge, U.K. ; New York, N.Y.: Ca mbridge University Press.

Wenger, E. (1998b). Communities of practice leaming as a social system. The Systems Thinker, 9(5).

Wenger, E. (1991). Communities of practice: Where leaming happens. Benchmark, 82-84.

Wenger, E. (1996). How we leam. Communities of practice. The social fabric of a leaming organization. Hea lthca re Forum J oumal, 39, 20 - 26.

Wenger, E. (2000). Communities of practice and social leaming systems. Organization, 7, 225 - 246.

Wenger, E. (2001). Comunida des de práctica: aprendizaje, significado e identidad. Barcelona: Paidós.

Wenger, E. (2004). Knowledge management as a doughnut: Shaping your knowledge strategy through communities of practice. Ivey Business J oumal, 68(3), 1-8.

Wenger, E., McDermott, R., y Snyder, W. M. (2002b). Seven Principles for Cultivating Communities of Practice. Recuperado de http://hbswk.hbs.edu/a rc hive/2855.html

Wenger, E., McDermott, R. A., y Snyder, W. (2002a). Cultivating communities of practice: a guide to managing knowledge. Boston, Mass: Harvard Business School Press.

Wenger, E., White, N., Smith, J. D., y Rowe, K. (2005). Outiller Sa Communauté De Pratique (L. Langelier, Trans.). En L. Langelier (Ed.), Guide De Mise En Place Et D'animation de communautés de pratique intentionnelles (pp. 47 - 66). Québec: CEFRIO.

Wenger, E. C., y Snyder, W. M. (2000). Communities of Practice: The Organizational Frontier. Harvard Business Review, 78 (1), 139-145.

Wensing, M., Wollersheim, H., y Grol, R. (2006). Organizational interventions to implement improvements in patient care: a structured review of reviews. Implementation Science, 1, 2.

Wemer, E. (1989). High-Risk Children in Young Adulthood: A Longitudinal Study Rec uperado de Birth to 32 Years. Americ an J oumal of Orthopsyc hiatry, 59(1).

Wemer, E., y Smith, R. (1992). Overcoming the odds: High risk children Recuperado de birth to adulthood. Ithaca, Nueva York: Corwel University Press.

West, M., Ainscow, M., y Stanford, J. (2005). Sustaining improvement in schools in challenging circumstances: a case study of successful practice. School Leadership and Management, 25(1), 77-93.

Whalen, S. P. (1997). Assessing flow experiences in highly able adolescent leamers. Ponencia presentada en Annual meeting of the American Educational Research Association, Chic ago.

Wild, E. L., Richmond, P. A., de Merode, L., y Smith, J. D. (2004). All Kids Count Connections: a community of practice on integrating child health information systems. J Public Health Manag Pract(Suppl), S61 - S65.

Wilkins, A. L., y Ouchi, W. G. (1983). Efficient cultures: Exploring the relationship between culture and organizational performance. Administrative Science Quarterly, 28, 468-481.

Wilson, M. (2003). Six views of embodied cognition. Psychonomic Bulletin and Review, 9(4), 625-636.

Wilson, W. (1967). Correlates of avowed happiness. Psychological Bulletin, 67, 294- 
306.

Willmott, H. (1993). Strength is ignorance; Slavery is freedom: Managing culture in modem organiza tions. J oumal of Mana gement Studies, 30(4), 515-552.

Winkelman, W. J., y Choo, C. W. (2003). Provider-sponsored virtual communities for chronic patients: improving health outcomes through organizational patientcentred knowledge management. Health Expectations, 6(4), 352 - 358.

Woods, S. (2002). Creating Inclusive Organizations: Aligning Systems with Diversity. Pro files in Diversity J oumal, J a nua ry/February, 38-39.

Yi, J. Q. (2000). Supporting business by facilitating organizational leaming and knowledge creation in the MOT community of practice (COP). Bloomington IN: Indiana University.

Zhang, W., y Watts, S. (2008). Online communities as communities of practice: a case study. J ournal of Knowledge Mana gement, 12(4), 55-71.

Zucker, L. G. (1988). Institutional Pattems and Organizations: Culture and Environment. Cambridge, MA: Ballinger. 



\section{Anexo I. \\ Cuestionario de Evaluación de los Indic adores del Index (CEI) (Versión preliminar)}




\section{CUESTIONARIO DE INDICADORES}

Porfavor, señale a continuación el centro en el que trabaja y su relación con él:

Centro:

Relación con el centro:

A continuación, en las siguientes páginas, se le presentan una serie de ítems. Su ta rea consiste en:

a) Indicar, desde su punto de vista, la categoría a la que pertenece cada ítem teniendo en cuenta las siguientes opciones:

\begin{tabular}{|c|c|c|}
\hline Categoría & Nombre & Descripción \\
\hline 1. & $\begin{array}{l}\text { Desarrollo de una } \\
\text { comunidad inclusiva. }\end{array}$ & $\begin{array}{l}\text { Todas las personas que están en contac to con el centro } \\
\text { se sienten partícipes de él. Los miembros de la } \\
\text { comunidad (profesionales, familias y personas usuarias) } \\
\text { se ayudan, se apoyan y colaboran para que todo el } \\
\text { mundo se sienta acogido, respetado y valorado. }\end{array}$ \\
\hline 2. & $\begin{array}{l}\text { Establecimiento de valores } \\
\text { inclusivos. }\end{array}$ & $\begin{array}{l}\text { En el centro se comparten los valores centrados en la } \\
\text { persona y en suscapacidades. Se considera a la } \\
\text { individualidad, como componente fundamental de la } \\
\text { diversidad del ser humano que supone considerarque } \\
\text { cada persona es única, con proyectos de vida, con } \\
\text { ilusiones y con la necesidad de que se crea en sus } \\
\text { capacidades, como sercargado de posibilidades se le } \\
\text { aportan oportunidades. }\end{array}$ \\
\hline 3. & $\begin{array}{l}\text { Desarrollo un centro para } \\
\text { todos. }\end{array}$ & $\begin{array}{l}\text { El centro tiene políticas y procesos enca minados a que } \\
\text { tanto las personas usuarias, sus familias y los profesionales } \\
\text { que trabajan en él se sientan acogidosy valorados. }\end{array}$ \\
\hline 4. & $\begin{array}{l}\text { Organización de la actividad } \\
\text { del centro para promover la } \\
\text { vida independiente de las } \\
\text { personas usuarias. }\end{array}$ & $\begin{array}{l}\text { En el centro se ponen en marcha todos los mecanismos y } \\
\text { esfuerzos en la búsqueda de la mejora de la calidad de } \\
\text { vida de las personas y de sus familias, dirigiendo sus } \\
\text { actuaciones a la potenciación de las capacidades. } \\
\text { Para ello, se centrará en las potencialidades de las } \\
\text { personas, en sus intereses y necesidades y coordinará sus } \\
\text { apoyos para conseguir los mejores resultados. }\end{array}$ \\
\hline 5. & $\begin{array}{l}\text { Dirección del proceso de } \\
\text { aprendizaje para promover } \\
\text { la vida independiente. }\end{array}$ & $\begin{array}{l}\text { Las activida des del centro estarán dirigidas a a poyar la } \\
\text { participación de las personas; haciendo realidad el } \\
\text { derecho de acceso a los senvicios comunitarios, y } \\
\text { contando con los a poyos que posibiliten el ejercic io del } \\
\text { derecho a gobemarse a símismas y promocionen su } \\
\text { condición de plena ciudadanía. }\end{array}$ \\
\hline 6. & Moviliza ción de recursos. & $\begin{array}{l}\text { El centro para conseguir sus objetivos optimizará los } \\
\text { recursos humanos, económic os y materiales de que } \\
\text { dispone, logrando una eficacia y efic iencia de los } \\
\text { mismos. Y buscará recursos y a poyos externos en la } \\
\text { sociedad. }\end{array}$ \\
\hline
\end{tabular}

b) Una vez valorada la categoría a la que pertenece cada indicador, necesitamos que valore la pertinencia o grado en que el ítem mide o representa dicha categoría, en una escala de " 1 " a " 4 ", teniendo en cuenta que el " 1 " indica una muy baja relevancia y el " 4 " 
indica una pertenencia o relevancia muy alta. Se han añadido unas preguntas asociadas a cada indic ador para ayudarle a entender mejor el indic ador.

Añada los comentarios que le parezcan oportunos en el apartado observaciones.

\section{¡Muchas gracias por su colaboración!}

\begin{tabular}{|c|c|c|c|}
\hline Indic ador & $\begin{array}{l}\text { Categońa } \\
\text { (de } 1 \text { a 6) }\end{array}$ & $\begin{array}{c}\text { Pertinencia } \\
\text { (de } 1 \text { a 4) }\end{array}$ & Observaciones \\
\hline $\begin{array}{l}\text { E centro tiene una política de acogida de las } \\
\text { personas usuarias. } \\
\text { - El centro tiene un programa de acogida. } \\
\text { - Se han establecido programas para facilitar la } \\
\text { transición entre la a nterior situación de la persona y } \\
\text { la nueva en el centro. }\end{array}$ & & & \\
\hline $\begin{array}{l}\text { E centro hace que sus instalaciones sean físicamente } \\
\text { accesibles para todas las personas. } \\
\text { - Todas las personas, independientemente de las } \\
\text { limitaciones que presenten, pueden acceder a } \\
\text { cualquier parte del centro. } \\
\text { - Se ha pensado el centro para que nadie tenga } \\
\text { problemasa la hora de desplazarse por él. }\end{array}$ & & & \\
\hline $\begin{array}{l}\text { E centro intenta admitir a todas las potenciales } \\
\text { personas usuarias de su zona. } \\
\text { - Todas las personas que quieran incorporarse al } \\
\text { centro lo pueden hacer siempre que existan plazas. } \\
\text { - Se motiva a todas las potenciales personas usuarias } \\
\text { de la zona a que asistan al centro, } \\
\text { independientemente de sus características y } \\
\text { necesidades. }\end{array}$ & & & \\
\hline $\begin{array}{l}\text { El centro tiene en cuenta la diversidad de las personas } \\
\text { y sus intereses a la hora de establecer grupos. } \\
\text { - Cuando hay posibilidades de elección, se permite a } \\
\text { todas las personas que hagan elec ciones reales. } \\
\text { - El criterio básico para construir los equipos es la } \\
\text { heterogeneidad (de género, de capacidades, de } \\
\text { intereses,...). }\end{array}$ & & & \\
\hline $\begin{array}{l}\text { Se reconoce la igualdad de las personas } \\
\text { independientemente de factores personales, sociales } \\
\text { y culturales. } \\
\text { - En el centro nadie se siente disc riminado por su } \\
\text { edad, capacidad o discapacidad, orientación } \\
\text { sexual, género o clase social. } \\
\text { - Los profesionales intentan contra rrestar las actitudes } \\
\text { estereotipadas hacia las personas con a lgún tipo de } \\
\text { limitación. }\end{array}$ & & & \\
\hline $\begin{array}{l}\text { Existe colaboración entre los profesionales y las } \\
\text { familias. } \\
\text { - Se respecta el derecho que tienen todas las fa milias } \\
\text { a participar en la toma de decisiones sobre el } \\
\text { centro. } \\
\text { - Lasfamilias disponen de una variedad de } \\
\text { oportunidades para involucrarse en el centro (desde }\end{array}$ & & & \\
\hline
\end{tabular}




\begin{tabular}{|c|c|c|c|}
\hline Indic ador & $\begin{array}{l}\text { Categońa } \\
\text { (de } 1 \text { a } 6)\end{array}$ & $\begin{array}{l}\text { Pertinencia } \\
\text { (de } 1 \text { a } 4 \text { ) }\end{array}$ & Obsenvaciones \\
\hline $\begin{array}{l}\text { apoyar en actividades puntua les hasta ayudar en el } \\
\text { desa rrollo de actividades concretas). }\end{array}$ & & & \\
\hline $\begin{array}{l}\text { La disciplina en el centro se basa en el respeto mutuo. } \\
\text { - Son consistentes y explíc itas las normas de } \\
\text { comportamiento del centro. } \\
\text { - Se involucra a las personas usua rias a que a yud en a } \\
\text { resolver las dific ulta des del centro. }\end{array}$ & & & \\
\hline $\begin{array}{l}\text { Se utiliza la diversidad de las personas como un } \\
\text { recurso para fomentar la autonomía personal. } \\
\text { - Se brindan oportunidades para que las personas de } \\
\text { distinta edad o con diferentes capacidades se } \\
\text { a poyen entre ellos. } \\
\text { - Se enseña a laspersonas usuarias lo que pueden } \\
\text { aprender de otras personas. }\end{array}$ & & & \\
\hline $\begin{array}{l}\text { La evaluación valora los logros de todas las personas } \\
\text { usuarias. } \\
\text { - Entienden las personas usua rias por qué están } \\
\text { siendo evaluadas. } \\
\text { - Se devuelve a las personas información que les } \\
\text { permita reconocer lo que han aprendido y lo que } \\
\text { deberían hacera continuación. }\end{array}$ & & & \\
\hline $\begin{array}{l}\text { En el centro se aprovecha toda la experiencia y las } \\
\text { competencias de los profesionales en beneficio de las } \\
\text { personas usuarias. } \\
\text { - En el centro hay un clima que posibilite proponer } \\
\text { a lternativas al resto de profesiona les en relación a } \\
\text { las preocupaciones respecto a las personas } \\
\text { usuarias. } \\
\text { - Los profesiona les con ha bilidades y conocimientos } \\
\text { específic os ofrecen su a yuda a los demás. }\end{array}$ & & & \\
\hline $\begin{array}{l}\text { En las actividades del centro se ve reflejada la política } \\
\text { de inclusión. } \\
\text { - Se considera que las personas usuarias poseen } \\
\text { diferentes intereses, conocimientos y habilidades en } \\
\text { vez de formar parte de un equipo homogéneo. } \\
\text { - La política del centro está dirigida al aumento del } \\
\text { aprendizaje y de la partic ipación y por tanto, a la } \\
\text { reducción de la exc lusión. }\end{array}$ & & & \\
\hline $\begin{array}{l}\text { Las actividades que se llevan a cabo en el centro } \\
\text { contribuyen a una mayor comprensión de la } \\
\text { diversidad. } \\
\text { - Se motiva a las personas a que conozcan opiniones } \\
\text { diferentesa las suyas. } \\
\text { - Se proporcionan oportunidades para que las } \\
\text { personastrabajen con otros que son diferentes a } \\
\text { ellosporsu contexto, etnia, capacidad o género. }\end{array}$ & & & \\
\hline $\begin{array}{l}\text { Las actividades de desamollo profesional ayudan a los } \\
\text { profesionales a dar respuesta a la diversidad de las } \\
\text { personas usuarias. } \\
\text { - Se utiliza la colaboración y el intercambio posterior } \\
\text { de reflexiones para apoyara los profesionales en su }\end{array}$ & & & \\
\hline
\end{tabular}




\begin{tabular}{|c|c|c|c|}
\hline Indicador & $\begin{array}{l}\text { Categoría } \\
\text { (de } 1 \text { a 6) }\end{array}$ & $\begin{array}{c}\text { Pertinencia } \\
\text { (de } 1 \text { a 4) }\end{array}$ & Obsenvaciones \\
\hline $\begin{array}{l}\text { trabajo. } \\
\text { - Tienen los profesionales la oportunidad de observar, } \\
\text { a nalizar y reflexionar sobre su propio trabajo. }\end{array}$ & & & \\
\hline $\begin{array}{l}\text { Las actividades tienen en cuenta la diversidad de las } \\
\text { personas. } \\
\text { - Está mejorando el aprendizaje de to das las personas } \\
\text { usuarias a partir de las activida des que se ponen en } \\
\text { marcha en el centro. } \\
\text { - Se planifican las actividades teniendo en cuenta la } \\
\text { diversidad de experiencias de las personas usuarias. }\end{array}$ & & & \\
\hline $\begin{array}{l}\text { Las actividades son accesibles para todos. } \\
\text { - Pueden partic ipar en las actividades pla nific a das, } \\
\text { en igua ldad de oportunidades, todos sus } \\
\text { destinatarios potenciales. } \\
\text { - Proporcionan los profesiona les modalidades } \\
\text { alternativas de acceso o de participación a las } \\
\text { personas que no tengan determinadas } \\
\text { capacidades. }\end{array}$ & & & \\
\hline $\begin{array}{l}\text { En el centro se promueve que las personas } \\
\text { aprendan de manera colaborativa. } \\
\text { - Se enseña a las personas usuarias a trabajar en } \\
\text { colaboración con sus compañeros. } \\
\text { - Las actividades de equipo permiten a las personas } \\
\text { usuarias dividir las tareas y compartir lo que han } \\
\text { a prendido. }\end{array}$ & & & \\
\hline $\begin{array}{l}\text { Las personas usuarias se ayudan unas a otras. } \\
\text { - Las personas entienden que de cada persona se } \\
\text { pueden esperar distintos logros. } \\
\text { - Las personas se ofrecen ayuda cuando es } \\
\text { necesario. }\end{array}$ & & & \\
\hline $\begin{array}{l}\text { Los valores del centro se vinculan con las } \\
\text { prácticas que se desamollan en el día a día. } \\
\text { - Las estrategias de apoyo empleadas son una } \\
\text { oportunidad para la reflexión acerca de los } \\
\text { modelos para mejorar la enseñanza y el aprendizaje } \\
\text { de todas las personas. } \\
\text { - Se preocupan los profesiona les de las barreras al } \\
\text { aprendizaje y la partic ipación en las políticas y las } \\
\text { culturas del centro a demás de en las prácticas. }\end{array}$ & & & \\
\hline $\begin{array}{l}\text { Los procesos de planificación y la evaluación } \\
\text { están orientados a que las personas desamollen } \\
\text { su potencial. } \\
\text { - Las prácticas de evaluación están dirigidas a } \\
\text { fomentar el apoyo en vez de a categorizar. } \\
\text { - Las planificaciones individualizadas se centran en } \\
\text { proporcionar el acceso y a poyar la participación } \\
\text { dentro de las actividades del centro. }\end{array}$ & & & \\
\hline
\end{tabular}




\begin{tabular}{|c|c|c|c|}
\hline Indic ador & $\begin{array}{l}\text { Categońa } \\
\text { (de } 1 \text { a 6) }\end{array}$ & $\begin{array}{l}\text { Pertinencia } \\
\text { (de } 1 \text { a 4) }\end{array}$ & Obsenvaciones \\
\hline $\begin{array}{l}\text { La gestión de recursos humanos se basa en el } \\
\text { mérito, la capacidad y la igualdad. } \\
\text { - El equipo directivo y de responsa bles del centro } \\
\text { están constituidos por las personas más a decuadas } \\
\text { para estar en él. } \\
\text { - Se fomenta la promoción de los profesionales } \\
\text { basándose en su competencia profesional. }\end{array}$ & & & \\
\hline $\begin{array}{l}\text { Los profesionales colaboran entre ellos. } \\
\text { - Los profesionales se tratan con respeto mutuo, } \\
\text { independientemente de su rol o posic ión en el } \\
\text { centro. } \\
\text { - Hay una a mplia participación activa en las } \\
\text { reuniones de planificación y gestión. }\end{array}$ & & & \\
\hline $\begin{array}{l}\text { Los profesionales generan recursos para apoyar } \\
\text { la vida independiente. } \\
\text { - Todos los profesionalesconocen los recursos } \\
\text { disponibles para a poyar las actividades que ponen } \\
\text { en marcha. } \\
\text { - Hay una preocupación para ir mejorando los } \\
\text { recursos del centro como una fuente de riqueza } \\
\text { para todos. }\end{array}$ & & & \\
\hline $\begin{array}{l}\text { Se considera que las barreras al aprendizaje y a } \\
\text { la participación están en los contextos y no en } \\
\text { las personas. } \\
\text { - Los profesionales evitan etiquetar a las personas. } \\
\text { - Los profesiona les evitan considerar que las ba rreras } \\
\text { al aprendizaje y la partic ipación son producto de la } \\
\text { discapacidad de la persona. }\end{array}$ & & & \\
\hline $\begin{array}{l}\text { En el centro se valora la diversidad de las } \\
\text { personas. } \\
\text { - Las diferencias personales y fa miliares son vistas } \\
\text { como factor enriquecedor de la vida del centro. } \\
\text { - Se considera a los padreso cuidadores igua Imente } \\
\text { valiosos para el centro, independientemente del } \\
\text { status social de su trabajo o de su situación laboral. }\end{array}$ & & & \\
\hline $\begin{array}{l}\text { Los profesionales planifican, trabajan y revisan } \\
\text { su práctica de forma colaborativa. } \\
\text { - Comparten los profesionales la planificación con la } \\
\text { persona usuaria. } \\
\text { - Participan los profesionales en actividades } \\
\text { conjuntas. }\end{array}$ & & & \\
\hline $\begin{array}{l}\text { Los profesionales promueven el aprendizaje y la } \\
\text { participación de todas las personas usuarias. } \\
\text { - Los profesionales tienen como objetivo que las } \\
\text { personas usuarias sean lo más independientes } \\
\text { posible de su a poyo directo. } \\
\text { - Cumplen los profesionales con su responsabilidad } \\
\text { de que todas las personas mejoren sus } \\
\text { competencias para a lcanzar una vida }\end{array}$ & & & \\
\hline
\end{tabular}




\begin{tabular}{|c|c|c|c|}
\hline Indic ador & $\begin{array}{l}\text { Categonía } \\
\text { (de } 1 \text { a 6) }\end{array}$ & $\begin{array}{c}\text { Pertinencia } \\
\text { (de } 1 \text { a 4) }\end{array}$ & Observaciones \\
\hline \multicolumn{4}{|l|}{ independiente. } \\
\hline \multicolumn{4}{|l|}{$\begin{array}{l}\text { Se respeta la dignidad y el rol de los } \\
\text { profesionales y de las personas usuarias. } \\
\text { - Se valora a las personas usua rias por ellas mismas y } \\
\text { no por sus capacidades o limitaciones. } \\
\text { - Los profesionales brindan a las personas usuarias un } \\
\text { trato familiaro afectivo. }\end{array}$} \\
\hline \multicolumn{4}{|l|}{$\begin{array}{l}\text { Los profesionales del centro trabajan bien juntos. } \\
\text { - Los profesionales y los miembros del equipo directivo } \\
\text { y de gestión comparten su punto de vista sobre la } \\
\text { identificación de las personas usua rias que } \\
\text { experimentan dificultades y sobre el modo en que } \\
\text { debería proporcionarles apoyo. } \\
\text { - En el centro existe una dinámica de trabajo en la } \\
\text { que cada persona a porta lo mejor de sus } \\
\text { cualidades personales y profesionales. }\end{array}$} \\
\hline \multicolumn{4}{|l|}{$\begin{array}{l}\text { Los miembros de la comunidad comparten } \\
\text { valores inclusivos. } \\
\text { - Existe un interés especial en va lorar a las personas } \\
\text { como seres diferentes y únic os en vez de intentar } \\
\text { encasillarlos en categorías uniformes. } \\
\text { - Se considera la diversidad como un recurso rico } \\
\text { para a poyar el aprendizaje más que un problema. }\end{array}$} \\
\hline \multicolumn{4}{|l|}{$\begin{array}{l}\text { Los recursos del centro se distribuyen de foma } \\
\text { que promuevan la autonomía de las personas } \\
\text { usuarias. } \\
\text { - Los profesionales revisan el uso de los recursos } \\
\text { regularmente, para que puedan usarse de manera } \\
\text { flexible para respondera las necesidades } \\
\text { cambiantes de todas las personas usuarias. } \\
\text { - Los recursos se centran en el fomento del } \\
\text { aprendizaje autónomo y de la vida independiente. }\end{array}$} \\
\hline \multicolumn{4}{|l|}{$\begin{array}{l}\text { El centro tiene una política de acogida del } \\
\text { personal. } \\
\text { - El centro hace que los nuevos miembros sientan que } \\
\text { la experiencia y el conocimiento que ellos traen son } \\
\text { valorados. } \\
\text { - Los profesionales del centro con más experiencia } \\
\text { evitan que los nuevos miembros se sientan como } \\
\text { alguien extemo, por ejemplo utilizando un } \\
\text { "nosotros" que les excluya. }\end{array}$} \\
\hline $\begin{array}{l}\text { Se conocen y se aprovechan los recursos de la } \\
\text { comunidad. } \\
\text { - Las personas que trabajan y viven en la zona } \\
\text { participan en las actividades que se ponen en } \\
\text { marcha desde el centro. } \\
\text { - Las familias y otros miembros de la comunidad } \\
\text { ayudan y a poyan en las acciones promovidas por el } \\
\text { centro. }\end{array}$ & & & \\
\hline
\end{tabular}




\begin{tabular}{|c|c|c|c|}
\hline Indic ador & $\begin{array}{l}\text { Categońa } \\
\text { (de } 1 \text { a 6) }\end{array}$ & $\begin{array}{c}\text { Pertinencia } \\
\text { (de } 1 \text { a 4) }\end{array}$ & Obsenvaciones \\
\hline $\begin{array}{l}\text { En el centro se coordinan todas las fommas de } \\
\text { apoyo para aumentar la autonomía personal. } \\
\text { - Se fomentan las formas de apoyo ordinarias (que } \\
\text { afectan al } 100 \% \text { de las personas usuarias) frente a } \\
\text { las específicas (dirigidas a un pequeño porcentaje) } \\
\text { utilizando éstas sólo cuando las primeras no han } \\
\text { funcionado. } \\
\text { - Se considera que el apoyo para las personas } \\
\text { usuarias que experimentan barreras de aprendizaje } \\
\text { y de participación es una responsabilidad de todos } \\
\text { los miembros del centro. }\end{array}$ & & & \\
\hline $\begin{array}{l}\text { El centro pone en marcha procesos de apoyo } \\
\text { para reducir el absentismo. } \\
\text { - Se analizan todas las barreras que impiden la } \\
\text { asistencia al centro, incluyendo las actitudes de las } \\
\text { personas usuarias y las de sus familias. } \\
\text { - El centro responde activamente para que las } \\
\text { personas usuarias que han sufrido la muerte de un } \\
\text { familiar, una enfermedad crónic a o una ausencia } \\
\text { larga encuentren en él apoyo. }\end{array}$ & & & \\
\hline $\begin{array}{l}\text { El centro pone en marcha procesos de apoyo } \\
\text { para reducir las relaciones de abuso de poder } \\
\text { entre iguales. } \\
\text { - Los profesionales, los padres, los miembros del } \\
\text { equipo directivo y las personas usuarias tienen una } \\
\text { opinión compartida sobre los factores que } \\
\text { configuran el abuso de poder entre iguales y la } \\
\text { intimidación. } \\
\text { - Se considera la intimidación como un derivado } \\
\text { potencial de todaslas relaciones de poder. }\end{array}$ & & & \\
\hline $\begin{array}{l}\text { Se implica activamente a las personas usuarias } \\
\text { en su propio aprendizaje. } \\
\text { - Se motiva a las personas a que se hagan } \\
\text { responsables de su propio a prendizaje. } \\
\text { - Se proporciona información clara a las personas } \\
\text { sobre las expectativas de a prendizaje en las } \\
\text { actividades y en el centro. }\end{array}$ & & & \\
\hline $\begin{array}{l}\text { El centro pone en marcha procesos de apoyo } \\
\text { para evitar la indisciplina. } \\
\text { - Se considera que la indisciplina puede reducirse con } \\
\text { el apoyo y la intervención en las relaciones que se } \\
\text { dan entre los profesionales y las personas usuarias. } \\
\text { - Hay reuniones, implicando a los profesionales, las } \\
\text { personas usuarias, los padreso allegados y otros } \\
\text { miembros de la comunidad, para intentar hacer } \\
\text { frente a los problemas de forma flexible antes de } \\
\text { que empeoren. }\end{array}$ & & & \\
\hline $\begin{array}{l}\text { Se valora la capacidad de todas las personas } \\
\text { para desamollar su potencial. } \\
\text { - Se cree en las oportunidades de progresar de las } \\
\text { personas y se les pone medios y oportunidades. }\end{array}$ & & & \\
\hline
\end{tabular}




\begin{tabular}{|c|c|c|c|}
\hline Indic ador & $\begin{array}{l}\text { Categoría } \\
\text { (de } 1 \text { a 6) }\end{array}$ & $\begin{array}{c}\text { Pertinencia } \\
\text { (de } 1 \text { a 4) }\end{array}$ & Obsenvaciones \\
\hline $\begin{array}{l}\text { - En el centro se cree que si se trabaja } \\
\text { permanentemente por el progreso de cada } \\
\text { persona, porgrave que sea su discapacidad, sus } \\
\text { limitaciones se aminoran. }\end{array}$ & & & \\
\hline $\begin{array}{l}\text { Todas las instituciones de la comunidad están } \\
\text { involuc radas en el centro. } \\
\text { - El centro implica a las distintas instituciones de la } \\
\text { comunidad (entidades locales, a sociaciones, } \\
\text { colectivos...) en sus actividades. } \\
\text { - El centro cree que trabajar con otras orga nizaciones } \\
\text { es muy importante. }\end{array}$ & & & \\
\hline $\begin{array}{l}\text { Se facilita la participación de todas las personas } \\
\text { usuarias en actividades complementarias a las } \\
\text { del centro. } \\
\text { - Se a nima a todas las personas a que partic ipen en } \\
\text { actividades de ocio. } \\
\text { - Se da a todas las personas oportunidades para } \\
\text { participar en actividades fuera del centro. }\end{array}$ & & & \\
\hline $\begin{array}{l}\text { Todo el mundo se siente acogido. } \\
\text { - El centro es acogedor para las personas usua rias, las } \\
\text { familias y otros miembros de instituc iones de la } \\
\text { comunidad. } \\
\text { - Las personas usuarias, los profesiona les, los miembros } \\
\text { del equipo directivo y los implic ados sienten parte } \\
\text { del centro. }\end{array}$ & & & \\
\hline
\end{tabular}




\section{Anexo II. \\ Cuestionario de Evaluación de los Indic adores del Index (CEI) (Versión \\ definitiva)}




\section{CUESTIONARIO DE INDICADORES}

Porfavor, señale a continuación el centro en el que trabaja y su relación con él:

\section{Nombre del Centro:}

\section{Relación con el centro:}

$\square$ Equipo directivo AMICA (1) $\square$ Personal técnico AMICA (2) $\square$ Personal extemo a AMICA (3)

Sexo: $\square$ Hombre (1) $\square$ Mujer (2)

Edad: ㅁ 16- 21 (1) प 22-30(2) प 31-40 (3) प 41-50 (4) प 51- 60 (5)

$\square$ Mayor de 60 (6)

A continuación, en las siguientes páginas, se le presentan una serie de ítems. Su tarea consiste en indicar, desde su punto de vista, la categoría a la que pertenece cada ítem teniendo en cuenta las siguientes opciones:

\begin{tabular}{|c|c|c|}
\hline Categoría & Nombre & Desc ripción \\
\hline 1. & $\begin{array}{l}\text { Desa rrollar una } \\
\text { comunidad inclusiva }\end{array}$ & $\begin{array}{l}\text { El centro es una comunidad en la que to do el mundo } \\
\text { se siente acogido y en la que predomina un } \\
\text { sentimiento de compromiso y pertenencia. }\end{array}$ \\
\hline 2. & $\begin{array}{l}\text { Establec er valores } \\
\text { inclusivos }\end{array}$ & $\begin{array}{l}\text { En el centro se comparten los valores centra dos en } \\
\text { considerar que cada persona es únic a, con sus } \\
\text { proyectos de vida, ilusiones, etc. }\end{array}$ \\
\hline 3. & $\begin{array}{l}\text { Fomentar estrategias y } \\
\text { políticas inclusivas }\end{array}$ & $\begin{array}{l}\text { En el centro se desa rollan unas políticasy estra tegias } \\
\text { que tienen en cuenta a todas las personas. }\end{array}$ \\
\hline 4. & $\begin{array}{l}\text { Promover una gestión } \\
\text { organizativa inclusiva }\end{array}$ & $\begin{array}{l}\text { El centro pone en marcha procesos orga nizativos } \\
\text { acordes con sus valores inclusivos. }\end{array}$ \\
\hline 5. & $\begin{array}{l}\text { Pla nifica r práctic as } \\
\text { inclusivas }\end{array}$ & $\begin{array}{l}\text { En centro planifica todas sus actividadesteniendo en } \\
\text { cuenta que cada persona tiene derecho a tener un } \\
\text { proyecto personal, a alc anzar sus aspiracionesy } \\
\text { metasy a poder decidir sobre su futuro. }\end{array}$ \\
\hline 6. & $\begin{array}{l}\text { Desa rrollar prácticas } \\
\text { inclusivas }\end{array}$ & $\begin{array}{l}\text { El centro a la hora de poneren marcha todassus } \\
\text { actividadesse adapta a cada persona. }\end{array}$ \\
\hline
\end{tabular}

Además, si desea incluir alguna observación, utilice la casilla correspondiente para ello.

\section{¡Muchas gracias por su colaboración!}


A la hora de realizar una actividad los pensamientos, sentimientos, capacidades y emociones de cada persona se tienen en cuenta y son importantes.

El centro hace partícipe de su proyecto a la sociedad. El centro intenta mejorar sus procesos de trabajo responder a las necesidades de cada persona.

El centro tiene una estrategia de comunicación para que se conozca su filosofía de inclusión.

El centro tiene una estrategia orientada a que todo el mundo tenga la información y los apoyos necesariospara tener una vida independiente.

El centro tiene una política de mejora continua orientada a solucionar los problemasque la discapacidad plantea. El modelo organizativo del centro promueve la inclusión. El respeto y la aceptación de todos son clave para que nadie se sienta excluido.

En el centro se considera que las ba reras al a prendizaje y a la participación están en loscontextos y no en las personas.

En el centro se reconoce la igualdad de laspersonas independientemente de factorespersonales, sociales y culturales.

En el centro se respetan los derechos de las personas. En el centro se valora la capacidad de todas laspersonas para desamollar su potencial.

En el centro se valora la diversidad, la individualidad y el potencial de cada persona.

En los procesos y proyectos del centro se ve reflejada la filosofía de inclusión.

Entre los profesionales del centro existen unas relaciones basadas en el compromiso, la responsabilidad y la comprensión.

Existe un compromiso entre todos los miembros que forman parte del centro.

La estrategia de formación de los profesionales del centro está diseñada para ayudarles a dar respuesta a la diversidad de las personas usuarias.

La evaluación de las diferentes activida des que se realizan motiva a todos a mejorar.

La gestión del centro implica a todos en la toma de decisiones, conciliando intereses y repartiendo ta reas. La gestión del centro se a poya en las alianzas, en la coopera ción institucional y en los recursos existentes en la sociedad.

La polític a de recursos humanos se basa en el mérito, la capacidad y la igualdad. 


\begin{tabular}{|c|c|c|}
\hline Ítem & $\begin{array}{l}\text { Categońa } \\
\text { (De } 1 \text { a 6) }\end{array}$ & Observaciones \\
\hline $\begin{array}{l}\text { Lasactividades se planifican para que las personas } \\
\text { puedan tomar decisiones sobre su propia vida y participar } \\
\text { plenamente en la sociedad. }\end{array}$ & & \\
\hline $\begin{array}{l}\text { Las actividades promueven la igualdad de oportunidades } \\
\text { y el derecho a poder elegir. }\end{array}$ & & \\
\hline $\begin{array}{l}\text { Lasactividades que se planifican implican hacercon cada } \\
\text { persona algo diferente porque cada individuo tiene sus } \\
\text { propias aspiracionese ilusiones. }\end{array}$ & & \\
\hline $\begin{array}{l}\text { Las actividades que se ponen en marcha en el centro son } \\
\text { accesiblespara todos. }\end{array}$ & & \\
\hline $\begin{array}{l}\text { Las actividades que se realizan en el centro implican de } \\
\text { forma activa a todas laspersonas favoreciendo su } \\
\text { autonomía personal y la vida independiente. }\end{array}$ & & \\
\hline $\begin{array}{l}\text { La sactividades que se realizan en el centro utilizan todos } \\
\text { los recursos que existen en la sociedad (espacios de ocio, } \\
\text { asociaciones, empresas, servic ios públicos, etc.) }\end{array}$ & & \\
\hline $\begin{array}{l}\text { Lasactividades se diseñan para fomentar la participación } \\
\text { de laspersonas en la sociedad. }\end{array}$ & & \\
\hline $\begin{array}{l}\text { Las activida des se planific an para que las personas se } \\
\text { relacionen y aprendan juntas. }\end{array}$ & & \\
\hline $\begin{array}{l}\text { Las activida des se planific an por equipos multidisciplinares } \\
\text { donde cada persona a porta lo mejor de sus cualidades } \\
\text { personales y profesionales. }\end{array}$ & & \\
\hline $\begin{array}{l}\text { Las personas usua rias, las fa milias, los profesiona les y el } \\
\text { equipo directivo comparten una filosofía de inclusión. }\end{array}$ & & \\
\hline $\begin{array}{l}\text { Las polític as del centro están orientadas a fomentar la } \\
\text { participación de las personas en la sociedad. }\end{array}$ & & \\
\hline $\begin{array}{l}\text { Las polític as del centro favorecen el ejercicio de derechos } \\
\text { de los miembros de la comunidad. }\end{array}$ & & \\
\hline $\begin{array}{l}\text { Los nuevos miembros se sienten bien acogid os en el } \\
\text { centro. }\end{array}$ & & \\
\hline $\begin{array}{l}\text { Los procesos de trabajo están orientadosa que las } \\
\text { personas puedan sacarlo mejor de si mimas. }\end{array}$ & & \\
\hline $\begin{array}{l}\text { Los profesionales del centro diseñan actividadespara } \\
\text { promoverla participación, el aprendizaje, la felic idad y el } \\
\text { bienestar de todaslas personas. }\end{array}$ & & \\
\hline $\begin{array}{l}\text { Los recursos del centro se distribuyen de forma que } \\
\text { promuevan la autonomía y la vida independiente de } \\
\text { todaslas personas. }\end{array}$ & & \\
\hline $\begin{array}{l}\text { Todas las personas en el centro pueden participar en } \\
\text { aquellas actividades que les interesan porque tienen los } \\
\text { apoyos nec esarios. }\end{array}$ & & \\
\hline $\begin{array}{l}\text { Todas las personas que tienen relación con el centro se } \\
\text { sienten parte de él. }\end{array}$ & & \\
\hline $\begin{array}{l}\text { Todos en el centro sienten que son parte de un proyec to al } \\
\text { que pueden a portar algo. }\end{array}$ & & \\
\hline
\end{tabular}


Anexo III.

Cuestionario de Indic adores de Inc lusión

(CII) 


\section{CUESTIONARIO DE INDICADORES DE INCLUSIÓN EN AMICA.}

Por favor, señale a continuación el centro en el que trabaja o con el que tiene relación:

Centro:

Tipo de relación con el centro:

口 Persona usuaria (1)

口 Fa miliar (2)

口 Profesional (3)

$\square$ Equipo directivo (4)

Sexo:

口 Mujer (1)

口 Hombre (2)

Edad:

ㅁ $16-21(1)$

ㅁ 22 - 30 (2)

ㅁ 31 - 40 (3)

ㅁ 41 - 50 (4)

ㅁ 51 - 60 (5)

प Mayorde 60 (6)

¿Cuánto tiempo lleva teniendo algún tipo de relación con AMICA?

प Menos 1 año (1)

ㅁ 1- 4 a ños (2)

5 años - 8 años (3)

ㅁ 9 - 12 años (4)

ㅁ 13 años - 16 años (5)

口 Más de 16 años (6)

A continuación se le presentan una serie de ítems. Su tarea consiste en indicar, desde su punto de vista, la presencia que tienen en AMICA. Para ello deberá poner una $\mathbf{X}$ en el recuadro que represente su opinión, puede elegir entre "Muy de acuerdo", “De acuerdo", “En desacuerdo" o “Muy en desacuerdo".

¡Muc has gracias por su colaboración! 


\begin{tabular}{|c|c|c|c|c|}
\hline Ítems & $\begin{array}{l}\text { Muy de } \\
\text { acuerdo }\end{array}$ & $\begin{array}{l}\text { De } \\
\text { acuerdo }\end{array}$ & $\begin{array}{l}\text { En } \\
\text { desacuerdo }\end{array}$ & $\begin{array}{l}\text { Muy en } \\
\text { desacuerdo }\end{array}$ \\
\hline $\begin{array}{l}\text { A la hora de realizar una actividad los } \\
\text { pensamientos, sentimientos, capacidades y } \\
\text { emociones de cada persona se tienen en } \\
\text { cuenta y son importantes. }\end{array}$ & & & & \\
\hline $\begin{array}{l}\text { AMICA hace partícipe de su proyec to a la } \\
\text { sociedad. }\end{array}$ & & & & \\
\hline $\begin{array}{l}\text { AMICA intenta mejorar sus procesos de } \\
\text { trabajo respondera las necesidades de } \\
\text { cada persona. }\end{array}$ & & & & \\
\hline $\begin{array}{l}\text { AMICA tiene una estrategia de } \\
\text { comunicación para que se conozca su } \\
\text { filosofía de inclusión. }\end{array}$ & & & & \\
\hline $\begin{array}{l}\text { AMICA tiene una estrategia orientada a } \\
\text { que todo el mundo tenga la información y } \\
\text { los apoyos necesarios para tener una vida } \\
\text { independiente. }\end{array}$ & & & & \\
\hline $\begin{array}{l}\text { AMICA tiene una política de mejora } \\
\text { continua orientada a solucionarlos } \\
\text { problemasque la discapacidad plantea. }\end{array}$ & & & & \\
\hline $\begin{array}{l}\text { El modelo organizativo de AMICA promueve } \\
\text { la inclusión. }\end{array}$ & & & & \\
\hline $\begin{array}{l}\text { El respeto y la aceptación de todos son } \\
\text { clave para que nadie se sienta excluido. }\end{array}$ & & & & \\
\hline $\begin{array}{l}\text { En AMICA se considera que las barrerasal } \\
\text { aprendizaje y a la participación están en los } \\
\text { contextosy no en laspersonas. }\end{array}$ & & & & \\
\hline $\begin{array}{l}\text { En AMICA se reconoce la igualdad de las } \\
\text { personas independientemente de factores } \\
\text { personales, socialesy culturales. }\end{array}$ & & & & \\
\hline $\begin{array}{l}\text { En AMICA se respetan los derechos de las } \\
\text { personas. }\end{array}$ & & & & \\
\hline $\begin{array}{l}\text { En AMICA se valora la capacidad de todas } \\
\text { las personas para desarrollar su potencial. }\end{array}$ & & & & \\
\hline $\begin{array}{l}\text { En AMICA se valora la diversidad, la } \\
\text { individualidad y el potencial de cada } \\
\text { persona. }\end{array}$ & & & & \\
\hline $\begin{array}{l}\text { En los procesos y proyectos de AMICA se ve } \\
\text { reflejada la filosofía de inclusión. }\end{array}$ & & & & \\
\hline $\begin{array}{l}\text { Entre los profesionales de AMICA existen } \\
\text { unas relaciones basadas en el compromiso, } \\
\text { la responsa bilidad y la comprensión. }\end{array}$ & & & & \\
\hline $\begin{array}{l}\text { Existe un compromiso entre todos los } \\
\text { miembros que foman parte de AMICA. }\end{array}$ & & & & \\
\hline
\end{tabular}




\begin{tabular}{|c|c|c|c|c|}
\hline Ítems & $\begin{array}{l}\text { Muy de } \\
\text { acuerdo }\end{array}$ & $\begin{array}{l}\text { De } \\
\text { acuerdo }\end{array}$ & $\begin{array}{l}\text { En } \\
\text { desacuerdo }\end{array}$ & $\begin{array}{l}\text { Muy en } \\
\text { desacuerdo }\end{array}$ \\
\hline $\begin{array}{l}\text { La estrategia de formación de los } \\
\text { profesionales de AMICA está diseñada para } \\
\text { ayudarles a dar respuesta a la diversidad de } \\
\text { las personas usuarias. }\end{array}$ & & & & \\
\hline $\begin{array}{l}\text { La evaluación de las diferentes ac tividades } \\
\text { que se realizan motiva a todos a mejorar. }\end{array}$ & & & & \\
\hline $\begin{array}{l}\text { La gestión de AMICA implic a a todos en la } \\
\text { toma de decisiones, conciliando intereses y } \\
\text { repartiendo tareas. }\end{array}$ & & & & \\
\hline $\begin{array}{l}\text { La gestión de AMICA se a poya en las } \\
\text { a lianzas, en la cooperación institucional y } \\
\text { en los recursos existentes en la sociedad. }\end{array}$ & & & & \\
\hline $\begin{array}{l}\text { La política de recursos humanos se basa en } \\
\text { el mérito, la capacidad y la igualdad. }\end{array}$ & & & & \\
\hline $\begin{array}{l}\text { Las actividades se planifican para que las } \\
\text { personas puedan tomar decisiones sobre su } \\
\text { propia vida y participar plenamente en la } \\
\text { sociedad. }\end{array}$ & & & & \\
\hline $\begin{array}{l}\text { Las actividades promueven la igualdad de } \\
\text { oportunidades y el derecho a poder elegir. }\end{array}$ & & & & \\
\hline $\begin{array}{l}\text { Las actividades que se pla nific an implican } \\
\text { hacer con cada persona algo diferente } \\
\text { porque cada individuo tiene sus propias } \\
\text { aspirac ionese ilusiones. }\end{array}$ & & & & \\
\hline $\begin{array}{l}\text { Lasactividadesque se ponen en marcha } \\
\text { en AMICA son accesiblespara todos. }\end{array}$ & & & & \\
\hline $\begin{array}{l}\text { Las actividades que se rea lizan en AMICA } \\
\text { implic an de forma activa a todas las } \\
\text { personas fa voreciendo su autonomía } \\
\text { personal y la vida independiente. }\end{array}$ & & & & \\
\hline $\begin{array}{l}\text { Las ac tivida des que se rea lizan en AMICA } \\
\text { utilizan to dos los recursos que existen en la } \\
\text { sociedad (espacios de ocio, a sociaciones, } \\
\text { empresas, servic ios públic os, etc.) }\end{array}$ & & & & \\
\hline $\begin{array}{l}\text { Las actividades se diseñan para fomentar la } \\
\text { participación de las personas en la } \\
\text { sociedad. }\end{array}$ & & & & \\
\hline $\begin{array}{l}\text { Las actividades se planific an para que las } \\
\text { personas se relacionen y a prendan juntas. }\end{array}$ & & & & \\
\hline $\begin{array}{l}\text { Las actividades se pla nific an por equipos } \\
\text { multid isciplinares donde cada persona } \\
\text { aporta lo mejor de sus cualidades } \\
\text { persona les y profesionales. }\end{array}$ & & & & \\
\hline
\end{tabular}




\begin{tabular}{|c|c|c|c|c|}
\hline Ítems & $\begin{array}{l}\text { Muy de } \\
\text { acuerdo }\end{array}$ & $\begin{array}{l}\text { De } \\
\text { acuerdo }\end{array}$ & $\begin{array}{l}\text { En } \\
\text { desacuerdo }\end{array}$ & $\begin{array}{l}\text { Muy en } \\
\text { desacuerdo }\end{array}$ \\
\hline \multicolumn{5}{|l|}{$\begin{array}{l}\text { Las personas usua rias, las fa milias, los } \\
\text { profesionales y el equipo directivo } \\
\text { comparten una filosofía de inclusión. }\end{array}$} \\
\hline \multicolumn{5}{|l|}{$\begin{array}{l}\text { Las polític as de AMICA están orientadasa } \\
\text { fomentar la participación de las personas } \\
\text { en la sociedad. }\end{array}$} \\
\hline \multicolumn{5}{|l|}{$\begin{array}{l}\text { Las polític as de AMICA favorecen el } \\
\text { ejercicio de derechos de los miembros de la } \\
\text { comunidad. }\end{array}$} \\
\hline \multicolumn{5}{|l|}{$\begin{array}{l}\text { Los nuevos miembros se sienten bien } \\
\text { ac ogid os en el c entro. }\end{array}$} \\
\hline \multicolumn{5}{|l|}{$\begin{array}{l}\text { Los procesos de trabajo están orientados a } \\
\text { que las personas puedan sacar lo mejor de } \\
\text { si mimas. }\end{array}$} \\
\hline \multicolumn{5}{|l|}{$\begin{array}{l}\text { Los profesionales de AMICA diseñan } \\
\text { actividadespara promover la participación, } \\
\text { el aprendizaje, la felicidad y el bienestar de } \\
\text { todaslas personas. }\end{array}$} \\
\hline \multicolumn{5}{|l|}{$\begin{array}{l}\text { Los recursos de AMICA se distribuyen de } \\
\text { forma que promuevan la autonomía y la } \\
\text { vida independiente de todaslaspersonas. }\end{array}$} \\
\hline \multicolumn{5}{|l|}{$\begin{array}{l}\text { Todas las personas en AMICA pueden } \\
\text { participar en aquellas activida des que les } \\
\text { interesan porque tienen los apoyos } \\
\text { necesarios. }\end{array}$} \\
\hline \multicolumn{5}{|l|}{$\begin{array}{l}\text { Todas las personas que tienen relación con } \\
\text { AMICA se sienten parte de ella. }\end{array}$} \\
\hline $\begin{array}{l}\text { Todos en AMICA sienten que son parte de } \\
\text { un proyecto al que pueden a portar algo. }\end{array}$ & & & & \\
\hline
\end{tabular}


Anexos 
Anexo IV. Index para la Inclusión adaptado para centros que prestan servicios a personas con discapacidad: Dimensiones, sec ciones, indic adores y preguntas 


\section{Dimensión A. Crear c ulturas inc lusivas}

\section{A.1 DESARROLLO DE UNA COMUNIDAD INCLUSIVA}

INDICADOR. A.1.1. Todas las personas que tienen relación con el centro se sienten parte de él.

a) ¿Cuándo se tiene el primer contacto con el centro sientes que vas a encontrarte con personas con las que tienes algo que compartir?

b) ¿El primer contacto que la gente tiene con el centro es agradable y familiar?

c) ¿Hay diferentes protocolos de acogida para las visitas, los nuevos miembros, etc.?

d) ¿El centro es acogedor, tanto para las personas que están en él permanentemente como para las que lo están temporalmente?

e) ¿El centro tiene las puertas abiertas a la sociedad?

f) ¿Si se escucha a los miembros del centro (equipo directivo, profesionales, personas usuarias y familiares), el mensaje de fondo es el mismo, todos hablan con entusia smo del centro?

g) ¿En el centro se piensa que todo es posible graciasa la implicación que existe en sus miembros?

h) ¿En el centro todo el mundo tiene la oportunidad de contribuir en lo que quiere y en lo que puede en cada momento?

i) ¿Las personas usuarias tienen sensación de pertenencia a el centro?

j) ¿Las personas usuarias, los profesionales, los miembros del equipo directivo y los implicados sienten parte del centro?

INDICADOR. A.1.2. Existe un compromiso entre todos los miembros que forman parte del centro.

a) ¿Los miembros del centro (equipo directivo, profesionales, personas usuarias y familiares) se sienten importantes por participar en el proyec to del centro?

b) ¿En el centro existen unas relaciones de participación muy fuertes que se han establecido a través de la práctica diaria?

c) ¿Los miembros que forman parte del centro se involucran en lo que para ellos tiene importancia?

d) ¿En el centro se sabe que los aspectos que pueden facilitar la cohesión entre sus miembros pueden ser muy sutiles y delicados, por lo que se cuidan los pequeños detalles?

e) ¿Cada miembro del centro encuentra él un lugar único, a través del cual adquiere una identidad propia que se definiendo, cada vez más, por medio del compromiso?

f) ¿En el centro se cree que el compromiso mutuo no supone homogeneidad pero crea relaciones muy profundas entre las personas?

g) ¿En el centro se piensa que es más importante saber cómo dar y recibir ayuda que intentar saber todo? 
INDICADOR. A.1.3. Entre los profesionales del centro existen unas relaciones basadas en el compromiso, la responsabilidad y la comprensión.

a) ¿Los profesionales del centro están comprometidos con el proyecto común que se está llevando a cabo?

b) ¿Los profesionales del centro se sienten importantes por participar en el proyecto, creen en él y trabajan por él decididamente?

c) ¿Los profesionales del centro piensan que es un gran proyecto al que pertenecen y que a su vez también les pertenece?

d) ¿Los profesionales se tratan con respeto mutuo, independientemente de su rol o posición en el centro?

e) ¿Hay una amplia participación activa en las actividades que se ponen en marcha desde el centro?

f) ¿Se implican y comprometen todos los profesionales en la planificación y la revisión de las actividades?

g) ¿El trabajo en equipo entre los profesionales es un modelo de colaboración para las personas usuarias?

h) ¿Existe trabajo compartido entre los profesionales en el desarrollo de las actividades?

i) ¿Los profesionales se sienten cómodos para poder disc utir problemas en su trabajo?

j) ¿Se motiva a los profesionales sustitutos para que estén involucrados activamente en la vida del centro?

k) ¿En el centro se ponen en común conocimientos y combinan ideas para avanzar en la actualización perma nente del trabajo conjunto?

I) ¿Se entiende que el trabajo conjunto es un complemento imprescindible de la tarea ind ividual?

INDICADOR. A.1.4. Todos en el centro sienten que son parte de un proyecto al que pueden aportaralgo.

a) ¿De los procesos de participación del centro se deriva un sentimiento de pertenencia, que conlleva percibir los problemas y objetivos del centro como propios?

b) ¿Son muchas las personas que han hecho del proyecto del centro un proyecto de vida, que va mucho más allá del vínculo profesional, del compromiso asociativo, o de la relación como persona usuaria o trabajadora?

c) ¿El sentimiento de pertenencia se ha alimentado, y transmitido a muchas personas que se han ido incorporando al centro, manteniendo precisamente la idea de que quien acaba de llegar puede seguir aportando ideas a lo ya realizado, que nada es ina movible?

d) ¿En el centro se cree que cada aportación puede ser importante?

e) ¿En el centro se es consciente de que queda mucho más por hacer que lo hecho hasta ahora?

f) ¿En el centro se cree que la adaptación permanente a las nuevas exigencias, a la diferente mentalidad de las familias más jóvenes, de los nuevos profesionales que se incorporan a los centros, y sobre todo a las demandas que las nuevas generaciones de jóvenes y adultos nos reclaman para superar sus discapacidades es fundamental? 
g) ¿Cuánta gente dice que "para mí el centro es como mi segunda familia; aquí es donde he encontrado gente que me comprende, aquí es donde me encuentro tan a gusto como en mi casa"?

h) ¿Todos en el centro hablan con entusiasmo del proyec to del centro?

i) ¿En el centro la mayoría de los miembros sienten que son parte del proyecto y participan de susideas?

\section{INDICADOR. A.1.5. Los nuevos miembros se sienten bien a cogidos en el centro.}

a) ¿Existe algún programa de acogida para los nuevos miembros (personas usuarias, profesionales, familias)?

b) ¿El programa de acogida funciona de forma adecuada independientemente del momento del año en el que se produzca su incorporación?

c) ¿Se proporciona a las personas que se incomoran la información básica que nec esita sobre el centro?

d) ¿Los nuevos miembros (personas usuarias, profesiona les, familias) tienen una persona de referencia desde el primer momento en el centro que siva de referencia?

e) ¿Se toman medidas para conocer hasta qué punto los nuevos miembros (personas usuarias, profesionales, familias) se sienten cómodos en el centro?

f) ¿Los nuevos miembros (personas usuarias, profesionales, familias) tienen claro a quién tiene que acudir si experimenta dific ultades?

g) ¿Hay algún apoyo para las personas usuarias que tienen dificultad para recordar la distribución del edificio, particularmente cuando entra por primera vez en el centro?

h) ¿Se han establecido programas para facilitar la transición entre la anterior situación de la persona usuaria y la nueva en el centro?

i) ¿Cuándo las personas usuarias pasan de un centro a otro, los profesionales de cada centro colaboran?

j) ¿El centro reconoce las dificultades que los profesionales del centro pueden tener al establecerse en su nuevo puesto de trabajo?

k) ¿El centro hace que los nuevos miembros sientan que la experiencia y el conocimiento que ellos traen son valorados?

I) ¿Se pregunta a las personas que se incomoran sobre la información adicional que necesitan, y se les proporciona?

m) ¿Las observaciones de los nuevos miembros sobre el centro son tenidas en cuenta y se valoran porque pueden contener novedosas reflexiones?

\section{INDICADOR. A.1.6. El centro hace partícipe de su proyecto a la sociedad.}

a) ¿El centro implica a las distintas instituciones de la comunidad (entidades locales, asociaciones, colectivos...) en sus actividades?

b) ¿El centro está implicada en actividades de las instituciones de la comunidad?

c) ¿Los miembros de las instituciones de la comunidad comparten recursos con los profesionales y las personas usuarias, tales como la biblioteca, aulas, ordenadores...?

d) ¿Las instituciones de la comunidad participan en el centro de igual manera, independientemente de su clase social, su religión y su raza?

e) ¿Se consideran a todos los servicios de las instituciones de la comunidad como un recurso para el centro?

f) ¿Los profesionales y los miembros del equipo directivo y de gestión buscan las opiniones de los miembros de la comunidad sobre el centro? 
g) ¿Los puntos de vista de los miembros de las instituciones de la comunidad afectan a las políticas del centro?

h) ¿Hay una opinión positiva del centro entre las instituciones de la comunidad?

i) ¿La red de relaciones y colaboradores son un pilar fime del centro?

j) ¿Se cree que solo trabajando con otros, a poyándose, compartiendo experiencias es cuando realmente se progresa?

k) ¿El centro desarrolla una cultura de alianzas, entendiendo la cooperación institucional como base para el desarrollo?

I) ¿El centro cree que trabajar con otras organizaciones es muy importante?

\section{A.2. Esta blecervalores inclusivos}

A.2.1. En el centro se valora la capacidad de todas las personas para desa rrollar su potencial.

a) ¿Todas las personas sienten que asisten a un centro donde es posible que consigan sus mayores logros?

b) ¿Se motiva a todaslas personas a que tenga aspiraciones altas sobre su a prendizaje y procesos de desarrollo?

c) ¿Se trata a todas las personas como si sus logros no tuvieran ningún límite?

d) ¿Se muestra a las personas que pueden aprender, si se lo proponen, en cualquier área?

e) ¿Se hace consciente a las personas de que su éxito depende de su esfuerzo?

f) ¿Se valora el logro de las personas con relación a sus propias posibilidades en vez de en comparación con el logro de los demás?

g) ¿Los profesionales evitan tener una visión de que las personas tienen unas competencias fijas basándose en sus logros del momento?

h) ¿Se motiva a todas las personas a que estén orgullosas de sus propios logros?

i) ¿Se motiva a todas las personas a que aprecien los logros de los demás?

j) ¿Se evita el uso de estereotipos de personas a través de etiquetas generales, especia Imente de las personas usuarias con dific ulta des de a prendizaje?

k) ¿Se ayuda a las personas que tienen rechazo al aprendizaje por miedo al fracaso?

l) ¿Los profesionales evitan relacionar el logro potencial de una persona con el de otra?

m) ¿Se evitan las comparaciones entre equipos, transmitiendo que todo equipo tiene grand es posibilida des de éxito?

n) ¿Se cree en las oportunidades de progresar de las personas y se les pone medios y oportunidades?

o) ¿En el centro se cree que si se trabaja permanentemente por el progreso de cada persona, por grave que sea su disc apacidad, sus limitaciones se a minoran?

A.2.2. Las personas usuarias, las familias, los profesionales y el equipo directivo comparten una filosofía de inclusión.

a) ¿En el centro se cree que la inclusión tiene que ver con el proceso de incrementary mantener la participación de todas las personas en la sociedad, el centro, la escuela o la comunidad de forma simultánea? 
b) ¿En el centro se orientan todos los esfuerzos a intentar eliminary/o disminuir todo tipo de procesos que lleven a la exclusión?

c) ¿El centro se caracteriza por la ausencia de toda forma de discriminación y por su defensa de cuestiones como la justicia social, la equidad, los derechos humanos y la no discriminación?

d) ¿Todos los miembros del centro comparten una filosofía basada en que todas las personas con sus diferencias culturales, sociales y de aprendizaje, deben gozar de los mismos derechos que el resto de ciudadanos?

e) ¿En el centro se defiende la idea de que se deben buscarprocedimientos, cada vez más adecuados, para: responder a la diversidad, aprender a convivir con la diferencia y aprender a aprender de ella?

f) ¿Todos los miembros del centro entienden que las barreras al aprendizaje y a la participación aparecen en los procesos de interacción que se dan entre las personas y sus contextos?

g) ¿En el centro se apuesta porque las acciones que se desarrollan para potenciar el desarrollo personal, profesional y social no se deben conformar con lo básico o desc uidar ámbitos que fomenten la vida independiente?

h) ¿En el centro la participación se concreta en el deber de reconocer y apreciar la identidad de cada persona y la preocupación por su bienestar personal (por ejemplo, la autoestima) y social (por ejemplo, relaciones de amistad y compañerismo) y, por lo tanto, por la ausencia de situaciones de maltrato, exc lusión o a isla miento social?

A.2.3. En el centro se valora la diversidad, la individualidad y el potencial de cada persona.

a) ¿En el centro se cree que la igualdad se sitúa en primer lugar porque sin ella no puede haberderechos?

b) ¿En el centro se cree que todos tenemos derecho a que nuestras necesidades básicas, de aprendizaje y de participación en la sociedad sean satisfechas?

c) ¿En el centro se cree que la participación conlleva "estar con" y "colaborar con otros" lo cual supone un compromiso activo y una implic ación total?

d) ¿El compromiso existe con el aprendizaje conlleva valorar los logros de todos?

e) ¿La existencia de una comunidad que da apoyo y que provoca sentimientos de hermandad se refleja en la vida diaria del centro?

f) ¿En el centro el respeto a la diversidad conlleva entender el daño que se ocasiona cuando rechazamos a otros, los consideramos menos importantes o incluso con menos derechos, a causa de una diferencia percibida?

g) ¿En el centro se considera que la confianza es fundamental para establecer dialogo entre las personas y fomentar la participación?

h) ¿El centro ofrece información sobre la inclusión y ofrece respuestas a las situaciones que plantea la discapacidad en diferentes ámbitos?

\section{A.2.4. En el centro se respetan los derechos de las personas.}

a) ¿El centro defiende los derechos fundamentales de las personas porque son la razón de ser del centro?

b) ¿El centro plasma en sus valores el compromiso que tiene con la defensa de los derechos de las personas?

c) ¿Se respecta el derecho que tienen todas las familias a participar en la toma de decisiones sobre el centro? 
d) ¿En el centro se piensa que dignificar implica reconocer los derechos de la persona. pero sobre todo potenciar todas sus capacidades y su autonomía?

e) ¿En el centro se ha superado la idea de que lo que hay que hacer es atender a las personas prestándoles la ayudan que precisan "en la medida que se pueda"?

f) ¿Se respetan los deseos de intimidad de las personas usuarias en todas las situaciones?

g) ¿Se valora a las personas usuarias por ellas mismas y no por sus capacidades o limitaciones?

h) ¿Se respeta el derecho de la persona a tomar sus decisiones y a realizar sus elecciones?

i) ¿Se fomenta el trato de igual a igual, superando la costumbre de relación como si se viviese en una minoría de edad permanente?

j) ¿Se mantiene la premisa de hablar siempre de la persona primero y de la disc a pacidad en segundo lugar?

k) ¿En el centro se utilizan los mensajes en positivo que no destaquen las defic iencias?

A.2.5. En el centro se considera que las barreras al aprendizaje y a la participación están en los contextos y no en las personas.

a) ¿Los profesionales entienden el potencial que tienen para prevenir las dificultades de las personas usuarias?

b) ¿Se considera que las dificultades de aprendizaje y de participación pueden presentarse, potencialmente, a cualquiera y en cualquier momento?

c) ¿Se entiende que las dificultades de aprendizaje aparecen en la interacción entre las personas y los contextos donde éstas se desenvuelven?

d) ¿Se reconocen y afrontan las barreras que surgen de las diferencias existentes entre la cultura organiza tiva y las familiares?

e) ¿Los profesionales evitan considerar que las barreras al aprendizaje y la participación son producto de la discapacidad de la persona?

f) ¿Los profesionales evitan etiquetar a las personas?

g) ¿Se entiende que etiquetar las personas usuarias puede conllevar un aislamiento social?

h) ¿Los profesionales evitan comparara unas personas con otras?

i) ¿Existe una preocupación por parte de los profesionales por encontrar recursos y apoyos de todo tipo que le ayuden a orquestar los procesos de aprendizaje y la participación?

j) ¿Los profesionales trabajan colaborativamente (en equipos o compartiendo espacios) para introducir mejoras que permitan el éxito de las personas usuarias?

A.2.6. En el centro se reconoce la igualdad de las personas independientemente de factores personales, sociales y culturales.

a) ¿El centro intenta disminuir toda discriminación institucional, con relación a la edad, la "raza", la clase, la orientación sexual, el género, la discapacidad o la capacidad de las personas usuarias?

b) ¿En el centro nadie se siente discriminado por su edad, capacidad o discapacidad, orientación sexual, género o clase social? 
c) ¿Las personas usuarias y los profesionales del centro entienden los orígenes de la discriminación en la intolerancia hacia la diferencia?

d) ¿Los profesionales y las personas usuarias entienden que las polític as y las prácticas deben reflejar la diversidad de las personas usuarias del centro?

e) ¿Los profesionales evitan estereotipos de género o de otro tipo al elegir a aquellos que ayuden con tareas de apoyo técnico (como mover mesas...)?

f) ¿El centro valora la homosexualidad como opción sexual legítima?

g) ¿Los profesionales consideran que la discapacidad se crea cuando las personas con defic iencias enc uentran ac titudes negativas y ba rreras instituciona les?

h) ¿Los profesionales evitan ver las deficiencias como la causa de las dificultades experimentadas en el centro por las personas usuarias?

i) ¿Los profesionales reconocen la limitada contribución que da el conocimiento de las deficiencias para entender las posibilidades educativas o de desarrollo personal de una persona en concreto?

j) ¿Se desafían las opiniones estereotipadas sobre la perfección físic a?

k) ¿Los profesionales intentan contra restar las actitudes estereotipadas hacia las personas con algún tipo de limitación (por ejemplo, que son incapaces de tener relaciones, que merecen compasión o que son luchadores heroicos contra la adversidad?

I) ¿Se entiende la exclusión de las personas usuarias con deficiencias severas como el reflejo de las limitaciones de las actitudes y las polític as en vez de como dificultades prácticas?

\section{A.2.7. El respeto y la aceptación de todos son clave para que nadie se sienta} excluido.

a) ¿Los profesionales se dirigen hacia las personas usuarias con respeto, por el nombre por el que desean llamarse o pronunciando correctamente su nombre?

b) ¿Los profesionales tratan a todos los profesionales con respeto, independientemente de su categońa profesional?

c) ¿Se solic itan las opiniones de las personas usuarias sobre cómo debería mejorarse el centro?

d) ¿Las aportaciones de las personas (personas usuarias, familias, profesionales) se utilizan para introduc ir mejoras en el centro?

e) ¿Tienen las personas usuarias foros específicos para discutir sobre aspectos organizativos?

f) ¿Las personas usuarias ayudan al personal cuando se lo piden?

g) ¿Existen espacios informales de contacto entre los profesionales, las personas usua rias y las fa milias?

h) ¿Los profesionales y las personas usuarias cuidan el entomo físico del centro?

i) ¿Las personas usuarias saben a quién acudir cuando tienen un problema?

j) ¿Están las personas usuarias seguras de que se tomarán acciones eficaces para resolver sus dific ulta des? 


\section{Dimensión B. POÚtTCAS inc lusivas}

\section{B.1. Fomentar estrategias y polític as inclusivas}

B.1.1. Las polític as del centro favorecen el ejercicio de derechos de los miembros de la comunidad.

a) ¿El ejercicio de derechos de ciudada nía es el eje de las polític as del centro?

b) ¿Las políticas del centro se basan en que todas las personas tienen iguales derechos?

c) ¿En el centro se hace todo lo posible para que las personas con mayores dific ultades puedan ejercer sus derechos de forma efectiva?

d) ¿Las políticas del centro están orientadas a la dignificación de la persona, que consiste en proyectar sus capacidades, en cualquier circunstancia, por encima de las limitaciones, y en a poyar la autonomía?

e) ¿Las políticas del centro están orientadas a que todas las personas ejercer el derecho de poder tomar sus propias decisiones y participar activamente en aquellas que afecten a su vida?

f) ¿En el centro se fomenta que se cuente con las opiniones propias de todas las personas?

g) ¿En el centro se respetan las equivocaciones, entendiendo que los errores forman parte del quehacer cotidiano?

h) ¿En el centro se cuida con esmero la intimidad de las personas y se defiende en el día a día?

i) ¿En el centro se fomenta el trato de igual a igual, superando la costumbre de ver a la persona con algún tipo de limitación con una minoría de edad pemanente?

j) ¿En el centro se propone continuamente la superación de expresiones de lástima hacia la "desgracia ajena"?

k) ¿En el centro se defiende que la discapacidad, lejos de ser una desgracia, es una manifestación de la diversidad humana, que no limita la dignidad personal?

I) ¿En el centro se trabaja con las familias para que la educación, la exigencia y el trato sean como con los demás hijos?

B.1.2. Las polític as del centro están orientadas a fomentar la participación de las personas en la sociedad.

a) ¿Se consideran todas las políticas de apoyo como parte de un plan general de mejora para atender la diversidad en to do el centro?

b) ¿Hay una política de apoyo general explícita y clara para los profesionales del centro y para aquellos que proporcionan apoyos extemos a los procesos que se ponen en marcha en el día a día?

c) ¿Se dirigen las políticas de a poyo a la prevención de las dific ultades de aprendizaje y de participación?

d) ¿Los apoyos que se dirigen directamente hacia las personas, buscan aumentar su independencia/ autonomía? 
e) ¿Se fomentan las formas de apoyo ordinarias (que afectan al $100 \%$ de las personas usuarias) frente a las espec íficas (dirigidas a un pequeño porcentaje) utilizando éstas sólo cuando las primeras no han funcionado?

f) ¿El retomo de las personas usuarias al apoyo ordinario se hace tan pronto como es posible?

g) ¿El centro refuerza la coordinación de los apoyos y está dirigida por un miembro de equipo de profesionales del centro con experiencia?

h) ¿Las polític as de a poyo están guiadas por lo que es mejor para las personas usuarias en vez de, por el mantenimiento de status quo entre profesionales?

i) ¿Se considera que el apoyo para las personas usuarias que experimentan barreras de aprendizaje y de participación es una responsabilidad de todos los miembros del centro?

B.1.3. El centro tiene una estrategia de comunicación para que se conozca su filosofía de inclusión.

a) ¿En el centro se cree que los esfuerzos de comunic ación siempre son sa tisfactorios?

b) ¿El centro basa su política de comunicación intema en el principio de que la información favorece la cohesión de la organización, crea mayor conciencia colectiva de la importancia de la participación y es la fuente de alimentación de muchos principios y valores?

c) ¿Todos los órganos de gobiemo tienen una información continua y actualizada?

d) ¿Diariamente o con la periodicidad que el centro puede, se genera información que es distribuida a los diferentes grupos y responsables, tanto de noticias que se producen en la propia organización (propuestas, iniciativas, temas pendientes y resueltos, organización de actos...), como informaciones de nuestro entomo (sobre la discapacidad, temas sociales, cursos de formación, eventos de interés, publicaciones, estudios, actividades de nuestra red de colaboradores...)?

e) ¿El centro tiene herramientas tecnológicas que le permiten fomentar tanto la comunic ación interna como la extema?

f) ¿El centro tiene página web actualizada?

g) ¿El centro participa en redes sociales para difundir información sobre la discapacidad, temas sociales o sobre el propio centro?

h) ¿El centro tiene public aciones que le permiten difund ir su actividad?

i) ¿Se publica una memoria anual con todas las actividades realizadas?

j) ¿La información que publica el centro es pública?

k) ¿El centro aparece en los medios?

l) ¿El centro tiene material gráfico y/o multimedia que apoya el mensaje que quiere difundir a la sociedad?

m) ¿Todos los miembros del centro son conscientes de que participan en la difusión de información sobre el centro?

B.1.4. La política de recursos humanos se basa en el mérito, la capacidad y la igualdad.

a) ¿En el momento de la elección, el equipo directivo presenta al conjunto de profesionales del centro un programa de actuación concreto?

b) ¿Cuándo se configuran los equipos directivos se tiende a mantener el equilibrio de género? 
c) ¿En los procesos de selección se tienen en cuenta, además de la formación y la experiencia laboral, las actitudes frente a la discapacidad?

d) ¿Los profesionales que se incorporan al centro conocen previamente su política y calidad de servicio?

e) ¿El equipo directivo y de responsables del centro están constituidos por las personas más adecuadas para estar en él?

f) ¿Se fomenta la promoción de los profesionales basándose en sus competencias profesionales?

g) ¿Se apoya y se fomenta entre los profesionales la demanda de licencias de estudio que permitan conocery aportar experiencias diferentes?

h) ¿Se establecen programas de formación vinculados a las necesidades del centro, con la participación de todos los miembros del equipo?

i) ¿Se fomenta que los profesionales del centro participen como docentes en acciones de formación para otras instituciones?

j) ¿Existe una estabilidad en la plantilla que permita ir avanzando en el desa rrollo de los planes de mejora acordados?

k) ¿Los profesionales del centro pueden actuar como profesionales de apoyo, si es necesario?

I) ¿Hay una actitud favorable de buscar otros apoyos (estudiantes en prácticas, voluntarios, ...), si es necesario?

m) ¿Hay disposiciones establecidas para sustituir a los trabajadores de apoyo además de a los profesionales cuando no pueden asistir?

n) ¿La política de recursos humanos está orientada a crear un clima que permita la comunicación fluida y la participación activa?

B.1.5. El centro tiene una estrategia orientada a que todo el mundo tenga la información y los a poyos nec esarios para tener una vida independiente.

a) ¿En el centro existen sistemas de información y comunicación que facilitan la difusión de los valores del centro en la sociedad?

b) ¿En el centro existe un plan de comunicación e información que refuerza la participación?

c) ¿El diseño y desa rrollo de las políticas y herramientas de comunicación intema en el centro establece un marco de actuación adecuado para todos aquellos elementos que inciden de forma signific ativa en el proceso de comunicación?

d) ¿En el centro se organizan foros de intercambio de información con otras instituciones que a porten una mayor especialización a los profesionales?

e) ¿En el centro se desarrolla un sistema de intercambio de opiniones en la página Web, en las redes sociales y en otros espacios trabajo y colaboración online para participar de forma interactiva (foros, comentarios de noticias, tablones de anuncios)?

f) ¿En el centro se recopila, almacena, administra y procesa la información (datos conocimientos y experiencias) generadas y se pone a disposición de todos sus miembros?

g) ¿En los documentos del centro, inc luso en los folletos info mativos, está claro que es parte de la rutina responder a la diversidad de las personas usuarias y de sus contextos?

h) ¿Los instrumentos de comunic ación del centro (boletín, revista, intra net...) recogen los intereses y la actividad de todos los implic ados? 
i) ¿Disponen los profesionales de herramientas de comunicación intema que les permitan desa rollar su trabajo de forma colaborativa?

B.1.6. El centro tiene una política de mejora continua orientada a solucionar los problemasque la discapacidad plantea.

a) ¿La política de calidad del centro apuesta por la calidad de los servicios que presta?

b) ¿La política de calidad del centro se basa en la opinión de las personas usuarias para lograr su satisfacción?

c) ¿La política de mejora y calidad del centro se refleja en un sistema de calidad certific ado por instituc iones extemas?

d) ¿En el centro existen procedimientos que reflejan las instrucciones de cómo realizar cada tarea?

e) ¿En el centro se han diseñando los procesos que entrañan los servicios que se prestan y se han creado sistemas de evaluación de los resultados, de la satisfacción de las personas usuarias y los clientes tanto extemos como intemos?

f) ¿En el centro se desarrollan actividades de formación que favorezcan un modelo de apoyo a las personas basado en una cultura de calidad?

g) ¿En el centro existe un sistema de gestión informatizado que permite, mediante la evaluación de indicadores, un seguimiento permanente de la actividad de la organización y un reparto de responsabilidades que favorece la autonomía de func ionamiento de los equipos?

h) ¿El sistema de gestión permite controlar las actividades así como medir permanentemente los resultados en las personas, que es lo más importante.

i) ¿En el centro todo lo que se decide y se hace queda registrado en diferentes protocolos, actas, que permiten el seguimiento y evaluación de la actividad, así como la verificación de su ejecución en los tiempos programados?

j) ¿En el centro se cree que la implicación de la dirección y del equipo de profesionales es fundamental para la implicación de todos en la calidad de los senvicios?

B.1.7. La estrategia de formación de los profesionales del centro está diseñada para ayudarles a dar respuesta a la diversidad de las personas usuarias.

a) ¿Las actividades de formación del centro ayudan a los profesionales a desempeñar un trabajo conjunto de forma más eficaz?

b) ¿Se utiliza la colaboración y el intercambio posterior de reflexiones para apoyar a los profesionales en su trabajo?

c) ¿Tienen los profesionales la oportunidad de observar, analizar y reflexionar sobre su propio trabajo?

d) ¿Hay oportunidades para que los profesionales y las personas usuarias aprendan sobre la tutoría entre iguales (trabajo cooperativo en parejas en la que el tutor aprende enseñando a su compañero y el tutorizado aprende por el apoyo personal y permanente del tutor)?

e) ¿Aprenden los profesionales a utilizar la tecnología para apoyar el trabajo que se lleva a cabo en el centro?

f) ¿El personal del centro y los miembros del equipo directivo se responsabilizan de evaluar sus propias nec esidad es de a prend izaje? 
g) ¿Tienen los profesionales del centro la formación necesaria para dar los diferentes tipos de apoyo que precisa una planificación centrada en la persona?

h) ¿Se motiva a todos los profesionales del centro a profundizar y compartir todas sus habilidades y conocimientos para a poyar la vida independiente de las personas, no sólo a quellos derivados de su cargo laboral?

i) ¿Se motiva a los profesionales a desa rrollar sus conocimientos y sus habilidades?

j) ¿Los profesionales con habilidades y conocimientos específic os ofrecen su ayuda a los demás?

k) ¿Los profesionales del centro aprenden de la práctica y de la experiencia de los expertos de otros centros?

I) ¿Los profesionales reciben formación sobre la creación y la gestión de actividades de aprendizaje colaborativo?

m) ¿En el centro se profundiza en el trabajo en red, en la promoción de la participación y la formación de las persona simplic adas en la organización a todos los niveles?

n) ¿En el centro se promueve la participación y la formación de las personas implicadas en la organización de la asociación en temas relacionadas con representación, organización y dirección?

\section{B.2. Promover una gestión inclusiva}

B.2.1. El modelo organizativo del centro promueve la inclusión.

a) ¿En el centro trabajan conjuntamente profesionales, familiares y personas con discapacidad?

b) ¿La gestión se basa en un componente de confianza excepcional?

c) ¿Existe un modelo de gestión en el que cada cual ejerce un papel importante: los profesionales tienen la tarea de buscar nuevas soluciones para las personas, las familias la de defender la calidad, y la personas usuarias de participar activamente en lo que atañe a su vida?

d) ¿En el centro se implica todos en la toma de decisiones estratégicas y de administración cotidiana, conciliando intereses y repartiendo las tareas?

e) ¿Las personas usuarias plantean sus demandas y necesidades, participando activamente en el gobiemo del centro?

f) ¿Las familias ejercen una labor de participación en la toma de decisiones y control de la calidad de funcionamiento?

g) ¿La confianza en la organización, en sus gestores, está basada en gran medida en la transparencia?

h) ¿El estilo transparente del centro se plasma en un afán de comunicación de todo lo que se hace, de presentar ante la sociedad de los resultados de los recursos que se reciben?

i) ¿Confían en el centro las Administraciones Públicas, las Entidades Bancarias, otros centros?

j) ¿La cohesión intema del centro se ha basa también en una gran confianza en la honestidad y la transpa rencia en la gestión?

k) ¿El centro es responsable en la gestión económic a?

l) ¿En el centro se desa rrollar fómulas efic aces de transmisión de la información entre los diferentes órganos de Gobiemo? 
m) ¿En el centro se profundiza en el modelo de gestión compartida entre personas usuarias, fa milia res y profesionales?

\section{B.2.2. En los procesos y proyectos del centro se ve refleja da la filosofía de inclusión.}

a) ¿Los profesionales realizan propuestas sobre los planes de trabajo y la gestión de los servicios?

b) ¿Existe entre todos los miembros del centro un debate sobre las debilidades y forta lezas intemas, así como las a menazas y oportunida des extemas?

c) ¿Las personas usuarias elaboran propuestas de actividades para incorporar al Plan de su centro?

d) ¿Se recogen propuestas sobre actividades a realizar y sobre sugerencias y quejas relativas a cualquiera de los servicios?

e) ¿El centro ha hecho de la transparencia un valor?

f) ¿En el centro se cree que los proyectos se realizan más eficientemente cuando se trabajo en equipo buscando que cada uno aporte lo mejor de si mismo?

g) ¿En el centro se está orgulloso de lo que los proyectos que pone en marcha?

h) ¿Al centro les gusta mostrar a los demás lo que hace, recibir opiniones sobre su trabajo y poder defender en cualquier sitio la bondad de lo hecho?

i) ¿Los líderes y gestores se caracterizan por sus valores y entre ellos destaca la honestidad?

B.2.3. Los procesos de trabajo están orientados a que las personas puedan desa rrollar su potencial.

a) ¿Hay tiempos y espacios suficientes para que el personal del centro desarrolle de forma conjunta una colaboración más eficaz?

b) ¿Todos los profesionales del centro conocen y comparten los procesos de trabajo?

c) ¿Los procesos de trabajo del centro están basado en los valores inclusivos?

d) ¿Analizan los profesionales las maneras de reducir la insatisfacción de las personas usuarias a través del aumento de la participación en las actividades que se desarrollan en el centro?

a) ¿Se tienen en cuenta las distintas culturas y experiencias previas de los profesionales en el desa rrollo de las planific aciones individua lizadas?

b) ¿Los profesionales tiene oportunidades formales e informales para resolver preocupaciones con respecto a las personas usuarias haciendo uso de la experiencia de cada uno de los demás?

c) ¿En el centro hay un clima que posibilite proponer alternativas al resto de profesionales en relación a las preocupaciones respecto a las personas usuarias?

d) ¿Se considera el apoyo como un derecho para aquellas personas usuarias que lo necesitan en vez de un suplemento especial?

e) ¿Los detalles de las modalidades de a poyo a las personas usua rias están c laras para todos y se muestran en los recursos de información del centro?

f) ¿Se proporciona apoyo cuando es posible y necesario, sin recumir a los procedimientos formales de evaluación?

g) ¿La política del centro está dirigida al aumento del aprendizaje y de la participación y portanto, a la reducción de la exclusión? 
B.2.4. La gestión del centro implica a todos en la toma de decisiones, conciliando intereses y repartiendo tareas.

a) ¿Los profesionales y los miembros del equipo directivo y de gestión se conocen mutuamente?

b) ¿Se invita a los miembros del equipo directivo y de gestión a que participen en las actividades que se llevan a cabo en el centro en cualquier momento?

c) ¿Las habilidades y el conocimiento de todos los miembros del centro se valoran ya sea del equipo directivo y de gestión como de los profesionales?

d) ¿Los miembros del equipo directivo y de gestión sienten que sus contribuciones son valoradas, independientemente de su categoría profesional?

e) ¿Los miembros del equipo directivo y de gestión comparten oportunidades de formación con los profesionales del centro?

f) ¿Se comparte un enfoque sobre las personas usuarias?

g) ¿Los profesionales y los miembros del equipo directivo y de gestión comparten su punto de vista sobre la identificación de las personas usuarias que experimentan dific ulta des y sobre el modo en que debería proporcionarles a poyo?

h) ¿En el centro existe una dinámica de trabajo en la que cada persona aporta lo mejor de sus cua lid a des perso na les y profesionales?

i) ¿En el centro existe una alta profesionalización de la intervención y de la gestión que se ha fomentado con la presencia en el centro de personas con una adecuada cualific ación y competencia personal?

j) ¿En el centro se valora la capacidad de las personas de aprender de las necesidades del día a día, de sacar conclusiones y de proponer mejoras?

B.2.5. La gestión del centro se apoya en las alianzas, en la cooperación instituc ional y en los recursos existentes en la sociedad.

a) ¿El centro implica a las distintas instituciones de la comunidad (entidades locales, a sociaciones, colec tivos...) en sus actividades?

b) ¿El centro está implicada en actividades de las instituciones de la comunidad?

c) ¿Los miembros de las instituciones de la comunidad comparten recursos con los profesionales y las personas usuarias, ta les como la biblioteca, aulas, ord enadores...?

d) ¿Las instituciones de la comunidad participan en el centro de igual manera, independientemente de su clase social, su religión y su raza?

e) ¿Se consideran a todos los servicios de las instituciones de la comunidad como un recurso para el centro?

f) ¿Los profesionales y los miembros del equipo directivo y de gestión buscan las opiniones de los miembros de la comunidad sobre el centro?

g) ¿Los puntos de vista de los miembros de las instituciones de la comunidad afectan a las polític as del centro?

h) ¿Hay una opinión positiva del centro entre las instituciones de la comunidad?

i) ¿La red de relaciones y colaboradores son un pilar fime del centro?

j) ¿Se cree que solo trabajando con otros, apoyándose, compartiendo experiencias es cuando realmente se progresa?

k) ¿El centro desarrolla una cultura de alianzas, entendiendo la cooperación institucional como base para el desa rrollo?

I) ¿El centro cree que trabajar con otras organizaciones es muy importante? 
B.2.6. Los recursos del centro se distribuyen de forma que promuevan la autonomía y la vida independiente de todas laspersonas.

a) ¿Todas las personas, independientemente de las limitaciones que presenten, pueden acceder a cualquier parte del centro?

b) ¿Se consideran las necesidades de las personas con discapacidad auditiva y visual, además de las personas con deficiencias físicas, a la hora de hacer los edificios accesibles?

c) ¿Se han tomado medidas para ir mejorando la accesibilidad del centro y sus dependencias?

a) ¿Los profesionales generan de una manera compartida recursos «reciclables» para apoyar la vida independiente?

b) ¿Todos los profesionales conocen los recursos disponibles para apoyar las actividades que ponen en marcha?

c) ¿Se ha enseñado a las personas usua rias a conocer y utilizar los recursos del centro para que finalmente puedan utilizarlos de manera autónoma?

d) ¿Hay una preocupación para ir mejorando los recursos del centro como una fuente de riqueza para todos?

e) ¿Existe una amplia gama de recursos de buena calidad para todos?

f) ¿Existe un espacio multimedia bien organizado?

g) ¿Los ordenadores se integran en las actividades que se ponen en marcha desde el centro?

h) ¿Existe un sistema para el uso eficaz de programas de televisión dentro de las ac tivida des del centro?

i) ¿Se da a todas las personas usuarias las oportunidades para comunicarse con otros por ejemplo, por escrito, por teléfono o por correo electrónico?

j) ¿Se explotan las nuevas oportunidades tec nológicas, cuando están disponibles, por ejemplo, programas de reconocimiento de voz, como un recurso de apoyo para las personas usuarias que tiene dificulta des extremas en la escritura?

k) ¿Se dispone de materiales apropiadamente adaptados para las personas usuarias con mayores dific ulta des visua les, por ejemplo, en letras grandes o Braille?

B.2.7. El centro intenta mejorar sus procesos de trabajo responder a las necesidades de cada persona.

a) ¿El centro es un laboratorio de ideas donde explorar nuevas formas de trabajo pory con las personas?

b) ¿En el centro la innovación constituye un pilar fundamental de la razón de ser del mismo?

c) ¿El centro basa la mejora de sus procesos de trabajo en la experimentación, la adquisición de nuevos conocimientos y de nuevas perspectivas para que cada persona sea la verdadera protagonista de su futuro?

d) ¿El centro se conforma con las fórmulas de trabajo "tradicionales" o siempre busca la mejora y la innovación en las mismas?

e) ¿En el centro la apuesta por la innovación implica poner la imaginación y todo el ingenio para encontrar soluciones a las situaciones que la limitación humana plantea? 
f) ¿La mejora de los procesos de trabajo tiene como objetivo el mejorar la calidad de vida, favorecer el ejercicio de derechos como persona, y en definitiva, ayudar a cada persona encontrar su hueco en la sociedad?

g) ¿En el centro se apuesta siempre porla innovación?

h) ¿En el centro se piensa que mejorar supone estar abiertos a probar formas nuevas de hacer?

\section{Dimensión C. PRÁCTICAS inc lusivas}

\section{C.1. Planific ar práctic as inclusivas}

C.1.1. Las actividades que se planifican implican hacer con cada persona algo diferente porque cada individuo tiene sus propias aspira cionese ilusiones.

a) ¿El centro tiene como principio fundamental a la hora de planificar la individualidad?

b) ¿Las actividades que se planifican en el centro se basan en que cada ser humano es único, con proyectos de vida, con ilusiones, con necesidades de que los demás crean en sus capacidades, como un ser cargado de posibilidades si tiene oportunidades?

c) ¿Las actividades son planificadas teniendo en cuenta que cada individuo tiene capacidades, necesidades y a poyos diferentes?

d) ¿Las activida des tienen en cuenta los ritmos individuales de las personas?

e) ¿En el centro se cree que acompañar supone descubrir con la persona su propio itinerario, no marcárselo?

f) ¿A la hora de llevar a cabo las actividades se parte que todo el mundo tiene derecho a decidiry a equivocarse?

g) ¿Las actividades tienen en cuenta que lo importante son las vivencias perso nales?

h) ¿Las actividades tienen en cuenta que cada instante guarda un posible tesoro si se aprende a vivirlo?

C.1.2. Las actividades se planifican para que las personas puedan tomar decisiones sobre su propia vida y participar plenamente en la sociedad.

a) ¿Se motiva a las personas usuarias a que aúnen su conocimiento, por ejemplo, sobre diferentes situaciones vividas, experiencias laborales, lugares dónde se ha estado o sobre historias familiares?

b) ¿Se enseña a las personas usuarias lo que pueden aprender de otras personas?

c) ¿Las personas usuarias con mayor nivel de conocimiento y habilidades en un área hacen tutoría algunas veces con otros de menor nivel?

d) ¿Se brindan oportunidades para que las personas de distinta edad o con diferentes capacidades se apoyen entre ellos?

e) ¿Se promueve que las personas usuarias busquen los apoyos cuando y como los necesitan tanto en centro como fuera de él? 
f) ¿Se considera que cada uno tiene conoc imientos importantes que enseñar en virtud de su individualidad, independientemente de su nivel de logro o capacidad?

g) ¿las diferencias entre las personas se utiliza como un recurso para el aprendizaje?

h) ¿Las personas usuarias que han sobrellevado un problema transmiten a los demás los benefic ios de su experiencia?

i) ¿Se utilizan las barreras al aprendizaje y la participación de algunas personas usuarias, por ejemplo conseguir el acceso físico a una parte de un edificio o a un aspecto de la participación en deteminadas actividades, como una tarea de resolución de problemaso proyectos?

j) ¿De entrada, el criterio utilizado para componer los equipos es el principio de máxima heterogeneidad?

C.1.3. Los profesionales del centro diseñan actividades para promover la participación, el aprendizaje, la felicidad y el bienestar de todas las personas.

a) ¿Cumplen los profesionales del centro con su responsabilidad de que todas las personas mejoren sus competencias para alcanzar la vida independiente y ser felic es?

b) ¿Comprueban los profesionales el progreso de todas las personas usuarias?

c) ¿Los profesionales prestan atención a las personas usuarias de forma equitativa?

d) ¿Sienten todas las personas usuarias que son tratadas de manera justa?

e) ¿Intentan los profesionales del centro ponerse en el punto de vista de las personas usua rias respec to al a prendiza je y al a poyo?

f) ¿Los profesionales se preocupan por aumentar la participación y el bienestar de todas las personas?

g) ¿Los profesionales tienen como objetivo que las personas usuarias sean lo más independientes posible de su apoyo directo?

h) ¿Se buscan altemativas al a poyo individual?

i) ¿Se considera que los intentos para eliminar las barreras al aprendizaje y la participación de una persona usuaria son oportunidades para mejorar el aprendizaje de todos?

j) ¿Facilitan los profesionales que las personas usuarias que precisan mayores necesidades de apoyo se apoyen o ayuden mutuamente?

k) ¿Tienen los profesionales una descripción clara y precisa respecto a las funciones y tareas que deben realizar?

I) ¿Tienen cuidado los profesionales de evitar inmiscuirse en las relaciones de las perso nas usua rias con sus iguales?

m) ¿Se solic ita la opinión de los profesionales sobre la natura leza de las funciones de su puesto de trabajo?

C.1.4. La evaluación de las diferentes actividades que se realizan motiva a todos a mejorar.

a) ¿Reflejan los informes de evaluación los logros en todas las habilidades y conocimientos, aficiones e intereses y experiencias?

b) ¿Se utilizan siempre las evaluaciones de manera formativa para que mejore el aprendizaje de las personas usuarias?

c) ¿Se utilizan diferentes estrategias de evaluación de forma que se permita a todas las personas usua rias mostrar sus ha bilida des? 
d) ¿Hay oportunidades para evaluar, en colaboración con otros, el trabajo realizado?

e) ¿Entiend en las personas usuarias por qué están siendo evaluadas?

f) ¿Se devuelve a las personas usuarias información que les pemita reconocer lo que han aprendido y lo que deberían hacera continuación?

g) ¿Se potencia la autoevaluación y la autorregulación del aprendizaje?

h) ¿Pueden las personas usuarias marc arse metas claras para su futuro a prendizaje?

i) ¿Se hace un seguimiento de los logros de diferentes grupos de usuarios, por si se pueden detectary abordar dific ulta des específic as?

j) ¿Los resultados de las evaluaciones se utilizan para introducir cambios en las planific aciones y así ajusta rlas a las necesida des detec tadas?

k) ¿Las personas saben que se valora su progreso personal por encima de cualquier comparación con el equipo?

I) ¿Las valoraciones de trabajo en equipo son utilizadas para valorar también el progreso individual?

m) ¿Se realiza un informe personalizado que refleje de forma cualitativa el progreso en forma positiva?

C.1.5. Las actividades se diseñan para fomentar la participación de las personas en la sociedad.

a) ¿Hay en la comunidad una oferta suficientemente amplia de actividades complementarias para que atraigan el interés de todas las personas usuarias?

b) ¿Se dispone de transporte que permita a las personas usuarias que tienen que trasladarse desde lejos o que tienen una movilidad reducida, para que puedan participar en las activida des complementa rias?

c) ¿Se anima a todas las personas a que participen en actividades de ocio?

d) ¿Hay oportunidades para que las personas usuarias participen indistintamente en actividades en las que suele predominar la presencia de un solo género, tales como la danza, el fútbol, los equipos de informática, ...?

e) ¿Se enseña a las personas usuarias un repertorio de actividades que puedan incluir a hombres y mujeres con distintos grados de habilidad?

f) ¿Las personas usuarias elegidas para representar al centro reflejan la diversidad existente en el mismo?

g) ¿Los viajes, incluyendo las visitas al extranjero, son accesibles para todas las personas usuarias del centro, independientemente de suscapacidades?

h) ¿Se da a todas las personas usuarias oportunidades para participar en actividades fuera del centro?

i) ¿Se brindan a todas las personas usuarias oportunidades para participar en actividades que apoyen y beneficien a lascomunidades locales?

j) ¿Los juegos y las actividades de educación física fomentan el deporte y las aptitud es físic as de todos?

k) ¿Las jomadas deportivas incluyen actividades en las que todos puedan participar, independientemente de su nivel de capacidad?

C.1.6. Las actividades se planifican para que las personas se relacionen y aprendan juntas.

a) ¿Consideran las persona s usuarias que ofrecer y recibir ayuda es una ta rea habitual de la actividad del centro? 
b) ¿Se han establecido reglas para que las personas usuarias sepan seguir tumos para hablar, escuchar y pedir aclaraciones a los demás compañeros y a los profesionales?

c) ¿Se enseña a las personas usuarias a trabajar en colaboración con sus compañeros?

d) ¿Se utilizan de forma sistemática y regular métodos de aprendizaje cooperativo (tutoría entre iguales, trabajo de investigación, enseñanza recíproca....)?

e) ¿Desean las personas usua rias compartir su conocimiento y sus habilidades?

f) ¿Las personas usuarias rechazan de forma correcta la ayuda cuando no la necesitan?

g) ¿Las actividades de equipo permiten a las personas usuarias dividir las tareas y compartir lo que han aprendido?

h) Cuándo otros compañeros/as del centro están enfrentados, ¿las personas usuarias ayudan a calmarlos en vez de animarlos?

i) ¿Las personas usuarias reconocen que cada persona es igual de importante a la hora de recibir la atención de los profesionales del centro?

j) ¿Las personas usuarias comparten la responsabilidad de ayudar a superar las dificultades que experimentan algunos compañeros durante la realización de determinadas tareas?

k) ¿Se implican las personas usuarias en la evaluación del aprendizaje de los demás?

l) ¿Se implican las personas usuarias en ayudarse mutuamente para establecer metas personales, educativas y sociales?

m) ¿Saben las personas usuarias que ayudar a los demás es una forma efectiva de aprendery mejorar?

C.1.7. Las actividades se planifican por equipos multidisciplinares donde cada persona a porta lo mejor de sus cualida des persona les y profesionales.

a) ¿Comparten los profesionales la planific ación con la persona usuaria?

b) ¿Participan los profesionales en actividades conjuntas?

c) ¿Se ha dispuesto de un tiempo para la coordinación de los profesionales que trabajan juntos en activida des del centro?

d) ¿Se utiliza el trabajo en equipo como una oportunidad para intercambiar reflexiones so bre las personas usuarias?

e) ¿Están abiertos/as los profesionales a los comentarios de otros colegas en relación con cuestiones como, por ejemplo, la claridad del lenguaje o la participación de las personas usuarias en las activida des planific adas?

f) ¿Modifican los profesionales su forma de trabajar en respuesta a las recomendaciones recibidas de sus colegas?

g) ¿Comparten los profesionales el trabajo con personas usuarias de forma individual y en equipo?

h) ¿Proporcionan los profesionales del centro un modelo de colaboración para las personas usuarias?

i) ¿Se comprometen unos profesionales con otros a la hora de resolver los problemas de forma conjunta cuando el progreso de una persona usuaria o un equipo es motivo de preocupación?

j) ¿Los profesionales que trabajan en colaboración, comparten la responsabilidad de ga rantizar que todas las personas usua rias partic ipen? 


\section{C.2. Desa rrollar prácticas inc lusivas}

C.2.1. Todas las personas en el centro pueden participar en aquellas actividades que les interesan porque tienen los a poyos necesarios.

a) ¿En el centro los recursos son distribuidos de una manera abierta y equita tiva?

b) ¿Está claro cómo se asignan los recursos para apoyar a las personas usuarias de diferentes edades y con diferente tipos de capacidades?

c) ¿Los recursos se centran en el fomento de la vida independiente?

d) ¿Los profesionales son conscientes de los recursos asignados al centro para las personas usuarias con mayor nec esidad de apoyo?

e) ¿Los recursos para responder a las necesidades de apoyo se utilizan para aumentar la capacidad del centro de atender a la diversidad?

f) ¿Los recursos de apoyo se dirigen a prevenir las barreras al aprendizaje y a la participación y a disminuir la clasific ación de las personas en el centro?

g) ¿Los profesionales revisan el uso de los recursos regularmente, para que puedan usarse de manera flexible para responder a las necesidades cambiantes de todas las personas usuarias?

C.2.2. A la hora de realizar una actividad los pensamientos, sentimientos, capacidades y emociones de cada persona se tienen en cuenta y son importa ntes.

a) ¿Está mejorando el aprendizaje de todas las personas usuarias a partir de las actividades que se ponen en marcha en el centro?

b) ¿Se planifican las actividades teniendo en cuenta la diversidad de experiencias de las personas usuarias?

c) ¿Participan las personas usuarias en la planific ación de sus ac tivida des?

d) ¿Se adaptan las actividades a los diferentes conocimientos de las personas?

e) ¿Reflejan las actividades los distintos ritmos en los que las personas completan sus tareas?

f) ¿Se adapta la metodología de trabajo para que puedan aflorar distintos estilos de aprendizaje?

g) ¿Están claros para las personas destina ta rias los objetivos de las ac tivida des?

h) ¿Se apela a las personas usuarias a que antes de empezar un tema encuentren sentido a lo que se les propone?

i) ¿Se evitan las actividades que no impliquen aprendizaje?

j) ¿Comienzan algunas veces las actividades partiendo de una experiencia compartida que puede, posteriomente, ser desa rrollada de distintas maneras?

k) ¿Está previsto el trabajo individual, en pareja, en equipos y con todo el gran grupo en distintos momentos del desa rrollo de una actividad determinada?

I) ¿Se plantean las actividades de forma que conlleven diferentes tipos de acciones?

m) ¿Permite la planificación que se aprenda de distintas formas para adaptarse al estilo de aprendizaje y a lascapacidades de cada uno?

n) ¿Tienen las personas usuarias oportunidades para realizar sus tareas de distintas formas? 
a) ¿Pueden participar en las actividades pla nificadas, en igualdad de oportunidades, todos sus destina ta rios potenciales?

b) ¿Proporcionan los profesionales modalidades altemativas de acceso o de participación a las personas que no tengan determinadas capacidades?

c) ¿Se presta atención específica a la adecuación del lenguaje oral y escrito?

d) ¿Se preparan las actividades teniendo en cuenta el lenguaje que las personas usuarias encuentran fuera del centro?

e) ¿Se explica y se practica con el vocabulario técnico que aparecerá en la actividad?

f) ¿Reflejan los materiales, los contextos y las experiencias de todas las personas?

g) ¿Se hacen las actividades igualmente accesibles para todos, al incluir en ellas actividades variadas que reflejan la diversidad de intereses de los dos géneros?

h) ¿Pueden las personas usuarias participar en todas las actividades en la ropa apropiada según sus creencias religiosas?

i) ¿Se hacen adaptaciones en las actividades para las personas que tienen reservas en partic ipar en ellas debido a sus creencias religiosas?

j) ¿Reconocen los profesionales el esfuerzo físico que algunas personas emplean para completarlas tareas, y el cansancio que ello puede causarles?

k) ¿Reconocen los profesionales el esfuerzo mental que emplean algunas personas, por ejemplo, porque tienen que leer los la bios o utilizar ayudas visuales?

I) ¿Reconocen los profesionales el tiempo suplementario que necesitan y emplean a lgunas personas para utilizar los instrumentos en el trabajo práctico?

C.2.4. Las actividades promueven la igualdad de oportunidades y el derecho a poder elegir.

a) ¿Se motiva a las personas a que conozcan opiniones diferentes a las suyas?

b) ¿Se proporcionan oportunidades para que las personas trabajen con otros que son diferentes a ellos por su contexto, etnia, capacidad o género?

c) ¿Los profesionales evitan el clasismo, el sexismo, el racismo, la homofobia, o las actitudes en contra de las personas con discapacidad u otras formas de comentarios discriminatorios y por ello, ac túan como mod elos positivos?

d) ¿Los profesionales demuestran que respetan y valoran las opiniones altemativas en los debates que se desarrollan en el centro?

e) ¿Se debate sobre el clasismo, el sexismo, el racismo, la discriminación por disca pacidad, la homofobia o los prejuicios religiosos?

f) ¿Se procura desde el centro un entendimiento de las diferencias de contextos, cultura, etnia, género, disc apacidad, orientación sexual o religión?

g) ¿Tienen todas las personas usuarias la oportunidad de comunic arse con personas de otra parte del mundo?

h) ¿Se fomentan actividades que promuevan el desarrollo de la empatía (juegos de rol, simulación, a nálisis de casos...)?

i) ¿Proporcionan las actividades una comprensión histónica sobre la opresión de ciertos grupos?

j) ¿Se defiende el derecho a poder elegir y a tomar las propias decisiones?

k) ¿Se cuestionan los estereotipos en las ac tividades y en el día a día del centro? 
C.2.5. Las actividades que se realizan en el centro implican de forma activa a todas las personas favoreciendo su a utonomía personal y la vida independiente.

a) ¿Se motiva a las personas a que se hagan responsables de su propio aprendizaje?

b) ¿Se cree que la motivación, el empeño, la tenacidad, son vitales para lograr progresos y mayorgrado de autonomía?

c) ¿Se proporciona información clara a las personas sobre las expectativas de aprendizaje en las activida des y en el centro?

d) ¿El ambiente del centro, su organización y los recursos existentes contribuyen al aprendizaje y a la vida independiente?

e) ¿Se favorece en las personas una progresiva autonomía para planificar su trabajo, regular su desempeño mientras lo realiza, y evaluar su actuación y los resultados obtenidoscon el fin de introducir mejoras en situaciones futuras?

f) ¿Se considera suficiente el apoyo y el «andamiaje» utilizado para ayudar a las personas a progresar en su aprendizaje, a la vez que les permite profundizar en su conoc imiento y en las habilidades y competencias que ya poseen?

g) ¿Se hacen explícitas las planificaciones a las personas usuarias para que ellos/as puedan trabajara un ritmo más rápido si lo desean?

h) ¿Son capaces las personas usuarias de utilizar diferentes recursos tecnológicos por ellos mismos?

i) ¿Se enseña a las personas a organizar su trabajo?

j) ¿Se enseña a las personas a hacer presentaciones de su trabajo y tanto individuales como en equipo?

k) ¿Se motiva a las personas a que resuman lo que han aprendido?

l) ¿Se enseña a las personas a revisar los resultados de su aprendizaje y el de sus compañeros?

m) ¿Se consulta a las personas sobre el apoyo que necesitan?

n) ¿Se consulta a las personas sobre la calidad de las actividades en las que participan?

o) ¿Se involucra a las personas en el diseño del material de apoyo a las actividades para los compañeros?

p) ¿Tienen las personas o portunida des para eleg ir entre ac tivida des distintas?

q) ¿Se identifican y se utilizan los intereses de las personas para construir a partir de ellos la planificación?

r) ¿Se valoran y se tienen en cuenta los conocimientos previos de las personas?

C.2.6. Las actividades que se realizan en el centro utilizan todos los recursos que existen en la sociedad (espacios de ocio, asociaciones, empresas, servicios públic os, etc.)

a) ¿Hay un registro actualizado de los recursos de la zona que pueden promover la vida independiente? Esto puede incluir:

- Centros y recursos de la administración local, autonómic a y nacional

- Hospitales

- Servicio de policía

- Servicio de bomberos

- Centros e instalaciones deportivas

- Asociaciones de voluntarios

- Museos, galerías de arte y archivos locales

- Parques 
- Centros loc a les religiosos

- Representantes de los equipos comunitarios y Asociaciones

- Empresaslocales

- Estaciones de trenes, a eropuertos, y servicios de a utobuses

- Sindic atos

- Bibliotecas

- Centros de estudio

- Otros centros y universidades

- Otros

b) ¿Los miembros de las entida des loca les participan en la acciones planific adas por el centro?

c) ¿Las familias y otros miembros de la comunidad ayudan y apoyan en las acciones promovidas por el centro?

d) ¿Participan los profesiona les de la comunidad (servicios sociales, juez de paz, policía loc al,...) en las diferentes a c tivida des promovidas por el centro?

e) ¿En el centro se involucra a adultos en el apoyo de las personas usuarias que lo precisen?

f) ¿Las personas que trabajan y viven en la zona actúan participan en las actividades que se ponen en marcha desde el centro?

g) ¿El centro no promueve actividades que se pueden realizar en servicios no malizad os y las que las personas usuarias pued an asistir? 